\title{
Measuring and managing poverty risks
}

\author{
Citation for published version (APA):
}

Notten, G. A. M. J. (2008). Measuring and managing poverty risks. [Doctoral Thesis, Maastricht University]. Maastricht University. https://doi.org/10.26481/dis.20080606gn

Document status and date:

Published: 01/01/2008

DOI:

10.26481/dis.20080606gn

Document Version:

Publisher's PDF, also known as Version of record

\section{Please check the document version of this publication:}

- A submitted manuscript is the version of the article upon submission and before peer-review. There can be important differences between the submitted version and the official published version of record.

People interested in the research are advised to contact the author for the final version of the publication, or visit the DOI to the publisher's website.

- The final author version and the galley proof are versions of the publication after peer review.

- The final published version features the final layout of the paper including the volume, issue and page numbers.

Link to publication

\footnotetext{
General rights rights.

- You may freely distribute the URL identifying the publication in the public portal. please follow below link for the End User Agreement:

www.umlib.nl/taverne-license

Take down policy

If you believe that this document breaches copyright please contact us at:

repository@maastrichtuniversity.nl

providing details and we will investigate your claim.
}

Copyright and moral rights for the publications made accessible in the public portal are retained by the authors and/or other copyright owners and it is a condition of accessing publications that users recognise and abide by the legal requirements associated with these

- Users may download and print one copy of any publication from the public portal for the purpose of private study or research.

- You may not further distribute the material or use it for any profit-making activity or commercial gain

If the publication is distributed under the terms of Article $25 \mathrm{fa}$ of the Dutch Copyright Act, indicated by the "Taverne" license above, 
Measuring and managing poverty risks 


\section{(c) Geranda Notten}

All rights reserved. No part of this publication may be reproduced, stored in a retrieval system, or transmitted in any form, or by any means, electronic, mechanical, photocopying, recording or otherwise, without the prior permission in writing, from the author.

ISBN 9789086660506

Artwork cover:

Layout:

Publisher:
Karen Bauer, Maastricht

Proefschrift Lay-out, Amsterdam, www.proefschriftlay-out.nl

Boekenplan, Maastricht 


\title{
Measuring and managing poverty risks
}

\author{
Dissertation
}

to obtain the degree of Doctor at the Maastricht University, on the authority of the Rector Magnificus Prof. dr. G.P.M.F. Mols

in accordance with the decision of the Board of Deans

to be defended in public on Friday 6 June 2008, at 12.00 hours

$$
\text { by }
$$

Gertruda Andrea Maria Jacqueline Notten 
Supervisor:

Prof. dr. C.J.N. de Neubourg

Co-supervisor:

Dr. F. Gassmann

Assessment Committee: Prof. dr. L. Borghans (chairman)

Prof. dr. B. Cantillon, Universiteit van Antwerpen, Belgium

Prof. dr. R.A. Cowan 


\section{Acknowledgements}

It is with some sense of bewilderment that I am writing these acknowledgements. Up to my Master's graduation I never considered an academic career or writing a $\mathrm{PhD}$ dissertation and now my dissertation is finished. I am still intrigued by the subjects I have investigated, I am enthusiastic about further improving these papers and I am also looking forward to work on new projects. I am not sure what exactly happened but I am glad it did and the persons I mention here certainly played an important role.

Chris, you are the one that got me into this and I am very grateful for that. What I now appreciate the most (though not in the beginning) is that you give me the freedom to develop my own ideas and arguments, to make my own mistakes and to learn from them. But when help is really needed, be it intellectual or practical, you are there. Also, one meeting with you typically yields 10 ideas for new projects. I am pretty sure that we will continue to work out some of them in the future. Franziska, discussing my research with you is a guaranteed reality check and convincing you when you think otherwise is an extreme challenge. I found that out already when you became my supervisor for the Master's thesis, but these qualities cannot easily be overstated. More recently we also found out that we are a good research team: one down, many more to come!

Denis and Sybrand, thanks to you I now understand what econometrists fuss about. Sylvia, if it was not for your flexibility in planning my fifty percent teaching load, I would have never been able to finish the dissertation within the required time. Kati, your advice and encouragement have given me the courage to contact the specialists in my field and to discuss with them my incomplete ideas and unfinished work. Topsy, improper English, horrendous economists' vocabulary and other blind spots, your meticulous checks tracked them down. Any remaining errors are mine.

And then there is the family of colleagues from Economics, the School of Governance, UNU-Merit and beyond. Mutual support is seamlessly accompanied by the exchange of gossip during a coffee break, a chat in the office, a walk through the park, having drinks after work, a kitchen party or doing sports. There is simply too many of you to mention you all but thank you for making the writing of a dissertation a good deal less solitary! Mindel, Christiane and Riccardo, you are the reassuring and advising 'seniors'. With 'contempories' Kirsten, Katharina, Andy, Jeroen, Jan and Bart many frustrations and victories are shared. 'Unwinding' with Ruud, Hanneke, Britta and Melissa usually means intensive exercise on race or spinning bikes.

Dear family and friends, thank you for your interest and thank you even more for keeping me in touch with the world beyond academia that is, after all, the 'real' world.

Dear Ruud, your overwhelming confidence and unconditional support are the ' $\mathrm{X}$ ' factors: whenever I am fretting, stressing or right out frustrated your 'you will manage' gives me the confidence that I actually will. 



\section{Contents}

List of figures $\quad$ xi

List of tables $\quad$ xiii

1 Introduction 1

1.1 Relative or absolute poverty in the USA and the EU? The battle of the rates 3

1.2 The policy relevance of absolute and relative poverty headcounts: what's in a number? 4

1.3 Size matters: targeting efficiency and poverty reduction effects of means-tested and universal child benefits in Russia 5

1.4 Poverty and consumption smoothing in Russia 6

1.5 Managing risks: what do Russian households do to smooth consumption? 8

1.6 Outline 9

2 Relative or absolute poverty in the USA and EU? The battle of the rates 11

2.1 Introduction $\quad 12$

2.2 Poverty measurement: concepts and definitions 15

2.3 Methodology and data 17

2.3.1 Laeken and Orshansky poverty measurement methods $\quad 17$

$\begin{array}{ll}2.3 .2 \text { Data } & 18\end{array}$

2.3.3 Making the comparison: definition and construction key variables 19

2.4 Dissecting the Laeken and Orshansky methodologies 20

2.4.1 Differences in poverty levels 22

2.4.1.1 Inequality in welfare $\quad 22$

2.4.1.2 Cost of living $\quad 26$

2.4.2 Differences in poverty trends $\quad 29$

2.4.2.1 Method for updating the poverty lines $\quad 29$

2.4.2.2 Changes in inequality $\quad 32$

2.4.3 Equivalence scales and the impact on poverty rates 35

2.5 Conclusion $\quad 39$

2.6 Appendix: summary statistics $\quad 42$

3 The policy relevance of absolute and relative poverty headcounts: $\begin{array}{ll}\text { what's in a number? } & 47\end{array}$

3.1 Introduction 48

3.2 More or less poverty? Orshansky and Laeken poverty in the EU and US 51

3.3 Long term poverty $\quad 54$ 
3.4 Poverty profiles $\quad 57$

3.5 Social transfer incidence and adequacy 62

3.6 Absolute and relative poverty concepts and policy: discussion $\quad 73$

3.7 Appendix: official poverty in the EU and US - methodology and data $\quad 76$

4 Size matters: targeting efficiency and poverty reduction effects of means-tested and universal child benefits in Russia $\quad 79$

$\begin{array}{ll}4.1 \text { Introduction } & 80\end{array}$

$\begin{array}{ll}4.2 \text { Universal versus means-tested cash benefits } & 81\end{array}$

4.3 Russia - from universal to means-tested child allowances $\quad 85$

4.4 Data and methodology 86

4.5 Prevalence of (chronic) poverty in families with children 88

$\begin{array}{ll}4.6 \text { Targeting efficiency of child allowances } & 90\end{array}$

4.7 Impact of child allowances on (chronic) poverty 96

4.8 Simulation alternative child benefit programmes 98

4.9 Conclusion 103

$\begin{array}{ll}4.10 \text { Appendix: summary statistics } & 105\end{array}$

5 Poverty and consumption smoothing in Russia $\quad 107$

$\begin{array}{ll}5.1 \text { Introduction } & 108\end{array}$

5.2 Data and methodology 110

5.3 Russia in transition $\quad 112$

5.4 Consumption smoothing: conceptual and theoretical framework $\quad 117$

$\begin{array}{ll}5.5 \text { Theoretical model of consumption smoothing } & 121\end{array}$

$\begin{array}{ll}5.6 \text { Estimation and specification } & 123\end{array}$

$\begin{array}{ll}5.7 \text { Consumption smoothing abilities and poverty risk } & 126\end{array}$

5.8 Conclusion 133

$\begin{array}{ll}5.9 \text { Appendix } & 135\end{array}$

5.9.1 Comparison cross-section and panel dimensions RLMS 135

5.9.2 Estimations error correction coefficients and specification tests $\quad 137$

6 Managing risks: what do Russian households do to smooth consumption? 141

$\begin{array}{ll}6.1 \text { Introduction } & 142\end{array}$

6.2 Conceptual framework 143

6.3 Data and methodology 150

6.4 Consumption smoothing in Russia: what do Russian households do? 156

6.4.1 Perceived ability of consumption smoothing 157

6.4.2 Ex ante consumption smoothing strategies: asset accumulation 
and insurance

6.4.3 Ex post consumption smoothing strategies: transfers, credit and adjustment in income generating activities

6.4.4 Income generating activities

173

6.5 Further research and concluding remarks

7 Conclusion

7.1 Absolute and relative poverty: what's in a number?

7.2 Universal versus means-tested provision of social transfers:

a cost-benefit analysis

182

7.3 Poverty risk and its relation to consumption smoothing abilities

7.4 Managing risks: what do (Russian) households do to smooth consumption?

\section{References}

9 Appendix: poverty in Europe and the USA

9.1 Introduction 198

9.2 Official poverty measurement methods in the USA and EU 199

9.2.1 Poverty measurement in the EU: the Laeken indicators 199

9.2.2 Poverty measurement in the USA: the Orshansky poverty lines 200

9.2.3 Application of both poverty measurement methods 201

9.3 Making poverty rates between Europe and the USA comparable 202

9.3.1 European Union - ECHP 202

9.3.2 United States - CNEF-PSID 204

9.4 Comparability of main variables used in poverty analysis 206

9.4.1 Definition of the household 206

$\begin{array}{ll}9.4 .2 \text { Income } & 207\end{array}$

$\begin{array}{ll}9.4 .3 \text { Orshansky poverty lines } & 211\end{array}$

9.5 Exchanging official poverty measurement methods: results 212

$\begin{array}{ll}9.5 .1 \text { Poverty incidence } & 212\end{array}$

$\begin{array}{ll}\text { 9.5.2 Long term poverty } & 215\end{array}$

$\begin{array}{ll}\text { 9.5.3 Poverty gap } & 216\end{array}$

$\begin{array}{ll}\text { 9.5.4 Age, gender and household type } & 217\end{array}$

$\begin{array}{ll}\text { 9.5.5 Main source of income } & 218\end{array}$

$\begin{array}{ll}\text { 9.5.6 Impact of social transfers } & 219\end{array}$

$\begin{array}{ll}9.6 \text { Conclusion } & 220\end{array}$

$\begin{array}{ll}9.7 \text { Appendix: tables } & 221\end{array}$ 
Summary in Dutch

Curriculum Vitae 


\section{List of figures}

Figure 2.1: Poverty incidence (in \% of individuals over the period 1993-2000) 21

Figure 2.2: Dispersion of income below median (2000) 25

Figure 2.3: Impact of PPP benchmark year on absolute (Orshansky) poverty in Greece 28

Figure 2.4: Change in poverty lines due to different updating mechanisms 30

Figure 2.5: The impact of updating mechanisms on poverty incidence 31

Figure 2.6: Growth incidence curves (expressed in real annual growth rates, based on income distributions of 1993 and 2000) 34

Figure 2.7: Difference between Laeken and Orshansky poverty rates due to different equivalence schemes (in percentage points)

Figure 2.8: Difference between Laeken and Orshansky poverty rates due to different equivalence schemes (by household type, in percentage points) 39

Figure 3.1: Incidence of pensions (below median income, 2000) 66

Figure 3.2: Mean value of pension (below median income, 2000) 67

Figure 3.3: Incidence of family allowances (below median income, 2000) 69

Figure 3.4: Mean value of family allowances (below median income, 2000) 70

Figure 3.5: Incidence of social assistance (below median income, 2000) 71

Figure 3.6: Mean value of social assistance (below median income, 2000) 72

Figure 4.1: Poverty reduction impact of child benefits (100\% RLMS poverty lines, 2000-2004) 97

Figure 6.1: Welfare Pentagon $\quad 146$

Figure 9.1: Poverty incidence per country (\% of individuals, 1993-2000) 224

Figure 9.2: Laeken poverty trends using income excluding social benefits (2000) 238 



\section{List of tables}

Table 2.1: Poverty incidence (in \% of individuals, 1996 and 2000) 13

Table 2.2: Indicators of income dispersion and poverty rates (2000) 24

Table 2.3: Total household weight using various equivalence weighing schemes 36

Table 2.4: Number of observations in cross-sections by country and survey year $\quad 43$

Table 2.5: Per capita income by country and survey year (in Euro) 44

Table 2.6: Adult equivalent income by country and survey year (in Euro) 45

Table 2.7: Poverty incidence (in \% of individuals over the period 1993-2000) 46

Table 3.1: Poverty headcount (in \% of individuals, 1996 and 2000) 52

Table 3.2: Long term poverty1 headcount (in \% of individuals, 1996 and 2000) 55

Table 3.3: Overlap between poverty groups (in \% of individuals, 2000) 57

Table 3.4: Population and poverty profile (in \% of individuals, 2000) 59

Table 3.5: Incidence of social transfers 1 (in \% of individuals, 2000) 62

Table 3.6: Incidence of social transfers for different population groups 64

(in \% of individuals, 2000)

Table 4.1: Households with children $\quad 87$

Table 4.2: Poverty indices (in \% of individuals, 2000-2004) 88

Table 4.3: Chronic poverty (\% of individuals in 2004, 2000-2004 panel) 90

Table 4.4: Targeting efficiency of child benefits (2000-2004) 92

Table 4.5: Probit regressions on cross-sections (Child benefit receipt: yes=1/no=0, 2000-2004) 94

Table 4.6: Simulation: Poverty reduction per programme type (all children) 100

Table 4.7: Simulation: Reduction in chronic poverty (all children, 2004) 102

Table 4.8: Monthly expenditures on child benefits by programme 103

Table 4.9: Household characteristics in RLMS cross-section $\quad 105$

Table 4.10: Household characteristics in RLMS panel 106

Table 5.1: Per capita average of income and expenditures (monthly - 1992 ruble) 112

Table 5.2: Macro-economic indicators $\quad 113$

Table 5.3: Poverty indices $\quad 114$

Table 5.4: Poverty profile based on headcount index 115

Table 5.5: Poverty dynamics (1994-2004, two year intervals) 116

Table 5.6: Results overall and partial estimations for total expenditures $\quad 125$

Table 5.7: Short-run consumption smoothing abilities by poverty characteristics $\quad 127$

Table 5.8: Short-run consumption smoothing abilities by household characteristics $\quad 130$

Table 5.9: Attrition in RLMS: comparison characteristics cross-section and panel 136

Table 5.10: Results overall and partial estimations by household characteristics 138

Table 6.1: Typology of consumption smoothing strategies $\quad 145$

Table 6.2: Consumption smoothing channels 148

Table 6.3: Average equivalent expenditure distribution (2000-2003) 152

Table 6.4: Characteristics of household panel (2000-2003 panel, in 2003) 153

Table 6.5: Indicators of consumption smoothing channels in the RLMS 154

Table 6.6: Indicators of income generating activities in the RLMS $\quad 155$

Table 6.7: Self-perceived ability of consumption smoothing 157

Table 6.8: Accumulation of financial capital - financial market / household 158 
Table 6.9: Accumulation of physical capital - household 159

Table 6.10: Seek insurance - financial market $\quad 160$

Table 6.11: Seek insurance - public authorities (social security) 162

Table 6.12: Seek insurance / seek transfers - family / social network 164

Table 6.13: Households with old-age pensioners 166

Table 6.14: Seek transfers - public authorities (social assistance or other benefits) 168

Table 6.15: Adjustment of income generating activities - labour and goods market 169

Table 6.16: Seek loans or credit - household / financial - goods - labour market $\quad 170$

Table 6.17: Income generating activities - wage labour / entrepreneurial activities $\quad 172$

Table 6.18: Income generating activities - home production $\quad 174$

Table 9.1: Income components in ECHP by country 222

Table 9.2: Poverty incidence per country (\% of individuals, 1993-2000) 223

Table 9.3: Poverty ranking based on poverty incidence (1993-2000) 225

Table 9.4: Indicators of dispersion and locus poverty lines (2000) 226

Table 9.5: At-Persistent-Risk-of-Poverty rate (\% of individuals, 1993-2000) 227

Table 9.6: Poverty gap (1993-2000) 228

Table 9.7: Poverty incidence by age category (2000) 229

Table 9.8: Poverty incidence for total population and children aged 0-15 (1993-2000) 230

Table 9.9: Poverty incidence by gender (2000) 232

Table 9.10: At-Persistent-Risk-of-Poverty rate by gender (2000) 233

Table 9.11: Poverty incidence by household type (2000) 234

Table 9.12: Poverty incidence by main income source of household (2000) 235

Table 9.13: Poverty incidence using income but excluding social benefits (2000) 236

Table 9.14: Poverty reduction impact of social transfers (2000) 237

Table 9.15: Population shares by gender and age groups (2001) 239

Table 9.16: Population shares by household type (2001) 240

Table 9.17: Population shares by main income category (2001) 241

Table 9.18: Population shares panel by gender (1997-2001 panel) 242 
1 Introduction 
Poverty is a miserable condition: the lack of resources to satisfy basic human needs is a problem that needs to be solved and, preferably, prevented from occurring at all. Many countries have social protection policies aiming at assisting people to have and to maintain an acceptable living standard. However, designing a viable, sustainable and effective social policy is difficult and requires a lot of information and analysis. This study addresses four key steps in understanding poverty and designing sound social policies: estimating the number of poor; identifying the poor; understanding how people deal with poverty and poverty risk; and assessing how social protection policies can be effective in assisting the poor and preventing poverty. The aim of the first step is to find out how much poverty exists. Getting such an estimate, however, involves making many conceptual and methodological decisions that affect the estimate. In the second step, the focus is on studying who is poor by identifying characteristics that are associated with a higher poverty risk. The third step aims at understanding what people do to make ends meet, why they do it and how these actions affect their well-being. The objective of the final step is to analyse whether and how social protection policies can help alleviate poverty or reduce the risk of becoming poor.

Starting from what is known from previous publications, this study addresses five specific issues related to the steps specified above:

- The implications of using an absolute versus a relative poverty indicator when estimating the number of poor;

- The implications of using an absolute versus a relative poverty indicator on identifying the poor and assessing the poverty alleviation effect of social policies;

- The costs and benefits of means-tested versus universal provision of social transfers as effective poverty alleviating instruments;

- The relation between a household's poverty risk and its ability to smooth consumption when faced with income shocks;

- The consumption smoothing arrangements of households and the role of social protection policies as part of these smoothing arrangements.

Each issue is addressed in a separate paper and contributes to a specific academic debate and a specific discussion about policy options. The next sections discuss the academic and policy contexts in which our contributions should be understood. 


\subsection{Relative or absolute poverty in the USA and the EU? The battle of the rates}

In this paper we analyse how and to what extent technical reasons account for differences between absolute and relative poverty rates. We estimate poverty using the official poverty measures of the EU (relative) and the US (absolute) and representative survey data from 1994-2001 for $15 \mathrm{EU}$ member states and the US. We identify methodological and technical decisions and explain how each of them contributes to the astonishing variety in the observed absolute and relative poverty rates. We compare and analyse differences within and between countries, at a given point in time and over time and compute, for each factor, its individual effect on poverty.

The choice for a particular indicator influences the estimates of the number of poor. Most countries monitor income poverty using a specific poverty indicator but they generally use either an absolute or a relative indicator: the EU has a relative poverty indicator while in the US uses an absolute measure. The adequacy of such indicators is the centre of many political and academic debates. Since its introduction in the 1960s, the US poverty measure has been disputed and led to the instalment of a scientific research board that proposed an alternative absolute poverty indicator (Citro et al, 1995). In 2001 the EU endorsed a set of indicators including a relative poverty indicator but the recent enlargements of the EU have raised doubt on the adequacy of the relative poverty indicator to monitor progress on poverty (Marx \& van den Bosch, 2007). ${ }^{1}$ The Social and Cultural Planning Office ${ }^{2}$ in the Netherlands also favours an absolute poverty indicator and recently proposed to use a poverty threshold that reflects the resources needed to satisfy a specific set of basic needs (Soede, 2006).

This study is one of the very few that provides comparable absolute and relative poverty estimates between the EU member states and the US. It is the first and only study that estimates poverty using the official EU and US poverty measures. The effects of the analysts' technological choices on poverty rates are discussed in the literature on poverty measurement. We use this literature to explain how these technical choices influence the estimates of absolute and relative poverty measures. Our extensive empirical analysis of the individual effects of these technical decisions on the estimates of poverty improves the understanding of the consequences that such choices may have.

\footnotetext{
${ }^{1}$ These indicators are used to monitor progress on the fight against poverty and social exclusion in its member states. Although the EU member states agreed at the Nice summit in 2001 to combat poverty and social exclusion, the design and implementation of policies to fight these problems is the responsibility of the member states. This is the so-called open method of coordination.

${ }^{2}$ Together with the Dutch Central Bureau of Statistics, the Social and Cultural Planning Office publishes the poverty monitor (Armoedemonitor). This annual publication provides an overview of the scope, causes and consequence of poverty in The Netherlands.
} 
The paper starts with presenting a snapshot of our absolute and relative poverty estimates in the 16 countries. This is followed by a discussion of the key concepts in poverty measurement. Subsequently, we explain the methodology of the US and EU poverty measures, how we estimated poverty and we discuss some key issues regarding the cross-national comparability of the estimates. In the core of the paper we explain and show how a range of technical factors influence differences in the level and trends of absolute and relative poverty rates. We first look at differences in poverty levels and explain how the position of absolute and relative poverty lines is influenced by differences in welfare and methods to compare the costs of living across countries. Secondly we explain how differences in poverty trends can be explained by methods of updating poverty lines and changes in the distribution of welfare. Finally, we examine the impact of (implicit) equivalence scales on absolute and relative poverty measures.

\subsection{The policy relevance of absolute and relative poverty headcounts: what's in a number?}

The official poverty headcounts receive a lot of attention in the media and changes in these figures are often interpreted as a measure for the failure or success of government policy. However, in order to make and evaluate specific poverty alleviation policies we additionally need to identify who is poor and how a particular policy affects poverty. Poverty headcounts are often used as a starting point in such analyses: since they determine which group of the population is further analysed in a poverty profile they show whether policies are targeted to the right people and they are used to evaluate the poverty reduction effect of a policy. In this paper, we investigate whether the use of an absolute or relative poverty indicator has implications for the identification of priority groups and the assessment of the poverty alleviating effect of social transfers. For these analyses we use the same data and poverty measures ${ }^{3}$ as in the first paper but we additionally include long term poverty indicators as the chronically poor constitute a priority group for social policy in itself. While the first paper points out that absolute and relative poverty measures can yield very different estimates of the number of poor, this analysis shows that using either of these poverty concepts also leads to the selection of different priority groups and to a different assessment of the efficiency and effectiveness of social protection policies.

\footnotetext{
${ }^{3}$ In the paper we make one adjustment to the US absolute poverty measure: we apply the EU equivalence scales also to the US poverty measure because equivalence scales alter the risk of poverty between population groups and thereby also influence the characteristics of the poor. We thus only analyse the policy consequences of using either an absolute or a relative poverty line.
} 
This research can be placed within the applied poverty assessment literature and uses common identification and policy evaluation techniques such as poverty profiles and static impact analysis. Our findings are broadly in line with what is observed in this literature. However, we compare these issues for a group of these countries and simultaneously apply two popular types of poverty indicators. As a result, our research provides a unique illustration of the complex relation between social protection systems and the problem these systems try to address across countries. This study is also the first and only to present comparable estimates of long term poverty using both absolute and relative poverty indicators for the 16 countries under study.

In the paper we start by showing the extent to which absolute and relative poverty groups overlap in the EU member states and the US using both short-term and longterm poverty indicators. Subsequently we analyse whether the characteristics of the people that are poor using both indicators are different from the people that are poor for only one indicator. We use the Netherlands, Ireland, Austria, the UK and the US as case studies. For the same group of countries we also evaluate the targeting efficiency and poverty alleviating effect of various social transfers by comparing the incidence and amount of these transfers for both poverty groups and the rest of the population. Finally we argue why, from a national policy and a cross-national comparative perspective, it makes sense to use both absolute and relative poverty indicators.

\subsection{Size matters: targeting efficiency and poverty reduction effects of means-tested and universal child benefits in Russia}

Policies that assist the poor can either be general or specific. For instance, access to low cost or free public services such as education and health care is typically not restricted to the poor population but it assists the poor because it enables them to use their limited resources to satisfy other basic needs. Certain transfers such as basic pensions or family benefits can achieve a similar effect even though they are not specifically aimed at the poor population. The alternative is to make policies that specifically target the poorest part of the population.

Counter intuitively, the first option may be preferred when it is difficult to distinguish those who are most in need from the rest of the population. It is not easy to find out whether a person or household belongs to the target group or not, and gathering such information is costly. Moreover, other costs arise as a result of imperfect targeting: some people that are not in the target group will benefit from the policy while some people from the target group will be excluded. As a result, the decision between universal or targeted policies is ultimately a cost benefit analysis; when do the costs of targeting outweigh the benefits in terms of poverty reduction? Within this broader 
context of how social protection policies can be effective in assisting the poor, this paper compares the provision of means-tested versus universal social transfers. As a case study, we use a rich dataset that covers a period of policy change from a universal to a means-tested child benefit regime in Russia. This information allows us to follow a cost-benefit approach and analyse these delivery mechanisms both in terms of targeting efficiency and poverty reduction effects. ${ }^{4}$

This research uses the literature on the theory of targeting in order to identify the determinants of the costs of each targeting mechanism and employs poverty impact measurement techniques to evaluate the benefits in terms of poverty reduction. In the empirical strand of this literature contributions typically focus on the effects of meanstested benefits or contrast the role of means-tested benefits to other parts of the welfare state such as social insurance programmes. Some clues with respect to differences in targeting efficiency and poverty reduction impact between means-tested and universal benefits can be found. Our study, however, entails a direct comparison of these effects.

This paper starts with a review of the theoretical and empirical literature. We then explain the 2000 reform of child benefits in Russia and analyse changes in targeting efficiency and poverty reduction from 2000-2004, using various indicators and employing descriptive and econometric techniques. Finally, we simulate different policy options and compare their performance and costs with that of the current system.

\subsection{Poverty and consumption smoothing in Russia}

In this paper we estimate to what extent Russian households are able to protect their consumption from income shocks and we analyse in what way this ability to smooth consumption is related to poverty risk. We estimate households' consumption smoothing abilities by means of a dynamic panel analysis and explore whether household characteristics associated with a low smoothing ability are similar to the characteristics associated with a high poverty risk.

In order to understand how people deal with poverty and poverty risk we must take a dynamic perspective; even when a household is not poor today, it faces the risk of becoming poor tomorrow. Households are exposed to a wide range of risks such as unemployment, illness, crop failure or loss of assets. They respond to such threats by saving, borrowing, adjusting labour supply and selling assets. They can also insure themselves against the consequences of such risks through informal, private or

\footnotetext{
${ }^{4}$ Despite the richness in information, our data do not allow us to take second order effects into account in this analysis.
} 
government risk sharing and insurance schemes. Depending on the success of such arrangements, a household may or may not end up in poverty when it is faced with a shock. In this and the next paper, we focus on households' consumption smoothing behaviour with the objective of better understanding households' risk management. This paper investigates the overall success of consumption smoothing arrangements and its relation to poverty risk. The next paper analyses how households smooth consumption, whether poor household use different arrangements and what role social protection policies play in households' risk management.

The economic literature on consumption smoothing behaviour is extensive and builds upon the work of Friedman's permanent income hypothesis that aimed to explain the empirical observation that consumption is more stable then income (1957). Contributions range from the development and testing of microeconomic models of consumer behaviour in perfect financial markets (developed economies) to the behaviour of self producing consumers dealing with risk in the absence of formal financial markets (developing economies). One strand of this literature aims at measuring the degree of consumption smoothing or 'insurance'. Although the underlying theoretical models differ, empirical models of smoothing abilities are very similar and typically capture short term responses to income shocks. However, the effects of an income shock do not necessarily influence consumption immediately and the degree of adjustment may also depend on previous levels of well-being. We model consumption smoothing behaviour using a more realistic model that incorporates both short and long term adjustments. The model reflects the basic idea that people have alternative means to finance consumption when their income is suddenly reduced but that, in the long term, their income and expenditures should balance.

To implement this model, panel data on income and expenditures covering at least three consecutive time periods are needed. Even though panel data are increasingly becoming available, data with such richness in information are scarce. We estimate our model using an extensive Russian household panel survey covering the period from 1994 - 2004. This is an interesting period as it largely covers Russia's turbulent transition from a centrally planned economy to a market economy. This period of structural change has been accompanied by a surge in uncertainty and economic shocks affecting the Russian people. We are thus able to investigate how well Russian households have been able to protect their consumption from income shocks during the transition. We also analyse whether those households that were having difficulties with smoothing consumption are more likely to be poor.

This paper is structured as follows: After a description of the data and the main variables we analyse macro-economic developments in Russia and estimate its impact on poverty during this period. Following a review of the literature on consumption 
smoothing we introduce, estimate and test our model. Thereafter, we divide the population in subgroups according to a number of potentially relevant characteristics and also estimate smoothing abilities for these subgroups. Finally, we discuss the smoothing abilities of these subgroups with their poverty risk.

\subsection{Managing risks: what do Russian households do to smooth consumption?}

Social protection systems are not the only arrangements that people use to have and maintain an acceptable living standard. As indicated in the previous section, people manage the risk of poverty in many ways. The relation between the various arrangements and the institutions involved in these arrangements is complex and highly context specific. To understand consumption smoothing behaviour in a particular country, region or within a specific group, it is also important to study how people actually smooth consumption. This paper develops and implements an approach to study the smoothing arrangements of households, which we apply to Russia: we empirically explore survey data to find out what Russian households do at a given point in time and how these actions may contribute to consumption smoothing. In doing this, we also investigate the role of the Russian social protection system.

Contributions to the literature on consumption smoothing seem to focus either on testing models that explain consumption smoothing in general or, on modelling and empirically testing highly specific consumption smoothing arrangements of people in particular regions or countries. However, households generally employ a range of smoothing arrangements at the same time and the prevalence and success of one arrangement may depend on the availability or functioning of other arrangements. It is therefore also important to understand how these smoothing arrangements are related and why arrangements vary across groups in the population. The conceptual framework that is developed in this paper takes the household as the central institution that manages risks. It offers an alternative way to analyse and interpret existing information and data without a priori restricting the scope of the analysis to a particular smoothing arrangement. The analysis provides information about which smoothing channels are worth further investigation and which linkages have to be taken into account. Such information is also relevant for making policies that aim to assist households with their risk management. The information helps to determine the role, scope and type of government interventions as well as possible feedback effects to other smoothing channels.

In this paper we first present the conceptual framework to analyse households' consumption smoothing strategies. Thereafter, we explain our data and point out in 
what way the selected smoothing indicators are linked to the conceptual framework. Subsequently, we analyse the smoothing indicators and sketch how Russian households smooth consumption, using which channels. We also investigate whether the observed patterns differ in terms of levels of wealth and rural or urban settlement areas. We conclude with a discussion of our main findings and hypotheses and we suggest a number of approaches to model specific smoothing arrangements. We further illustrate how this information can be used for policy making.

\subsection{Outline}

In addition to this introductory chapter, this dissertation consists of five papers (chapters 2 to 6 ), a concluding chapter (chapter 7), a joint reference list (chapter 8) and a technical appendix (chapter 9).

In the conclusion we separately discuss the main conclusions of each paper and how they contribute to assessing and managing poverty risks. We also indicate the limitations of the study and point out which aspects merit further research.

The appendix explains in more detail the technical aspects of the headcount and other poverty estimates that are calculated and used in chapters 2 and 3 . 

2 Relative or absolute poverty in the USA and EU? The battle of the rates 


\subsection{Introduction 1234}

The differences in poverty levels between the European Union and the United States are striking: almost one out of four persons in the USA was poor in 2000 compared to around one out of ten in many European countries. More precisely, in 2000, 23.5 percent of the US population lived below the poverty line if the official EU poverty estimation method is used. Following the same estimation method, poverty levels in 2000 were 13.3 percent in Belgium and 10.4 percent in Sweden. However, when using the official poverty estimation method of the USA, poverty rates for 2000 are 8.7 percent in the USA compared to 3.6 percent in Belgium and 6.7 percent in Sweden. The 'official' poverty estimation method for the EU (further referred to as Laeken method and Laeken indicators ${ }^{5}$ ) is based on a relative poverty concept. The official poverty estimation method for the USA is based on an absolute poverty concept (further referred to as Orshansky method and indicators). The differences between relative and absolute poverty estimates for the same country and the same year are considerable but far from uniform. The differences in the figures quoted above are, for example, very large for the USA and Belgium but much smaller for Sweden. For the first time in poverty analysis research, this paper estimates poverty levels applying both methodologies to the USA and old EU countries (EU-15) and analyses the sources of the differences between the two estimates. The estimates can be made for all the years between 1993 and 2000.

Table 2.1 provides the estimates according to the two methodologies for 1996 and 2000 for the 16 countries under study. It can be seen that from the 16 countries the USA definitely shows the highest poverty rate when the EU (relative) method is used,

\footnotetext{
${ }^{1}$ This chapter is based on: Notten, G. \& C. de Neubourg (2007). Relative or absolute poverty in the US and the EU? The battle of the rates. MGSoG Working Paper (2007/001), Maastricht Graduate School of Governance, Maastricht University.

${ }^{2}$ In this chapter we use data from the European Community Household Panel (ECHP). The results and conclusions of this chapter are ours and not those of Eurostat, the European Commission or any of the national authorities whose data have been used.

${ }^{3}$ This research benefited from a grant provided by the EuroPanel Users' Network (EPUNet) that financed a research visit to CEPS/INSTEAD (Differdange, Luxembourg) and from a travel grant provided by the Dutch Scientific Organization (NWO) which funded a research visit to the Kennedy School of Government (Cambridge, USA).

${ }^{4}$ We thank our colleagues at CEPS/INSTEAD (Differdange, Luxembourg), Kennedy School of Government (Cambridge, USA), National Poverty Institute (Ann Arbor, USA), Panel Study of Income Dynamics (Ann Arbor, USA) and the participants in the conference on 'New Directions in the Study of Inequality' (Princeton, April 2006, USA) who have contributed to the progress of this research. We are especially grateful for the constructive suggestions of Emil Tesliuc, Christopher Jencks, Mary Jo Bane, Erzo Luttmer and Gary Sandefur.

${ }^{5}$ The Laeken indicators are a set of commonly agreed indicators which are used to monitor progress on poverty and social inclusion in the European Union and its member states. The Laeken indicators complement, but do not replace the poverty indicators used by each member state.
} 
Table 2.1: Poverty incidence (in \% of individuals, 1996 and 2000)

\begin{tabular}{|c|c|c|c|c|}
\hline & \multicolumn{2}{|c|}{ Laeken (relative) poverty } & \multicolumn{2}{|c|}{ Orshansky (absolute) poverty } \\
\hline & 1996 & 2000 & 1996 & 2000 \\
\hline Belgium & 14.2 & 13.3 & 6.1 & 3.6 \\
\hline Denmark & 9.3 & 10.8 & 3.2 & 3.4 \\
\hline Germany & 12.1 & 11.1 & 7.0 & 5.1 \\
\hline Greece & 21.5 & 20.5 & 28.1 & 26.1 \\
\hline Spain & 20.3 & 18.8 & 29.8 & 19.1 \\
\hline France & 14.9 & 15.4 & 8.8 & 6.5 \\
\hline Ireland & 19.1 & 21.4 & 20.1 & 10.6 \\
\hline Italy & 19.5 & 19.3 & 23.0 & 16.7 \\
\hline Luxembourg & 11.4 & 12.5 & 0.7 & 0.6 \\
\hline Netherlands & 10.5 & 11.3 & 6.1 & 6.6 \\
\hline Austria & 13.0 & 11.9 & 5.8 & 4.8 \\
\hline Portugal & 21.6 & 20.1 & 38.1 & 32.2 \\
\hline Finland & 8.3 & 11.4 & 4.5 & 4.9 \\
\hline Sweden & 8.9 & 10.4 & 7.1 & 5.7 \\
\hline United Kingdom & 17.8 & 17.1 & 11.4 & 9.3 \\
\hline United States & 21.7 & 23.5 & 8.5 & 8.7 \\
\hline
\end{tabular}

Source: Own calculations ECHP and CNEF-PSID

although the Mediterranean countries (Greece, Spain and Portugal) and Ireland show high figures as well. Using an absolute poverty estimate, as done with the US method, the picture becomes very different. Albeit still higher, the USA poverty rates do not show that much difference with most European countries while Greece, Spain and Portugal have figures four times higher than the USA. Excluding the Mediterranean countries, differences in poverty levels between countries seem smaller when an absolute poverty concept is used compared to a relative based estimate, but Belgium shows even lower poverty rates than Sweden that in turn does no longer differ that much from the USA. Even though we can not calculate absolute poverty rates for the new EU Member States, there are similarly large differences in relative poverty for these countries. For instance, Laeken poverty in Lithuania is 17 percent but only 8 percent in the Czech Republic which has the lowest poverty rate in the whole European Union! ${ }^{6}$ Moreover,

\footnotetext{
6 These poverty statistics have been retrieved from the website of Eurostat, http://epp.eurostat. ec.europa.eu/portal/page?_pageid $=1996,45323734 \&$ dad $=$ portal\&_schema $=$ PORTAL\&screen=wel comeref\&open $=/ \mathrm{C} / \mathrm{C} 5 / \mathrm{C} 53 \&$ language $=$ en\&product $=\bar{Y}$ earlies_new_population\&root $=$ Yearlies_new_ population\&scrollto=1068 (accessed March 2007).
} 
differences between absolute and relative poverty rates not only influence poverty levels but also affect the poverty developments over time: since 1995 absolute poverty in Ireland declined by 9.5 percentage points to 10.6 percent in 2000; while relative poverty increased by 2.3 percentage points to 21.4 percent over the same period. How can these differences between absolute and relative poverty rates be explained? This question will be addressed in the next sections.

Focussing on (differences in) official poverty estimates makes a lot of sense, for these statistics are used by governments to evaluate and adjust social and economic policies. Politicians and interest groups quote them to argue their case and the publication of the results receives considerable media coverage every year. The official USA poverty measurement method was developed by Molly Orshansky in the 1960s and is based on an absolute concept of poverty. Albeit regularly criticized and at times hotly debated, the Census Bureau still uses this method for its annual poverty assessments. ${ }^{7}$ At the start of this millennium, the Member States of the EU agreed to use a common set of poverty and social exclusion indicators also called the 'Laeken' indicators. The subset of these indicators that is concerned with financial poverty in EU Member States uses a relative concept of poverty.

Given the importance of these official poverty statistics for policymaking and advocacy groups, it is important to be able to explain the differences between absolute and relative poverty rates. Are they the result of conceptual and methodological differences in the measurement of absolute and relative poverty or do they simply reflect differences in social and economic policy regimes? In this paper we focus on the technical reasons that account for the differences between relative and absolute poverty rates and their impact on poverty levels and poverty trends. This exercise improves our understanding of how poverty statistics are influenced by often hidden and forgotten methodological and technical decisions. Our analysis shows how some differences in poverty are inherent to choosing either an absolute or a relative approach to poverty while other differences are related to more general aspects of poverty measurement. In short, we explain and illustrate how differences in inequality and changes in inequality over time affect absolute and relative poverty levels and poverty trends. Additionally, we investigate the impact of Purchasing Power Parity rates (PPP) and yearly updating methods of poverty lines. Finally, even though equivalence scales are used in every poverty approach, we show that equivalence scales have a different impact on absolute and relative poverty rates and explain how this result comes about.

Section 2.2 defines the poverty concepts and notations used and section 2.3 further explains the Laeken and Orshansky poverty indicators, discusses the data used

\footnotetext{
${ }^{7}$ We believe that the US method could be improved in many ways. For a comprehensive overview of its problems and how the method could be improved see Citro et al. (1995).
} 
and also the main variables used in the poverty comparisons. Section 2.4 analyses the differences between relative and absolute poverty rates for the 16 countries under study and estimates the impact of various measurement choices on poverty incidence; section 2.5 concludes.

\subsection{Poverty measurement: concepts and definitions}

There exists an extensive literature that elaborates at length on the wide range of issues involved in making poverty comparisons (see for instance Duclos \& Araar, 2006; Ravallion, 1994). Although we certainly discuss some of the arguments used in this literature it is beyond the scope of this paper to give a comprehensive review. We briefly introduce the general concepts and notation used in the analysis.

Key concepts involved in any poverty analysis are the welfare indicator, poverty line, unit of observation, unit of analysis, equivalence scales and poverty measure. The welfare indicator is a measure for the dimension of well-being (or deprivation) under study. In this study, we use disposable (after tax) income as a welfare indicator. ${ }^{8}$ The poverty line represents the threshold value of the welfare indicator which in turn determines the poverty status. When income is lower than the poverty line, the unit of analysis is considered 'poor'. With income poverty, the level at which information is collected (unit of observation) differs from the level at which poverty is calculated (unit of analysis). Information on income is collected at a household level while poverty is typically calculated counting individuals. This is because income and the items on which income is spent are generally shared at a household level and thus contribute to the level of well-being of all household members. Equivalence scales are then used to adjust for differences in household size and composition because these differences ceteris paribus also generate differences in well-being. Equivalence scales can adjust for differences in food requirements between age and gender groups. They can also take into account that larger households typically have lower expenditures per member because they share resources (i.e. house, car) or because they can buy larger quantities of food for a lower unit price. Equivalence scales may be used to correct the welfare indicator to an adult equivalent level, or they adjust the poverty line to fit the characteristics of the household. Finally, a poverty measure aggregates the poverty result from the unit of analysis to the population. A widely used group of

\footnotetext{
${ }^{8}$ Thus, disposable income is used as an indicator for the economic well-being of their citizens. Income is by far the most important source for financing consumption in developed economies. Nevertheless, measuring income has a number of drawbacks. One drawback of this indicator is that it labels households that are financing current consumption from assets (such as savings or loans) as 'poor', while their stock of assets may be more than sufficient to finance an acceptable level of economic well-being. Similarly, it can also label households that are financing large debt repayments from current income as 'non poor'.
} 
poverty measures is the Foster Greer Thorbecke (FGT) class of decomposable poverty measures which reflect the percentage of poor individuals as well as the depth and severity of poverty experienced (Foster et al, 1984). In this study we mainly use the percentage of poor individuals, also called headcount or poverty incidence.

Summarizing the above discussion more formally, we can denote adult equivalent income with y and let $\mathrm{F}(\mathrm{y})$ represent cumulative distribution function which gives the probability of observing someone with an income less than $\mathrm{y}$.

$$
F(y)=\int_{0}^{y} f(y) d y
$$

where $\mathrm{f}(\mathrm{y})$ is the probability of observing income with a value of $\mathrm{y}$. The poverty line (z) can take the values $0<\mathrm{z}<\mathrm{y}_{\max }$, where $\mathrm{y}_{\max }$ is the highest income value. The headcount index can be described as:

$$
H=F(z)=\int_{0}^{z} f(y) d y
$$

The poverty line can be determined by using some objective benchmark such as the cost to fulfil basic needs (food, shelter, clothing etc.). It can also be set in relation to the typical living standard in a society. As commonly stated in the literature on poverty, we call the first an 'absolute' method while we label the latter as 'relative'. Authors such as O’Boyle (1999) and Ravallion (1994) have argued that this terminology is misleading: the term absolute poverty suggests that the approach taken is objective but every approach involves some normative judgement about what is insufficient in a given society. Therefore, 'an absolute poverty line is best thought of as one which is fixed in terms of living standards and fixed over the entire domain of poverty comparison; a relative poverty line, by contrast, varies over that domain and is higher the higher the average standard of living' (Ravallion, 1994, p. 30). In formal notation, an absolute poverty line is determined by:

$\mathrm{z}_{\mathrm{a}}=\mathrm{f}(\mathrm{x})$

where $f(x)$ represents the value of attaining some benchmark $x$. A relative poverty line is determined by a fraction ( $k$ ) of some moment $(\mathrm{m})$ of the income distribution $\mathrm{f}(\mathrm{y})$, usually the median:

$\mathrm{z}_{\mathrm{r}}=\mathrm{k}^{*}[\mathrm{~m} \mid \mathrm{f}(\mathrm{y})]$

where $0<\mathrm{k}<1$. 
Absolute and relative poverty lines thus reflect conceptually distinct approaches to determining insufficient levels of well-being: an absolute poverty line identifies those people who have insufficient resources to satisfy basic needs while a relative poverty line identifies those who have much less than what is considered typical or normal in a given society.

\subsection{Methodology and data}

The USA and EU have developed distinctive approaches to poverty measurement. The task of applying both approaches to each country or group of countries while ensuring comparability of the results is not an easy or a trivial one. In turn, we discuss the Laeken and Orshansky poverty measurement methods, the data and main variables used in the poverty comparisons. ${ }^{9}$

\subsubsection{Laeken and Orshansky poverty measurement methods}

The official poverty method (Orshansky) used in the United States is based on an absolute concept of poverty while the European method (Laeken) uses a relative poverty concept.

The US poverty line was developed in the 1960s by Molly Orshansky, an economist working for the Social Security Administration. The Orshansky poverty line incorporated both food and non-food components. Firstly, Orshansky used the cheapest food plan from the Agriculture Department, which measured the costs of food for families under economic stress, to develop a food poverty line. Subsequently, the poverty line was multiplied by the reciprocal of the average share of food expenditures in total income. Although there have been some minor changes in the method over time, the poverty line currently used is essentially the same as when it was developed in the 1960s. In fact, the Orshansky poverty line is a set of poverty lines; depending on the family size and the age of household members, one of the 48 poverty lines applies. ${ }^{10}$ Every year, the poverty lines are updated for inflation using the consumer price index for urban consumers, which is the same for the whole USA. ${ }^{11}$ The official poverty rates are estimated annually by the Bureau of Census using the March Supplement of

\footnotetext{
${ }^{9}$ We have also documented these issues more in detail in Notten and de Neubourg (2007b).

${ }^{10}$ The poverty lines do not differ by state or region in the USA. The thresholds are available for each year on the website of the Bureau of Census on www.census.gov/hhes/www/poverty/threshld.

${ }^{11}$ Thus, except for the annual adjustment with the consumer price index, the current US poverty lines are the same as those calculated by Orshansky in the sixties: they are based on the costs of a food plan in the sixties multiplied by the reciprocal of the food share of the average household in the fifties. This is one of the main shortcomings of the Orshansky measure (for further information see Citro et al., 1995).
} 
the Current Population Survey (CPS). The poverty status of a family is obtained by comparing its gross annual income to the poverty line of that family type.

During the Nice summit in 2001, the EU Member States decided to combat poverty and social exclusion by means of the open method of coordination. This method 'involves fixing guidelines for the Union, establishing quantitative and qualitative indicators to be applied in each member state, and periodic monitoring' (Atkinson et al, 2002). The design and implementation of policies to fight poverty and social exclusion, however, remain predominantly the responsibility of the Member States. To monitor progress in these areas, a set of common statistical indicators was developed. Named after the Laeken European Council who endorsed the indicators in 2001, these 'Laeken indicators' cover four dimensions of social inclusion; financial poverty, employment, health and education. We use the subset of the Laeken indicators that is concerned with financial poverty. The Laeken poverty line is a relative poverty line that is set at $60 \%$ of national median disposable income. Household income is adjusted for the demographic composition of the household using the modified OECD equivalence scales. ${ }^{12}$

\subsubsection{Data}

For the European Union we use the European Community Household Panel (ECHP). The ECHP is a survey on household income and living conditions carried out in eight waves from 1994 until 2001 and includes the so-called EU-15 countries. ${ }^{13}$ The data provide cross-section and longitudinal information at a household and individual level on topics such as income, education, housing, health and social relations. Comparability of the ECHP data is achieved through common survey structure and procedures, common standards on sampling requirements and where possible on data processing and statistical analysis as well as the use of a 'blue-print' questionnaire used as a point of departure for the national surveys. The European statistics office (Eurostat) also uses the ECHP to calculate the Laeken poverty indicators.

For the United States, we use data from the Panel Study of Income Dynamics (PSID) from 1994-2001. The PSID is a nationally representative longitudinal survey containing information on an individual and family level on economic and demographic topics. Started as an annual survey in 1968, the PSID became a biennial survey since 1997. The PSID is available in two formats; the original PSID and the so-called CrossNational Equivalent Files (CNEF) which contains equivalently defined variables for

\footnotetext{
${ }^{12}$ The modified OECD equivalence scale gives a weight of 1 to the first adult in the household, a weight of 0.5 to other members aged over 14 years and a weight of 0.3 for children under age 14 .

${ }^{13}$ These are: Belgium, Denmark, France, Germany, Greece, Ireland, Italy, Luxembourg, the Netherlands, Portugal, Spain, United Kingdom, Austria (1995-2001), Finland (1996-2001) and Sweden (1997-2001).
} 
the panel surveys of four countries (Germany, United Kingdom, Canada and United States). We use the CNEF because the main variables in the PSID are harmonized with two datasets that are also the basis for the ECHP. This facilitates the construction of comparable welfare indicators.

\subsubsection{Making the comparison: definition and construction key variables}

The main challenge lies in the construction of comparable welfare indicators and poverty thresholds. Both the EU and USA use income as a welfare indicator for the poverty analyses. However, in the US gross income is used while the EU uses disposable income. We prefer to use disposable income because disposable income better reflects the funds that a household can spend on consumption. The advantage of using the CNEF-PSID is that these data also include imputed variables indicating the tax burden of households and thus provide an indicator for disposable income in the USA. ${ }^{14}$ Furthermore, both datasets contain a range of variables indicating the annual value of various income sources such as wages and salary, earnings from self employment, capital, private transfers and social protection benefits. Our indicator of total net disposable income includes income from these sources. Capital gains (or losses) and benefits in kind are not included, with one exception. For the USA we included the value of food stamps because these can be considered as 'near money' as they are issued in the form of an electronic debit card that can be used to purchase food items in a range of supermarkets. Moreover, the food stamp programme is one of the main programmes that targets poor households in the USA; not including the value of these benefits would ignore this important poverty reduction effort in the poverty estimates.

The income variables in the ECHP are constructed using the same (or similar) method for all Member States. There are, however, two aspects that may affect our cross-national poverty comparisons. Firstly, the use of register data for Sweden, Finland and Denmark may yield higher poverty rates than survey-based poverty estimates. ${ }^{15}$ Secondly, the simulated tax burden in the CNEF-PSID also incorporates the higher deductions for low income families with children (Earned Income Tax Credit (EITC). The simulated tax burden assumes a 100 percent EITC take up rate but not all eligible

\footnotetext{
${ }^{14}$ Federal and state income tax burdens have been imputed using the NBER TAXSIM model and PSID data while payroll taxes have been estimated using the tax rates reported by the Social Security Bulletin (Lillard et al, not dated).

${ }^{15}$ ECHP data from Sweden, Denmark and Finland are based on statistical registers drawn from administrative records. Comparison of Finnish household survey data with the Finnish ECHP data based on statistical registers shows considerably higher income levels for the lowest two income deciles using survey data. As the other ECHP countries use survey data this affects cross-country rankings of poverty levels (Rendtel et al, January 2004).
} 
households actually receive the EITC. ${ }^{16}$ This assumption may therefore result in an underestimation of USA poverty rates.

While both survey data have been collected from 1994-2001, the income variables reflect household income in the year previous to the survey (thus, from 19932000). The information on the household size and composition, which is also used to determine the poverty rate, is based on the survey year. The calculated poverty rates therefore reflect the period 1993-2000 rather than 1994-20001.

We took the Bureau of Census US poverty lines and converted the 1993 dollar poverty lined to the Member States' currencies using 1993 Purchasing Power Parity (PPP) indices. After converting the US thresholds to national purchasing power values, we updated the thresholds to other years using national consumer price indices. Our methodology thus translates the purchasing power of the 1993 US poverty lines to that of each of the member states, while the following annual adjustments of the poverty lines depend on the change in consumer prices in that member state. ${ }^{17}$ The Laeken poverty lines depend on the income distribution and are thus based on the income variable in both datasets. Furthermore, we constructed a variable indicating the household level weight of the modified OECD-equivalence scales and a variable indicating which of the 48 Orshansky poverty lines should be applied to the household. Tables 2.4 to 2.6 in the appendix summarize the number of households and individuals as well as the mean (annual) per capita and adult equivalent income levels by country and survey round.

\subsection{Dissecting the Laeken and Orshansky methodologies}

Using the method explained above we have calculated the official EU (Laeken relative) and the US (Orshansky - absolute) poverty rates for each country over time. ${ }^{18}$ Figure 2.1 shows that there are both level and trend differences in official poverty rates and that the experience differs between countries. ${ }^{19}$ Ireland shows opposing trends in poverty rates: according to the Orshansky indicator poverty declines over time while poverty increases using the Laeken indicator. For Germany, Netherlands, Belgium and

\footnotetext{
${ }^{16}$ To claim the EITC a special tax form has to be completed and submitted. According to a study of the Internal Revenue Service on participation in the EITC programme for the tax year 1996, up to $18 \%$ of the of the eligible individuals did not file a tax return (Internal Revenue Service, 2002).

${ }^{17}$ This method firstly assumes that the current US poverty lines are still good indicators of the minimum costs of living in the US and, secondly, that these costs of living (in PPP terms) also reflect the minimum costs of living in the member states. Although it is likely that these assumptions are violated to some degree (see also footnote 10 and section 2.4.1.2), these poverty lines behave in a similar fashion.

${ }^{18}$ We thus compare the poverty rates of each EU member state with that of the USA as a whole. We focus on sovereign nations as the relevant group for the poverty comparison because this is the main level at which official poverty statistics are feeding into (national) policy processes.

${ }^{19}$ Table 2.7 in the appendix lists the annual poverty rates.
} 
Figure 2.1: Poverty incidence (in \% of individuals over the period 1993-2000)
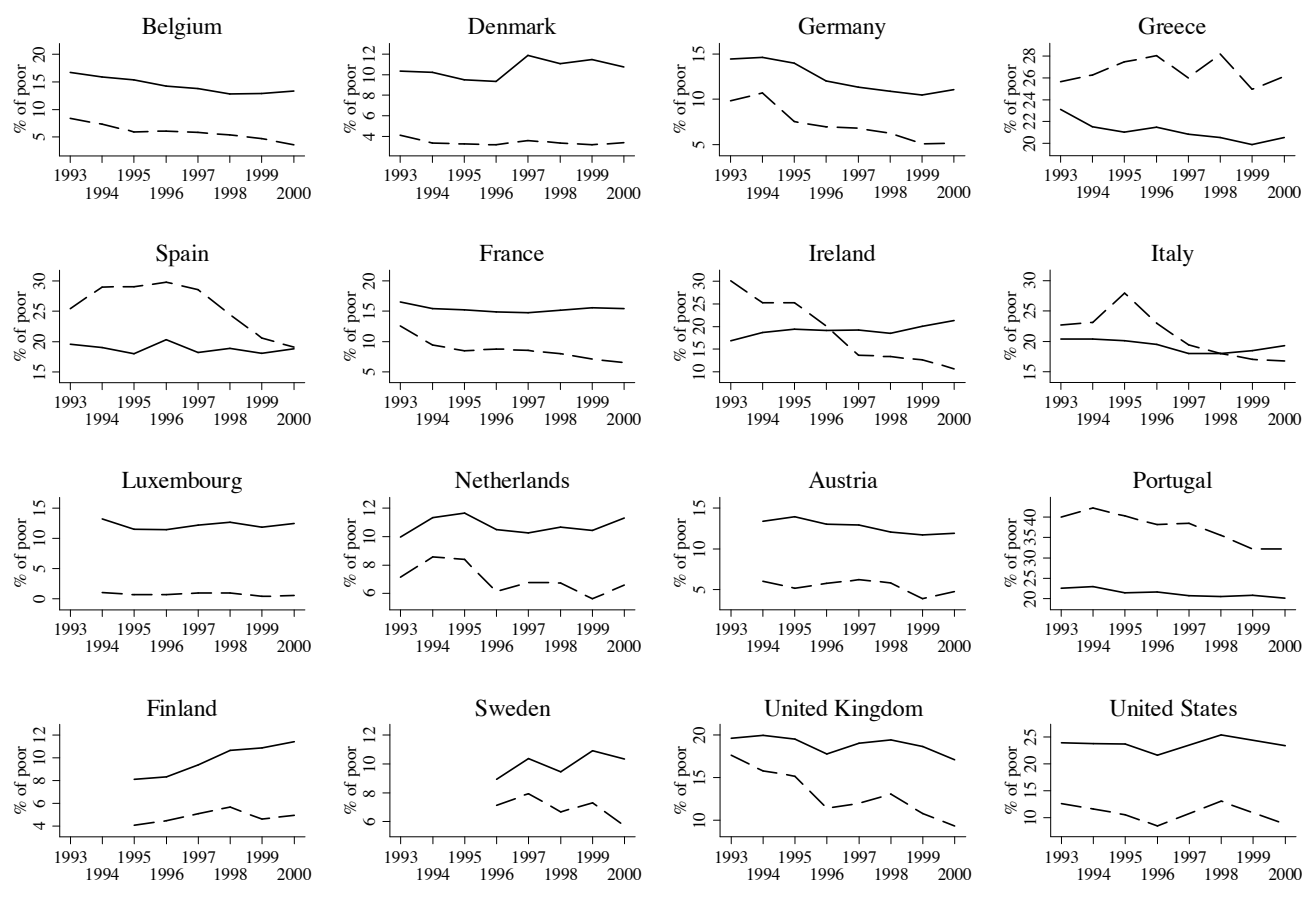

Laeken poverty

Orshansky poverty

Note: To facilitate comparison of Orshansky and Laeken poverty trends within countries, we used different scales on the vertical axes. For the USA there are no observations in 1999 and 1997. Source: Own calculations ECHP and CNEF-PSID

the United States both poverty indicators follow the same trend. In most countries, the Laeken poverty rates are higher than the Orshansky poverty rates but this does not hold for Portugal, Greece and Spain. The difference between Orshansky and Laeken poverty rates is larger in the United States and Luxembourg but considerably smaller in the Netherlands, Denmark and Sweden.

In order to explain and empirically illustrate the impact of methodological and technical decisions in relative and absolute poverty measurement methods we focus on three aspects: differences in poverty levels, poverty trends and poverty risk for particular population groups. Within each of these dimensions the effect of underlying determinants was analysed while keeping everything else equal. Firstly, absolute and relative poverty levels are affected by income inequality and the conversion of the US poverty lines to European price levels. Then, we analyse how absolute and 
relative poverty trends are influenced by inflation and changes in income inequality. Finally, we show how equivalence weighting affects absolute and relative poverty rates differently.

\subsubsection{Differences in poverty levels}

There are two important reasons why the Laeken and Orshansky poverty levels differ within and between countries; differences in inequality (i.e. shape of the income distribution) and the use of Purchasing Power Parity (PPP) rates to convert the US poverty lines to country specific thresholds. Differences in income inequality affect the relative (Laeken) poverty lines but not the absolute (Orshansky) poverty lines. Differences in cost of living and PPP rates affect the value of the Orshansky poverty lines.

\subsubsection{Inequality in welfare}

Relative poverty rates depend on the degree of welfare inequality in a society because the threshold is set relative to the living standard of a 'typical' or 'benchmark' resident in that society. It is important to note that by taking a relative approach to poverty, one is not concerned about inequality as such, but about the welfare inequalities between the typical resident and those residents that have fewer resources than this person. Differences in relative poverty rates between countries (or any other group) arise because in some countries there is more dispersion at the left part of the welfare distribution than in others. ${ }^{20}$ In the Laeken method, the typical resident is the median and the poverty line is set at $60 \%$ of the income earned by the median person. When using the Laeken method (or any similar approach), higher inequality results in higher relative poverty rates; but only under specific conditions. This becomes clear when we try to state these conditions more formally. Firstly, we shift our focus from the whole income distribution to its left part only. ${ }^{21}$ Let $F_{m}(y)$ represent the cumulative income distribution up to the income of the typical resident, $\mathrm{y}(\mathrm{m})$ :

\footnotetext{
${ }^{20}$ Thus, relative poverty methods do not necessarily yield higher poverty rates in a country with more inequality than in a country with less inequality. For instance, countries $\mathrm{X}$ and $\mathrm{Y}$ have exactly the same welfare distribution at and below the 'typical' resident, but above this 'typical' resident the welfare in $\mathrm{X}$ is distributed more equally than in country $\mathrm{Y}$. Country $\mathrm{Y}$ has higher inequality than country $\mathrm{X}$ but any relative poverty method will yield the same poverty rate for country $\mathrm{X}$ and $\mathrm{Y}$.

${ }^{21}$ We illustrate this argument using the median as the benchmark but we could have used the mean as well. In both cases one focuses on the left part of the distribution; in case of the median one focuses exactly on the lower half of the distribution while the mean typically covers a larger part of the distribution (as the mean is more sensitive to outliers in the right part of the distribution).
} 


$$
F_{m}(y)=\int_{0}^{y(m)} f(y) d y
$$

where $f(y)$ is rescaled by $y(m)$ such that $0 \leq y \leq 100$ and $y(m)=100 .{ }^{22}$ The relative poverty line $(z)$ is determined as a constant fraction of the income of the typical resident (see equation 2.4). Now take two countries, whose cumulative income distributions are indicated with $F^{A}(y)$ and $F^{B}(y)$. Country A only has higher relative poverty rates than country B when its cumulative income distribution evaluated at the poverty line, $\mathrm{z}$, lies above that of country B.

$$
F_{m}^{A}(z)>F_{m}^{B}(z)
$$

In other words, there is more income dispersion below the poverty line in country A than in country B. This is a very specific concept of inequality because country B could have higher relative poverty rates if we use other fractions $(\mathrm{k})$ of the income of the typical resident or if we take another moment to select the typical resident. ${ }^{23}$ Relative poverty rates can also contradict other inequality measures as we will illustrate in Table 2.2.

Countries with higher income dispersion below the median have higher relative poverty rates. Moreover, as absolute thresholds do not take distributional characteristics into account, countries with a higher dispersion of income are more likely to have larger differences between absolute and relative poverty rates. ${ }^{24}$ Especially when the absolute threshold is based on an assessment of the minimum needed to cover the basic cost of living in a country, large differences between absolute and relative poverty levels can arise.

We now illustrate the income dispersion within the US and the EU Member States in a number of ways and examine to what extent they are consistent with the poverty outcomes. Figure 2.2 shows boxplots for each country using the 2000 income distribution. ${ }^{25}$ The boxplots are drawn using only the observations in the lower half of the income distribution. We have rescaled income by setting median income in each

\footnotetext{
${ }^{22}$ The rescaling allows us to compare the income distributions of different countries whilst only taking the dispersion of these income distributions into account.

${ }^{23}$ If $F_{m}^{A}(y)>F_{m}^{B}(y)$ for all incomes below $\mathrm{y}(\mathrm{m})$, country A always has higher relative poverty rates then country B.

${ }^{24}$ Additionally, in countries with a high dispersion of incomes around the poverty line, poverty rates are very sensitive to the locus of the poverty line; a slight change in the level of the poverty line can have a large impact on the poverty rates (i.e. the poverty elasticity is high).

${ }^{25}$ Boxplots are a means to graphically summarize a number of key characteristics of a distribution. The box includes all observations within the $25^{\text {th }}$ and $75^{\text {th }}$ percentile and the vertical line within the box indicates the $50^{\text {th }}$ percentile (i.e. the median). The larger the spread of a distribution, the wider the box is. The lines outside the box are called 'whiskers', the end of the whisker does not necessarily indicate the lowest or highest observation. Outliers are located outside the whiskers.
} 
Table 2.2: Indicators of income dispersion and poverty rates (2000)

\begin{tabular}{lrrrrrrr}
\hline & $\begin{array}{r}\mathrm{y}(\mathrm{m}) \\
(\text { in Euro })\end{array}$ & $\begin{array}{r}\text { Gini of } \\
F(y)\end{array}$ & $\begin{array}{c}\text { Gini of } \\
F_{m}(y)\end{array}$ & $\mathrm{z}_{\mathrm{r}} / \mathrm{y}(\mathrm{m})$ & $\mathrm{z}_{\mathrm{a}} / \mathrm{y}(\mathrm{m})$ & $\mathrm{H}_{\mathrm{r}}$ & $\mathrm{H}_{\mathrm{a}}$ \\
\hline Belgium & 15,493 & 0.280 & 0.144 & 0.60 & 0.51 & 13.3 & 3.6 \\
Denmark & 20,620 & 0.216 & 0.139 & 0.60 & 0.50 & 10.8 & 3.4 \\
Germany & 15,760 & 0.253 & 0.142 & 0.60 & 0.54 & 11.1 & 5.1 \\
Greece & 7,119 & 0.328 & 0.200 & 0.60 & 0.80 & 20.5 & 26.1 \\
Spain & 9,034 & 0.327 & 0.191 & 0.60 & 0.70 & 18.8 & 19.1 \\
France & 14,914 & 0.270 & 0.160 & 0.60 & 0.54 & 15.4 & 6.5 \\
Ireland & 14,271 & 0.288 & 0.182 & 0.60 & 0.51 & 21.4 & 10.6 \\
Italy & 10,401 & 0.294 & 0.201 & 0.60 & 0.66 & 19.3 & 16.7 \\
Luxembourg & 23,114 & 0.265 & 0.136 & 0.60 & 0.36 & 12.5 & 0.6 \\
Netherlands & 13,820 & 0.261 & 0.150 & 0.60 & 0.57 & 11.3 & 6.6 \\
Austria & 15,292 & 0.242 & 0.145 & 0.60 & 0.52 & 11.9 & 4.8 \\
Portugal & 5,983 & 0.369 & 0.187 & 0.60 & 0.91 & 20.1 & 32.2 \\
Finland & 14,866 & 0.244 & 0.142 & 0.60 & 0.53 & 11.4 & 4.9 \\
Sweden & 16,353 & 0.242 & 0.142 & 0.60 & 0.54 & 10.4 & 5.7 \\
United Kingdom & 17,724 & 0.306 & 0.179 & 0.60 & 0.52 & 17.1 & 9.3 \\
United States & 24,785 & 0.394 & 0.228 & 0.60 & 0.39 & 23.5 & 8.8 \\
\hline
\end{tabular}

Note: $\mathrm{y}(\mathrm{m})$ adult equivalent median income, $\mathrm{F}(\mathrm{y})$ total income distribution, $\mathrm{F}_{\mathrm{m}}(\mathrm{y})$ income distribution below median, $\mathrm{z}_{\mathrm{r}}$ relative poverty line, $\mathrm{z}_{\mathrm{a}}$ absolute poverty line $\mathrm{H}_{\mathrm{r}}$ (relative (Laeken) poverty rate), $\mathrm{H}_{\mathrm{a}}$ (absolute (Orshansky) poverty rate). $\mathrm{z}_{\mathrm{a}}$ reflects the single working age adult US poverty line.

Source: Own calculations ECHP and CNEF-PSID

country to 100 , so that the horizontal axis is the same for all countries. The wider the box, the larger is the income dispersion below the median. The vertical line in the figure at $60 \%$ indicates the Laeken threshold. Individuals with an income below this line are living in relative poverty. ${ }^{26}$ We can see that countries with higher dispersion below the median also have higher relative poverty rates (United States, United Kingdom, Ireland, Portugal, Italy, Greece, and Spain). The position of the box also matters, if the box of the United States would lie more to the right, relative poverty rates would be lower than in the current situation. This underlines the argument that relative poverty methods use a specific concept of inequality; it is the degree of income dispersion below the median and around the poverty line that ultimately determines the poverty rate.

\footnotetext{
${ }^{26}$ The relative poverty rate can also be read approximately from the figure. Take for instance Luxembourg. For this country the $60 \%$ of median income line coincides with the $25^{\text {th }}$ percentile of the income distribution thus implying a poverty rate of $12.5 \%$.
} 
Figure 2.2: Dispersion of income below median (2000)

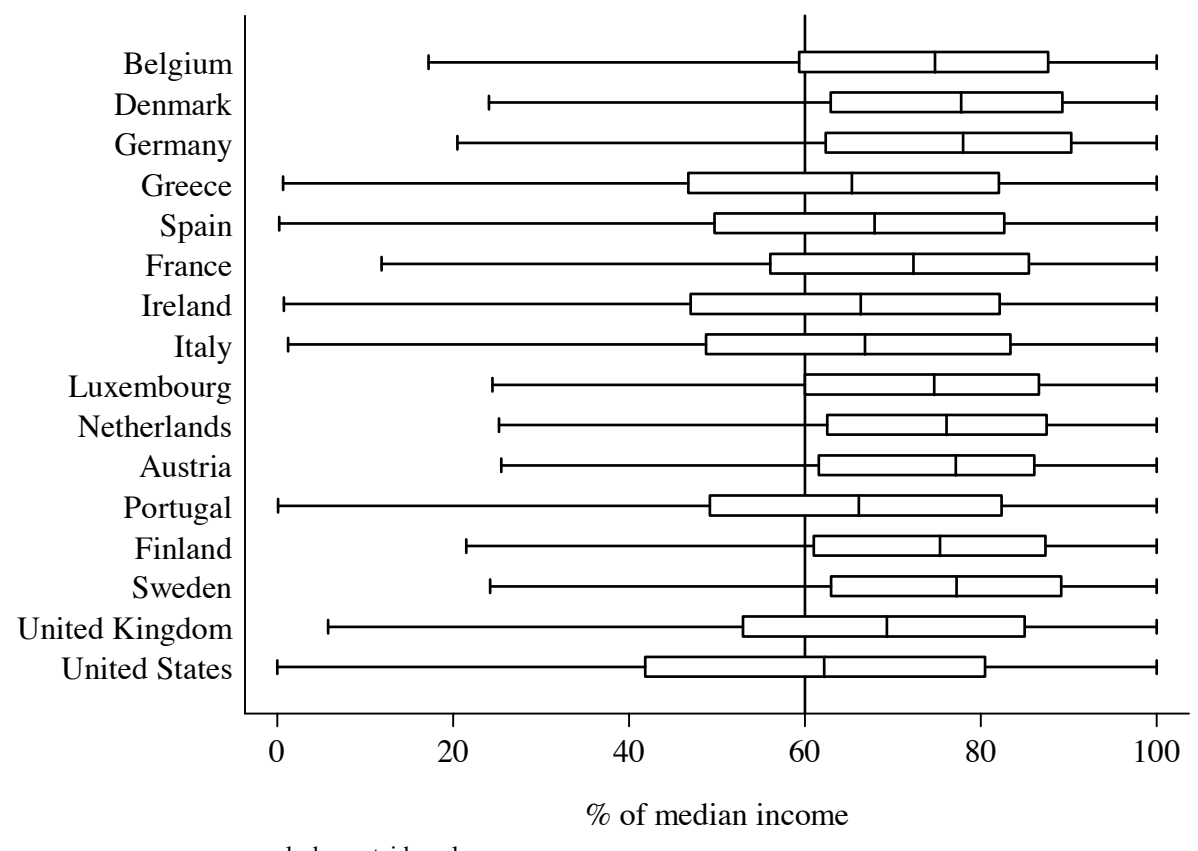

excludes outside values

Source: Own calculations ECHP and CNEF-PSID

Table 2.2 relates the absolute (Orshansky) and relative (Laeken) poverty rates to a number of other indicators of dispersion. The second column displays the national median income expressed in Euros, using the average annual exchange rate in 2000. The third and fourth column show the Gini indices calculated for the whole distribution and for the lower half of the distribution. Countries with a higher Gini for the whole distribution also have a higher Gini for the lower part of the distribution. Empirically, countries that score high on this inequality measure also have higher relative poverty rates. Nevertheless, rankings between countries may differ according to the inequality indicator used. The Dutch Gini is lower than that of Luxembourg, but the Gini taking only the lower half of the distribution is higher in the Netherlands. Moreover, even though inequality below the median is higher in the Netherlands, the Dutch relative poverty rate is lower than that of Luxembourg. A similar observation can be made for Portugal and Spain.

The other columns show the ratio of both poverty lines over median income and the headcount poverty rates. Clearly, differences between the income levels at which the absolute and relative poverty lines are set also affects the discrepancy between absolute 
and relative poverty rates. The extremely large difference between absolute and relative poverty rates in the United States can be explained by the high dispersion of incomes below the median and by the different position of the thresholds; the absolute threshold is much lower than the relative threshold.

\subsubsection{Cost of living}

The countries which we use in our poverty analysis have different currencies and different price levels. International poverty comparisons are only possible when the absolute poverty threshold reflects a similar living standard in each country. Thus, an income equal to the poverty line in Italy should allow a household to purchase the same goods and services as the income value of the poverty line in the United States. To obtain the absolute poverty lines for the European Members States we converted the official 1993 US thresholds using the 1993 Purchasing Power Parity (PPP) rates provided by the OECD. For the other years, we updated the national thresholds using the Consumer Price Index (CPI) of each country. ${ }^{27}$ We discuss the appropriateness of using PPP rates and we show the impact on poverty of using a different benchmark year.

The PPP indices have been developed to accurately compare macroeconomic indicators such as GDP while controlling for differences in price levels and exchange rates between countries. In practise, the PPP indices are used for various purposes, including international poverty comparisons (Schreyer \& Koechlin, 2002; Smeeding et $a l, 2000) .{ }^{28}$ The dollar-a-day poverty estimates of the World Bank are obtained using the same method. The main problem with the PPP rates is that they may not reflect the actual costs of buying those goods and services that are consumed at income levels around the poverty thresholds. One problem is that PPP rates are based on the prices of a goods basket that does not only include consumer products. A second issue is that people with an average income may consume other goods than those with a (below) poverty line income. Moreover, the relative quantities of goods consumed also vary by income; low income individuals or households spend more resources on basic costs of living (food, shelter) while expenditures on luxury goods and leisure activities are proportionally higher as income is higher. The International Comparison Programme

\footnotetext{
${ }^{27}$ An alternative would be to construct for each country (including the US) a minimum goods basket along the same principles but taking into account local consumption habits. Such an effort, although evidently useful, was well beyond the scope and funding resources of this research project. Following the recommendations of a National Academy of Sciences panel (Citro et al., 1995), the US Census Bureau (June 2005) has constructed such a threshold and performed a poverty analysis for the US. Following a very similar method, Soede (2006) has constructed a similar poverty line for the Netherlands.

${ }^{28}$ See Gottschalk et al (2000) and Castles (1996) for a discussion on the use of PPP rates and micro-based data comparisons of well-being.
} 
(ICP) of the World Bank is currently developing so-called Poverty-relevant PPPs (PPPP) which specifically take into account the costs and quantities of goods and services consumed by people living on the threshold level. ${ }^{29}$ The PPPPs are not yet available, so we can only explore differences in poverty using PPP rates. Given our current poverty estimates, we find it difficult to believe that in 1993 about $40 \%$ of the Portuguese had an income that was insufficient to cover the basic cost of living. We expect to find lower absolute poverty rates for countries such as Portugal, Greece, Italy and Spain if the absolute poverty line would be based on the newly developed PPPP rates. ${ }^{30}$

Irrespective of the conversion rate used, poverty estimates are sensitive to the choice of the benchmark year. The PPP rate $(q)$ is defined as the number of currency units required to purchase the amount of goods and services equivalent to what can be bought with one unit of the currency of the base country. For the OECD PPP rates, the US is the base country. ${ }^{31}$ The poverty line (z) of country A at time $t$ is obtained by multiplying the US thresholds with the PPP rate (q) at time t:

$$
z_{A t}=z_{U S t} * q_{t}
$$

Then, for any other year the poverty lines of country A are updated for the cost of living using consumer inflation rates $(\pi)$ :

$$
z_{A t+1}=z_{A t} *\left(1+\pi_{t}\right)
$$

Year to year PPP rates change when the relative cost of living changes between countries (i.e. the inflation rates differ) or when there are changes in the exchange rate. If the costs of living in country A rise with respect to the cost of living in the United States, the PPP rate will increase (and the poverty line in country A as well). Even when inflation rates are constant, changes in the exchange rate influence the PPP rate and thereby the level of the poverty line.

The choice for a particular PPP benchmark year thereby influences the poverty estimates. From 1993 to 2000, there were considerable changes in the PPP rates of countries such as Greece, Spain, Ireland, Italy and Portugal. Take for instance Greece,

\footnotetext{
${ }^{29}$ These PPPPs will be made available in 2007 (ICP Newsletter, volume 3, number 3, October 2006, available on www.worldbank.org).

${ }^{30}$ It is important that an absolute poverty line actually reflects a minimum living standard in a particular country, not only for monitoring socio-economic progress but also for policy making and evaluation (see also Notten and de Neubourg (2007a).

${ }^{31}$ If there is only one good in the basket, the PPP rate would be calculated as follows: $q_{t}=P_{A} * E / P_{U S}$ where $P_{A}$ is the price of this good in country A, $P_{U S}$ the price in the United States and $\mathrm{E}$ is the dollar exchange rate.
} 
Figure 2.3: Impact of PPP benchmark year on absolute (Orshansky) poverty in Greece

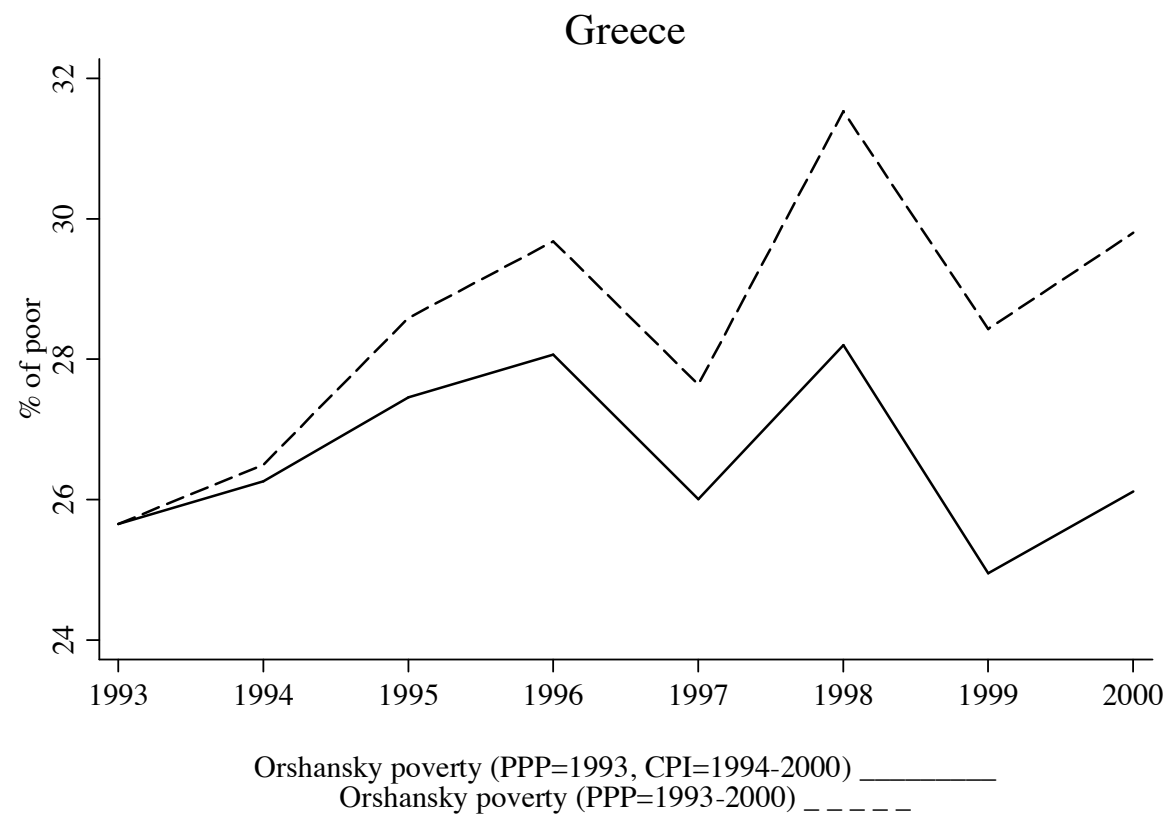

Source: Own calculations ECHP and CNEF-PSID

whose dollar PPP rate increased from 0.494 in 1993 to 0.685 in 2000 (an increase of $38 \%){ }^{32}$ Figure 2.3 shows how absolute poverty in Greece changes by taking different benchmark years for PPP rates. The solid line shows the Orshansky poverty trends using the1993 PPP rates. The dashed line illustrates the Greek poverty rates if we would convert the US thresholds to Greek living standards every year. The impact of choosing a certain base year for PPP conversion on poverty levels is reflected by the vertical distance between the lines. ${ }^{33}$

Thus, if we had used the $2000 \mathrm{PPP}$ rates, the absolute poverty rate in 2000 would be $30 \%$ as compared to $26 \%$. Choosing a different base year therefore has an effect on the level of the absolute poverty rate but does not affect the poverty trend. ${ }^{34}$ The

\footnotetext{
${ }^{32}$ Expressed in ECU/Euro.

${ }^{33}$ The difference in poverty levels in Figure 2.3 may not only arise because of exchange rate trends. It may also be the result of inflation differences between consumer goods $(\pi)$ and the goods basket used for constructing PPP rates.

${ }^{34}$ Converting the thresholds every year using the yearly PPP rates is not a good alternative, particularly if one is interested in studying changes in absolute poverty over time. This is because changes in the exchange rate could then affect the poverty trend.
} 
PPP changes for the other countries were considerably smaller and have therefore a much smaller impact on the level of poverty. Concluding, there is a certain arbitrariness involved in the choice for a benchmark year, although it makes sense not to choose an 'unusual' year in terms of exchange rate or inflation levels. ${ }^{35}$

\subsubsection{Differences in poverty trends}

Orshansky poverty trends are explained by changes in price levels vis-à-vis changes in income while Laeken poverty trends are explained by distributional income changes. We study the impact of these mechanisms on Laeken and Orshansky poverty trends by analyzing the impact of changes in the year to year poverty lines on poverty rates (i.e. the updating mechanism) separately from distributional income changes (i.e. changes in inequality).

\subsubsection{Method for updating the poverty lines}

As shown in equation 2.8, the US thresholds are updated annually with the change in the consumer price index. ${ }^{36}$ This implies that the percentage change in this absolute threshold is equal to the inflation rate.

$\% \Delta z_{a}=\pi$

The updating mechanism of the Laeken threshold is more implicit because the Laeken poverty line is determined by the yearly median income level. Thus, the Laeken threshold is updated every year with the percentage change in median income.

$$
\% \Delta z_{r}=\% \Delta y_{m}
$$

\footnotetext{
${ }^{35}$ Most of the EU-15 countries were member of the European Monetary System (EMS) during the observed period and were thus involved in a joint effort to curb volatility of exchange rates. We preferred not to use the late nineties because in these years the EMS was replaced by the European Monetary Union (EMU) which introduced a common currency for most of the Member States. Speculations on the success of these policy changes affected the exchange rates between those countries adopting the Euro and those not (United Kingdom, Sweden, Denmark) as well as those with the most important reserve currency in the world, the US Dollar. Furthermore, we chose 1993 simply because it was the first year in our data.

${ }^{36}$ In addition to price changes, consumption patterns also change in a more structural way over time. For example, as the living standard of a country increases people typically spend a smaller share of their resources on food. As a consequence, the average food ratio will decline. Alternatively, certain goods (i.e. telephone, computer) increasingly play role in satisfying basic needs. Generally, the view is that such changes also need to be reflected in an absolute poverty line but that such adjustments should be made once every 5 or 10 years (Citro et al., 1995; Soede, 2006).
} 
Figure 2.4: Change in poverty lines due to different updating mechanisms

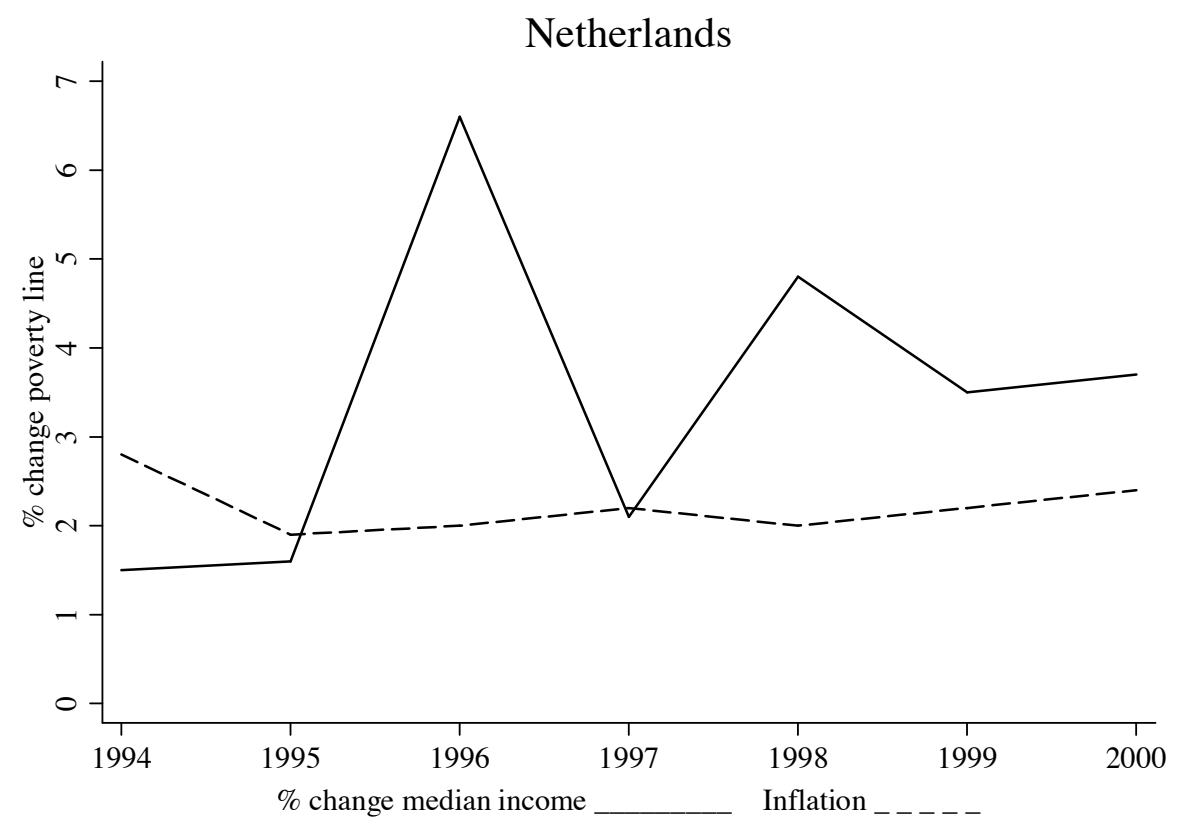

Source: Own calculations ECHP and CNEF-PSID

In the countries we study here, low and stable inflation is an explicit monetary policy target and the monetary authorities are rather successful in achieving this target. As a result, price changes are less volatile than changes in economic growth (and income) over the business cycle. This implies that the updating mechanism used in the Laeken indicator functions as an in-built stabilizer on the poverty rates. In good times, the threshold is increased by the increase in median income but in bad times, the threshold could even decline (or increase by less than the inflation rate, a decline in real terms). Figure 2.4 illustrates with which growth rates the Orshansky and Laeken poverty lines are updated for the Netherlands.

Figure 2.5 shows the effects of both updating methods on poverty trends for all countries. To isolate the effect of the updating mechanism we start from the relative poverty threshold in 1993 and update this threshold using both methods. ${ }^{37}$ Subsequently, we calculate the poverty rate according to each updating mechanism. The updating methods influence the poverty trends in all countries; over time we can see a divergence

\footnotetext{
${ }^{37}$ For Austria, Finland and Sweden we start with the year in which their first survey was held.
} 
Figure 2.5: The impact of updating mechanisms on poverty incidence
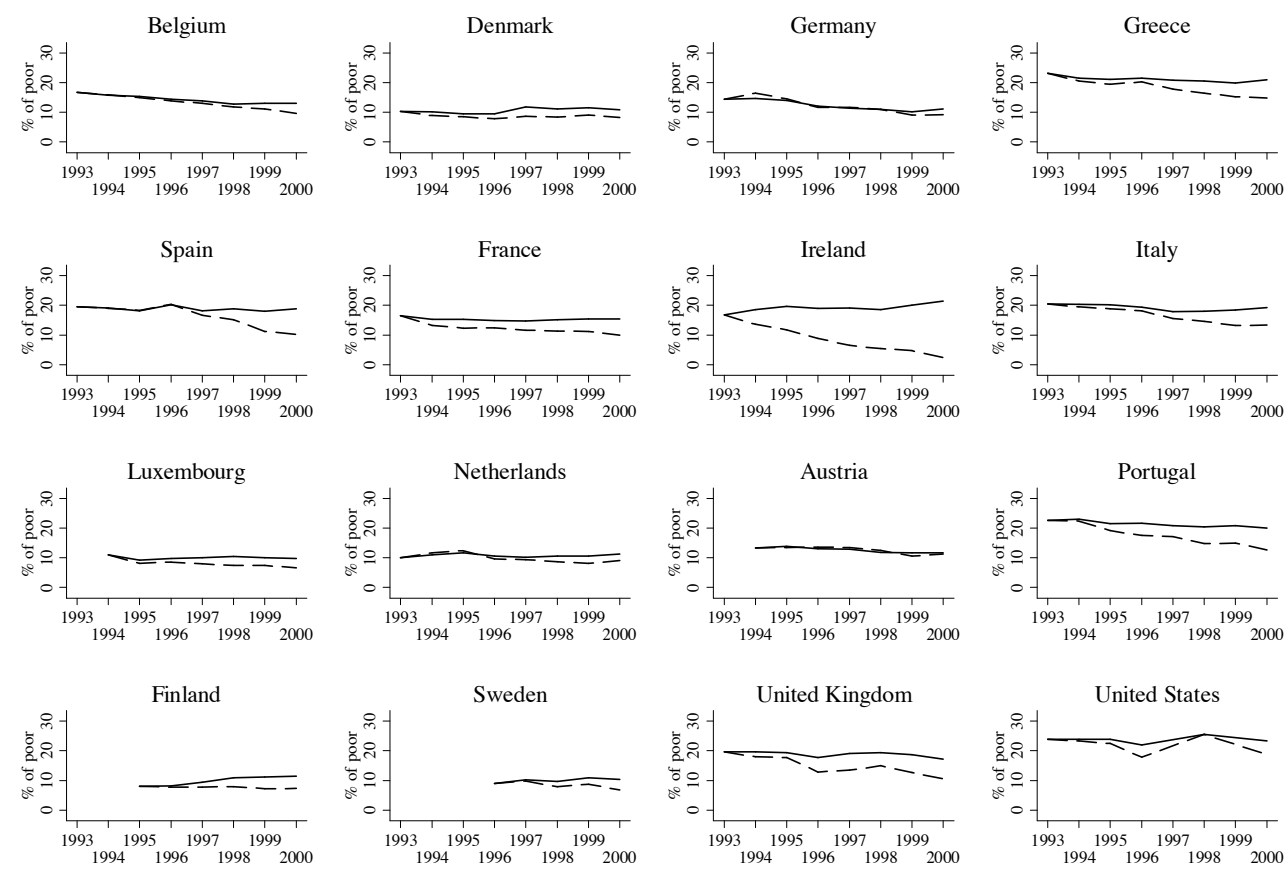

Update change median income

Update Consumer Price Index

Note: For the USA there are no observations 1999 and 1997.

Source: Own calculations ECHP and CNEF-PSID

in poverty trends with higher poverty rates when the change in median income as used as an updating mechanism. Divergence in trends is largest for countries that experienced high economic growth. This happens when median income levels also benefit from real economic growth; then the poverty line is not only adjusted for inflation but it is also adjusted for real income changes in society. Ireland is the extreme case in this respect, because the poverty trends are not just diverging but even move into the opposite direction. Also, the poverty trends with the Laeken updating mechanism appear more stable than the trends using inflation updating. This observation empirically supports the hypothesis that the Laeken updating mechanism has a stabilizing effect on the poverty rates. 


\subsubsection{Changes in inequality}

The previous section discussed that relative poverty lines are adjusted over time, in line with economic development. Another key factor in explaining poverty trends is distributional change (i.e. changes in inequality). Typically, the costs and benefits of economic development are not equally distributed across the (income) distribution. Income changes at the lower end of the income distribution also affect relative and absolute poverty trends. The intuition is as follows. Relative poverty rates do not change when all incomes grow at the same rate. This is because the relative poverty line and everyone's income are updated with the same percentage growth rate. If the income of the poorer percentiles of the population grows less than that of the median; relative poverty rates are likely to increase. When the income of low income groups increases in real terms, absolute poverty declines.

We use growth incidence curves (GIC) to further illustrate this argument. A GIC shows the growth of income at each percentile of the distribution. Using the cumulative income distribution (CDF) specified in equation 2.1 and following Ravallion and Chen (2003), inverting the CDF at the $\mathrm{p}^{\text {th }}$ quantile gives the income of that quantile:

$$
y_{t}(p)=F_{t}^{-1}(p)=L_{t}^{\prime}(p) \mu_{t} \quad\left(y_{t}^{\prime}(p)>0\right)
$$

where $L_{t}(p)$ is the Lorenz curve (with slope $L_{t}^{\prime}(p) \mu_{t}$ and the mean $\mu_{t}$ ). The Lorenz curve shows the income share of total income owned by the bottom percent of the population (when incomes are ranked from low to high). The growth rate in income of the $\mathrm{p}^{\text {th }}$ quantile is:

$$
g_{t}(p)=\left[y_{t}(p) / y_{t-1}(p)\right]-1
$$

Letting $\mathrm{p}$ vary from zero to one, $g_{t}(p)$ indicates the growth incidence curve. It follows from equation 2.11 that:

$$
g_{t}(p)=\frac{L_{t}^{\prime}(p)}{L_{t-1}^{\prime}(p)}\left(\gamma_{t}+1\right)-1
$$

where $\gamma_{t}=\left(\mu_{t} / \mu_{t-1}\right)-1$ is the growth rate of average income $(\mu)$. Thus, if there are no changes in inequality (i.e. the Lorenz curve stays the same), the GIC will be a flat line at the average income growth rate. If $g_{t}(p)$ is a decreasing function for all $\mathrm{p}$, then inequality is reduced over time (and vice versa).

A GIC explains the growth patterns of the aggregate distribution. It does not necessarily reflect the experienced income growth of the individuals or households 
making up that distribution because they can also move within the income distribution; individuals lose a job, get promotion, retire and thereby change their position in the income ranking. Being poor (or not) is a status which applies to individuals and not to $\mathrm{p}^{\text {th }}$ quantiles. Nevertheless, GIC's are a useful tool to explain poverty trends because trends in aggregate poverty measures can, to a large extent, be explained by changes in the income distribution.

For simplicity, imagine a world with no distributional mobility (individuals do not switch ranks in the income distribution) or, equivalently, there is mobility, but each move in rank is compensated by a countervailing move. The absolute poverty is only adjusted for inflation. In such a situation, changes in absolute poverty can be entirely explained by the real income changes of the percentiles around the poverty line. Everything else equal, absolute poverty increases (decreases) when the real income growth rates of those percentiles just above (under) the poverty line are negative (positive). For relative poverty rates the argument changes because the poverty line is determined endogenously by the income distribution. In the case of the Laeken approach, relative poverty rates can be explained by a combination of the real income changes of the percentiles around the poverty line and those of the median $\left(50^{\text {th }}\right.$ percentile). Relative poverty increases (decreases) when the real growth rate at the median is higher (lower) than the growth rates of the percentiles above (below) the poverty line.

The GIC's for each country using the 1993 and 2000 income distributions are displayed in Figure 2.6 and express average annual real growth rates. For most countries, the growth rates are averaged over eight years. The curve shows the GIC and the horizontal line reflects the average annual growth rate of median income. ${ }^{38}$ If all incomes grow at the same rate, the GIC is flat and there are no changes in inequality. Note that the GIC's are drawn comparing the 1993 and 2000 income distributions; they do not necessarily reflect inequality changes occurring between intermediate years.

The growth patterns of the countries are very different in terms of levels of growth as well as in the way growth in income is distributed over the population. In many countries, the lower end of the income distribution benefited most from economic growth, but this is not the case in Denmark, Finland, Sweden, the Netherlands and Ireland where the opposite pattern occurs. To see how poverty trends can be explained by these growth patterns, we need to focus on those income percentiles around the poverty line and the median percentile (the latter only for Laeken poverty). The case

\footnotetext{
${ }^{38}$ To enhance comparability between countries, we excluded the lowest and highest 5 percentiles because they had a too large effect on the scaling of the vertical axis. For the same purpose, we allowed the scale of the vertical axis to differ by country.
} 
Figure 2.6: Growth incidence curves (expressed in real annual growth rates, based on income distributions of 1993 and 2000)
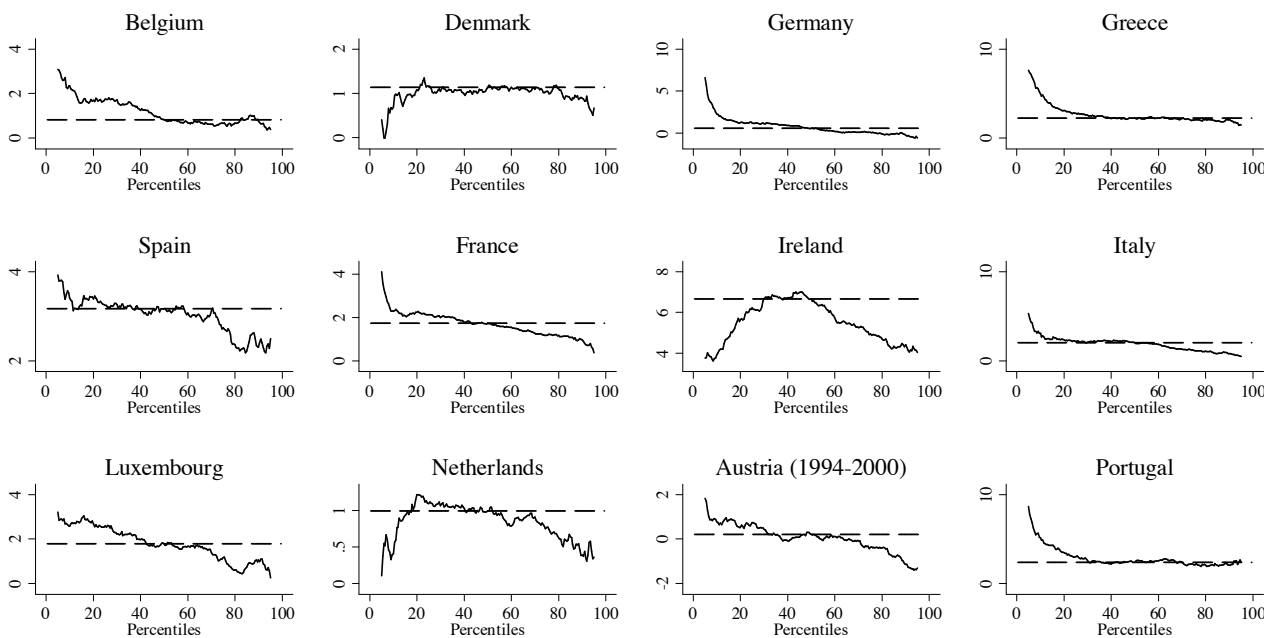

Finland (1995-2000)
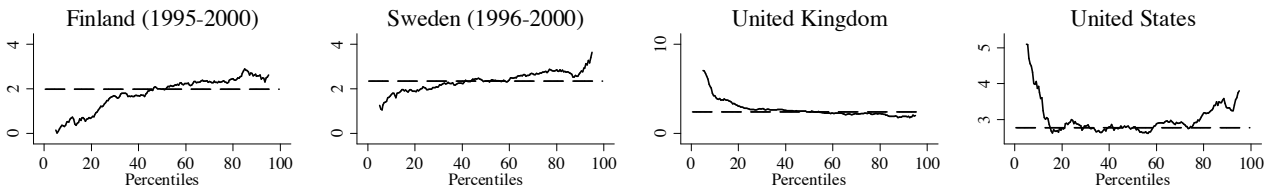

Annual growth rate income

Annual growth rate median income

Note: To facilitate comparison of Orshansky and Laeken poverty trends within countries, we used different scales on the vertical axes and excluded the lowest $5 \%$ and highest $5 \%$ observations.

Source: Own calculations ECHP and CNEF-PSID

of Ireland clearly illustrates these effects. ${ }^{39}$ In the period from 1993 to 2000, Ireland experienced rapid economic growth. Every percentile benefited from this growth; percentile income growth rates are mostly at or above $4 \%$ per annum. As the Orshansky threshold did not change in real terms, absolute poverty rates in Ireland have decreased.

\footnotetext{
${ }^{39}$ Our analysis of Ireland confirms what other contributions that specifically studied poverty in Ireland have found (Maitre et al, January 2006; Whelan et al, November 2003; Whelan et al, February 2006). In these contributions, developments in the relative Laeken poverty indicator are compared to the trend of a deprivation index: these studies report significant reductions in the number of deprived people from 1994 to 2001. This is because the deprivation index and our Orshansky poverty indicator both monitor real improvements in economic well-being while the Laeken indicator captures only relative improvements in well-being. Nevertheless, our cross-national comparisons emphasize the diversity in absolute and relative poverty experiences across countries: even among the faster growing member states the Irish experience is extreme.
} 
In 1993, 30\% of the Irish had an income below the Orshansky threshold and in 2000 this figure had decreased to below $11 \%$ (Table 2.7 in the appendix). However, the GIC from Ireland shows that the middle income groups benefited much more than other groups; median income growth was above $6 \%$. The relative poverty threshold therefore also increased by more than $6 \%$ per annum while the growth rates around the poverty line percentiles (16-21) were about $5 \%$. Relative poverty consequently increased from $17 \%$ in 1993 to $21 \%$ in 2000 in Ireland. For most of the countries, the GIC patterns explain the poverty trends rather well, although at low poverty rates and/or low growth rates it is more difficult to graphically show the effects. Note that there are contrasting experiences among the faster growing countries (Greece, Spain, Portugal, and Ireland). In Greece, Spain and Portugal the lower 20 percentiles had higher growth rates than the median income percentile while Ireland experienced the opposite.

\subsubsection{Equivalence scales and the impact on poverty rates}

Equivalence scales adjust for the economies of scale that larger households have as compared to a single person household. They also adjust for differences in cost of living for different age and/or gender groups. Cross-national poverty comparisons typically apply the same equivalence scales to every country even though it is likely that such costs differ between countries. The Laeken and Orshansky methods also use different equivalence scales. We explore how these weighting schemes differ and how they affect the Laeken and Orshansky poverty estimates.

The modified OECD equivalence scales used in the Laeken indicator assign a weight to each household member. The first adult receives a weight of one and subsequent adults get a weight of 0.5 . Children aged below 14 , each obtain a weight of 0.3. A household consisting of two parents and two children thus receives a weight of 2.1. Adult equivalent income is obtained by dividing a household's income by 2.1. All individuals in the household are poor when the adult equivalent income lies below the adult equivalent poverty line. The Orshansky equivalence scales are derived from the 48 poverty lines; which poverty line is applied depends on the number and age of the household members. Household members under the age of 18 are counted as children. For the single and two person households a further distinction is made with respect to the age of the head of the household. If the head is older than 65 , the household has a lower threshold. We calculated these implied Orshansky equivalence scales by taking the single adult household poverty line as a benchmark. ${ }^{40}$

\footnotetext{
${ }^{40}$ For example, the poverty line of a single adult is $\$ 1,000$ and $\$ 2,000$ for a household consisting of two adults and two children. The (implied) equivalence weight of the latter household is $\$ 2,000 / \$ 1,000=2$.
} 
Table 2.3: Total household weight using various equivalence weighing schemes

\begin{tabular}{lllll}
\hline Household types & Individual & $\begin{array}{l}\text { Modified OECD } \\
\text { scales (Laeken) }\end{array}$ & $\begin{array}{l}\text { Implied } \\
\text { Orshansky scales }\end{array}$ & Household \\
\hline Single adult & 1 & 1 & 1 & 1 \\
Single elderly & 1 & 1 & 0.92 & 1 \\
Adult couple & 2 & 1.5 & 1.29 & 1 \\
Elderly couple & 2 & 1.5 & 1.16 & 1 \\
Single parent, one child & 2 & 1.3 & 1.32 & 1 \\
Single parent, two children & 3 & 1.6 & 1.55 & 1 \\
Parents one child & 3 & 1.8 & 1.55 & 1 \\
Parents two children & 4 & 2.1 & 1.95 & 1 \\
Parents three children & 5 & 2.4 & 2.29 & 1 \\
\hline
\end{tabular}

Table 2.3 compares the total household weights for a number of household types using the OECD and Orshansky weighting schemes. We have also included two extreme scales; the individual scheme which gives a weight of one to every individual and the household scheme which gives a weight of one to each household, irrespective of its composition. Single elderly households get a weight of one for all schemes except the Orshansky scheme, which attributes a weight of 0.92 . Thus, single elderly 'need' only $92 \%$ of the income required for a single adult. Compared to the household and individual weighting schemes the OECD and Orshansky scales are rather similar. For most household types the Orshansky scales have a lower value than the OECD scales, which implies that the Orshansky scales assume lower cost to reach the same level of economic well-being. ${ }^{41}$ In contrast to the OECD scales, the Orshansky scales often give a slightly higher weight to children than to additional adults. For instance, single parents with one child receive an Orshansky weight of 1.32 and an OECD weight of 1.3. For an adult couple household the OECD weight is 1.5 while the Orshansky weight is 1.29. Even though the differences between the Laeken and Orshansky equivalence scales are not so large, they can have a considerable impact on overall poverty rates as well as on poverty rates for certain groups in society. The impact is especially large when differences in equivalence scales apply to large parts of the population.

Equivalence scales also affect the Laeken and Orshansky poverty rates differently. To see this, the adult equivalent income (y) of household $\mathrm{i}$, is obtained by dividing household income by its equivalence scale $E_{i}$. Then, for most households the OECD

\footnotetext{
${ }^{41}$ For some more atypical households, notably households with many children and relatively few adults, the Orshansky scales indicate a higher cost than the modified OECD scales.
} 
equivalence scale is larger than the Orshansky equivalence scale, resulting in a lower equivalent adult income. Using the same absolute (equivalent adult) poverty line, it can easily be seen that absolute poverty rates using the Orshansky weights are higher than with the OECD scales. If, for most households, $E_{O E C D}>E_{\text {orshansky }}$, then $y_{O E C D}<y_{\text {orshansky }}$ and for a given $z_{a}$ then $H_{O E C D}>H_{\text {orshansky }}$.

Knowing the weighting schemes is not sufficient to predict how equivalence schemes affect the relative poverty rates. This is because the equivalence scales not only weigh income differently, but they also determine the locus of the relative poverty line as median income $\left(\mathrm{y}_{\mathrm{m}}\right)$ is also affected by the weights. The net effect on poverty depends on the demographic composition of the population (the relative size of the three generations and how they are spread over household types) and the income of these households. If, for most households, $E_{O E C D}>E_{\text {orshansky }}$, then $y_{O E C D}<y_{\text {orshansky }}$

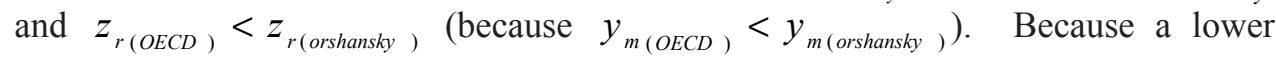
equivalent adult income tends to increase poverty rates while a lower poverty line decreases poverty rates, the net impact on relative poverty is not clear.

We have calculated the 2000 Laeken and Orshansky poverty rates using the modified OECD equivalence scales and the implied Orshansky weights. Figure 2.7 shows the impact of both weighting schemes on the overall poverty rates by illustrating the percentage point difference for each poverty indicator (poverty rate using OECD equivalence scale minus poverty rate using implied Orshansky scale). As expected, Orshansky poverty rates are higher when using the modified OECD scales. For example, in Ireland Orshansky poverty rates are 5 percentage points higher if we would apply OECD equivalence scales. The differences in Laeken poverty rates are much smaller and are positive in some countries while negative in others. In general, relative poverty rates are less sensitive to the use of different equivalence scales. The magnitude of these differences varies by country and may thus affect international poverty rankings. The 2000 Orshansky poverty rate is $5.7 \%$ in Sweden and 5.1\% in Germany. When Orshansky poverty rates are computed using the modified OECD scheme, poverty is now $6.8 \%$ in Sweden and $7.7 \%$ in Germany (Germany is now ranked above Sweden).

We also illustrate the impact of the Orshansky and OECD weighting schemes for six household types: single adult, single elderly, adult couple, elderly couple, single adult with child(ren) and two adults with child(ren) (Figure 2.8). As the number of observations for single parents is very low in some countries, the results for this group should be interpreted with caution. Generally, Orshansky poverty risk increases for most household types when modified OECD weights are applied (excluding single adult households as they have the same weight). Austria is the only country where single parents (of one or more children) have a lower poverty rate using the Orshansky scales. The higher the proportion of a particular household in a population, the larger 
Figure 2.7: Difference between Laeken and Orshansky poverty rates due to different equivalence schemes (in percentage points)
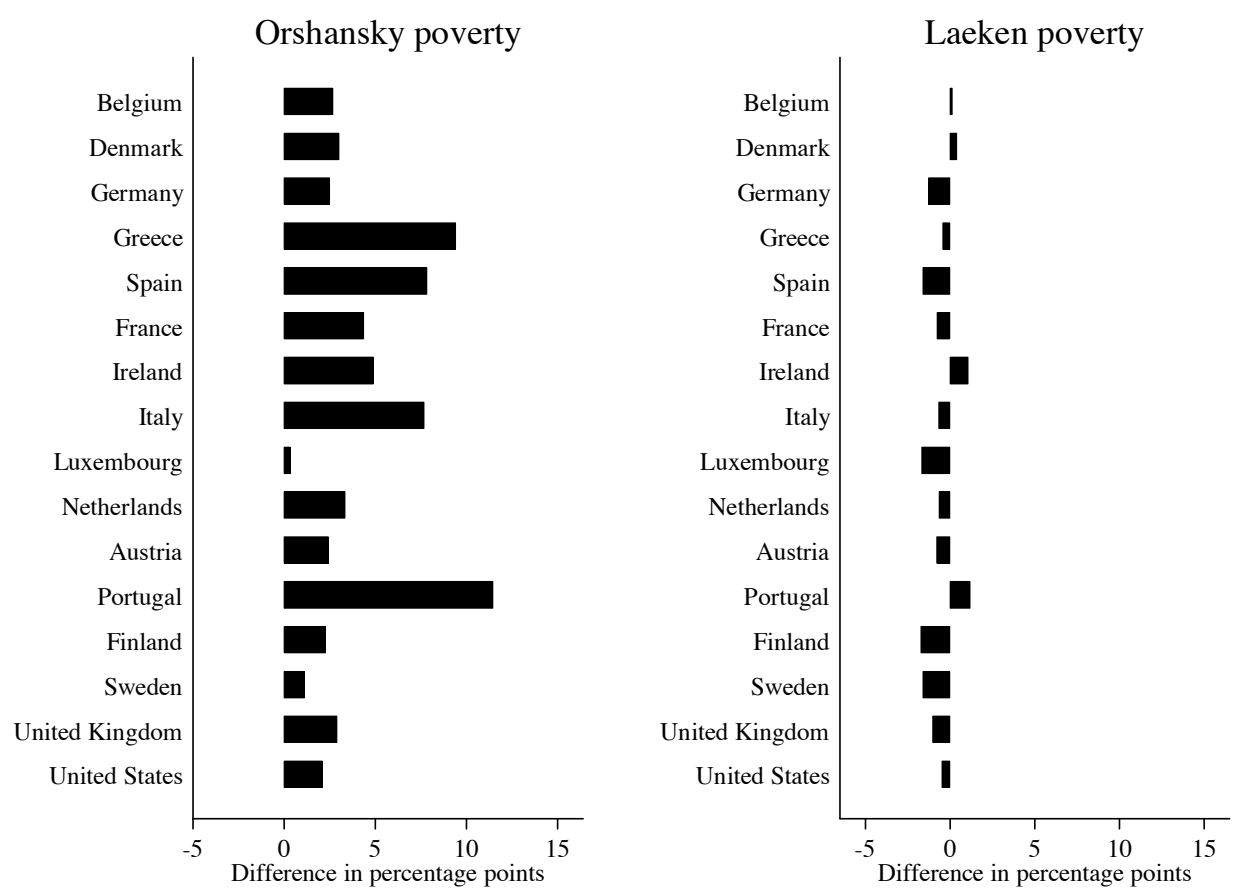

Note: The bars reflect the difference in poverty rate using OECD equivalence scale minus the poverty rate using implied Orshansky scale.

Source: Own calculations ECHP and CNEF-PSID

is its effect on Orshansky poverty rates. The figure further shows that the small overall Laeken poverty differences mask considerable changes in relative poverty risk for different household types. The poverty differences are negative for some household types and positive for other types but the direction of the effect is common between countries. Poverty rates among elderly couples are greater in all countries when using OECD equivalence scales while poverty rates among single adults, single elderly and single parents are lower. The differences for adult couples and parents with children are only small. Thus, equivalence scales affect the relative poverty risks of groups in society; using a different equivalence scale alters the poverty risk of one group relative to the other. Knowing the equivalence weighting schemes, it is easy to assert the direction of change in absolute poverty risk for a certain population group or household type but the magnitude of the effect is determined by the share in the population of 
Figure 2.8: Difference between Laeken and Orshansky poverty rates due to different equivalence schemes (by household type, in percentage points)
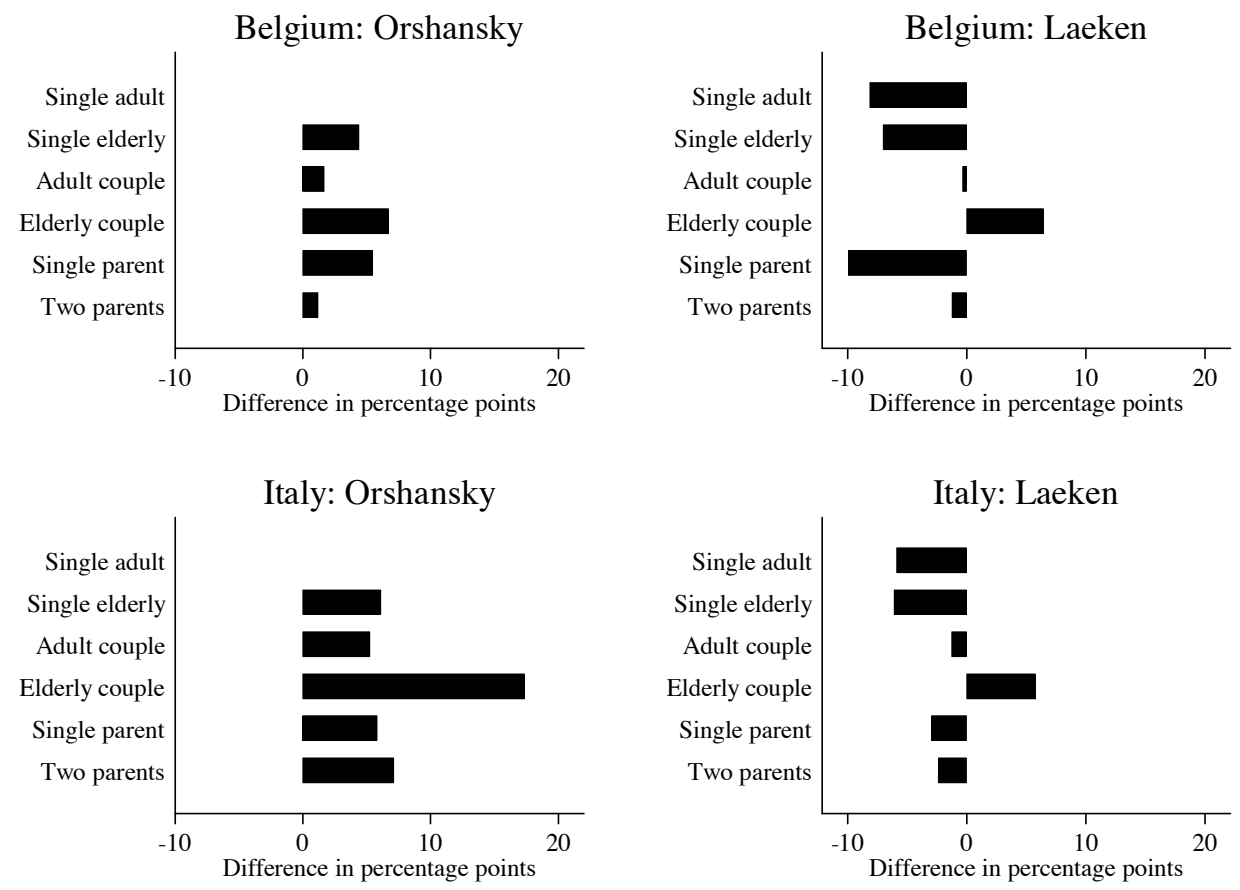

Note: The bars reflect the difference in poverty rate using OECD equivalence scale minus the poverty rate using implied Orshansky scale.

Source: Own calculations ECHP and CNEF-PSID

that particular group. If children receive a higher equivalence weight, child poverty increases. Using a relative approach to poverty, the direction of change in poverty risk for specific groups depends not only on the equivalence weights but also on the composition of the population.

\subsection{Conclusion}

US poverty is much higher than poverty in Europe when a relative poverty measure is used. Using an absolute poverty measurement method, the picture looks different: poverty in some European countries is higher. Over time, both poverty indicators may develop in a parallel, converging or diverging fashion. In this study we applied the official poverty measurement methods of the United States and the European Union 
to both regions in order to explain underlying reasons for these differences in relative and absolute poverty. We used within and between country perspectives to explain differences in poverty levels and trends and showed the impact of each of these aspects on poverty levels and poverty trends while keeping other explanatory factors constant. Poverty figures reflect the net outcome of a complex set of factors. On the one hand they incorporate (changes in) the welfare dimensions they are meant to capture (minimum living standard, income inequality, economic development). On the other hand, technical aspects such as PPP rates and equivalence scales also have considerable influence on poverty rates. Our paper showed that there is a lot of variation across countries in the relative importance of each of these technical aspects on the difference between absolute and relative poverty headcounts.

As absolute poverty concepts are based on a minimum acceptable living standard while relative poverty concepts are distribution dependent (but in a very specific way), resulting differences between poverty levels and trends across countries are explained by the interplay of distributional and non-distributional factors. The degree of income dispersion at and below median income influences relative poverty rates but also resulting differences with absolute poverty levels. Countries with wider income dispersion have higher relative poverty levels and the gap between absolute and relative poverty rates is more likely to be wider. However, over time, this gap between absolute and relative poverty levels may change. We showed that poverty trends are affected firstly by changes in the year to year poverty lines (i.e. the updating mechanism) and secondly by distributional income changes (i.e. changes in inequality). While absolute poverty lines are updated with the inflation rate, the Laeken relative poverty line changes with the percentage growth rate of median income. The final impact on both poverty indicators, however, depends on the degree of real income change at the lower end of the income distribution; real income increases are sufficient to reduce absolute poverty while income increases at the lower end need to be higher than proportional in order to reduce relative poverty. Although relative and absolute poverty indicators each evaluate the outcome of economic development by focusing on its impact on low income levels, their perspective on what constitutes progress in welfare is different; the absolute indicator evaluates real progress while the relative indicator only detects progress when it is more than proportionally shared. In sum, this research showed that the relation between a minimum income standard and inequality in the lower part of the income distribution differs considerably between countries and that this relation is also not stable within a country over time.

Furthermore, in international poverty comparisons, PPP rates are often used to compare absolute poverty. However, differences in the development of living standards between countries are reflected in the PPP rate and thereby also affect the estimates 
of absolute poverty in a country. Taking a different base year for the conversion of a foreign absolute poverty line can amount to a difference of various percentage points in headcount rates, particularly for fast growing economies. We also showed that equivalence scales change the shape of the income distribution and that even seemingly small differences in weights have a very large effect on estimating the number of poor. The net difference in headcount poverty is much larger for an absolute poverty indicator than for a relative indicator. Nevertheless, differences between equivalence scales significantly change the poverty risk of population groups for both indicators. The effect of equivalence scales on poverty risk, however, is also determined by the composition of the population in a country as well as their typical living arrangements.

This suggests that it makes sense to use both absolute and relative poverty indicators. Absolute poverty analyses provide insights into the parts of the population that do not attain the minimum living standard. Relative poverty analyses inform about the group of people whose living standard is low compared to that of the society they live in. Relative and absolute approaches thus each portray different but common perceptions of poverty. Monitoring one dimension does not provide information on developments in the other dimension. Ignoring one dimension may lead to developments in society that at some point may conflict with societies' preferences. In sections 2.3 and 2.4.1.2 we discussed a number of drawbacks regarding the method that we used in this paper to construct the absolute poverty lines. What is important for the public and policy making is that an absolute poverty line actually gives an indication of the level of resources that is needed to satisfy a range of basic needs in a particular country. The limitation of our method is that the absolute poverty lines we used may not reflect such a minimum living standard. ${ }^{42}$ We therefore do not propose to use this method when developing a comparable absolute poverty indicator for the EU member states. 'Anchoring' a relative poverty line is however not a proper alternative. An anchored poverty line is a relative poverty line that is updated to subsequent years using the inflation rate (the EU Laeken indicators also include an anchored relative poverty line). The problem with an anchored line is that the initial level of the poverty line is based on the income distribution and not on the costs of satisfying basic needs. Moreover, the analysis of growth incidence curves has shown that incomes grow differently across the income distribution. Thus, when an anchored relative poverty line differs considerably from that of an absolute poverty line, they may still show different trends in poverty.

Even though most countries in the developed and developing world report (semi) official poverty statistics on a regular basis, only few countries actually report both absolute and relative poverty statistics. In fact, it is not easy to find comparable

\footnotetext{
${ }^{42}$ Nevertheless, our absolute poverty lines behave in the same way as those that would be based on actual minimum living standards.
} 
absolute and relative poverty data (the poverty research based on the Luxembourg Income Study (LIS) data being a noteworthy exception). Unfortunately, it seems that a 'battle of the rates' takes place only when deciding about which official poverty indicator to choose (EU) or to discuss the deficiencies of the current indicator (US and EU). In the USA, a national academy of sciences panel proposed an improved absolute poverty indicator (Citro et al., 1995). Relative poverty indicators do not seem to play any role of significance. Although in the USA inequality may generally be perceived as less problematic than in Europe, does that mean that any level of inequality is acceptable or that the situation of those having considerably less than the rest should not be monitored? Differences between absolute and relative poverty indicators are extremely large in the US; what are the implications for a society if about one quarter of its population has much less than its middle person? And why does the EU only use a relative approach while differences in living standards between Member States are large and have further increased with current expansions of the European Union? How should we interpret the fact that the Czech Republic has the lowest Laeken poverty rate within the EU? If the Laeken indicators were to be complemented with an absolute poverty indicator reflecting the cost of achieving a minimum living standard in each member state (including costs such as food, rent, clothing, health and education), the impact of the reforms resulting from the European integration process could also be evaluated from this perspective. The new Member States are still in the process of restructuring their economies and it is expected that there will be strong economic growth; all reasons for expecting divergence between absolute and relative poverty levels and trends in these countries.

\subsection{Appendix: summary statistics}




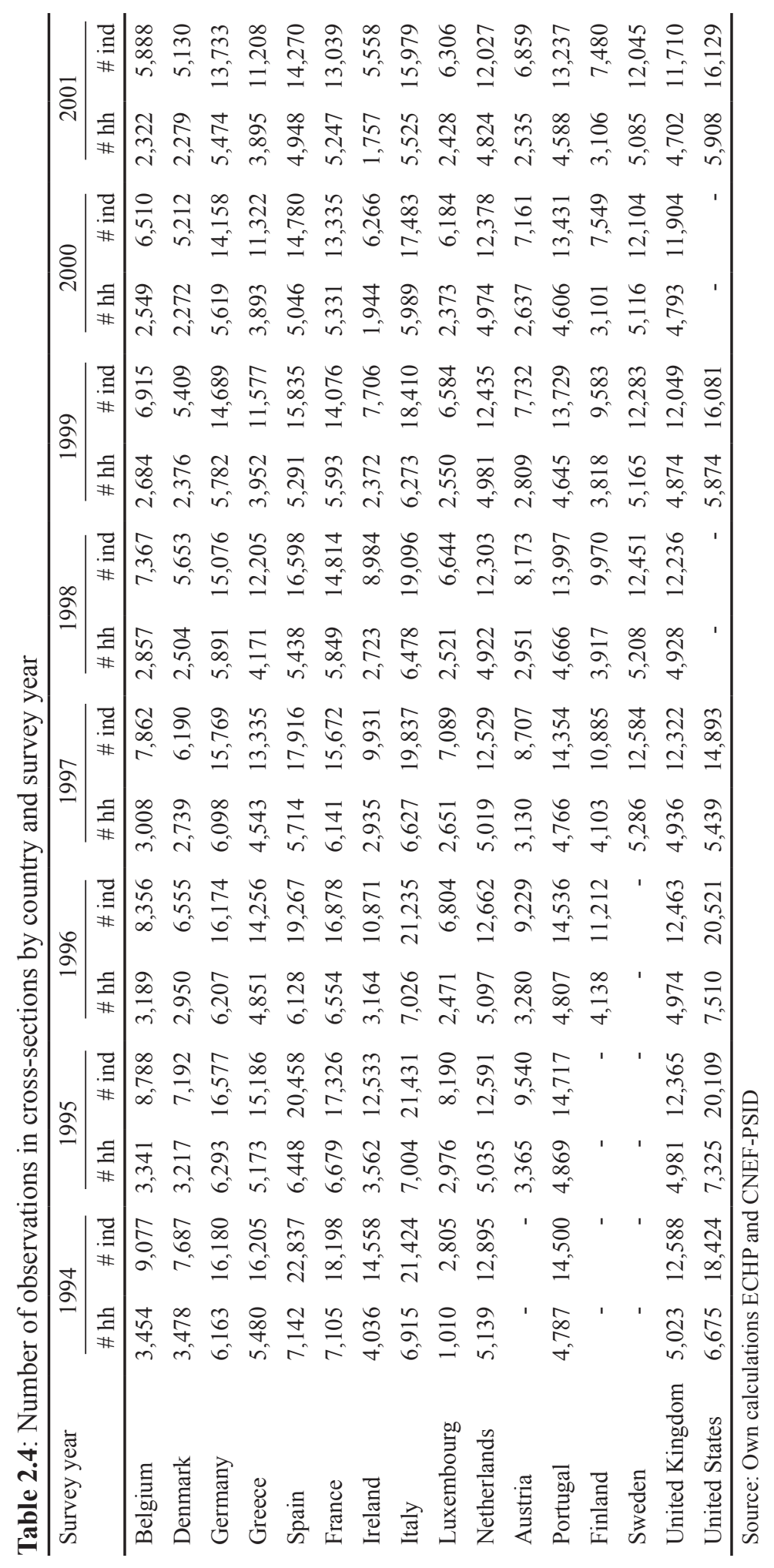




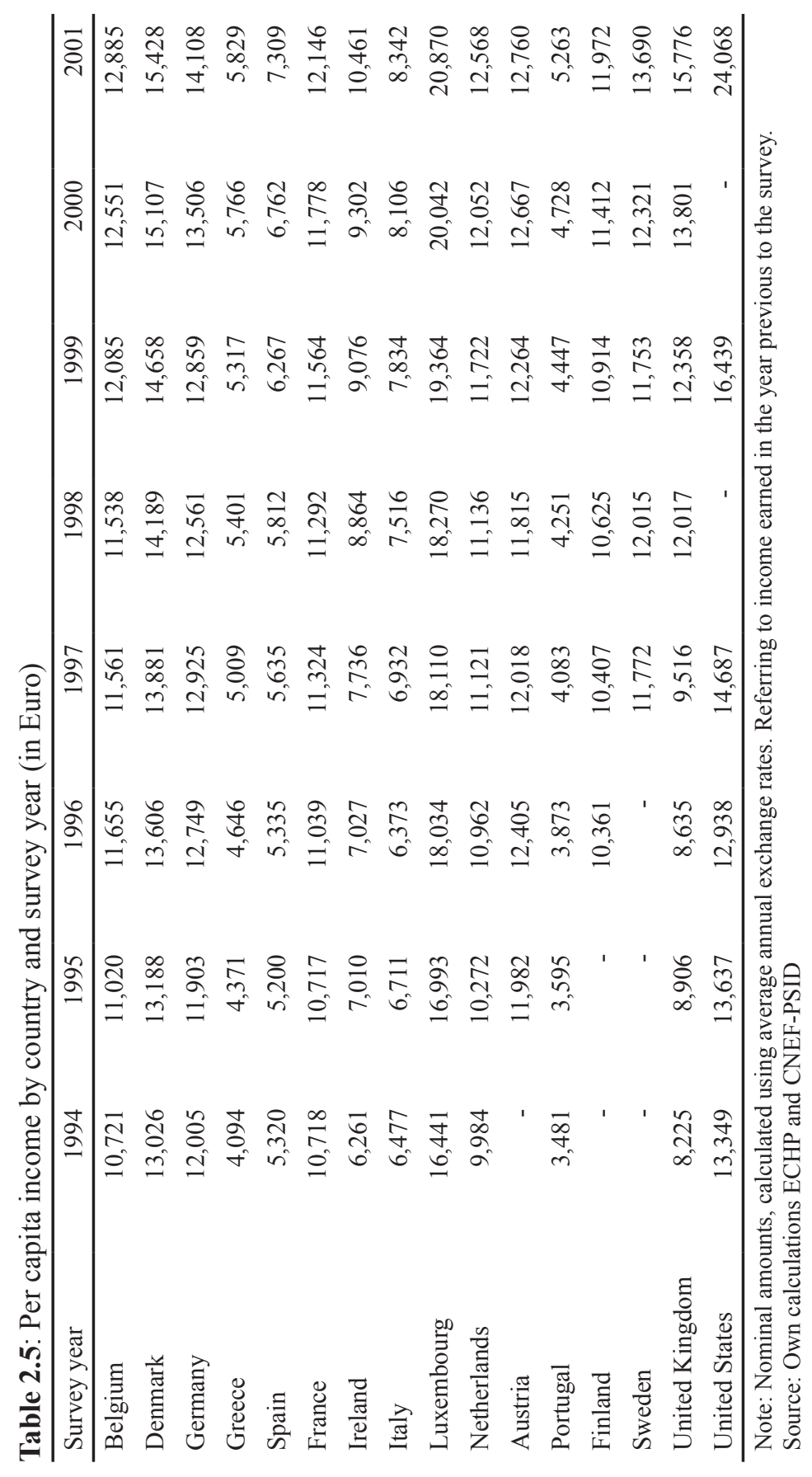




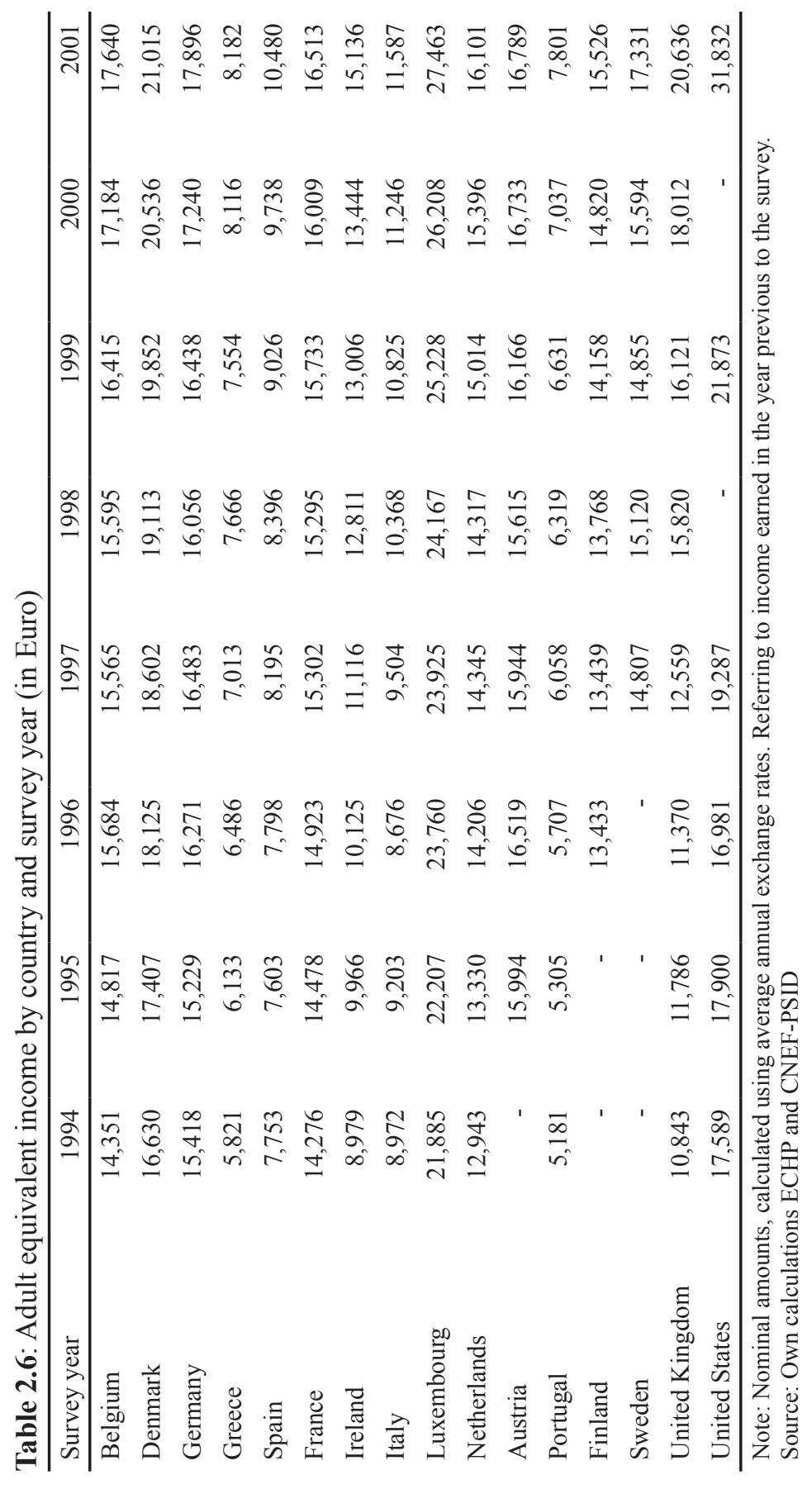




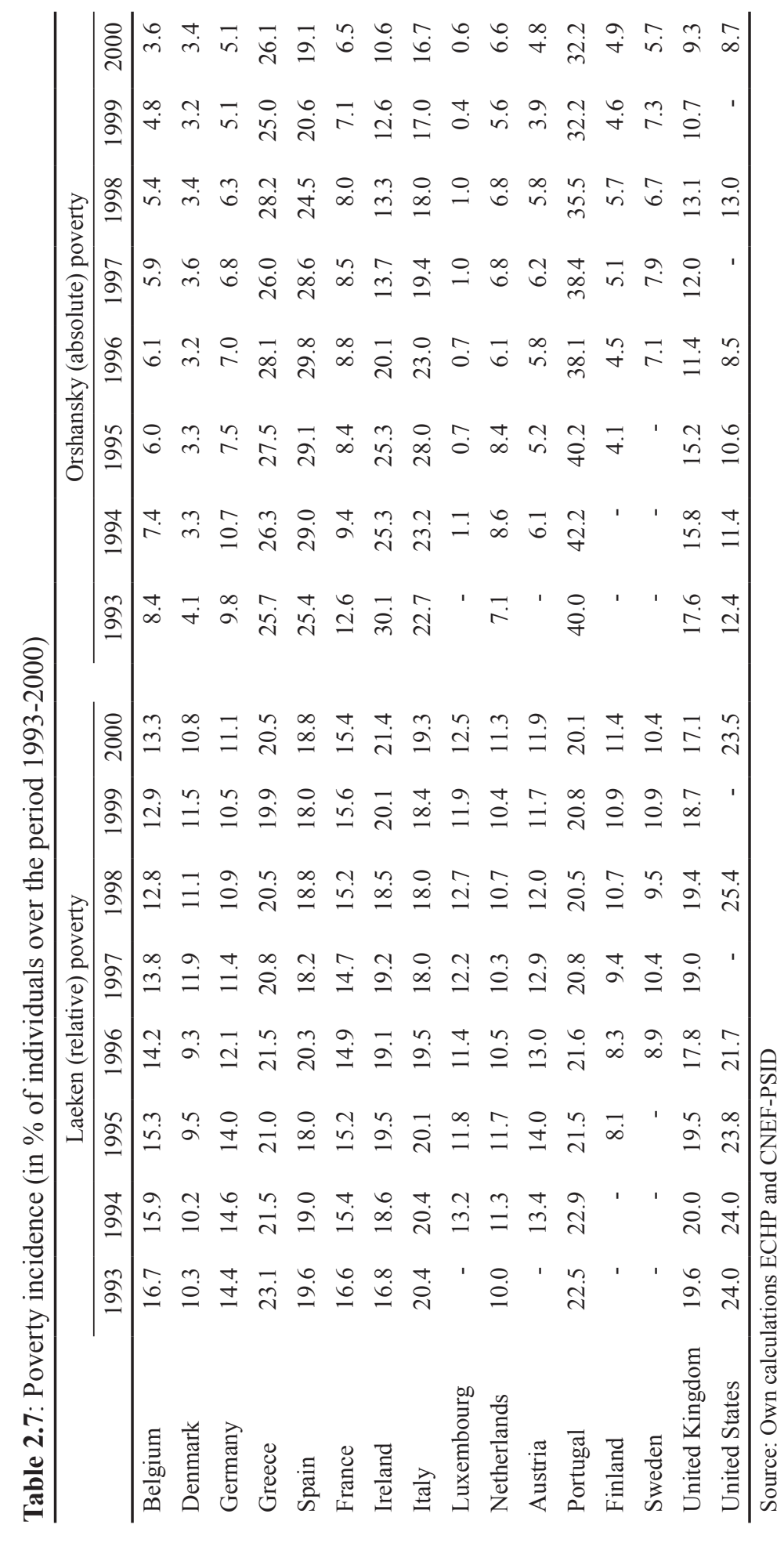


3 The policy relevance of absolute and relative poverty headcounts: what's in a number? 


\subsection{Introduction ${ }^{1} 234$}

Despite critical theoretical and technical concerns expressed by many scholars, financial poverty indicators still play a very important role in policymaking and evaluation. Most countries use one or several 'official' financial poverty indicators on which progress is regularly monitored and which serve as a basis for many large scale policy interventions. The United States use an absolute poverty indicator that is based on a minimum cost of living threshold which is compared to a families' gross income. ${ }^{5}$ The financial poverty indicator as used by the EU member states is based on a relative concept of poverty: the poverty threshold is set at 60 percent of national median income and compared to household's disposable income. Every year, the annual publication of the official poverty estimates receives considerable attention in the media and public debate in all countries. The issue of financial poverty rates is hotly debated especially when poverty rates increase or when financial poverty among specific groups (e.g. children or elderly) is on the rise. Moreover, national governments use financial poverty headcounts to illustrate the success of their policies or use them as a basis for target setting in the core political arena (e.g. Blair government on child poverty in the UK). The financial poverty headcount figures are also used to guide and implement actual policy. The Orshansky poverty line in the US is, for example, used as a tool to determine eligibility for programmes or benefits targeted at low income families (e.g. households are eligible for food stamps if their income is below a value of $130 \%$ of the poverty line).

\footnotetext{
${ }^{1}$ This chapter is written as a separate paper: Notten, G. \& C. de Neubourg (2007). The policy relevance of absolute and relative poverty headcounts: What's in a number? MGSoG Working Paper, 2007/006, Maastricht Graduate School of Governance, Maastricht University, Maastricht. As a result, part of the information in sections 3.1 and 3.2 has already been discussed in chapter 2 . In the concluding discussion of this paper we also draw upon the main insights from chapter 2 to argue why it makes sense to use both absolute and relative poverty indicators. Readers of chapter 2 can skip section 3.7 of this chapter altogether.

${ }^{2}$ In this chapter we use data from the European Community Household Panel (ECHP). The results and conclusions of this chapter are ours and not those of Eurostat, the European Commission or any of the national authorities whose data have been used.

${ }^{3}$ This research benefited from a grant provided by the EuroPanel Users' Network (EPUNet) that financed a research visit to CEPS/INSTEAD (Differdange, Luxembourg) as well as from a travel grant provided by the Dutch Scientific Organization (NWO) which funded a research visit to the Kennedy School of Government (Cambridge, USA).

${ }^{4}$ We thank our colleagues at CEPS/INSTEAD (Differdange, Luxembourg), Kennedy School of Government (Cambridge, USA), National Poverty Institute (Ann Arbor, USA), Panel Study of Income Dynamics (Ann Arbor, USA) and the participants in the conference on 'New Directions in the Study of Inequality' (Princeton, April 2006, USA) who have contributed to the progress of this research. We are especially grateful for the constructive suggestions of Emil Tesliuc, Christopher Jencks, Mary Jo Bane, Erzo Luttmer and Gary Sandefur.

${ }^{5}$ This indicator was developed by Molly Orshansky in the 1960s and, except for some minor changes, has merely been updated for inflation ever since.
} 
In the EU member states the poverty indicators are mainly used as a monitoring tool. ${ }^{6}$ However, the presence of European funds ${ }^{7}$ earmarked for socially excluded groups or the development of disadvantaged regions stimulates the use of financial poverty indicators to tap into these funds by using them as solid arguments in funding proposals and project evaluations. ${ }^{8}$

The use of a particular financial poverty indicator is often the result of a (political) debate in the past. Once chosen, it often proves difficult to switch to or incorporate another poverty indicator. Choice then becomes convention. However, by choosing either an absolute or relative poverty concept, developments in the other dimension receive less attention or are missed altogether. In the US, relative poverty indicators play no role whatsoever while out of the 18 Laeken indicators in the EU there is not even a single indicator reflecting the minimum cost of living in a particular country or region. Even if poverty were to be considered predominantly as an absolute concept in a given society, does that mean that relative poverty can be ignored completely (or vice versa)? Is the fight against poverty and social exclusion only an issue when poverty means that individuals have less than an agreed minimum living standard? Or is poverty also an issue when it means that certain groups of people have considerably less than what is considered typical or normal in a given society?

In Notten and de Neubourg (2007c) we estimated both official EU and US poverty indicators for the US and $15 \mathrm{EU}$ member states and analysed to what extent and how technical reasons account for differences between estimates of absolute and relative poverty headcounts. In this paper, we use the same poverty indicators but now we focus on the relation between poverty headcounts and their policy uses: poverty headcounts are not only used to evaluate economic progress and the overall effect of government interventions but they are also used when making and evaluating specific policies. ${ }^{9}$ Poverty profiles based on headcount poverty statistics are key elements for the design and evaluation of poverty alleviation policies; they provide information about the size

\footnotetext{
${ }^{6}$ There is no common European social policy; each member state is responsible for its own social policies and may also use different poverty concepts. However, there are regular meetings between the ministers of social affairs and their employees and each member state is required to define and evaluate its targets in terms of poverty and social inclusion in National Action Plans on Social Inclusion (NAPincl) using the Laeken indicators on poverty and social inclusion (Atkinson et al., 2002; Marlier et al, 2007).

${ }^{7}$ The European Social Fund (ESF) and the European Regional Development Fund (ERDF).

${ }^{8}$ For instance, during the second European Round Table on Poverty and Social Exclusion held in Turin on 16-17 October 2003, a workshop was organized to examine the ways in which Member States have made, or plan to make, use of Structural Funds to support measures to combat poverty and social exclusion, as identified in their National Action Plans on Social Inclusion (NAPincl) for 2003-2005.

${ }^{9}$ We refer to the US official poverty indicator as the 'Orshansky' indicator and to the EU indicator as the 'Laeken' indicator (named after the place where the EU countries agreed upon the use of this common indicator).
} 
and characteristics of the target group and help policy makers and politicians decide about the potential scope of such policies as well as the type of policy instruments that can be used. ${ }^{10}$ Moreover, poverty headcounts are often used to evaluate the targeting efficiency and poverty reduction effect of a policy. In this paper we investigate the implications of choosing either a relative or an absolute poverty concept for these policy uses. We firstly analyse how these measures affect the size and profile of the poor: would they lead to selecting different priority groups? We also estimate and study long term poverty headcounts as the chronically poor constitute a priority group for social policy in itself. Finally, we investigate the poverty alleviating effect of various social transfers using information on the incidence of benefits and the amount of benefits received: Are current social transfers successful in lifting people out of poverty altogether. Are they beneficial predominantly for the group of 'hard core' poor (i.e. those people who are poor using both indicators) or do they reach the 'single indicator' poor and non-poor equally?

We find significant differences between poverty groups defined by Orshansky and Laeken indicators in terms of size, characteristics, benefit incidence and benefit levels. The differences between groups in a particular year are in some cases already considerable, but the implications of using either an absolute or relative poverty indicator over time could be great, especially for fast growing economies such as the new European member states. This also holds for countries with high levels of inequality. From a policy perspective, it would therefore make sense to use a poverty indicator reflecting the costs of attaining some minimum living standard as well as a poverty indicator that identifies those that have considerably fewer resources than what is considered normal or typical in a society.

The next section discusses the differences in the poverty headcount using the two poverty lines for the 16 countries under study. The impact of the choice of the poverty line on the size and the composition of the long term poor is the main issue discussed in the section thereafter. Differences between poverty profiles resulting from the absolute and the relative poverty analyses and their potential impact on social policy as well as the benefit incidence and benefit adequacy are covered in the two larger sections before the conclusion. The technical differences between the US Orshansky poverty count and the EU Laeken poverty estimates are briefly explained in the appendix.

\footnotetext{
${ }^{10}$ Poverty profiles also play an important role in formulating poverty reduction plans as they are now mandatory for obtaining funds from donors in nearly all developing countries.
} 


\subsection{More or less poverty? Orshansky and Laeken poverty in the EU and US}

Laeken and Orshansky poverty measurement methods for the United States and the old EU member states (EU-15) yield considerable differences in terms of poverty incidence (Table 3.1). Using disposable household income to calculate both poverty indicators, the rate of relative poverty (Laeken) is considerably higher than absolute poverty (Orshansky) in the richer countries. For the Mediterranean countries the rate of Orshansky poverty is higher than that of Laeken poverty. It is not difficult to understand that higher poverty rates put the poverty problem higher on the policy agenda. It thus matters for specifying policy priorities whether countries use a relative or an absolute indicator as their yardstick. The success of all poverty reduction programmes, typically being judged by the reduction in the poverty headcount and the poverty gap, is consequently very sensitive to the choice of indicator on which the poverty line is constructed. More importantly, the choice for an absolute or a relative indicator may yield very different poverty profiles, which in turn may lead to differences in targeting groups in policy reduction policies. In order to analyse these differences, Table 3.1 also calculates the overlap between the households belonging to the poor according to the Orshansky and the Laeken indicator. Looking at the estimates for $2000,88 \%$ of the poor in Spain and $83 \%$ in Italy is poor according to both indicators but the overlap is much lower for the other countries, with the USA (37\%), Belgium (27\%) and Luxembourg (4\%) showing the smallest overlap.

Table 3.1 shows very clearly that it makes a big difference whether one uses the US Orshansky approach or the EU Laeken approach. The degree to which poverty is considered a serious or a modest problem depends on the magnitude of the phenomenon; it makes a difference in the minds of people (including those of policymakers and politicians) whether the official poverty indicator shows that 'only' $9 \%$ of the population is poor as compared to $24 \%$ (United States). Although the USA is an extreme case, the magnitude of poverty typically doubles going from Orshansky to Laeken poverty for the richer EU member states (2000). This difference in poverty does not only affect the general sense of urgency of the problem at hand but also has serious budgetary implications. The implementation of an income support programme may be financially feasible when it assists $5 \%$ of the population but may soon become problematic when a substantially larger group of people is involved. Magnitude also influences the type of policy response (for instance transfers versus tax breaks or training programmes versus changes in labour protection legislation) as well as the potential impact of that response (considerable or negligible). 


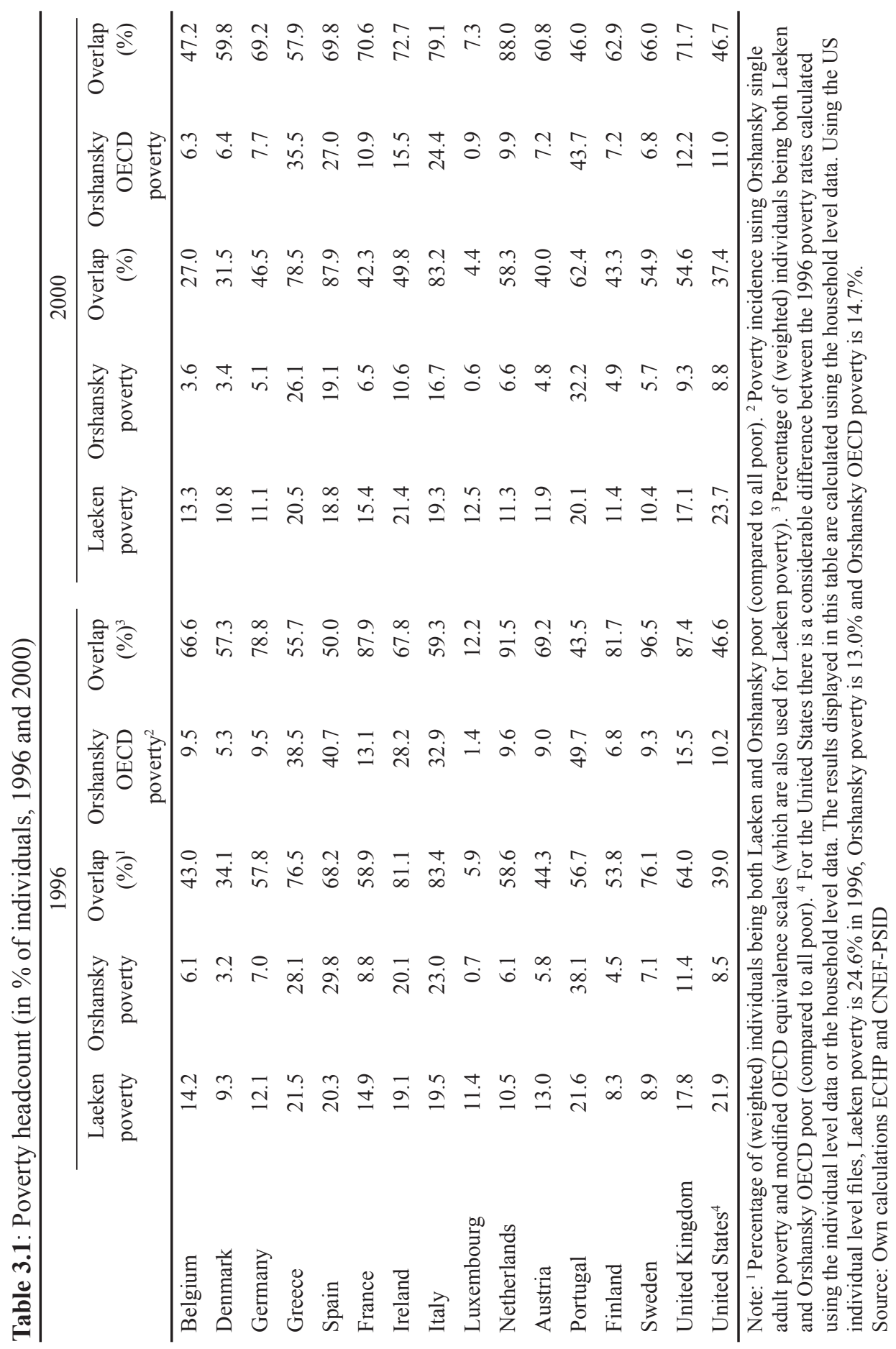


Comparing poverty in 1996 with 2000 estimates, it is also clear that Orshansky poverty is declining over time in most countries while Laeken poverty changes only moderately, albeit in either direction. This implies that according to one indicator the poverty situation in a country is improving while the other indicator may suggest no change or deterioration. Ireland is a striking example in this respect, having experienced a decrease in Orshansky poverty of nearly 20 percentage points and an increase in Laeken poverty of about 5 percentage points over the period 1993 to 2000.

Notten and de Neubourg (2007c) have shown the impact of the main underlying technical mechanisms determining these poverty differences. As the Orshansky poverty line is set irrespective of a countries' income distribution while the Laeken poverty line depends on national median income, distributional characteristics are a main explanatory factor. The level of income inequality below the median and changes in this inequality affect the level of absolute and relative poverty rates. In countries with higher income inequality the overlap between Laeken and Orshansky poverty is typically low(er). Furthermore, differences between absolute and relative poverty trends are more pronounced in faster growing economies. Other factors explaining poverty differences are the use of Purchasing Power Parity rates to convert the US Orshansky thresholds to national price levels and the different equivalence scales used by the EU and the US poverty measurement methods. The effect of PPP conversion only influences differences between Laeken and Orshansky poverty levels but does not affect poverty trends because national inflation rates are used to update the poverty lines over time. ${ }^{11}$ Despite moderate differences in equivalence weighting schemes, the impact on the poverty estimates is considerable.

We have therefore also calculated the Orshansky poverty rates using the modified OECD-equivalences weights as used in the Laeken indicator (columns 4 and 8, Table 3.1). ${ }^{12}$ Using the same equivalence scale for both poverty indicators considerably reduces the differences between Laeken and Orshansky estimates. In 2000, the effect is particularly large in Denmark, France, Spain and the Netherlands. The Netherlands is now the country with the highest overlap $(88 \%)$. However, in most countries the overlap is below $70 \%$ and in Belgium, Portugal, United States and Luxembourg even below $50 \%$. The use of the same weighting scheme also reduces the heterogeneity in

\footnotetext{
${ }^{11}$ In another paper we already indicated that the exceptional deviation of the Mediterranean countries may be related to the PPP converter that is used (Notten \& Neubourg de, 2007c). In this paper we further discuss the appropriateness of using PPP rates.

${ }^{12}$ The modified OECD equivalence scale attribute a weight of 1 to the first adult in a household, 0.5 for subsequent adults and a weight of 0.3 for children under age 14 . The Orshansky scales are implicit in the sense that there are 48 poverty lines, depending on the household size and age of household members. To calculate Orshansky OECD scale poverty rates we compared the single adult poverty line with the adult equivalent income of a household.
} 
the characteristics of both poverty groups (Notten \& Neubourg de, 2007c). Differences between weighting schemes alter the poverty risk of demographic groups and the household types they live in. If additional children in a household have a lower weight than additional adults (as is the case in the OECD scheme) fewer children are counted as poor as compared with a scheme attributing equal weights. A weighting scheme that attributes higher economies of scale to larger households reduces the poverty risk of such households and its members. Moreover, as the share of large households in the population increases, its effect on poverty rates and risk profiles becomes larger. Given this impact of the US and OECD weighting schemes, we focus on the policy consequences of poverty differences caused by the Laeken and Orshansky poverty lines in the remainder of this paper (using the OECD modified equivalence scales to measure Laeken and Orshansky poverty). The next sections address the differences between the Orshansky and the Laeken methodology for analysing long term poverty, poverty profiles, social benefit incidence and social benefit adequacy.

\subsection{Long term poverty}

Compared to other groups in society, the group of long term poor is of special concern because having low income levels for a long time not only implies the lack of resources to finance current living standards, but also reduces investment opportunities in health and education thereby also reducing prospects of a better future (especially when asset levels are also low). Generally, long term poverty levels are considerably lower than annual poverty rates. But even when countries have similar poverty rates, their longterm poverty rates may differ. Take, for instance, Denmark, Germany, the Netherlands, Austria and Finland. The annual Laeken poverty rates in these countries are similar (10$11 \%$ ), but the long term poverty rates vary from $5.2 \%$ in Denmark to $7.1 \%$ in Austria. Or alternatively, countries with similar long term poverty rates such as Luxembourg and France (respectively $8.6 \%$ and $8.7 \%$ ) have different annual poverty rates $(12.5 \%$ and $15.4 \%$ ). Exploiting the panel dimensions of the datasets we estimated long term Orshansky and Laeken poverty rates (Table 3.2). This indicator is also called the 'at persistent risk of poverty' rate and labels individuals as long term poor if they are currently poor and have also lived in poverty in at least two out of three previous years. To our knowledge, this is the first study that is providing comparable estimates of long term poverty between Europe and the United States.

Focussing on the 'at persistent risk of poverty' according to the Laeken indicators, the countries can be distinguished in two groups: Mediterranean countries and the USA with a high percentage of long term poor and the other European countries with a lower percentage of their population at risk of persistent poverty. The estimate for long term 


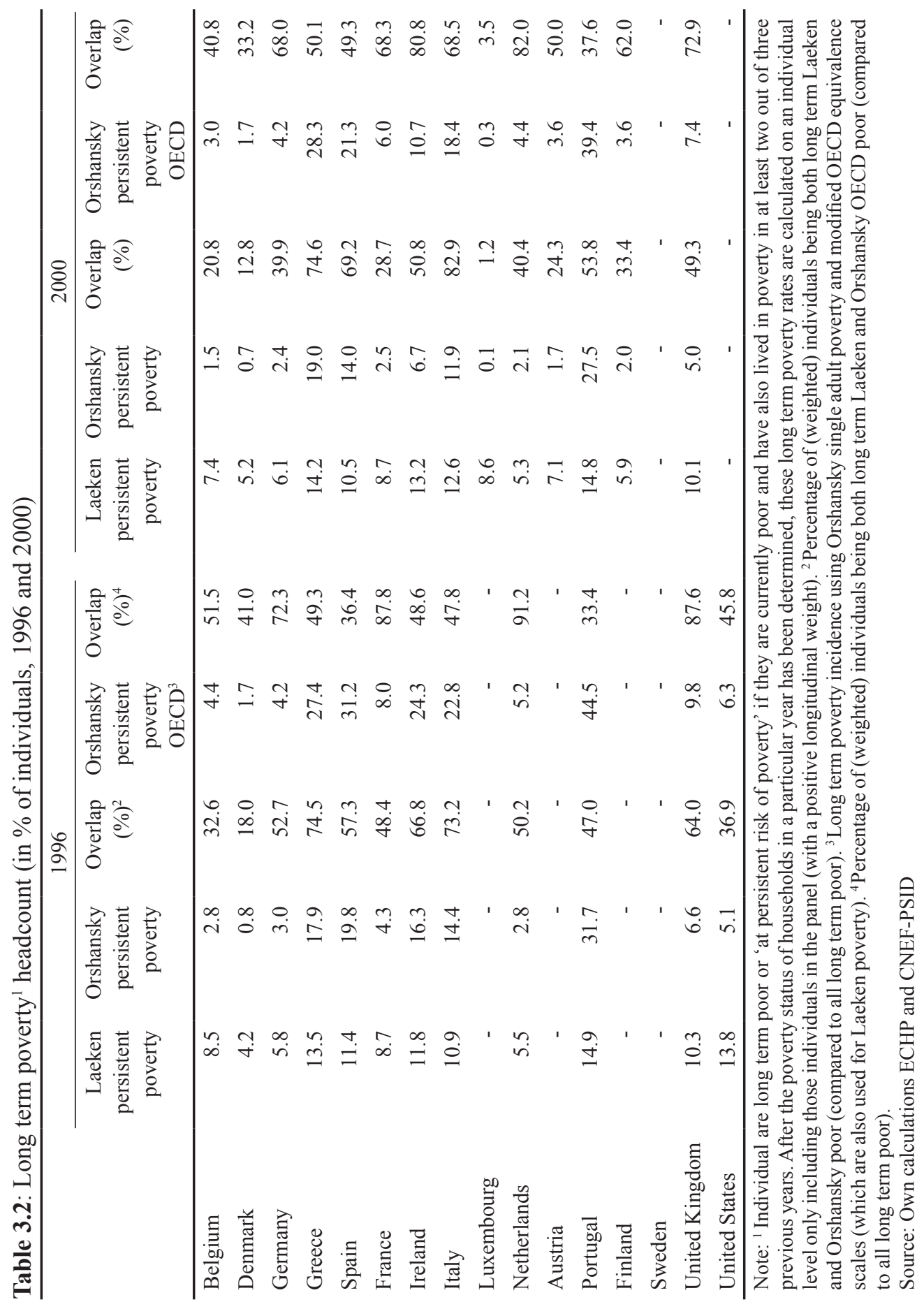


poverty using the Orshansky method is consistently higher than the Laeken estimate for Mediterranean countries and Ireland and lower for the other countries. Exploring the changes between 1996 and 2000, it is clear that the changes in the relative indicator were very moderate while the Orshansky indicator showed a decline for all the countries (in some cases e.g. Ireland, spectacularly) except for Greece. It should be noted that the changes in the absolute poverty count are bigger than in the relative poverty estimate, suggesting that quite a lot of the long term poor experienced an income increase lifting them out of absolute poverty in that period but not getting them above the - for most countries - higher relative poverty line.

It is of course interesting to study whether the Orshansky poverty estimate would be a good proxy for the long term (at persistent risk of) poverty rate; Orshansky poverty estimates do not require panel data, but long term poverty estimates do. It would also be also interesting to know from a policy perspective to what extent there is an overlap between the poorest in any given year using an absolute poverty measure and the long term poor? A first indication is given in the columns 5 and 10 of Table 3.2 where it can be seen that the overlap between the two 'at persistent risk of poverty' rates is only considerable for four countries: France, Germany, the Netherlands and the UK. However, the overlap between the Laeken 'at persistent risk of poverty' rate and Orshansky 'at persistent risk of poverty' rate does decline considerably over the short period between 1996 and 2000, indicating not much stability. A more direct exploration is provided in Table 3.3.

We selected a number of 'rich' countries with varying degrees of overlap between absolute and relative poverty groups: the Netherlands, Ireland, Austria, United Kingdom and the United States. For these countries, the Orshansky poor are a subset of the Laeken poor (Table 3.3). In 2000, the percentage of Laeken poverty is high in the United States and Ireland (well above 20\%), low in the Netherlands and Austria (11-12\%) and in between for the United Kingdom (17\%). The overlap between annual Laeken and Orshansky poverty groups is highest for the Netherlands (88\%) and lowest for the United States (47\%). In Ireland, slightly less than half of the Laeken poor (about $10 \%$ of the total population) have also been long term poor in a relative sense and are currently also poor in an absolute sense. In the other countries this group covers $42 \%$ of the Laeken poor in the UK, 33\% in Austria and 29\% in the Netherlands. The overlap is thus very limited and the Orshansky poverty rate cannot be regarded as a proxy for the long term poor.

The overlapping group, that is to say, the group of people that are both absolute poor and long term poor is, however, very interesting from a policy perspective; not only do these individuals currently have a very low income (insufficient to finance an acceptable minimum living standard), their income levels have been low compared to 
Table 3.3: Overlap between poverty groups (in \% of individuals, 2000)



Note: ${ }^{1}$ Orshansky OECD poverty incidence is calculated using Orshansky single adult poverty and modified OECD equivalence scales (which are also used for Laeken poverty). ${ }^{2}$ Percentage is based on Laeken poor individuals in the panel. Individual are long term poor or 'at persistent risk of poverty' if they are currently poor and also lived in poverty in at least two out of three previous years.

Source: Own calculations ECHP and CNEF-PSID

the rest of the population over the past years as well. What are the characteristics of the people? From what sources do they derive their income? How did they end up in this situation and what do they think about their situation themselves? The limitation of this paper does not allow us to try to answer this questions but, clearly, such vulnerable groups can only be identified when poverty is measured using both relative and absolute poverty concepts.

\subsection{Poverty profiles}

For policies to have a poverty alleviating effect, both the size and characteristics of the poor (poverty profile) are relevant information. Such findings can be used to determine the type of assistance that could be provided to a target group. An increase in the social minimum pension is an obvious option if a large part of the poor are elderly people. In contrast, when working individuals and the households they live in are a major share of the poor, other policy options such as tax breaks may be considered. When especially families with children are victim to poverty, family allowances seem to be a serious option. When absolute and relative poverty lines are very different it may well be that the poverty profiles of the two groups of poor differ as well.

To study whether this is actually the case in the EU or the USA, we compare the characteristics of the group of poor who are poor according to both indicators with group of poor who are only poor according to one of the indicators. To avoid unreadable 
tables we focus on the same subset of 'rich' countries as in Table 3.3; in these countries individuals are either poor regardless of whether a Laeken and Orshansky poverty indicator is used, or only poor when using the Laeken indicator. As before we call the (overlap) group that is poor according to both the Orshansky and the Laeken indicator, the 'Orshansky poor' and we call the persons belonging to the other (single indicator) group 'Laeken-poor'. We investigate differences in gender, age, household type and main source of income in 2000 and test whether the prevalence of these characteristics differs significantly between both groups using a simple Wald test (taking the specific national sampling design into account). The results are displayed in Table 3.4.

Women are disproportionately more often poor than men in all countries, except for the Netherlands. However, the percentage of women being poor both according to the Laeken and Orshansky poverty indicator differs significantly from the percentage of the women that is poor according to the Laeken indicator only in Austria. In that country the percentage of women being 'Laeken poor' (68\%) is 10 percentage points higher than the female 'Orshansky poverty '( $58 \%)$. The differences between the two groups ('Orshansky poor' and 'Laeken poor') for the share of men are small and not significant. Looking at different age groups, we find significant differences between both poverty groups ('Orshansky or absolute' and 'Laeken or relative') for individuals between age 25 and 49 as well as for the elderly (65 or older) in Ireland, Austria and UK. In these countries the percentage of individuals aged 25-49 is lower than average in both poverty groups, but when they are poor they are more likely to be poor in an absolute sense. Older individuals in these countries, on the other hand, are more likely to be only poor when using the (relative) Laeken indicator. Note though, that their overall poverty risk may be high (Ireland and Austria) or low (UK) comparing their poverty rate with their population share. People aged 50-64 are more likely to be relatively poor in the Netherlands ('Laeken poor') rather than absolutely poor ('Orshansky poor').

When looking at the type of living arrangements, significant differences between the 'Orshansky poor' and the 'Laeken poor' are very different according to the country that we study. In the United States, we find significant differences for nearly all types of living arrangements (with significantly higher absolute poor among single adult households and 'other households with children' and lower rates of absolute poor among couples and households with two adults and children), while there are no significant differences between household groups in the UK. Single adults are more likely to be found in the 'Orshansky poverty' group in Ireland, contrary to Austria, where they are more likely to appear in the 'Laeken poverty' group.

When dividing the population according to their main income source, a more general pattern appears across countries. In the overlapping Laeken and Orshansky poverty group (the 'absolute poor'), the share of individuals living in households where 


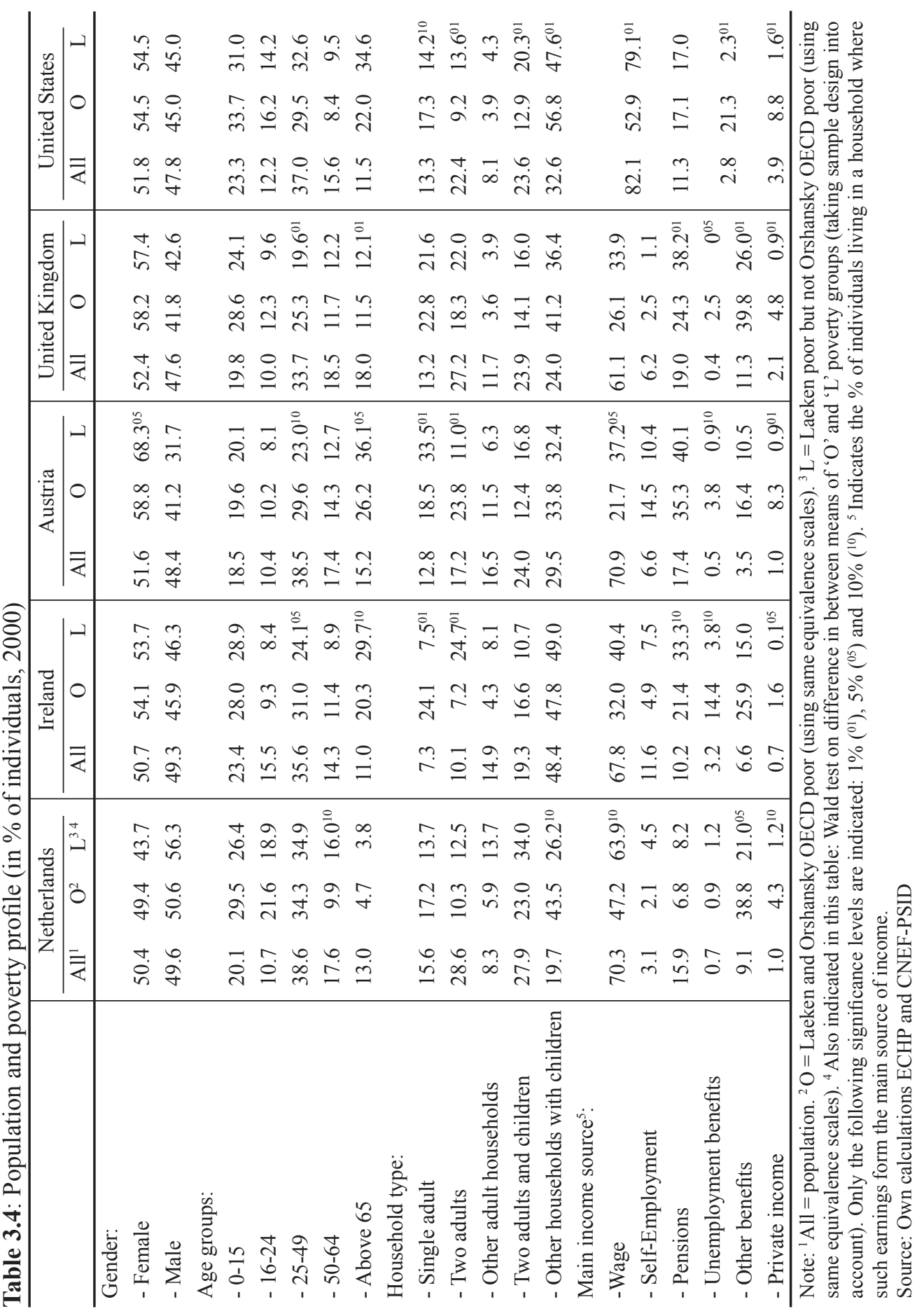


either social assistance, unemployment benefits or other benefits are the main source of income, is larger than among the 'relative poor'. On the other hand, individuals living in households with employment related earnings as the main income source are more likely to be present in the 'Laeken poor' group in Austria, the Netherlands and the USA. In Ireland and the UK, old age pensions seem to play an important role lifting people above the (lower) Orshansky poverty line but less often above the (higher) Laeken poverty line. It is remarkable that individuals living in households where private income is the main source of income are more often to be found in the absolute poor category than in the group of relative poor, although their poverty rate is much lower than that of any other income-source group: it seems that most people living on private income are doing very well and are not likely to belong to lowest income category.

What is to be learned from this analysis of the differences in the poverty profiles between an analysis based on an absolute (Orshansky) poverty line and one that is based on a relative (Laeken) poverty line? Assuming that we would use the poverty profile only for targeting social policy (and implicitly assuming our aim is to target social policy), we can now see which groups in which countries would get more or less attention according to the poverty measurement method that is used. The first conclusion, however, should be that, for targeting purposes the choice of the poverty indicator does not seem to matter terribly for a large number of groups, especially in the Netherlands and the UK where we found few significant differences between the two estimates in this respect. There are, however, differences that would lead to very different policy options depending on whether we base the poverty profile of a country on a relative or an absolute poverty estimate. Adopting the lower absolute headcount would lead to relatively more attention to:

in the Netherlands:

- 'other households with children' and

- individuals living in a household with 'other benefits' as the main income source; in Ireland:

- individuals aged $25-49$

- single person households and

- people living on an unemployment benefit;

in Austria:

- individuals aged $25-49$ and

- two adult households; 
in the UK:

- individuals aged $25-49$

- people living on an unemployment benefit and

- people living on other benefits (largely social assistance); in the USA:

- single adult household

- other families with children

- people with a social benefit as the main source of income.

If we would use a relative poverty measure in the five countries we would target our policies more towards the following groups:

in the Netherlands:

- individuals aged $50-64$ and

- wage earners;

in Ireland:

- the elderly age groups (65 and above)

- two adult households without children and

- pensioners;

in Austria:

- women

- the elderly

- single adult families and

- wage earners;

in the UK:

- pensioners;

in the USA:

- two adult families

- two adult families with children and

- wage earners.

As already remarked and accounted for in more detail in Notten and de Neubourg (2007b), there is, however, a considerable degree of consistency in identifying the groups in the economy that are hardest hit by poverty between estimates based on a absolute and a relative poverty definition. For many of the breakdowns the choice of the poverty measurement method would have no influence on the group that experienced the highest poverty rate. 
Table 3.5: Incidence of social transfers ${ }^{1}$ (in $\%$ of individuals, 2000)

\begin{tabular}{lrrrrr}
\hline & \multicolumn{5}{c}{ Incidence by benefit category } \\
\cline { 2 - 6 } & $\begin{array}{r}\text { Old age } \\
\text { Pensions }^{2}\end{array}$ & $\begin{array}{r}\text { Family } \\
\text { allowance }\end{array}$ & $\begin{array}{r}\text { Other social } \\
\text { insurance }^{3}\end{array}$ & $\begin{array}{r}\text { Social } \\
\text { assistance }\end{array}$ & $\begin{array}{r}\text { Other } \\
\text { benefits }^{4}\end{array}$ \\
\hline Netherlands & 18.7 & 46.7 & 13.2 & 3.5 & 8.5 \\
Ireland & 23.6 & 65.4 & 30.6 & 14.3 & 7.3 \\
Austria & 35.5 & 58.4 & 18.1 & 0.6 & 9.1 \\
United & 29.1 & 47.6 & 18.4 & - & 15.0 \\
Kingdom & & & & & 13.7 \\
United States & & & & & \\
\hline
\end{tabular}

Note: ${ }^{1}$ The incidence rate represents the $\%$ of individuals living in households receiving income from a particular benefit category. ${ }^{2}$ Pensions include social and private pensions. ${ }^{3}$ Other social insurance includes unemployment and sickness/disability benefits. ${ }^{4}$ Other benefits include education, housing and other allowances. ${ }^{5}$ For the United States we can only distinguish between pensions and other social transfers.

Source: Own calculations ECHP and CNEF-PSID

Nevertheless, we find that in quite some cases the poverty risk for a particular group is more or less pronounced when using either a Laeken or an Orshansky poverty line. The pension system seems to be another underlying factor contributing to many inconsistencies in poverty risk; inconsistencies between both poverty indicators occur more often with elderly age groups and households whose main source of income is a pension. It should also not be forgotten that absolute and relative poverty lines evaluate progress differently and may thus show opposing or diverging poverty trends. Over a decade, the underlying composition of both poverty groups may change considerably, especially in fast growing economies or countries experiencing substantial social and demographic changes or structural reforms. For these cases it still would make a big difference whether a relative or an absolute poverty line is chosen as a basis for targeting social and economic policy.

\subsection{Social transfer incidence and adequacy}

The tax and social transfer systems in Europe and the USA are complex systems that redistribute funds from rich to poor, from working age adults to the young and the elderly and from workers to non-workers. In doing so, they affect the shape of the (disposable) income distribution and thus also influence absolute and relative poverty rates. If one excludes social transfers from household income, Laeken poverty rates would be $35 \%$ in the Netherlands and Ireland, 38\% in Austria, 39\% in the United Kingdom and 33\% in the United States. Orshansky poverty would be somewhat lower varying from $32 \%$ in the United Kingdom to $19 \%$ in the United States (Notten \& 
Neubourg de, 2007b). ${ }^{13}$ These numbers reflect the joint impact social transfers. Here we study the impact of transfers separately. Whether social transfers are targeted at low income groups and whether a particular type of transfer is successful in lifting people out of absolute (Orshansky) and relative (Laeken) poverty, are questions that will be addressed in the rest of this section.

We evaluate how various types of social transfers affect the poor and non-poor population, again dividing the poor population into the absolute (Orshansky) poor and the relative (Laeken) poor and contrast the presence of social transfers for these groups with transfers to non-poor population. More specifically, we investigate to what extent both poverty groups are covered by the social transfer system by looking at incidence rates (whether a person is actually receiving social transfers) and mean value (adequacy of social transfers). We examine three ${ }^{14}$ types of transfers: old age pensions (private and public), family allowances and social assistance. For the United States we have only two transfer types; pensions (social security pensions ${ }^{15}$ and private retirement income) and other social transfers (including temporary assistance to needy families and food stamps).

Table 3.5 lists the benefit incidence of five social transfer categories in the same five countries that we studied in the previous sections. The incidence rates reflect the percentage of individuals living in households that reported receiving a particular benefit. Although pensions, family allowances and other social insurance benefits are common transfers in all countries, the incidence of these transfers clearly differs by country. The incidence of pensions varies from $23 \%$ in the US to $36 \%$ in Austria, while family benefits have the highest incidence rates in the European countries varying from $47 \%$ in the Netherlands to $65 \%$ in Ireland. The lower incidence of non-pension social transfers in the United States can partly be explained by the fact that we ignore 'transfers' through the tax system such as tax breaks and tax credits. ${ }^{16}$ Differences between the countries are not always a reflection of differences in policies but can also be influenced by basic demographic and economic differences: e.g. the incidence of old age pensions is clearly related to the share of elderly in the economy.

The classification of the transfer categories suggests which type of risk is being covered; old age pensions cover the risk of no or low income in old age while other

\footnotetext{
${ }^{13}$ Orshansky poverty rates calculated using the United States implied equivalence scales.

${ }^{14}$ Except for the figures in Table 3.5 and Table 3.6, we do report the results for two other types of benefits that we studied - other social insurance benefits (unemployment, sickness and disability) and other benefits (housing allowance, education allowance and other stipends). The differences found were not very big or different from what we found for the three others.

${ }^{15}$ Social security pensions include public old age, survivor and disability pensions.

${ }^{16}$ Although our estimates of the US disposable income incorporate the value of such tax 'transfers', the data do not allow us to analyse them separately. This implies that we cannot identify their presence or mean value.
} 


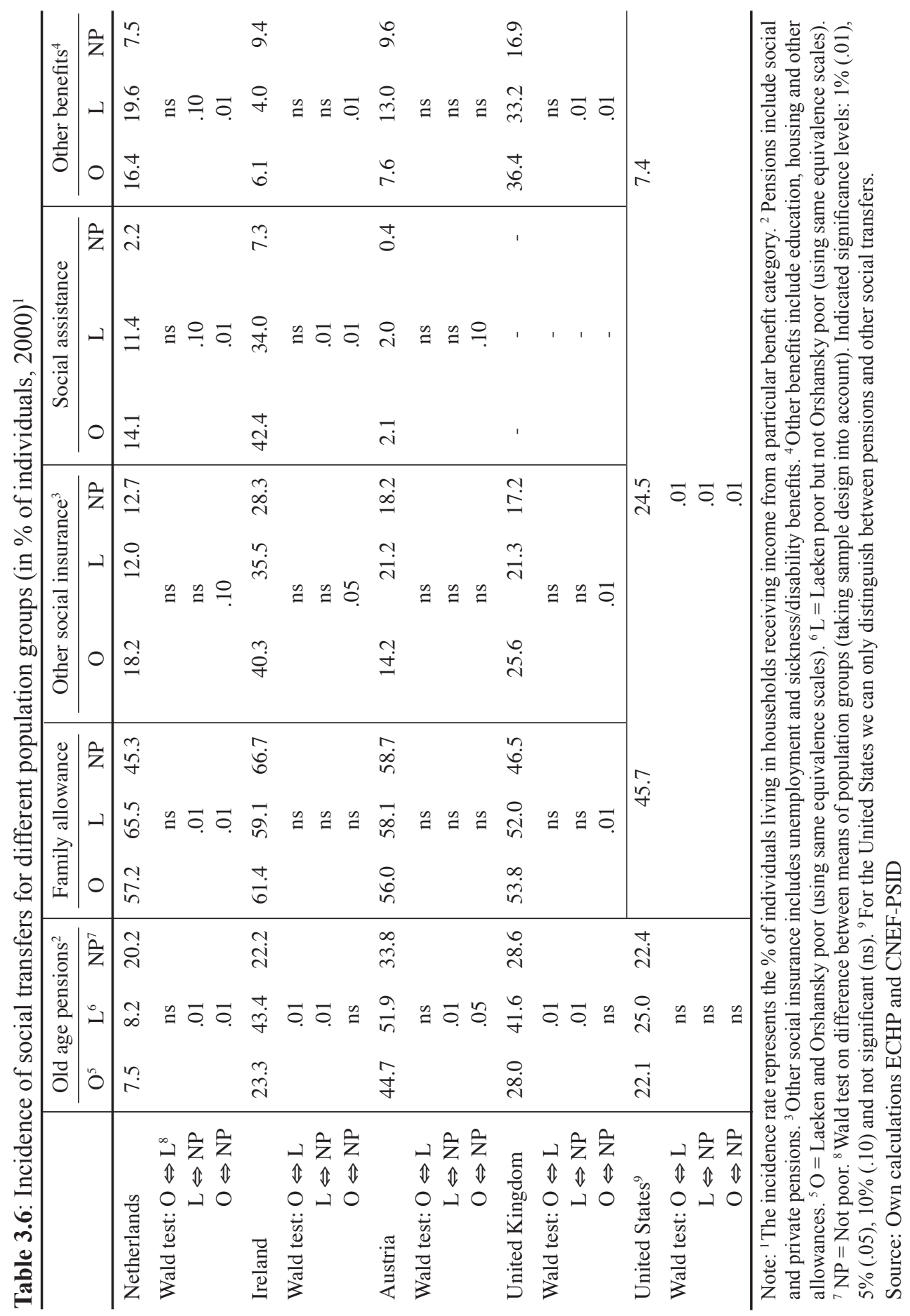


social insurance transfers insure the retention of some income in the event of illness, disability or unemployment. Family allowances financially support parents with raising their children and social assistance helps households that have no (or a very low) income. This, however, does not mean that the prevention of that risk is the sole motive or that the transfer is successful in achieving its objective. The degree to which such transfers are targeted at those individuals that really need such support, differs by transfer category and by country. Some transfers are targeted at specific demographic groups while other transfers (also) require an income or means-test. Moreover, the generosity of each type of transfer varies, as does its resulting impact on the level of economic well-being of the individual and its household. In this paper we focus on evaluating the impact of these transfers on the partially overlapping absolute and relative poverty groups as compared to the rest of the population. This may, or may not, correspond with the actual objectives of these policies in the studied countries. Table 3.6 shows a decomposition of the benefit incidence for three different groups: the 'Orshansky poor', the 'Laeken poor' ${ }^{17}$ and the non-poor in 2000. A first observation is that incidence levels vary considerably between these population groups but not necessarily systematically across countries. We discuss each transfer category in turn (patterns in 'other social transfers' in the United States are discussed under social assistance benefits).

\section{Pensions}

In the Netherlands, receipt of old age pensions in both poverty groups is significantly lower than for the non-poor group. In Ireland and the United Kingdom, pension incidence in the Laeken and Orshansky poverty group is similar to that in the nonpoor group while it is much higher in the Laeken only group. There are no significant differences between the population groups in the United States while in Austria the pension incidence is higher in both poverty groups. Thus, depending on the country, receipt of pensions is associated with a lower poverty risk (Netherlands), an increased poverty risk (Austria), with a higher risk for those in relative - Laeken only - poverty (Ireland and United Kingdom) or an average poverty risk (United States).

Pensions systems are complex systems that are designed to help individuals with smoothing their income over the life cycle. Although the prevention of poverty

\footnotetext{
${ }^{17}$ As in the former sections, 'absolute or Orshansky poor or poverty' refer in the case of the countries under study in this section to the people that are poor according to both the Orshansky and the Laeken poverty line; 'relative of Laeken poor or poverty' refers to the group of individuals that are poor according to the Laeken indicator only; they are the group between the 2 poverty lines as used in the figures; this all holds because for the five countries that we study, the persons poor according to the Orshansky poverty line is a subset of the group of people that is poor according to the Laeken indicator.
} 
Figure 3.1: Incidence of pensions (below median income, 2000)
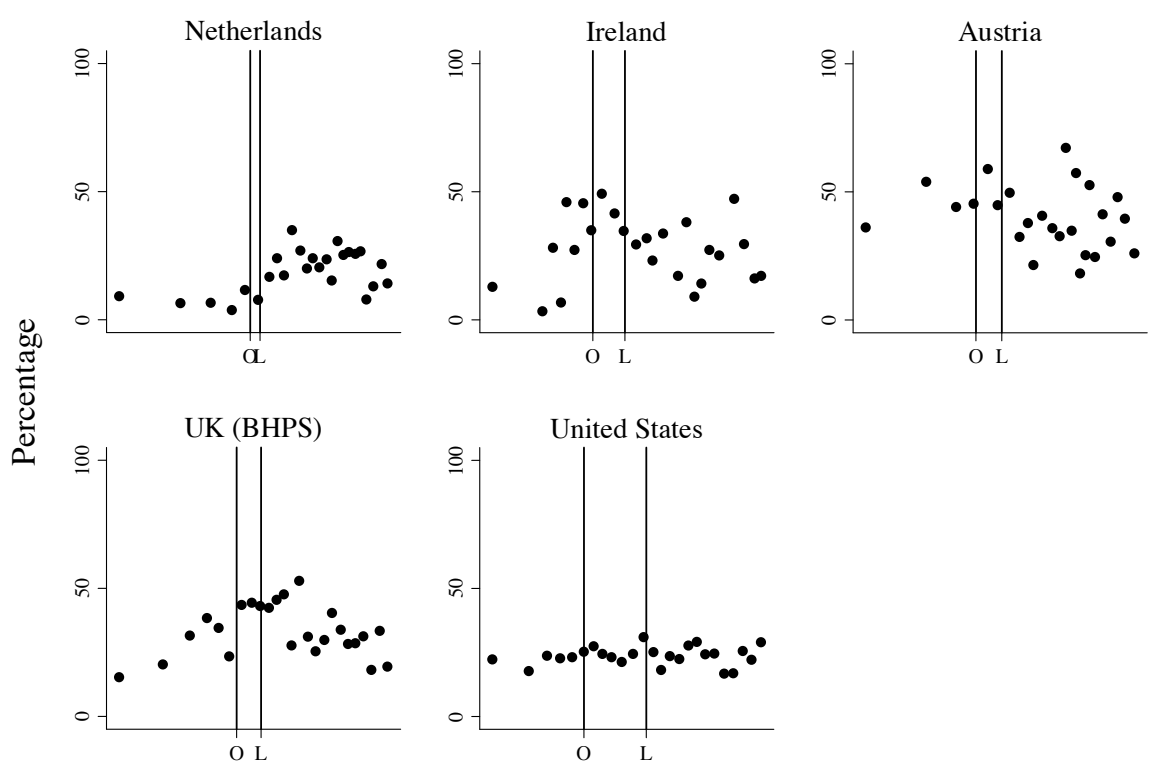

Equivalent income

Note: The figures include only observations below median income and all values are expressed in equivalent adult values (thus $50 \%$ of the total sample). Each dot represents the mean incidence or value (only including positive observations) of adult equivalent pension received by $2 \%$ of the sample. The horizontal and vertical lines represent the adult equivalent Laeken $(\mathrm{L})$ and Orshansky $(\mathrm{O})$ poverty lines.

Source: Own calculations ECHP and CNEF-PSID

at old age has certainly been an important motive for the development of pension systems, benefits depend for a large part on the contribution history of the individual in a lot of countries. Persons with a long contribution record and/or high income during working life have acquired more pension rights and are thus receiving a higher pension. Another factor influencing incidence patterns is that pension recipients may be part of a household that also includes non-elderly persons. The indicator of pension incidence used in this paper counts only individuals living in the household receiving a pension, not just those individuals that are eligible. Even though an elderly person's pension may be sufficient to lift that person out of poverty, the pension and other income sources may fall short when all individuals of the household are taken into account (or vice versa). These explanations are consistent with the distributional patterns observed in Figure 3.1 and Figure 3.2. The figures plot the mean incidence and value of pensions received against the mean income of the receiving individuals in 2000. Each dot represents $2 \%$ of the total population. The figures include only observations below median income and 
Figure 3.2: Mean value of pension (below median income, 2000)
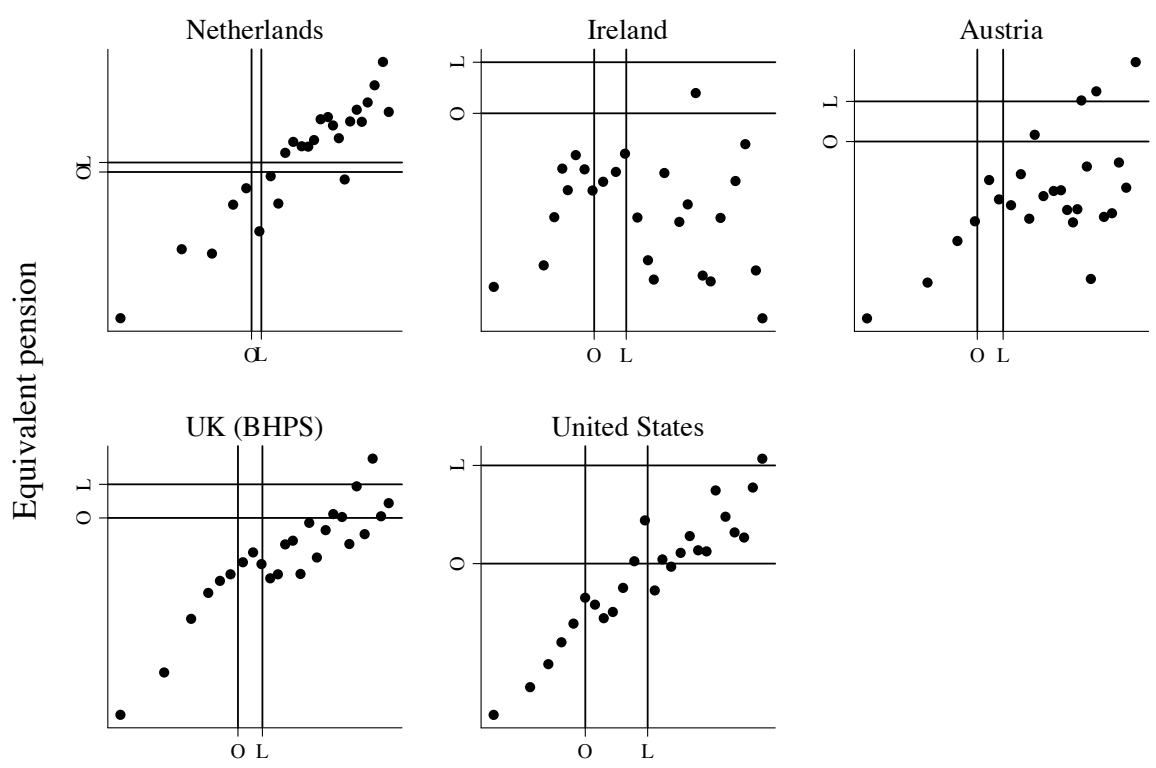

Equivalent income

Note: The figures include only observations below median income and all values are expressed in equivalent adult values (thus $50 \%$ of the total sample). Each dot represents the mean incidence or value (only including positive observations) of adult equivalent pension received by $2 \%$ of the sample. The horizontal and vertical lines represent the adult equivalent Laeken $(\mathrm{L})$ and Orshansky $(\mathrm{O})$ poverty lines.

Source: Own calculations ECHP and CNEF-PSID

all values are expressed in equivalent adult values. The horizontal and vertical lines represent the locus of the Laeken (L) and Orshansky (O) poverty lines. Individuals with an equivalent income below and left of the poverty lines are living in absolute and/or relative poverty.

Figure 3.1 shows that the incidence of benefits across the income distribution is approximately linear in the US but non-linear in the other countries. Interestingly, in the Netherlands and United Kingdom, incidence rates peak beyond the relative poverty lines. In Austria and Ireland the highest incidence rates are covering the area of the Laeken and Orshansky poverty lines. By determining who is eligible for how much benefit, social transfer systems also exercise influence on the prevalence of particular individual and household level characteristics along the income distribution. For instance, the peaks in pension incidence also provide some information about the characteristics of the individuals in that area of the income distribution; a high incidence of pension benefits typically also indicates a higher prevalence of elderly persons. In 
the Netherlands, the share of elderly persons in both poverty groups is well below their average population share (Table 3.4). However, it need not be the case that high rates of pension incidence beyond the poverty line also imply that elderly persons also have a lower than average poverty risk. Take for instance the US, where there are no significant differences in the incidence of pensions across the income distribution and where the age group 65 and above comprises $12 \%$ of the total population; the population shares of the poor pension aged individuals are well above their average population share $(22 \%$ for the 'Orshansky poverty group' and 35\% for the 'Laeken poverty group'). Figure 3.2 offers an explanation as the mean value of pensions received in the US lies well below the Orshansky and, in quite some cases, also below the Laeken poverty line.

The pattern of pension transfers is proportional in all countries: as equivalent income increases, the mean equivalent value of pensions rises as well. The relation is strong in the Netherlands, United Kingdom and United States, somewhat weaker in Austria and rather weak in Ireland. The pension systems in all these countries have multiple pillars; there is a first pillar reflecting a minimum or basic pension while the second and third pillars reflect contributions-related benefits (International Social Security Association, 2002, 2003). The minimum pension is means or income-tested in most countries, except in the Netherlands where a basic pension is provided to every citizen. Despite the limitations discussed above, the figures provide an impression of the poverty reduction impact of these (minimum) pensions. In the Netherlands, most of the dots in Figure 3.2 lie to the right and above the absolute and relative poverty lines, implying that the mean value of pension received is sufficient to lift an equivalent adult out of poverty. This happens much less in the other countries. Even though quite a number of dots lie to the right of the vertical Orshansky poverty line, most of those dots lie under the horizontal Orshansky poverty line (Austria, Ireland and the UK); although these individuals have sufficient income to lift themselves out of absolute poverty, pensions play only a partial role in achieving this outcome. As income levels increase, pensions in the US clearly contribute to achieving above Orshansky poverty line income levels but not sufficiently to reach an income above the Laeken poverty line.

What are the possible scenarios when pension transfers are inadequate in order to finance a given living standard? In some cases, pensioners may have accumulated sufficient assets over their lifetime to finance current consumption. For instance, when pensioners live in their own house with no need for mortgage payments (the disposable income indicator does not include imputations for home owners). As they do not have to pay rent, such pensioners may be counted as poor while their actual living standard may be above the poverty line. However, when low pensions are the result of a short contribution history combined with a low minimum pension, recipients most likely do not own large reserves of assets. As the opportunities of paid work are decreasing with 
Figure 3.3: Incidence of family allowances (below median income, 2000)
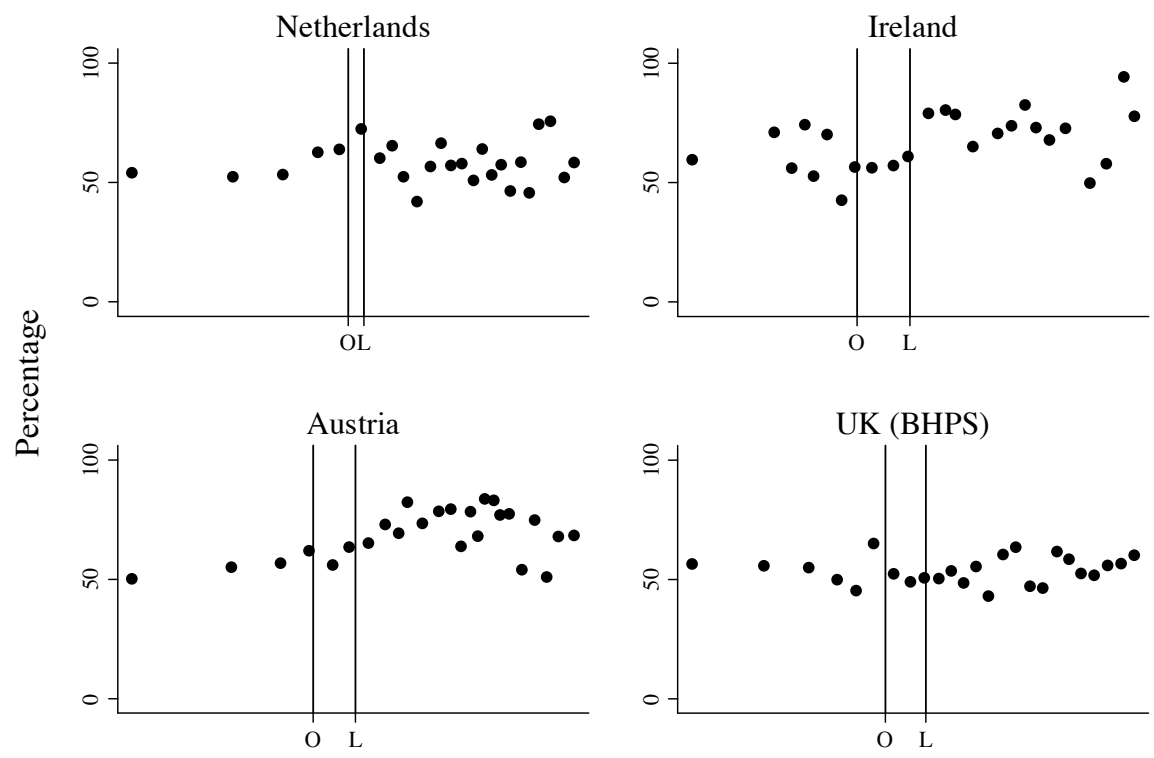

Equivalent income

Note: The figures include only observations below median income and all values are expressed in equivalent adult values (thus $50 \%$ of the total sample). Each dot represents the mean incidence or value (only including positive observations) of adult equivalent family allowances received by $2 \%$ of the sample. The horizontal and vertical lines represent the adult equivalent Laeken $(\mathrm{L})$ and Orshansky $(\mathrm{O})$ poverty lines.

Source: Own calculations ECHP and CNEF-PSID

old age, the main alternative to a life in poverty for these pensioners would be to move in with relatives. Looking at the incidence and mean value patterns in the figures, this option may explain the patterns in Austria and Ireland where a considerable subgroup of non poor is having rather low average pensions. Is it acceptable that (means or incometested) minimum pensions are not sufficient to cover a minimum acceptable living standard? Or is it problematic when pensioners are more likely to be (only) relatively poor? The answers to such questions remain the responsibility of the political arena and ultimately the electorate. However, having official poverty indicators reflecting both absolute and relative dimensions may be very useful in such a discussion.

\section{Family allowances}

The incidence of family allowances is very high in the four European countries that we consider. While there are some significant differences between either of the poverty 
Figure 3.4: Mean value of family allowances (below median income, 2000)
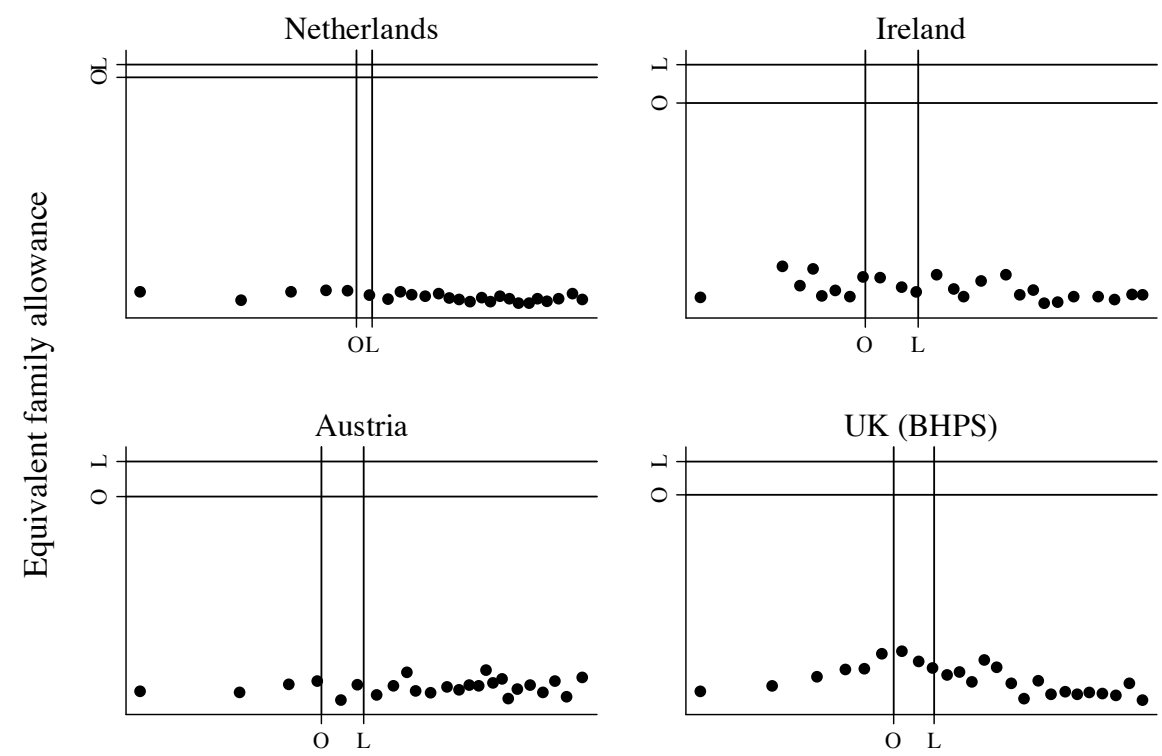

Equivalent income

Note: The figures include only observations below median income and all values are expressed in equivalent adult values (thus $50 \%$ of the total sample). Each dot represents the mean incidence or value (only including positive observations) of adult equivalent family allowances received by $2 \%$ of the sample. The horizontal and vertical lines represent the adult equivalent Laeken (L) and Orshansky (O) poverty lines.

Source: Own calculations ECHP and CNEF-PSID

groups and the non poor population (Netherlands and UK), there are no significant differences between the incidence rates both poverty groups. Figure 3.3 and Figure 3.4 indeed show that benefit incidence is rather constant across income levels, although some local 'peaks' can be identified. The pattern is also relatively constant in terms of mean benefit value. Clearly, benefit levels are well below the adult equivalent level and one third of this level (the equivalence weight of a child under age 14). The mean values of family allowance received seem to be somewhat higher at income levels in the middle of the figures as compared to very low and 'near' median incomes; this is especially clear in the case of the United Kingdom. These peaks may indicate a higher presence of households with one or more children. Family allowances in each of these countries are universal and vary by country as well as by the number of dependent children (International Social Security Association, 2002). Only in Ireland are low income families and single parents eligible for an additional income-tested allowance. In the UK there is an income dependant tax credit (the value of this credit is not included 
Figure 3.5: Incidence of social assistance (below median income, 2000)
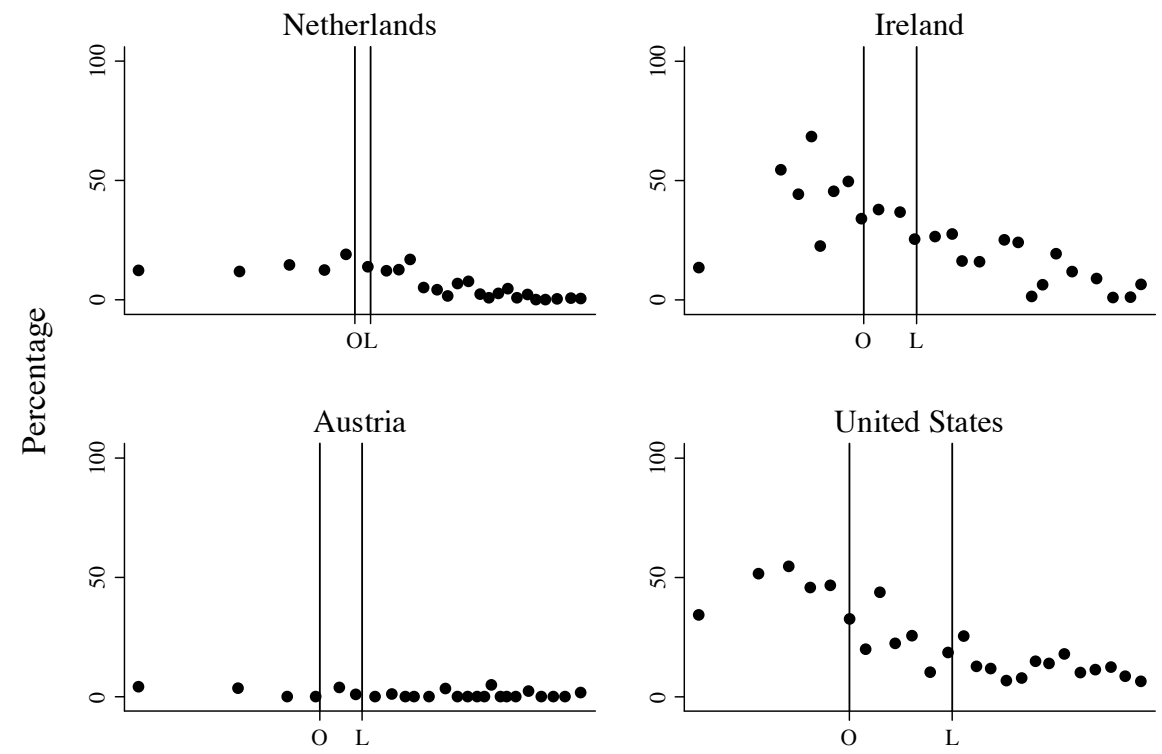

Equivalent income

Note: The figures include only observations below median income and all values are expressed in equivalent adult values (thus $50 \%$ of the total sample). Each dot represents the mean incidence or value (only including positive observations) of adult equivalent family allowances received by $2 \%$ of the sample. The horizontal and vertical lines represent the adult equivalent Laeken $(\mathrm{L})$ and Orshansky $(\mathrm{O})$ poverty lines.

Source: Own calculations ECHP and CNEF-PSID

in the mean transfer amounts). In sum, the prevention of child poverty, either in an absolute or relative sense, is not the main objective of these allowances.

\section{Social assistance benefits}

Social assistance benefits are typically provided to low income households. Often an income or means-test is accompanied by other criteria (i.e. having children, job search or willingness to work). ${ }^{18} \mathrm{We}$ include the 'Other social transfer category' from the US under this heading as two of the main low income support programmes are included in these transfers (food stamps and temporary assistance to needy families). In some countries such assistance is limited to a certain time period (US) while in other benefits

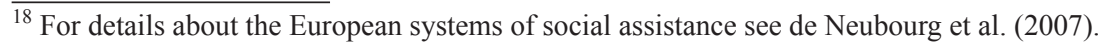


Figure 3.6: Mean value of social assistance (below median income, 2000)
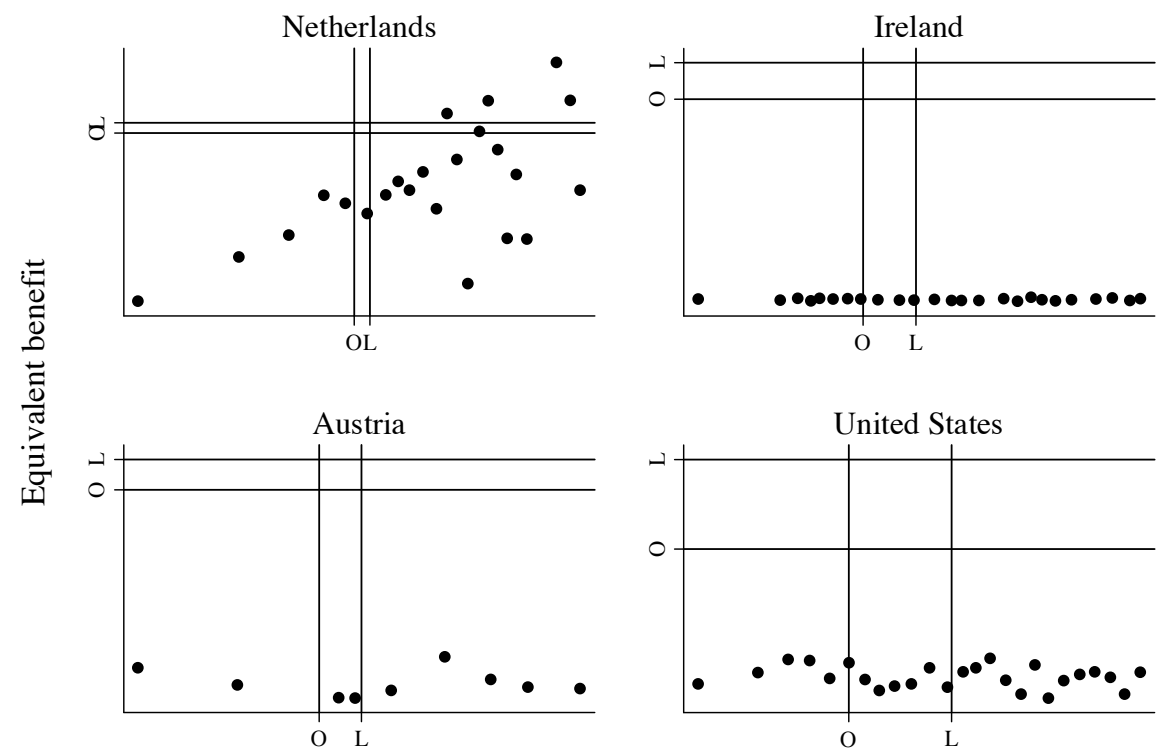

Equivalent income

Note: The figures include only observations below median income and all values are expressed in equivalent adult values (thus $50 \%$ of the total sample). Each dot represents the mean incidence or value (only including positive observations) of adult equivalent social assistance benefit received by $2 \%$ of the sample. The horizontal and vertical lines represent the adult equivalent Laeken (L) and Orshansky (O) poverty lines.

Source: Own calculations ECHP and CNEF-PSID

may be received over a prolonged period (Netherlands). ${ }^{19}$ Incidence levels vary considerably between countries ranging from $42-46 \%$ of the Laeken and Orshansky poor individuals in Ireland and the US to $2 \%$ in the same poverty group in Austria. In the European countries significant differences in incidence levels can only be found between the poor and non poor population groups while in the US the benefit incidence level vary significantly between all population groups. These patterns are confirmed in the distributional plots; especially in Ireland and the US incidence levels show a steep decline as income levels increase. Such patterns correspond to slow phasing out of income support, in order to prevent the creation of a poverty trap. However, the plots of mean benefit values show that the level of benefits does not vary greatly by income levels. If a phasing out in benefits would be applied, it can be expected that such income-

\footnotetext{
${ }^{19}$ The UK is not discussed as the ECHP data do not include separate information on social assistance benefits in the UK.
} 
tested benefits would be higher at lower income levels, but for Ireland, Austria and the US benefits are rather constant and for the Netherlands the mean benefit value increases as income increases. In the case of Ireland and the US, benefits are clearly meanstested but generosity is not higher for the worst off. The pattern in the Netherlands does not correspond with formal eligibility rules; even though in some cases recipients are allowed to some other earnings these are not large amounts. ${ }^{20}$ There exist two possible (non-exclusive) explanations. Firstly, part of reported income may not be formal and are thus also not reported to the benefit agency. Secondly, part of other income is also derived from other income-tested transfers such as housing allowance or income-tested study grants for studying children. ${ }^{21} \mathrm{~A}$ general observation is that these benefits, by themselves, are insufficient to lift people out of absolute or relative poverty. However, with this type of benefits it is probably more appropriate to look at shorter spells than annual figures as the typical spell of benefit receipt may be shorter than a year.

\subsection{Absolute and relative poverty concepts and policy: discussion}

Using absolute Orshansky and relative Laeken poverty indicators on data from the EU member states (EU-15) and the USA showed significant differences between these partially overlapping groups of poor. We found not only differences between the size of absolute and relative poverty groups but also significant variations in terms of characteristics and we also showed how such differences would influence the selection of priority groups based on each poverty indicator. Moreover, this variation is not necessarily systematic across countries or across time. We further discussed how various types of social transfers affect absolute and relative poverty groups differently (in terms of benefit incidence and benefit level). In this concluding section we discuss the relevance of monitoring absolute and relative poverty concepts from a more general policy perspective.

Absolute and relative poverty indicators reflect related, but conceptually distinct, approaches to determining insufficient levels of well-being. They are related because absolute or relative concepts of poverty may be applied to the same welfare dimension (i.e. economic well-being) and measured by the same welfare indicator (i.e. income, expenditures or assets). They are conceptually distinct because the benchmark used to determine the cut-off separating well-being from ill-being either depends on the distribution of this welfare indicator (relative) or on some assessment of what constitutes a minimum achievement, basic need or right (absolute). This difference in approach has

\footnotetext{
${ }^{20}$ See for instance the website Recht op Algemene Bijstand.nl http://www.rechtopalgemenebijstand.nl/ inhoud/index/pid/35\#geen (accessed May 2007, in Dutch only).

${ }^{21}$ These transfers are included in the 'Other benefits' category but are not further discussed.
} 
important implications. Take for instance a country or region where large parts of the population are facing an ongoing struggle to satisfy their basic needs in terms of food and shelter. If having just one or two sober meals a day is common in this society, absolute poverty exceeds relative poverty. Imagine that the $50^{\text {th }}$ percentile person in that society has two meals a day wile there is also a smaller group of persons having only one meal. Taking an internationally accepted standard of minimum food requirements or calorie intake as a benchmark, absolute (food) poverty rates may be well above $50 \%$ of the population. If, instead, one would use a relative poverty line where the middle person is taken as the benchmark, it is likely that only the persons having a single meal a day would be considered poor. The opposite situation may hold for a country in which the living standard is generally higher and perhaps some resources are being redistributed from the better off to the less well off; in such a country absolute poverty levels could be similar to relative poverty levels or considerably lower. ${ }^{22}$

'Not having enough to satisfy basic or main needs' or 'having much less than what is considered typical or normal in a given society' are distinct concepts of ill-being and their indicators may yield very different outcomes, especially over time. From a national policy perspective, it is therefore relevant to monitor both poverty concepts. Take for instance a steadily growing economy where the benefits from growth are equally distributed over the population; if one would only measure relative poverty one would 'miss' the fact that increasingly large parts of the population are able to afford a minimum basket of goods. If, instead, growth in this economy is unevenly distributed but nonetheless positive, a decrease in absolute poverty may be accompanied by increasing relative poverty. The groups of absolute and relative poor in a country partly overlap, but the degree of overlap changes over time. Thus, when designing or evaluating a policy, it makes sense to consider the potential impact that these policies may have on the absolute and relative poor. For the 'richer' countries (where absolute poverty is typically lower than relative poverty) a condition may be that only policies having a positive effect on absolute poverty reduction and a neutral effect on relative poverty will be given the consideration of actually being implemented. This is not to say that one should ignore other distributional effects, but from an equity perspective one might care more about those people having much less than what is considered minimal than those that have more.

\footnotetext{
$\overline{{ }^{22} \text { For some, this example }}$ illustrates the rationale for the argument that the use of relative poverty lines in poor regions or countries is nonsensical. We use this example because it illustrates that relative and absolute poverty statistics may yield very different outcomes. In addition, the example shows that there is a value judgement underlying every poverty concept of what is sufficient well-being or not and that the determination of a poverty line is always relative to some kind of benchmark (whether this is the society being studied or some global standard).
} 
Over time, the underlying composition of both poverty groups may change considerably, especially in fast growing economies or countries experiencing substantial social and demographic changes or structural reforms. As long as lower incomes profit at least a little from economic growth in real terms, absolute poverty will typically decline. Trends in relative poverty rates depend on the distributional implications of economic growth, social and demographic change and government policies in a particular country; these factors not only affect the number of people living below the poverty line (i.e. changes in the shape of the income distribution at its lower end) but also affect the determination of the relative poverty line itself (i.e. changes in the middle section of the income distribution). Changes in overall poverty trends can thus mask larger (and opposing) welfare changes between socio-economic groups. For instance, if (minimum) pensions are annually adjusted for inflation while wages increase in tandem with real economic growth; working households experience an increase in purchasing power while pensioner households do not. Moreover, as working households are often also found in the middle of the income distribution, the relative poverty line rises with the real wage increase of the median household. As a result, absolute poverty under pensioners remains equal while absolute poverty under working households declines. However, relative poverty among pensioners will rise while it may or may not remain constant among working households. This is certainly relevant for the new EU member states but the distributional impact of ageing societies in the US and the 'old' EU member states should also not be underestimated.

The Laeken indicators as used by the European Union do not inform us to what extent the extent the Italian or Dutch population has the resources to finance a minimum basket of goods. ${ }^{23}$ They only tell us that only $8 \%$ of the population in the Czech Republic has an income that is lower than $60 \%$ of the income of the 'median' Czech (the Czech Republic has the lowest relative poverty level in the EU). ${ }^{24}$ Or take a country like Romania, with a relative poverty of $17 \%$ in 2000 ; it is very likely that an absolute poverty rate based on the minimum cost of living lies well above the current relative poverty rate. It is however, expected that the Romanian economy will continue to grow considerably, thereby reducing absolute poverty rates. Depending on how the

\footnotetext{
${ }^{23}$ The Laeken indicators also include a relative poverty indicator which is 'anchored at a moment in time' (Atkinson et al., 2002). This means that the relative poverty line for a given year is updated to subsequent year using the rate of inflation. However, the anchoring of a relative poverty line over time is not an alternative for a minimum living standard indicator because the initial level of the poverty line is based on the income distribution and not on the costs of satisfying basic needs.

24 These poverty statistics have been retrieved from the website of Eurostat, http://epp.eurostat. ec.europa.eu/portal/page?_pageid=1996,45323734\&_dad=portal\&_schema=PORTAL\&screen=wel comeref\&open $=/ \mathrm{C} / \mathrm{C} 5 / \mathrm{C} 53 \&$ language $=$ en\&product $=\bar{Y}$ earlies_new_population\&root $=$ Yearlies_new_ population\&scrollto=1068 (accessed March 2007).
} 
benefits of this growth will be distributed across the population, relative poverty will increase, decline or remain constant. In the United States there is an ongoing debate over the problems associated with the Orshansky poverty indicator. As a result of this general dissatisfaction, the Bureau of Census also publishes alternative poverty statistics computed using various income definitions and another absolute poverty line which better reflects the current costs of basic needs but a relative poverty indicator is not part of such analyses (US Census Bureau, June 2005). Absolute and relative poverty statistics enable the identification and monitoring of distinct but partially overlapping groups. Each group reflects a vulnerable group in society and should be given special consideration. It therefore makes absolutely (!) sense to monitor progress using both relative and absolute poverty indicators.

\subsection{Appendix: official poverty in the EU and US-methodology and data}

The key difference between the US and EU official poverty measurement methods, is that the US method is based on an absolute poverty concept while the EU method is based on a relative poverty concept. The US poverty line was developed by Molly Orshansky in the 1960s and has been based on a low cost food plan for families under distress but also includes a non-food component. Being annually updated for inflation, the current US poverty line is essentially the same as the 1960s poverty line. Although there is general agreement that the US poverty line is outdated because its monetary value is not based on a recent assessment of the minimum costs of living in US society, it is still being used simply because replacing it is politically not feasible. In Europe, and certainly at a European Union level, there is a tradition of using relative poverty lines especially in cross-national comparisons (Atkinson et al., 2002). Thus, when the fight against poverty and social exclusion also became an objective for the EU after the Nice summit in December 2000, a relative poverty line was the (politically) preferred option to measure financial poverty.

The Laeken and Orshansky poverty measurement methods also differ in other aspects; the EU and US methods use different equivalence scales to adjust for differences in household size and demographic composition and even though both methods use income as the indicator of household welfare, the EU method uses disposable (after tax) income while the US method uses gross income. ${ }^{25}$

We apply both the Laeken and Orshansky poverty lines on nationally representative survey data from the United States and the old EU member states (15 countries). The USA data come from the Panel Study on Income Dynamics (PSID) and for the

\footnotetext{
${ }^{25}$ See section 9.2 in the appendix Poverty in Europe and the USA (Notten \& Neubourg de, 2007b) for a more elaborate discussion on the conceptual differences between both methods.
} 
European member states we use the European Community Household Panel (ECHP). Although our main focus is on the years 1996 and 2001, we also have information covering the period 1994-2001. Household annual disposable income is our welfare indicator. For the US we use the Cross National Equivalent Files (CNEF) version of the PSID because this dataset includes information on disposable income while the original PSID does not. The income variables in the ECHP are generally collected to provide an indication of household disposable income. In both datasets, the variable for total disposable income includes income from comparable sources such as wages, salaries, (entrepreneurial) earnings, other private income from transfers and capital as well as a range of social cash transfers. We use the resulting national (equivalent) income distributions in the data to derive the Laeken poverty lines for each country in each survey year. We converted the Orshansky poverty lines to the national price level of each European member state using 1993 Purchasing Power Indices. Subsequently we re-valued these poverty lines to later years using the national Consumer Price Indices. ${ }^{26}$ When analyzing the results, we assume that the absolute poverty line indeed reflects the cost of a minimum basket of goods in each country. ${ }^{27}$

Because both datasets also include a panel component, we not only estimate the percentage of poor individuals in each country but are also able to provide estimates of long term poverty. To estimate long term poverty we follow the definition of the so-called 'At-persistent-risk-of-poverty' indicator as used by the European Union. Individuals are considered long term poor if they are poor in the current period and they have been poor at least twice in the previous three years.

\footnotetext{
${ }^{26}$ See section 9.3 in the appendix Poverty in Europe and the USA (Notten \& Neubourg de, 2007b) for a more elaborate discussion on the preparation of both datasets and the cross-national comparability of the poverty estimates.

${ }^{27}$ This assumption is not crucial to the main objectives and arguments in our analysis as our absolute poverty indicator behaves in a similar manner as a minimum cost indicator. Nevertheless, it is likely that this assumption is violated (Notten \& Neubourg de, 2007c).
} 

4 Size matters: targeting efficiency and poverty reduction effects of means-tested and universal child benefits in Russia 


\subsection{Introduction ${ }^{1}$}

The debate whether universal or means-tested benefits are the preferred policy instrument in reducing (child) poverty is a longstanding one and centres around costs, incentives and the political economy. Under the condition of a constrained budget and assuming perfect targeting, poverty is reduced more effectively and efficiently when benefits are targeted to the poor based on means (Besley, 1990; Besley \& Kanbur, 1990). Higher administrative costs, targeting errors and labour market disincentives reduce the efficiency and effectiveness of means-tested benefits (Atkinson, 1998; Walle van de, 1998). Proponents of universal benefits argue that the costs related to means-testing may outweigh the actual benefit. Using the introduction of means-tested child benefits in Russia in 2000 as a case study this paper assesses the impact of a policy change from universal to means-tested child allowances in terms of targeting efficiency and poverty reduction. We focus on the core costs of targeting; namely leakage, exclusion errors and benefit costs, and relate these to the benefits in terms of poverty reduction.

Our focus is on child benefits because, as in many other countries, children in Russia are particularly at risk of living in poverty. In 2003, the poverty incidence among children younger than 16 years old was $27 \%$ compared to the national average of $20 \%$. Young children have an even higher risk of living in poverty (World Bank, 2004). Family allowances are the main instrument in most social protection systems to provide income support to families with children, and they always played an important role in Russian (and Soviet) social policy. In 2000, the eligibility requirements for child benefits in Russia changed from universal to means-tested allocation.

We compare means-tested and universal child allowance schemes both in terms of targeting efficiency and poverty reduction. Using the cross-section and panel dimensions of the Russia Longitudinal Monitoring Survey (RLMS) from 2000 to 2004, we investigate changes in targeting efficiency and poverty reduction over time. We measure targeting efficiency using a range of coverage and adequacy indicators; by calculating these indicators for two poverty lines and the quintiles of the expenditure distribution we gain insight into the scope of inclusion and exclusion errors. The poverty reduction impact is measured in three dimensions; poverty incidence, poverty gap and chronic poverty. Finally, we also simulate various means-tested and universal child benefit schemes using static micro simulation and analyse differences in poverty reduction and total benefit expenditures.

\footnotetext{
${ }^{1}$ This chapter is based on: Notten, G. \& F. Gassmann (2006). Size matters: Poverty reduction effects of means-tested and universal child benefits in Russia. MGSoG Working Paper(2006/001), Maastricht Graduate School of Governance, Maastricht University. A more recent version of this paper is forthcoming in The European Journal of Social Policy (2008).
} 
The remainder of the paper is structured as follows: firstly we review the main arguments of the debate between proponents of universal and means-tested cash benefits as the most effective and efficient instruments to support poor households and we discuss which aspects of this debate have been empirically investigated and which not. Then, we discuss the data and variables used in our analysis followed by a discussion of the poverty indicators used as well as their trends from 2000-2004. Sections five and six respectively analyse the targeting performance and poverty reduction effectiveness of the current child benefit scheme in Russia. Section seven simulates different policy options and compares their targeting performance with the current system. The final section summarizes the main findings.

\subsection{Universal versus means-tested cash benefits}

The debate whether universal or means-tested child benefits are the preferred policy instrument in reducing child poverty, is a longstanding one and centres around costs, incentives and the political economy (Atkinson, 1998; Barr, 2004; Besley, 1990; Besley, 1995; Coady et al, 2004a; Walle van de, 1998). Strictly speaking, a policy maker has two choices: allocate a benefit to all children of a certain age-group, i.e. provide a universal benefit, or limit the eligibility to children of poor families. Under a given government budget constraint, allocating the benefits to poor children will result in a higher benefit for each eligible child, and consequently, will have a greater effect on poverty reduction. However, targeting comes at a cost.

If benefits are targeted to the poor, the policy maker will have to determine an indicator that identifies the poor children. Governments have imperfect information about the true welfare level of households. It is difficult to find out whether a person or household belongs to the target group or not, and gathering such information is costly. In addition to screening costs, other inefficiencies arise as a result of imperfect targeting: some of the benefits will flow to children outside the target group while some children in the target group will not get a benefit. The former inefficiency is called 'leakage' or 'inclusion error' while the latter is known as 'exclusion error'. When screening costs are high and there are errors of inclusion and exclusion, universal benefits become more attractive as a benefit allocation mechanism. Moreover, as targeting becomes stricter in order to reduce leakage, screening costs rise further and exclusion errors also increase. Therefore, the decision between universal or targeted child benefits is ultimately a cost benefit analysis; when do the costs of targeting outweigh the benefits in terms of poverty reduction?

It makes sense that a targeting regime which aims at poverty relief needs to use poverty indicators as a screening device. There are, however, a number of pitfalls 
involved in poverty measurement that need to be considered. One issue is that poverty is a multidimensional concept; another is that there are various ways to measure each of these dimensions. Additionally, to determine whether a person is poor or not involves the (subjective) choice of a poverty threshold below which a person cannot fulfil his/ her basic needs, has poor health or an unacceptably low standard of living. Firstly, this implies that it is a priori not clear who the target group is (one first needs to determine the relevant dimension(s)). Secondly, the target group differs in size and characteristics according to the chosen measurement method and poverty threshold.

The academic literature also identifies other targeting costs such as incentive costs, social costs and political costs (Atkinson, 1998; Barr, 2004; Coady et al., 2004a; Gelbach \& Pritchett, 1997; Moene \& Wallerstein, 2001; Sen, 1995). Incentive costs arise when households adjust their behaviour in order to meet eligibility criteria. These responses can involve a cost (i.e. a household reduces labour supply so that their income falls below the eligibility threshold) but can also be beneficial (i.e. school attendance increases because benefit eligibility requires the children to go to school). Strict targeting might also increase social costs such as stigma and reduce the available budget for transfers if the budget is politically determined.

In addition, poverty alleviation may not be the only objective of child and other social benefits. Most social protection systems have several functions. They alleviate poverty, smooth income over the life cycle, provide insurance against certain risks and redistribute welfare. A benefit that is said to be 'poorly targeted' based on the poverty objective may be effective in terms of another objective (Atkinson, 1998).

In this paper we analyse the core costs of targeting, namely leakage, exclusion errors and total benefit expenditures, and relate these to the benefits in terms of poverty reduction. We limit our focus because the data allow for a thorough analysis of these aspects while they do not provide sufficient information to analyse the influence of other factors such as administration costs, incentive costs, social costs and political costs. ${ }^{2}$ Although there are various other targeting methods (Coady et al., 2004a), we focus on means-testing and compare the efficiency of this targeting method to one of universal provision in the context of child benefits in Russia.

Our analysis contributes to the debate in a number of ways. Firstly, many studies focus either on targeting efficiency or on poverty reduction (Coady et al., 2004a; Edmonds, 2005; Förster \& Tóth, 2001; Immervoll et al, 2000). The discussion above

\footnotetext{
${ }^{2}$ Information about the scope of, and cross-country variations in, administrative costs can be found in Coady et al (2004a). Furthermore, there is a large body of literature that empirically studies behavioural effects of government interventions. Especially, the effects of interventions on labour supply have received a lot of attention (among others Alvarez, September 2001; Blank, 2002; Cantillon et al, 2004; Cantillon $\&$ van den Bosch, December 2002; Moffitt, 2002, 2003). In section 4.8 we discuss how such costs could influence our results.
} 
suggests that there is a trade off between the costs of targeting and the benefits in terms of poverty reduction for means-tested and universal child benefits. This implies that it is important to measure both effects. Secondly, other contributions only focus on the effects of means-tested benefits or contrast the role of means-tested benefits to other parts of the welfare state such as social insurance programmes (Behrendt, 2000; Heady et al, 2001; Nelson, 2004; Sainsbury \& Morissens, 2002). Such analyses are useful in the sense that they provide information about how social protection programmes can complement each other or about the variation in impact of different means-tested schemes. However, they do not provide insights into the differences in impact of means-tested vis-à-vis universal cash benefit programmes for a specific group in the population. In this paper we analyse the impact of universal and means-tested child benefits using various targeting efficiency and poverty reduction indicators and apply it to the recent reforms of the Russian child benefit programme. Another contribution of this paper is that, in addition to the poverty incidence and poverty gaps indicators, we also analyse the poverty reduction impact of these schemes in terms of chronic poverty. The chronically poor, measured in this paper as those households that have average expenditures below the poverty line over a given period, are of particular interest because of the potentially high costs that long-term poverty has on the development of children.

The empirical literature provides some clues regarding to differences in targeting efficiency and the success in reducing poverty between means-tested and universal benefits. Matsaganis et al (2004) and Edmonds (2005) indeed find that under meanstested programmes leakage of benefits to the non-poor is considerably lower than under a universal programme, resulting in a higher share of the benefits going to the poor with means-tested child benefits (Matsaganis et al., 2004). A cross-national comparison of 122 anti-poverty interventions Coady et al (2004a) show that in terms of median targeting performance both means-tested benefits and child benefits score highest when compared with other targeting methods but both methods have approximately equal scores. Thus, both means-tested and child benefits distribute more resources to the poor than any other targeting method. However, because their definition of child benefit programmes includes all types of child benefits (universal, (proxy) meanstested, geographical etc.), it is not clear whether means-tested child benefits outperform universal benefits in terms of targeting efficiency ( $\mathrm{p} 27-31$, table 3.3).

The problem of exclusion or under-coverage receives attention in studies like Behrendt (2000) and Edmonds (2005), albeit from different perspectives: Behrendt evaluates the reduction in poverty of means-tested benefits and notes that recipient rates are 'astonishingly low' (i.e. exclusion rates are high, p. 31). Edmonds, being more concerned about the targeting efficiency of means-tested child benefits in Slovenia, 
mentions that the problem of under coverage does not appear 'to be so large that it could undermine the progressiveness of the means-tested programme' (p. 195). Additionally, both studies report that leakage of means-tested benefits is mainly to the 'near poor' population and thus less of an efficiency problem. It is important to realize that the problem of under-coverage represents a missed opportunity in terms of poverty reduction while at the same time it is the result of (increased) targeting efficiency. By comparing means-tested and universal schemes, our study therefore also analyses the potential poverty reduction that can be achieved by universal schemes.

According to the empirical literature, the impact of means-tested and universal schemes on various poverty measures differs. Forster and Tóth (2001) identify a move from universal to means-tested benefits in the Visegrad countries ${ }^{3}$ during the midnineties and find that the impact on poverty in terms of poverty incidence was reduced after reforms but that benefits were better targeted in terms of intensity and thus had a greater effect on the reduction of the poverty gap. In the study of Matsaganis et al (2004), which compares current (mostly means-tested) and simulated universal child benefit schemes in Southern European countries, the reduction in poverty differs not only per poverty measure but also per country. Unfortunately, it is not clear to what extent the poverty reduction effects can be attributed to the means-tested - universal difference or to other differences in programme characteristics such as the type and level of benefits (flat-rate - progressive, smaller or larger) and differences in benefits according to the number of children. Nevertheless, Matsaganis' study also shows another important point; other targeting criteria and/or benefit variations matter for the impact on poverty reduction and targeting efficiency. For instance, high poverty risk groups can be targeted by including their demographic characteristics as eligibility criteria (Greece for instance provides special benefits to households with three or more children). Another point that is addressed by the empirical literature is the manner in which the programme is implemented is of great importance, also for targeting efficiency and poverty reduction (Behrendt, 2000; Coady et al, 2004b).

A final aspect is concerned with the adequacy of the benefit level. The amount of benefits clearly matters; more generous benefits have a larger impact on poverty (Matsaganis et al., 2004). On the other hand, higher benefits put a larger strain on the government budget. If the benefit is small, the costs of strict means-testing may outweigh the benefit, both for the beneficiary and the administrator.

As for the means-test itself, the underlying objective is essential for its validation. Does the means-test aim at targeting the poor or is it meant to cut-off the wealthy households and to redirect some of the resources to poorer households? The latter 'mild' targeting may offer an alternative that comes close to an optimum as discussed by

\footnotetext{
${ }^{3}$ Czech Republic, Poland and Hungary.
} 
Besley and Kanbur (1990). In addition, the amount of leakage of benefits to households close to the poverty line may not be considered as a cost under the presumption that the poverty line is not a stringent concept. This 'mild' evaluation takes into account that income may not be perfectly observable and that there is no such thing as a single poverty line. This study therefore uses various benefit levels for the simulations, measures the poverty reduction impact using two poverty lines and analyses targeting efficiency in terms of the expenditure distribution in the population.

\subsection{Russia - from universal to means-tested child allowances}

Child allowances and other family policies always played a prominent role in Russian (and Soviet) social policy. The objective of providing child allowances is to assist families in having and bringing up children (Karelova, 2003). The main law regulating child and family allowances was passed in $1995 .{ }^{4}$ Up to 1999 , child allowances were officially allocated according to the universal principle but as early as 1995 some regional governments decided to introduce means-tested child benefits (Denisova et $a l, 2000)$. In 1999, federal law officially introduced a means-test for child allowances. The eligibility rules changed two more times before they were finally set and approved in the amended law (2000). In 2001, child allowances started to be financed from the federal budget. ${ }^{5} 6$

Families with children aged under 16 (or 18 if they still go to school) and with average per capita income below the Minimum Subsistence Level (MSL) are entitled to a child allowance. The methodology for calculating the MSL is governed by federal law. Regions are free within the boundaries of the law to determine the content of the minimum consumer basket and adjust its composition to regional needs and habits. ${ }^{7}$ The income-test for child allowances only takes the income of the parent(s) into account and divides the total family income by the number of family members, i.e. parent(s) and underage children. The application procedure is un-bureaucratic and simple. One of the parents (usually the mother) has to apply for the child allowance at the social security office in her home town. The test includes all formal income from employment

\footnotetext{
${ }^{4}$ This legislation describes a package of family and maternity benefits; we only focus on the monthly child benefits to families with children below 16 years (or 18 if still in school).

${ }^{5}$ The allocation of the funds is based on applications from the regions. Transfers are earmarked and cannot be used for other purposes than targeted child allowances. This financing procedure was legally established in 2002 .

${ }^{6}$ Our analysis covers the period 2000-2004 but reforms in child benefits continued to take place. In 2005, 'the authority to finance and legislatively regulate this benefit was transferred back to the level of the Russian Federation constituent entities' (Ovcharova \& Popova, 2005).

${ }^{7}$ As a result, the value of the official MSL may differ per region, and sometimes even within regions (Gassmann, 2003).
} 
or self-employment including bonuses, all types of pensions, benefits and allowances and income such as alimony payments over the three months prior to the application. The applicant fills in an application form, stating the total family income (no official documents or further income documentation have to be submitted) and providing the birth certificate for the child. The benefit is 70 ruble per child from 18 months to age 16 (or 18 if still in high school) (International Social Security Association, 2004). In the case of a single parent or when one of the parents is avoiding alimony payments, the benefit is higher (140 and 105 ruble).

\subsection{Data and methodology}

This study uses data from the Russia Longitudinal Monitoring Survey (RLMS) from 2000 until 2004. ${ }^{8}$ The RLMS can be used for (repeated) cross-section as well as panel analyses. For most of our analysis we use the cross-section dimensions which are representative for the Russian population as a whole. ${ }^{9}$ Included in the cross-section are those households that were observed in at least one round and had no missing observations on demographic, expenditure and income variables. We use the panel dimension of the RLMS to analyse the impact of child benefits on chronic poverty. Households are part of the panel if they participated in all five rounds and if they have no missing observations for the main variables.

The RLMS includes variables on household demographics, expenditures, income, poverty lines, education, of child benefit receipt and some variables on household participation in the labour market. We measure the poverty status of a household using the RLMS poverty lines and household expenditures. The RLMS poverty lines are based on regional age-gender specific food-baskets that are valued at regional prices. ${ }^{10}$ We prefer to use expenditures instead of income because households have a tendency to underreport income from informal and semi-formal activities (Atkinson et al, 1995; Deaton, 1997; Ravallion, 1994). Household income is therefore systematically below expenditures, which is a common feature of these data. Total expenditures are composed of food and non-food goods and services. Total food consumption is obtained by adding the expenditures on all foodstuffs, both purchased and from home produced

\footnotetext{
${ }^{8}$ For detailed information on the RLMS project, see www.cpc.unc.edu/projects/rlms/home.html.

${ }^{9}$ We use the RLMS post-stratification weights to obtain representative estimates.

${ }^{10}$ The RLMS poverty lines are based on an individual subsistence food basket but also include a nonfood component. Individual poverty lines are aggregated to the household level and subsequently adjusted for economies of scale. The adjustment factor varies between 1 for single person households and 0.7 for households with six or more members. Poverty lines are updated annually using the consumer price index.
} 
Table 4.1: Households with children

\begin{tabular}{lrrrrr}
\hline & 2000 & 2001 & 2002 & 2003 & 2004 \\
\hline \# of households with children & 1,280 & 1,269 & 1,232 & 1,207 & 1,136 \\
\# of children & 1,836 & 1,795 & 1,728 & 1,683 & 1,580 \\
Households with child (\%) & 42.5 & 41.0 & 40.1 & 39.1 & 35.8 \\
Excluding children under 18 months (\%) & 40.9 & 39.2 & 38.2 & 37.2 & 34.0 \\
Households with children & & & & & \\
per expenditure quintile (\%) & & & & & \\
\hline I & 50.5 & 40.4 & 40.2 & 37.2 & 41.3 \\
II & 44.2 & 42.1 & 41.1 & 41.7 & 36.7 \\
III & 41.0 & 41.6 & 41.6 & 40.3 & 35.4 \\
IV & 38.4 & 41.9 & 40.3 & 40.3 & 33.5 \\
V & 39.4 & 39.8 & 37.8 & 36.6 & 33.2 \\
\hline
\end{tabular}

Note: Includes all children aged up to 16 years, or 18 years if they are still in school.

Source: Own calculations based on the RLMS.

consumption. Total non-food consumption consists of expenditures on tobacco, clothing, fuel, health, services, luxury goods, rent, and utilities. ${ }^{11}$

We focus on households with children aged 16 years or 18 if still in school because these are the households that are potentially eligible for child benefits. ${ }^{12}$ For children under 18 months there is a 'child care leave allowance'; this social insurance benefit is set at 500 ruble a month ( 70 ruble for unemployed workers). Although we want to analyse the impact of the child allowance for children of 18 months and older, we can only distinguish between the benefits received by these age categories from 2003 on. ${ }^{13}$ To maintain consistency over time we therefore decided to use the slightly larger group of households with children below 16 (or 18 if in school) for our targeting and poverty impact analyses. Table 4.1 shows that the total number of households with children in this category is decreasing over time. This is in line with demographic trends reported in other data (Federal Service of State Statistics, 2002; World Bank 2005). It

\footnotetext{
${ }^{11}$ Not included are gifts or loans provided to other households, expenditures for tax and insurance, and savings and expenditures on stocks and bonds because these expenses are not made for the benefit of the household or are not used for current consumption. Also excluded are expenditures on durable goods because the consumption benefits from such goods extend over multiple periods.

${ }^{12}$ The main characteristics of the households in the cross-section and panel dimensions are summarized in the appendix. Comparing the weighted cross-section with the panel samples shows that in the panel urban households are underrepresented while households with children are somewhat overrepresented. Income and expenditures are somewhat lower in the panel, but the main trends are similar.

${ }^{13}$ From 2003 on the household questionnaire makes a distinction between the child care allowance received for children below 1.5 years and benefits received for children between 1.5 and 16 years old (or 18 if still in high school).
} 
Table 4.2: Poverty indices (in \% of individuals, 2000-2004)

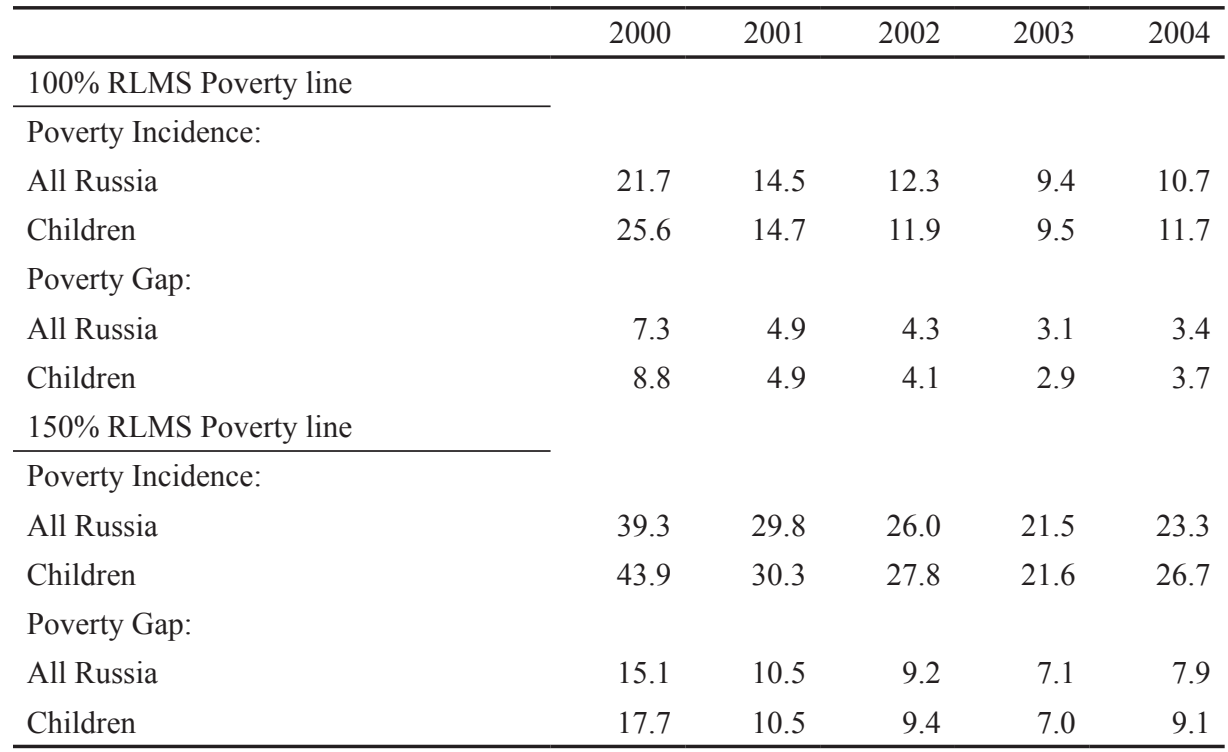

Note: Includes all children aged up to 16 years, or 18 years if they are still in school.

Source: Own calculations based on the RLMS.

can also be seen that households with children find themselves disproportionately more often in lower expenditure quintiles.

\subsection{Prevalence of (chronic) poverty in families with children}

We analyse trends in poverty using poverty incidence and poverty gap measures (Foster et al., 1984) ${ }^{14}$ as well as a spells-based chronic poverty indicator (Hulme \& Shepherd, 2003). We have calculated these poverty statistics for the RLMS poverty line and for a value of $150 \%$ of the RLMS poverty line. We do this for two reasons. Firstly, poverty statistics are sensitive to the level of poverty threshold and we want to evaluate the manner in which changing the threshold level influences our poverty estimates. Secondly, the Russian authorities use a different poverty line (Minimum Subsistence

\footnotetext{
14 The Foster-Greer-Thorbecke class of decomposable poverty indices (1984) can be represented as follows:

$F G T=1 / n * \sum_{c_{\mathrm{c}}<\mathrm{z}}^{\mathrm{q}}\left[\frac{z-c_{i}}{z}\right]^{\alpha}$

, where $\mathrm{n}=$ total number of individuals, $\mathrm{q}=$ number of poor, $\mathrm{z}=$ poverty line and $\mathrm{c}_{\mathrm{i}}=$ individual expenditure. If $\alpha=0$, the equation represents the headcount index (poverty rate). Taking $\alpha=1$ results in the poverty gap, measuring the mean proportionate expenditure shortfall over the total population.
} 
Level) to establish whether a family falls below the income threshold and is thus eligible for child benefits. The 150\% RLMS cut-off is comparable to the Minimum Subsistence Level and thus better reflects the target group at which the child benefit programme is aimed. ${ }^{15}$

The expenditure-based estimates in Table 4.2 show that all poverty indicators declined until 2003, and rose again in 2004. In 2004, $11 \%$ of the Russians had expenditures below the poverty line, having an average shortfall of expenditures over the total population of $3.4 \%$ and poverty severity index of $1.7 \%$. Using the $150 \%$ threshold values most poverty indices more than double in value, a sign that the expenditure distribution around the poverty line is rather dense. In other words, many Russian households have expenditures that are only slightly above the poverty line; a shift of the poverty line therefore has a large impact on poverty indicators. ${ }^{16}$ In comparison with the total population, children have a higher than average or average poverty risk, depending on the survey year.

For our analysis of chronic poverty, we use an indicator that is based on a combination of the number of poverty spells and the mean value of household expenditures vis-à-vis the poverty line. Households are classified in four categories: always poor, usually poor (mean expenditures under the poverty line), occasionally poor (mean expenditures above the poverty line) and never poor. Chronic poverty studies have shown that the experience of poverty is not homogenous over time; some individuals experience poverty only once, others regularly and some only know a life of poverty. In terms of need, the chronically poor are a group that should receive special attention from policymakers. Children living in chronically poor households are of particular concern because the sustained low level of household resources also increases the risk of living in poverty as an adult due to insufficient investment in health and human capital. In Russia about one third of the panel's households experienced poverty at least once in the period 2000-2004 (Table 4.3). The 'occasionally poor' comprise the largest group with $30 \%$ while $7.3 \%$ can be classified as chronically poor

\footnotetext{
${ }^{15}$ Comparing the average household poverty lines used in the RLMS with the average Minimum Subsistence Level (MSL) in the Russian Household Budget Survey for the year 2000 shows that the average weighted MSL is about $150 \%$ of the average weighted RLMS threshold. Note that the RLMS poverty lines assume economies of scale while the MSL is based on a per capita basis. Thus, even if the individual RLMS and MSL poverty lines were the same, households with children are more likely to be poor using the MSL method than the RLMS method. As we do not have more details on the methodologies for the construction of both poverty lines, we cannot make any further inferences as to why the poverty lines differ.

${ }^{16}$ The use of a different welfare indicator and/or poverty line threshold can have large effects on aggregate poverty indices, particularly in a country with a tight welfare distribution at the lower end. We therefore checked the consistency of our estimates with other poverty studies. Other studies using different welfare aggregates and/or poverty thresholds (Gassmann, 2003; World Bank, 2004) find higher poverty rates in general as well as an increased poverty risk for children but the overall trends in poverty indices are very similar to our findings.
} 
Table 4.3: Chronic poverty ( $\%$ of individuals in 2004, 2000-2004 panel)

\begin{tabular}{lrrrrrr}
\hline & \multicolumn{2}{c}{$100 \%$ RLMS Poverty line } & & \multicolumn{2}{c}{$150 \%$ RLMS Poverty line } \\
\cline { 2 - 3 } \cline { 5 - 6 } & All Russia & Children $^{1}$ & & All Russia & Children \\
\hline Always poor & 2.0 & 1.4 & 6.9 & 7.6 \\
Usually poor $^{2}$ & 5.3 & 6.9 & & 15.2 & 17.9 \\
Occasionally poor $^{3}$ & 29.5 & 34.0 & & 38.2 & 39.7 \\
Never poor $^{3}$ & 63.2 & 57.7 & & 39.7 & 34.8 \\
\hline
\end{tabular}

Note: ${ }^{1}$ Includes all children aged up to 16 years, or 18 years if they are still in school. ${ }^{2}$ Mean expenditures $\leq$ poverty line ${ }^{3}$ Mean expenditures $>$ poverty line.

Source: Own calculations based on the RLMS.

i.e. those households with mean expenditures under the poverty line. Using the higher poverty line, about $22 \%$ of Russians lived in chronic poverty and $38 \%$ experienced occasional poverty spells. Children have a higher than average risk to live in either of the poverty groups; they are more likely to live in chronically poor and occasionally poor households.

\subsection{Targeting efficiency of child allowances}

We have seen that, even though several local administrations already introduced some form of means-testing during the mid-nineties it was only in 1999 that child benefits became means-tested by federal law. Since mid-2000 there were no further changes in eligibility requirements. Therefore, we use the 2000 survey data as a benchmark year for analyzing changes in the targeting efficiency. We measure targeting efficiency by using a range of indicators on child benefit coverage and adequacy; coverage indicators provide information on the beneficiaries while adequacy indicators give insight into the size benefits and the allocation of total benefits. To analyse whether child benefits indeed target poor children in Russia and to what extent, we relate our coverage and adequacy indicators to the poverty status of the beneficiaries as well as the poverty threshold. For instance, the percentage of children receiving benefits indicates which proportion of the children in Russia receives child allowance, but it does not indicate to what extent these beneficiaries belong to the target group (correct targeting) or not (leakage or inclusion error) and which part of the target group is excluded (exclusion error). By calculating the percentage of poor beneficiaries we can gain insight into these targeting aspects (using the same poverty thresholds as in the previous section). Under a means-tested scheme, leakage of benefits to 'near poor' children is typically considered less problematic than leakage of resources to 'rich' children (Atkinson, 1998; Behrendt, 2000). In addition, the poverty analysis in the previous section has 
shown that the size of the target population is very sensitive to the choice of the poverty line. We therefore complement our analysis of targeting efficiency by decomposing our indicators into expenditure quintiles.

Households in Russia with children under 16 (or 18 if the child is still going to high school) are potentially eligible for child benefits under the current means-tested scheme, but all would be eligible under a universal benefit. Table 4.4 shows that benefit coverage increased over the whole period; the percentage of children receiving child benefits doubles from $33 \%$ in 2000 to $63 \%$ in 2004. From 2001 onwards, poor children are more likely to receive benefits than their non-poor. This suggests that there have been two effects. Firstly, there has been a general increase in the number of benefits provided. It is likely that the move from local to federal funding of earmarked benefits has been an important contribution in this respect. ${ }^{17}$ Secondly, the increase in coverage of poor children as compared to overall coverage rates suggests that the means-test indeed targeted the poor. ${ }^{18}$

Nevertheless, one third to a quarter of the poor children does not receive a benefit. It is not clear whether the applications for child benefits were denied or whether the parents decided not to file an application. The only insight that the RLMS provides is whether the household thinks it is eligible for child benefits. ${ }^{19}$ In $2004,32 \%$ of the non-poor households with children thought they were not eligible as compared to $23 \%$ of the poor households. This suggests that lack of information might be one reason for non-take up. The distributional decomposition of the data confirms that child benefits are progressive; children in lowest two quintiles have higher coverage rates. There is nevertheless considerable leakage to other quintiles.

Coverage rates only show one aspect of targeting efficiency. The selected adequacy indicators show how much benefit is received in three dimensions; the absolute level of benefits, the level of benefits as compared to total expenditures and the share of total benefits going to the lowest expenditure quintiles. A first indicator of benefit adequacy is the benefit level. We only report median benefit levels because there are a number of outliers in the reported child benefits which cannot be fully explained by supplementary benefits, birth grants or maternity benefits (from local authorities or employers). To facilitate comparison between survey years, we denote the values of

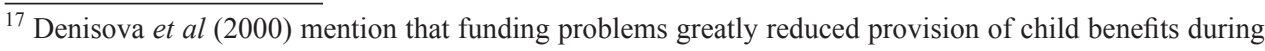
the mid-nineties.

${ }^{18}$ Incidence rates look at receipt of benefits over the total population while coverage rates focus on benefit receipt among children or households with children. The trends in terms of incidence rates (not shown here) are similar to the coverage rates but differ in level; they increased from less than $13 \%$ in 2000 to $21 \%$ in 2004. There was a strong increase in benefit receipt among (consumption) poor households.

${ }^{19}$ For more information check for instance the household questionnaire of 2004, question 5 page 24F (http:// www.cpc.unc.edu/projects/rlms/data/questionnaires/rmhouse.pdf, accessed October 2006).
} 
Table 4.4: Targeting efficiency of child benefits (2000-2004)

\begin{tabular}{|c|c|c|c|c|c|c|}
\hline & & 2000 & 2001 & 2002 & 2003 & 2004 \\
\hline \multicolumn{7}{|c|}{ Benefit Coverage } \\
\hline \multicolumn{2}{|c|}{ \# of children, $\%$ of which } & 1,280 & 1,269 & 1,232 & 1,207 & 1,136 \\
\hline- & receives child benefits & 32.5 & 49.8 & 57.8 & 60.9 & 62.9 \\
\hline- & $\begin{array}{l}\text { is poor and receives child benefits } \\
\text { (100\% RLMS poverty line) }\end{array}$ & 31.7 & 60.3 & 73.6 & 78.8 & 67.0 \\
\hline- & $\begin{array}{l}\text { is poor and receives child benefits } \\
\text { (150\% RLMS poverty line) }\end{array}$ & 31.3 & 58.5 & 68.4 & 74.3 & 73.4 \\
\hline \multicolumn{7}{|c|}{ Children receiving child benefit per expenditure quintile (\%) } \\
\hline \multicolumn{2}{|l|}{ I } & 34.2 & 61.2 & 71.0 & 74.8 & 74.3 \\
\hline \multicolumn{2}{|l|}{ II } & 29.0 & 59.7 & 62.7 & 74.3 & 72.5 \\
\hline \multicolumn{2}{|c|}{ III } & 36.5 & 49.4 & 59.9 & 60.7 & 60.0 \\
\hline \multicolumn{2}{|c|}{ IV } & 30.5 & 43.7 & 53.5 & 54.8 & 58.0 \\
\hline \multicolumn{2}{|l|}{ V } & 31.8 & 34.4 & 39.5 & 39.0 & 45.2 \\
\hline \multicolumn{7}{|c|}{ Benefit Adequacy } \\
\hline \multicolumn{7}{|c|}{ Child allowance per child (median) } \\
\hline \multicolumn{2}{|c|}{ Nominal rubles } & 60 & 70 & 73 & 70 & 80 \\
\hline \multicolumn{2}{|c|}{ Real 1992 rubles } & 85 & 84 & 76 & 65 & 66 \\
\hline \multicolumn{7}{|c|}{ Total benefit as \% of household expenditure for poor household (median) } \\
\hline \multirow{2}{*}{-} & Poor (100\% RLMS Poverty line) & 6.9 & 5.9 & 5.0 & 4.3 & 3.9 \\
\hline & Poor (150\% RLMS Poverty line) & 5.3 & 4.0 & 3.6 & 2.9 & 2.5 \\
\hline \multicolumn{7}{|c|}{ Total benefit as $\%$ of household expenditure per expenditure quintile (median) } \\
\hline \multicolumn{2}{|l|}{ I } & 8.0 & 5.0 & 4.3 & 2.9 & 2.7 \\
\hline \multicolumn{2}{|l|}{ II } & 3.3 & 2.7 & 2.0 & 1.6 & 1.6 \\
\hline \multicolumn{2}{|c|}{ III } & 1.8 & 1.6 & 1.4 & 1.1 & 1.0 \\
\hline \multicolumn{2}{|c|}{ IV } & 1.6 & 1.3 & 1.0 & 0.8 & 0.7 \\
\hline \multicolumn{2}{|l|}{$\mathrm{V}$} & 0.8 & 0.6 & 0.6 & 0.4 & 0.4 \\
\hline \multicolumn{7}{|c|}{ Benefit share to the poor as $\%$ of total benefits (excluding outliers) } \\
\hline \multirow{2}{*}{$\begin{array}{l}- \\
-\end{array}$} & Poor (100\% RLMS Poverty line) & 25.1 & 18.2 & 17.1 & 13.6 & 14.4 \\
\hline & Poor (150\% RLMS Poverty line) & 46.5 & 37.2 & 33.6 & 28.6 & 32.6 \\
\hline \multicolumn{7}{|c|}{ Benefit share per quintile as $\%$ of total benefits (excluding outliers) } \\
\hline \multicolumn{2}{|l|}{ I } & 26.9 & 25.1 & 26.7 & 26.1 & 28.8 \\
\hline \multicolumn{2}{|l|}{ II } & 20.5 & 26.0 & 20.8 & 26.6 & 22.9 \\
\hline \multicolumn{2}{|c|}{ III } & 18.5 & 19.8 & 21.4 & 20.0 & 17.8 \\
\hline \multicolumn{2}{|c|}{ IV } & 16.3 & 16.8 & 18.4 & 16.2 & 16.6 \\
\hline \multicolumn{2}{|l|}{ V } & 17.8 & 12.3 & 12.6 & 11.2 & 13.9 \\
\hline
\end{tabular}

Note: Includes all children aged up to 16 years, or 18 years if they are still in school.

Source: Own calculations based on the RLMS. 
child allowances in real 1992 ruble as well as in nominal values. The nominal amount of child allowance received in 2004 is 80 ruble. The median value of child allowance has been decreasing in real terms since 2000. This is mainly because child benefits are not indexed for inflation. ${ }^{20}$

What is the relative contribution of child allowance to the household budget? Compared to average monthly expenditures, child benefits are rather modest. The benefit shares are also decreasing over time. For the lowest welfare quintile the benefit share over total expenditures decreases from $8 \%$ in 2000 to $2.7 \%$ in 2004 . This decline can be explained by an increase of household real expenditures $(33 \%$ for the lowest quintile $)^{21}$ combined with a decline in the real value of child benefits $(22 \%$ for the median child benefit).

To what extent do programme benefits flow to households in the target group and what proportion of the benefits is spent on beneficiaries outside the target group? The benefit share per quintile shows the percentage of the programme resources is flowing to the target group and which percentage of the resources leaks away to richer households. Using the higher poverty line, which corresponds better to the income threshold used by Russian authorities, we can see that about half of the benefits flow to poor households in 2000 but this share declines to about a third in 2004. From the decomposition into quintiles we can see that over the observed period about $50 \%$ of the benefits are going to the poorest $40 \%$ of the population. Possible explanations for this could be that the means-test is not strictly applied, or alternatively, benefit receipt is rather sticky possibly indicating a lack of regular household re-evaluation. ${ }^{22}$

In addition to the descriptive indicators of targeting efficiency we also want to test if there is statistical evidence for the changes in the targeting efficiency of child benefits. We estimate a binary model with child benefit receipt as a dependent variable and a number of explanatory variables such as the number of eligible children and other demographic characteristics, the logarithm of nominal income minus child benefits ${ }^{23}$, a dummy for the poverty status of the household, a dummy taking the value of one if at

\footnotetext{
${ }^{20}$ We also checked both poverty lines whether there is a difference in the median benefit per child for poor and non-poor children. The median benefit per child of a poor household was about 10 ruble higher in 2000/2001 and 7 ruble higher in 2002. In 2003 and 2004 there was no difference anymore.

${ }^{21}$ See Table 4.9 in the appendix.

${ }^{22} \mathrm{We}$ analysed patterns of benefit receipt for the household panel and found that the majority of households continue to receive benefits in subsequent years. Of those households receiving child allowance in 2000, $53 \%$ still received child allowances in 2004 . Of those who did not receive benefits anymore, $26 \%$ still had children in the eligible age category. Households that lost benefits but still had eligible children had higher expenditures on average.

${ }^{23}$ Income (provided by RLMS) includes all earnings from (self-) employment and social transfers (cash and non-cash). We used income because child benefits in Russia are income-tested. Doing the same analyses using the logarithm of household expenditures minus child benefits yields similar results.
} 
Table 4.5: Probit regressions on cross-sections (Child benefit receipt: yes $=1 /$

\begin{tabular}{|c|c|c|c|c|c|}
\hline & 2000 & 2001 & 2002 & 2003 & 2004 \\
\hline $\begin{array}{l}\text { \# of households } \\
\text { Model } 1\end{array}$ & 1,261 & 1,259 & 1,223 & 1,195 & 1,132 \\
\hline $\begin{array}{l}\text { Log income before child } \\
\text { benefits }\end{array}$ & $\begin{array}{l}-0.017 \\
-0.015\end{array}$ & $\begin{array}{l}-0.081 \\
(0.018)^{01}\end{array}$ & $\begin{array}{l}-0.06 \\
(0.017)^{01}\end{array}$ & $\begin{array}{c}-0.1 \\
(0.020)^{01}\end{array}$ & $\begin{array}{l}-0.091 \\
(0.022)^{01}\end{array}$ \\
\hline $\begin{array}{l}\text { Number of children in } \\
\text { eligible category }\end{array}$ & $\begin{array}{c}0.1 \\
(0.019)^{01}\end{array}$ & $\begin{array}{l}0.175 \\
(0.024)^{01}\end{array}$ & $\begin{array}{c}0.21 \\
(0.026)^{01}\end{array}$ & $\begin{array}{l}0.151 \\
(0.025)^{01}\end{array}$ & $\begin{array}{l}0.101 \\
(0.032)^{01}\end{array}$ \\
\hline Model 2 & & & & & \\
\hline $\begin{array}{l}\text { Expenditures under poverty } \\
\text { line }\end{array}$ & $\begin{array}{r}-0.016 \\
-0.03\end{array}$ & $\begin{array}{l}0.101 \\
(0.042)^{01}\end{array}$ & $\begin{array}{l}0.165 \\
(0.045)^{01}\end{array}$ & $\begin{array}{l}0.172 \\
(0.045)^{01}\end{array}$ & $\begin{array}{r}0.046 \\
-0.048\end{array}$ \\
\hline $\begin{array}{l}\text { Number of children in } \\
\text { eligible category }\end{array}$ & $\begin{array}{l}0.099 \\
(0.018)^{01}\end{array}$ & $\begin{array}{l}0.169 \\
(0.023)^{01}\end{array}$ & $\begin{array}{l}0.212 \\
(0.026)^{01}\end{array}$ & $\begin{array}{l}0.147 \\
(0.024)^{01}\end{array}$ & $\begin{array}{l}0.103 \\
(0.030)^{01}\end{array}$ \\
\hline Model 3 & & & & & \\
\hline $\begin{array}{l}\text { Log income before child } \\
\text { benefits }\end{array}$ & $\begin{array}{l}-0.027 \\
-0.018\end{array}$ & $\begin{array}{l}-0.052 \\
(0.020)^{01}\end{array}$ & $\begin{array}{l}-0.036 \\
-0.019\end{array}$ & $\begin{array}{l}-0.071 \\
(0.023)^{01}\end{array}$ & $\begin{array}{l}-0.059 \\
(0.022)^{01}\end{array}$ \\
\hline $\begin{array}{l}\text { Number of children in } \\
\text { eligible category }\end{array}$ & $\begin{array}{l}0.101 \\
(0.021)^{01}\end{array}$ & $\begin{array}{l}0.176 \\
(0.025)^{01}\end{array}$ & $\begin{array}{c}0.214 \\
(0.029)^{01}\end{array}$ & $\begin{array}{l}0.145 \\
(0.027)^{01}\end{array}$ & $\begin{array}{c}0.081 \\
(0.033)^{01}\end{array}$ \\
\hline $\begin{array}{l}\text { At least one unemployed } \\
\text { person }\end{array}$ & $\begin{array}{r}0.072 \\
-0.045\end{array}$ & $\begin{array}{r}0.059 \\
-0.048\end{array}$ & $\begin{array}{r}-0.017 \\
-0.05\end{array}$ & $\begin{array}{r}0.05 \\
-0.053\end{array}$ & $\begin{array}{r}0.023 \\
-0.052\end{array}$ \\
\hline Head of household is female & $\begin{array}{r}0.064 \\
-0.058\end{array}$ & $\begin{array}{l}0.165 \\
(0.057)^{01}\end{array}$ & $\begin{array}{l}0.146 \\
(0.055)^{01}\end{array}$ & $\begin{array}{r}0.046 \\
-0.058\end{array}$ & $\begin{array}{r}0.016 \\
-0.059\end{array}$ \\
\hline $\begin{array}{l}\text { Household living in semi- } \\
\text { urban area }\end{array}$ & $\begin{array}{r}0.16 \\
-0.089\end{array}$ & $\begin{array}{r}-0.08 \\
-0.086\end{array}$ & $\begin{array}{r}0.023 \\
-0.095\end{array}$ & $\begin{array}{l}-0.241 \\
-0.097^{05}\end{array}$ & $\begin{array}{r}-0.08 \\
-0.103\end{array}$ \\
\hline $\begin{array}{l}\text { Household living in rural } \\
\text { area }\end{array}$ & $\begin{array}{r}0.115 \\
-0.067\end{array}$ & $\begin{array}{l}0.163 \\
(0.069)^{05}\end{array}$ & $\begin{array}{r}0.056 \\
-0.071\end{array}$ & $\begin{array}{r}0.121 \\
-0.075\end{array}$ & $\begin{array}{r}0.059 \\
-0.075\end{array}$ \\
\hline $\begin{array}{l}\text { Dummies indicating primary } \\
\text { sampling } \\
\text { unit ( } 38-1=37 \text { dummies) }\end{array}$ & $\begin{array}{c}\text { Not } \\
\text { reported }\end{array}$ & $\begin{array}{c}\text { Not } \\
\text { reported }\end{array}$ & $\begin{array}{r}\text { Not } \\
\text { reported }\end{array}$ & $\begin{array}{r}\text { Not } \\
\text { reported }\end{array}$ & $\begin{array}{r}\text { Not } \\
\text { reported }\end{array}$ \\
\hline $\begin{array}{l}\text { F-test on joint significance } \\
\text { of primary sampling units, } \\
\text { critical value (p-value) }\end{array}$ & $\begin{array}{c}32.81^{01} \\
(0.0000)\end{array}$ & $\begin{array}{l}13.12^{01} \\
(0.0003)\end{array}$ & $\begin{array}{r}2.59 \\
(0.1078)\end{array}$ & $\begin{array}{l}8.35^{05} \\
(0.0154)\end{array}$ & $\begin{array}{r}7.24^{05} \\
(0.0268)\end{array}$ \\
\hline
\end{tabular}

Note: Model is estimated with households that have children in eligible age category. Estimates are displayed in marginal effects. Robust standard errors in parentheses. ${ }^{01}$ significant at a $1 \%$ level, ${ }^{05}$ significant at a $5 \%$ level. Included in all estimations but not reported: variables on demographic composition of household

Source: Own calculations based on the RLMS. 
least one household member is unemployed, a dummy for a female headed household, dummies indicating a semi urban and rural dwelling place and dummies for the primary sampling units. ${ }^{24}$ We only include households that have children in the eligible age category i.e. under age 16 or 18 if the child is still in high school.

Our estimation strategy is rather straightforward; for each cross-section we use Probit regressions to estimate a number of models. In our first model the main explanatory variables are the number of children in the eligible age category and household income. The second model replaces household income with a dummy variable on the poverty status of the household. The third model includes in addition to the number of children in the eligible age category, household income and a number of control variables that potentially can be correlated with the dependent variable. ${ }^{25}$ As we repeat the estimation for each year, changes in sign, magnitude and significance of the estimated parameters can be interpreted as indicators for policy change. The results are reported in Table 4.5 and displayed as marginal effects indicating the change in the probability for a small change in each independent, continuous variable and the discrete change in the probability for dummy variables.

As expected, the number of eligible children in the household is positively correlated with benefit receipt for all models and every survey year; households with more children are more likely to receive child benefits. Additionally, the likelihood of receiving child benefits with an additional child increases from $10 \%$ in 2000 to $21 \%$ in 2002 and then drops to a value of around $10 \%$ in 2004 . The estimated marginal effects for household income are very small and insignificant in 2000 but increase in magnitude and become significant at a $1 \%$ level from $2001 \mathrm{on}$. The negative sign of the coefficient confirms the progressiveness of child benefits; as income increases the probability of child benefit receipt falls.

In our second model, the coefficient for poverty status also becomes significant at a $1 \%$ level in 2001 suggesting that poor households are more likely to receive child allowance. This effect, however, disappears in 2004.

In the third model, the estimates for the unemployment and most of the estimates for rural/semi-urban dummies are insignificant. The dummy indicating female head of the household is significant in 2001 and 2002 and points to an increased probability of receiving child benefits. There is also an interesting pattern in the explanatory power of

\footnotetext{
${ }^{24}$ The model can be written as $\operatorname{Pr}[Y=1 \mid x]=\lambda\left(\beta^{\prime} x\right)$, where $\mathrm{Y}=$ dependent variable, $\lambda=$ standard normal cumulative distribution function, $x=$ vector of explanatory variables and $\beta=$ vector of parameters to be estimated (Greene, 2003). The dependent variable takes on $Y=1$ when the household receives a child benefit and $\mathrm{Y}=0$ otherwise.

${ }^{25}$ Control variables: labour status of household members, dwelling place (urban, semi-urban or rural), and dummies indicating the primary sampling units.
} 
the primary sampling dummies; the joint explanatory power of these location dummies is very high in 2000 (see the results of the F-test in Table 4.5) but decreasing thereafter being insignificant at in 2002 and significant on a 5\% level in 2003 and 2004. We believe that these dummies control for regional differences in the implementation and financing of child benefits for two reasons. Firstly, these dummies act as a control for faster/slower implementation of the reforms in the regions. Secondly, it was only in the course of 2001 that child allowances were fully financed from the federal budget via a compensation fund. The decrease of explanatory power in the coefficients of the primary sampling units might indeed reflect the harmonization of the child benefit programme in the Russian Federation.

\subsection{Impact of child allowances on (chronic) poverty}

This section evaluates the impact of child benefits in terms of poverty from 2000 to 2004. So far we have seen that the size of child allowances is rather modest and that its real value is decreasing over time. Does this mean that the poverty reduction effect of the benefits also decreased? We analyse the impact of child benefits on poverty by comparing expenditures before and after child benefits. This is a static analysis; it does not take into account any behavioural changes of households in the absence of child benefits nor any responses to changes in the benefit level or eligibility criteria. We investigate the impact of the benefit on the incidence of poverty, the poverty gap and the incidence of chronic poverty, both in terms of the total population as well as children. ${ }^{26}$

Figure 4.1 shows the pre and post benefit poverty rates as well as the absolute and relative poverty reduction effects. The reduction in poverty rates is rather small. Overall poverty reduction rates are between 0.3 and 0.7 percentage points (3.2 to $5.7 \%$ ) while the reduction of child poverty for recipient households varies between 0.6 and 1.6 percentage points (5.5 to $11.1 \%$ ). The impact of child allowances on the mean proportionate poverty gap among children is declining in an absolute sense; in 2000 child benefits still reduced the mean poverty gap with 0.6 percentage points compared to 0.2 percentage points in 2004. In a relative sense the poverty gap reduction varies between 5.4 and $10.3 \%$. Changing the poverty line does not have a different effect; the percentage point poverty reductions using the $150 \%$ RLMS poverty line, are of similar magnitude (not shown here).

\footnotetext{
${ }^{26}$ Households with extreme amounts of reported child benefits were excluded for the calculation of the poverty gap. Outliers were identified using the 'iqr' syntax in Stata 9.0. 'iqr' indicates an outlier as severe when it 'comprises about $.0002 \%$ of the normal population. In samples, they lie far out enough to have a substantial effect on means, standard deviations, and other classical statistics.' (Stata 9.0 Viewer).
} 

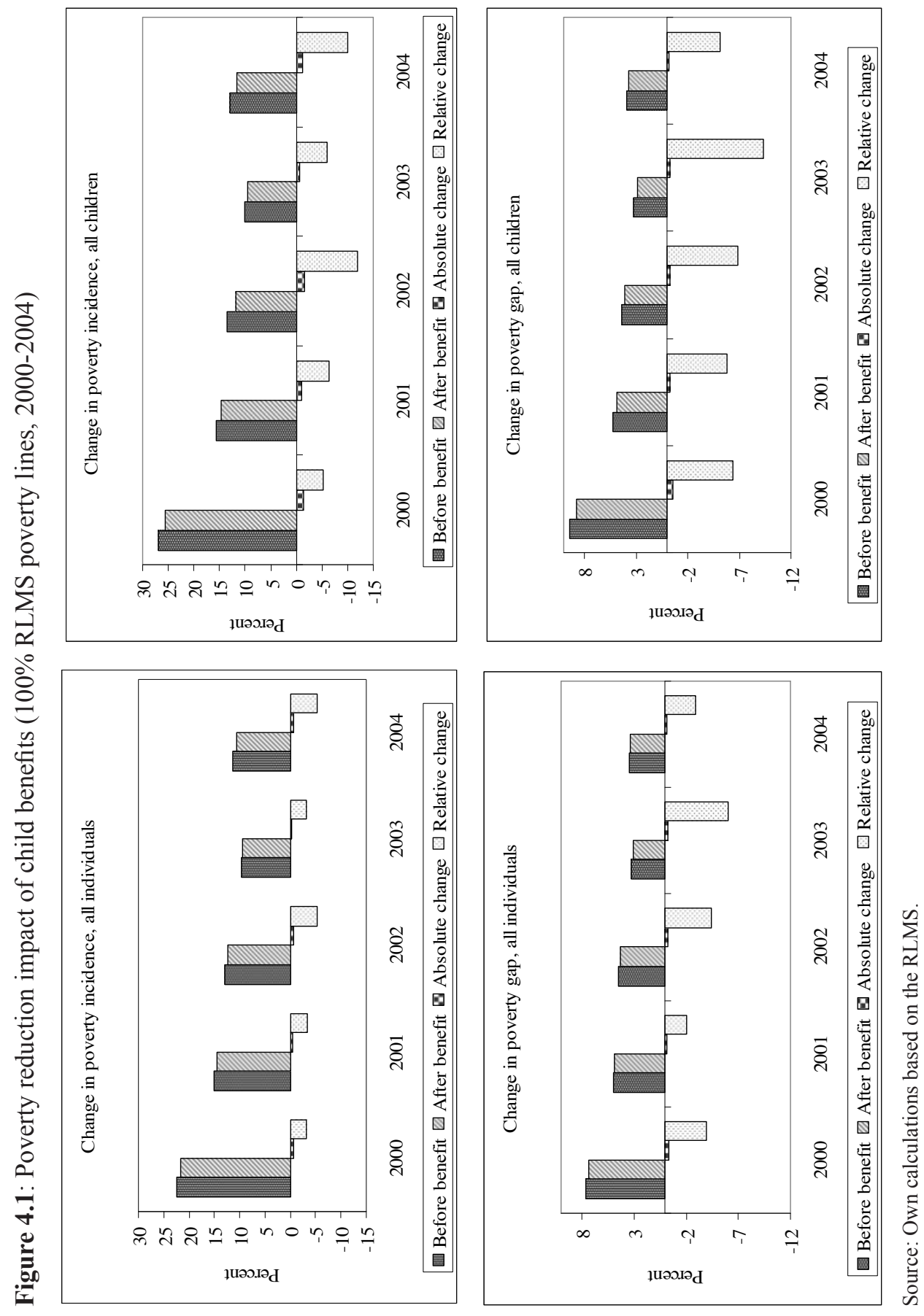
Did the introduction of mean-testing influence the reduction in poverty measured by these indicators? When we compare the poverty reduction effects in Figure 4.1 using the year 2000 as a benchmark, we see that the reduction in the number of poor children is lowest in 2000 and higher in all other years (and this holds for both poverty lines). The trend in terms of poverty gap is less clear but 2000 also shows comparably less success in reducing the poverty gap. Using the higher poverty line, the poverty gap reduction in 2000 is clearly the lowest. It is however not clear to what extent this improvement is due to the introduction of a means-test or because of the substantial increase of overall benefit coverage. Moreover, what would be the poverty reduction impact of a universal scheme? Even though the overall poverty reduction impact is modest for all indicators, child benefits in Russia have the greatest poverty reduction effect on chronically poor children (a relative reduction of 19.3\%). Without child benefits, 9.9\% of the children would live in chronic poverty, but child benefits reduce chronic poverty with 1.6 percentage points to $8.3 \%$ (the reduction is similar using the higher poverty line). The percentage of children experiencing occasional poverty declines with 0.8 percentage points for the lower poverty line but rises with 0.3 percentage points for the higher poverty line.

\subsection{Simulation alternative child benefit programmes}

The previous section showed that there was (some) improvement in terms of poverty reduction over time. Taking the means-testing capacities of public authorities as a given; what would be the poverty reduction effect when introducing a universal scheme? And what impact would a change in the level of benefits have? We investigate the poverty impact of a range of alternative child benefit programmes and compare it with the current situation. We simulate six alternative scenarios, starting with a budget neutral universal benefit ( 42 ruble), and a universal benefit at the current benefit level. For the other four scenarios we increase the benefit level and simulate means-tested and universal eligibility rules. The underlying idea for these simulations is that the child benefit should cover a substantial share of the costs of a child living at the poverty line. We decided to use the child weight of the modified OECD equivalence scales to indicate the cost share of the child ( 0.3 equivalent adult).

The RLMS poverty lines are already specified at a household level. To obtain the ruble value of a child's share of the poverty line in 2004, we use the average single male poverty line to obtain a value for the adult equivalent poverty line level. Then, we multiply this poverty line by 0.3 . Note that the level of child benefit differs by region.

The following scenarios are simulated; both applying means-tested and universal eligibility rules: 
A monthly benefit that covers half of the poverty line child costs

( 0.15 equivalent adult, about 280 rubles)

A benefit that covers the entire poverty line child costs

( 0.3 equivalent adult, about 560 rubles)

We use the 2004 cross-section as our benchmark and analyse the impact of benefits on children between 18 months old and 16 years (18 if still in school). For the meanstested scenarios we assume that the same households receive a benefit as those under the current mean-tested scheme. To obtain estimates for the total costs of each benefit option we use the 2004 population data as provided in the UNICEF TransMONEE data (2005). ${ }^{27}$ The 2004 GDP and social expenditure data are retrieved from the statistical appendix of the IMF country report on Russia (International Monetary Fund, 2005).

The impact on child poverty and chronic child poverty under current and simulated policy options is summarized in Table 4.6 and Table 4.7. In comparison to the current programme, poverty incidence and poverty gap among children would be further reduced by 0.1 percentage point if all children would receive a benefit of 70 ruble (irrespective of the poverty line used). For the budget neutral scheme, the poverty reduction effects are equal or less as compared to the current means-tested scheme. The 70 ruble universal scheme achieves slightly higher chronic poverty reduction rates while the effects of the budget neutral scheme are less obvious. Table 4.8 summarizes the total benefit expenditures per scheme. We estimated current expenditures on child benefits by multiplying the number of children in Russian with the child coverage rate and the nominal benefit value per child. Expenditures in the current programme reported are about 1,300 million ruble, which represents $0.008 \%$ of Russia's nominal GDP in 2004 and $0.08 \%$ of subsidies and transfers. Benefit expenditures would rise with approximately $162 \%$ for the 70 ruble universal scheme. ${ }^{28}$

The overall poverty reduction impact of a universal scheme along the current lines, either with 70 or budget-neutral 42 ruble is modest. Only a significant increase of the benefit level results in considerably higher poverty reduction impacts as the tables show. Providing a child benefit which is equal to $15 \%$ of the male adult poverty line (equivalent to 280 ruble) would reduce poverty incidence by 10 to 15 percent, and close the poverty gap by 20 percent if the benefit is means-tested and 31 percent if the benefit is universally provided. A universal child benefit equal to $30 \%$ of the male adult

\footnotetext{
${ }^{27}$ In 2004, Russia's population was 144 million of which $20.9 \%$ was younger than 18 years. The total benefit expenditures are slightly overestimated since all children under 18 years are included.

${ }^{28}$ We assumed $100 \%$ take up rates under the universal schemes, possibly overestimating total benefit expenditures. However, administration costs are not included.
} 
Table 4.6: Simulation: Poverty reduction per programme type (all children)

\begin{tabular}{|c|c|c|c|c|}
\hline & \multicolumn{2}{|c|}{$100 \%$ RLMS poverty line } & \multicolumn{2}{|c|}{$150 \%$ RLMS poverty line } \\
\hline & Incidence & Poverty gap & Incidence & Poverty gap \\
\hline \multicolumn{5}{|c|}{ Means-tested benefits of 70 ruble per child (current situation) } \\
\hline Before allowance & 12.3 & 3.9 & 27.4 & 9.4 \\
\hline After allowance & 12.1 & 3.7 & 26.8 & 9.1 \\
\hline Absolute change & -0.2 & -0.2 & -0.6 & -0.3 \\
\hline Relative change & -1.6 & -5.1 & -2.2 & -3.2 \\
\hline \multicolumn{5}{|c|}{ Budget Neutral Universal benefits of 42 ruble per child } \\
\hline After allowance & 12.2 & 3.7 & 26.8 & 9.2 \\
\hline Absolute change & -0.1 & -0.2 & -0.6 & -0.2 \\
\hline Relative change & -0.8 & -5.1 & -2.2 & -2.1 \\
\hline \multicolumn{5}{|c|}{ Universal benefits of 70 ruble per child } \\
\hline After allowance & 12.0 & 3.6 & 26.7 & 9.0 \\
\hline Absolute change & -0.3 & -0.3 & -0.7 & -0.4 \\
\hline Relative change & -2.4 & -7.7 & -2.6 & -4.3 \\
\hline \multicolumn{5}{|c|}{ Universal child benefit of 0.15 eq adult ( 280 ruble) per child } \\
\hline After allowance & 10.4 & 2.7 & 24.8 & 7.7 \\
\hline Absolute change & -1.9 & -1.2 & -2.6 & -1.7 \\
\hline Relative change & -15.4 & -30.8 & -9.5 & -18.1 \\
\hline \multicolumn{5}{|c|}{ Means-tested child benefits of 0.15 eq ad ( 280 ruble) per child } \\
\hline After allowance & 10.9 & 3.1 & 25.4 & 8.2 \\
\hline Absolute change & -1.4 & -0.8 & -2.0 & -1.2 \\
\hline Relative change & -11.4 & -20.5 & -7.3 & -12.8 \\
\hline \multicolumn{5}{|c|}{ Universal child benefit of 0.3 eq ad ( 560 ruble) per child } \\
\hline After allowance & 6.9 & 1.8 & 22.5 & 6.1 \\
\hline Absolute change & -5.4 & -2.1 & -4.9 & -3.3 \\
\hline Relative change & -43.9 & -53.8 & -17.9 & -35.1 \\
\hline \multicolumn{5}{|c|}{ Means-tested child benefits of 0.3 eq ad ( 560 ruble) per child } \\
\hline After allowance & 8.2 & 2.5 & 23.6 & 7.1 \\
\hline Absolute change & -4.1 & -1.4 & -3.8 & -2.3 \\
\hline Relative change & -33.3 & -35.9 & -13.9 & -24.5 \\
\hline \# of children & \multicolumn{4}{|c|}{1,487} \\
\hline \# of households & \multicolumn{4}{|c|}{1,079} \\
\hline
\end{tabular}

Note: Chronic poverty groups are based on households in 2000-2004 panel, the table reports chronic poverty estimates for the children living in either category in 2004.

Source: Own calculations based on the RLMS. 
poverty line would reduce the poverty gap by half. The universal scheme outperforms the means-tested scheme. The rate of reduction depends on the level of the poverty line. When the lowest level is taken, there is a greater impact on the reduction of the poverty gap. Since we assume that only the households currently receiving a means-tested child benefit will gain from increased benefits, the poverty reduction effects for the simulated means-tested scenarios may be an underestimation, as the benefit increase is likely to induce more households to file an application. The same applies to the total benefit expenditures. The effects are similar for chronic poverty, the chronically poor particularly benefit from an increase in the benefit level. ${ }^{29}$ Naturally, the costs for the bold scenarios are considerably higher than for the current programme. However, even the boldest scenario requires only one tenth of a percent of GDP, and slightly more than one percent of total social expenditures.

These simulations illustrate a number of relevant issues. Clearly, total benefit expenditures on benefits are higher under universal programmes and, in this respect, potentially less efficient. An issue that has received little attention in the universal - means-tested debates is that when targeting is not perfect (i.e. there are errors of exclusion), universal schemes outperform means-tested schemes in terms of poverty reduction. The additional poverty reduction is achieved because those who were by error excluded under the means-tested scheme now do receive a benefit. While keeping the capacity of means-testing constant, this paper estimated and compared both effects. The results also show that the difference in poverty reduction between means-tested and universal benefits increases as the benefit level increases. Whether the additional benefit expenditures are worth the extra poverty reduction, is a decision to be made by society.

An important limitation of the simulations is that we can only speculate what the behavioural effects of these schemes would be on programme's administration costs, targeting efficiency and poverty reduction. For instance, moving from the current scheme to the 70 ruble universal benefit scheme would have two opposing effects; firstly administration costs rise as more households apply under the universal child benefit scheme and secondly, decrease as a result of the abolishment of the income-test. With current coverage rates ( $56 \%$ of the households), local administration offices can expect an increase in applications of $79 \%$ (if every household with children in this category would actually apply). It is a priori not clear whether the increment in administration costs due to more applications outweighs the decreased costs due to a reduced workload.

\footnotetext{
${ }^{29}$ For the chronic poverty impact we use the 5-year panel. For 2000-2003 we cannot distinguish between child benefits received for children under and over 18 months age. Therefore, the chronic poverty simulations also incorporate children less than 18 months. These children receive the same benefit as the older children.
} 
Table 4.7: Simulation: Reduction in chronic poverty (all children, 2004)

\begin{tabular}{|c|c|c|c|c|}
\hline \multirow[b]{2}{*}{ Change } & \multicolumn{2}{|c|}{$100 \%$ RLMS poverty line } & \multicolumn{2}{|c|}{$150 \%$ RLMS poverty line } \\
\hline & Absolute & Relative & Absolute & Relative \\
\hline \multicolumn{5}{|c|}{ Means-tested benefits of 70 ruble per child (current situation) } \\
\hline Always poor & -0.6 & -28.6 & -0.1 & -1.3 \\
\hline Usually poor & -0.6 & -7.8 & -1.1 & -5.8 \\
\hline Occasionally poor & 0.3 & 0.9 & 0.6 & 1.5 \\
\hline Never poor & 0.9 & 1.6 & 0.6 & 1.8 \\
\hline \multicolumn{5}{|c|}{ Budget Neutral Universal benefits of 42 ruble per child } \\
\hline Always poor & 0.0 & 0.0 & -0.4 & -5.0 \\
\hline Usually poor & -0.9 & -11.7 & -0.4 & -2.1 \\
\hline Occasionally poor & -0.1 & -0.3 & 0.3 & 0.8 \\
\hline Never poor & 1.2 & 2.2 & 0.5 & 1.5 \\
\hline \multicolumn{5}{|c|}{ Universal benefits of 70 ruble per child } \\
\hline Always poor & -0.6 & -28.6 & -0.5 & -6.3 \\
\hline Usually poor & -0.8 & -10.4 & -1.1 & -5.8 \\
\hline Occasionally poor & -0.7 & -2.0 & 0.4 & 1.0 \\
\hline Never poor & 2.1 & 3.8 & 1.2 & 3.6 \\
\hline \multicolumn{5}{|c|}{ Universal child benefits of 0.15 equivalent adult male } \\
\hline Always poor & -0.9 & -42.9 & -1.2 & -15.0 \\
\hline Usually poor & -2.4 & -31.2 & -2.9 & -15.3 \\
\hline Occasionally poor & -2.8 & -8.0 & 0.9 & 2.3 \\
\hline Never poor & 6.1 & 11.0 & 3.3 & 9.8 \\
\hline \multicolumn{5}{|c|}{ Means-tested child benefits of 0.15 equivalent adult male } \\
\hline Always poor & -0.9 & -42.9 & -0.7 & -8.8 \\
\hline Usually poor & -1.8 & -23.4 & -2.5 & -13.2 \\
\hline Occasionally poor & -0.4 & -1.1 & 1.8 & 4.6 \\
\hline Never poor & 3.1 & 5.6 & 1.5 & 4.5 \\
\hline \multicolumn{5}{|c|}{ Universal child benefits of 0.3 equivalent adult male } \\
\hline Always poor & -1.0 & -47.6 & -2.4 & -30.0 \\
\hline Usually poor & -3.8 & -49.4 & -5.3 & -27.9 \\
\hline Occasionally poor & -6.3 & -18.1 & 1.5 & 3.8 \\
\hline Never poor & 11.2 & 20.2 & 6.2 & 18.5 \\
\hline \multicolumn{5}{|c|}{ Means-tested child benefits of 0.3 equivalent adult male } \\
\hline Always poor & -1.0 & -47.6 & -1.9 & -23.8 \\
\hline Usually poor & -2.5 & -32.5 & -4.0 & -21.1 \\
\hline Occasionally poor & -1.8 & -5.2 & 2.8 & 7.1 \\
\hline Never poor & 5.4 & 9.7 & 3.2 & 9.5 \\
\hline \# of children & \multicolumn{4}{|c|}{1,319} \\
\hline \# of households & \multicolumn{4}{|c|}{948} \\
\hline
\end{tabular}

Source: Own calculations based on the RLMS. 
Table 4.8: Monthly expenditures on child benefits by programme

\begin{tabular}{|c|c|c|c|c|c|}
\hline Programme & $\begin{array}{l}\text { Benefit } \\
\text { per child }\end{array}$ & $\begin{array}{l}\text { Total } \\
\text { benefits }^{1}\end{array}$ & $\begin{array}{l}\% \text { of current } \\
\text { programme }\end{array}$ & $\begin{array}{l}\% \text { of } \\
\text { GDP }^{2}\end{array}$ & $\begin{array}{l}\% \text { of social } \\
\text { expenses }^{2}\end{array}$ \\
\hline Current means-tested benefits & 70 ruble & 1,300 & 100 & 0.008 & 0.09 \\
\hline Universal benefits & 70 ruble & 2,100 & 162 & 0.013 & 0.15 \\
\hline Budget neutral universal benefits & 42 ruble & 1,300 & 100 & 0.008 & 0.09 \\
\hline Universal benefits & 0.15 eqad & 8,500 & 654 & 0.051 & 0.58 \\
\hline Means-tested benefits & 0.15 eqad & 5,100 & 392 & 0.030 & 0.35 \\
\hline Universal benefits & 0.3 eqad & 16,900 & 1,300 & 0.101 & 1.17 \\
\hline Means-tested benefits & 0.3 eqad & 10,100 & 770 & 0.061 & 0.70 \\
\hline
\end{tabular}

Note: ${ }^{1}$ In million ruble and rounded to $100 .{ }^{2}$ GDP in 2004: 16,751 billion ruble; Federal Government expenditures on social policy: 154 billion ruble (International Monetary Fund, 2005).

Source: Own calculations based on the RLMS.

Furthermore, a general increase in the benefit level will increase administrative costs in both scenarios compared to current expenditures on administration; comparing to the current scheme, higher benefits induce more households to file an application. Higher benefits also affect targeting efficiency and poverty reduction effects: the non-take up of benefits will be reduced because applying for benefits becomes more attractive (i.e. fewer errors of exclusion and larger poverty reductions) but inclusion errors will rise as well. The effect of current benefit levels on labour supply can be assumed to be marginal given the low and flat rate benefit levels. Substantial rises in child benefits, particularly in combination with a means-tested scheme, may affect labour supply to some degree. ${ }^{30}$

\subsection{Conclusion}

Using the 2000 introduction of means-tested child benefits in Russia as a case study; this paper assessed the impact of a policy change from universal to means-tested child allowances in terms of targeting efficiency and poverty reduction. We focused on the core costs of targeting, namely leakage, exclusion errors and total benefit expenditures, and related these to the benefits in terms of poverty reduction. Our analysis has been comprehensive; using both the cross-section and panel dimensions of the Russia Longitudinal Monitoring Survey (RLMS) from 2000 to 2004, we investigated changes in targeting efficiency and poverty reduction over time. We measured targeting

\footnotetext{
${ }^{30}$ With a universal benefit scheme there is only an income effect on labour supply while with a means-tested scheme both income and substitution effects work toward a reduction of labour supply (for a discussion of these effects see for instance Grosh, 1994).
} 
efficiency using coverage and adequacy indicators; by calculating these indicators for two poverty lines and the quintiles of the expenditure distribution we gained insight into the scope of inclusion and exclusion errors. The poverty reduction impact was measured in three dimensions; poverty incidence, poverty gap and chronic poverty. Finally, we also simulated various means-tested and universal child benefit schemes and analysed differences in poverty reduction and total benefit expenditures. Due to limited data availability, the influences of behavioural effects on targeting efficiency and poverty reduction have not been taken into account in our simulations.

The analysis of targeting efficiency showed an improvement in overall coverage rates (more children receive child benefits) and evidence of improved targeting to children living in low income households (poor children or children in lower expenditure deciles are more likely to receive benefits). Nevertheless, both inclusion and exclusion errors are considerable; in 2004 one third to a quarter of the poor children does not receive benefits while the benefit coverage rate of children in the three highest expenditure quintiles is still $50 \%$. When is means-testing considered successful in terms of targeting efficiency? When two-thirds of the target group are reached, one third is missed and two thirds of total benefits flow to non-poor children? In our view, that would be a very modest assessment of success.

The impact of child benefits on poverty has been very modest over the whole period, but we found some evidence that the poverty reduction effect has increased somewhat as compared to the benchmark year (2000). It is not clear to what extent this improvement is due to the introduction of a means-test or due to the increase of overall benefit coverage. The simulations of universal and means-tested schemes for 2004 showed that when targeting is not perfect (i.e. there are errors of exclusion), universal schemes achieve additional reductions in poverty. And above all, size matters; considerably increasing benefit levels makes the poverty reduction impact more substantial. Moreover, differences in poverty reduction effect between means-tested and universal benefits increase as the benefit level increases, with universal benefits outperforming means-tested benefits.

To what extent are means-tested child benefits in Russia desirable? We show that abolishing means-testing would improve the (chronic) poverty reduction performance of child allowances, but increasing the benefit level would have an even stronger effect. We find it difficult to argue why a programme with benefits as low as current benefit levels, should be means-tested. Given the characteristics of the expenditure distribution in a country such as Russia, where inequality is rife and the welfare differences between households at the lower end of the distribution are small, many benefits leak to 'near' poor households. Leakage is also lower because households with children are disproportionately more present at the lower part of this distribution. Moreover, 
the road of economic transition in Russia has been rather bumpy and led to a surge in uncertainty, also in terms of living standards. In that respect, even when child benefits are modest, they can assist families with children to smooth consumption by providing a stable source of cash income (Notten \& Crombrugghe de, 2006).

\subsection{Appendix: summary statistics}

Table 4.9: Household characteristics in RLMS cross-section

\begin{tabular}{lrrrrr}
\hline & 2000 & 2001 & 2002 & 2003 & 2004 \\
\hline \# of households in cross-section & 3,094 & 3,203 & 3,206 & 3,176 & 3,114 \\
Dwelling place (\%): & & & & & \\
Urban & 65.9 & 67.2 & 68.1 & 65.1 & 64.7 \\
Rural/Semi-urban & 34.2 & 32.8 & 31.9 & 34.9 & 35.3 \\
Children (<18) in household (\%): & & & & & \\
0 & 55.0 & 57.0 & 57.1 & 58.5 & 61.7 \\
1 & 28.2 & 27.5 & 27.9 & 27.3 & 25.7 \\
2 & 14.2 & 13.2 & 12.5 & 11.8 & 10.5 \\
3 or more & 2.6 & 2.3 & 2.4 & 2.4 & 2.1 \\
Elderly in household (\%): & & & & & \\
0 & 52.6 & 52.8 & 51.9 & 51.7 & 50.6 \\
1 & 31.5 & 32.0 & 32.4 & 32.9 & 34.3 \\
2 or more & 16.0 & 15.2 & 15.7 & 15.5 & 15.1 \\
Household type (\%): & & & & & \\
Single person household & 20.3 & 21.5 & 21.1 & 22.1 & 23.9 \\
Couple no children & 21.5 & 20.9 & 20.6 & 20.9 & 21.1 \\
Single caretaker and children & 4.6 & 4.4 & 4.7 & 4.2 & 4.2 \\
Parents and children & 19.5 & 18.3 & 17.4 & 17.6 & 16.5 \\
Triple generations and children & 8.6 & 8.0 & 8.2 & 8.4 & 7.7 \\
Other households and children & 8.2 & 8.5 & 7.9 & 7.1 & 5.6 \\
Other households & 17.4 & 18.4 & 20.1 & 19.9 & 20.9 \\
Distribution (mean per capita expenditures per quintile in real & 1992 ruble): & & \\
I & 643 & 774 & 805 & 910 & 857 \\
II & 1,252 & 1,509 & 1,577 & 1,673 & 1,632 \\
III & 1,836 & 2,180 & 2,282 & 2,417 & 2,385 \\
IV & 2,661 & 3,220 & 3,306 & 3,519 & 3,483 \\
V & 7,072 & 7,718 & 7,913 & 9,469 & 9,170 \\
\hline Not Chl & & & & &
\end{tabular}

Note: ${ }^{1}$ Children aged between 1.5 and 18 .

Source: Own calculations based on RLMS. 
Table 4.10: Household characteristics in RLMS panel

\begin{tabular}{|c|c|c|c|c|c|}
\hline & 2000 & 2001 & 2002 & 2003 & 2004 \\
\hline$\#$ of households in panel & & & 2,458 & & \\
\hline \multicolumn{6}{|l|}{ Dwelling place (\%): } \\
\hline Urban & & & 61.1 & & \\
\hline Rural/Semi-urban & & & 38.9 & & \\
\hline \multicolumn{6}{|l|}{ Children $(<18)$ in household $(\%)$ : } \\
\hline 0 & 51.2 & 53.6 & 54.9 & 55.9 & 58.9 \\
\hline 1 & 30.0 & 29.1 & 29.1 & 29.1 & 27.2 \\
\hline 2 & 15.3 & 14.1 & 12.8 & 12.0 & 11.3 \\
\hline 3 or more & 3.5 & 3.2 & 3.2 & 3.0 & 2.6 \\
\hline \multicolumn{6}{|l|}{ Elderly in household (\%): } \\
\hline 0 & 55.6 & 54.9 & 52.4 & 51.8 & 50.6 \\
\hline 1 & 28.0 & 29.0 & 30.6 & 32.0 & 33.0 \\
\hline 2 or more & 16.4 & 16.9 & 17.0 & 16.2 & 16.4 \\
\hline \multicolumn{6}{|l|}{ Household type (\%): } \\
\hline Single person household & 15.8 & 16.7 & 17.8 & 19.2 & 20.5 \\
\hline Couple no children ${ }^{1}$ & 22.7 & 23.0 & 22.6 & 21.9 & 22.1 \\
\hline Single caretaker and children & 4.7 & 4.4 & 4.8 & 4.3 & 4.2 \\
\hline Parents \& children & 22.6 & 21.6 & 20.8 & 20.0 & 19.2 \\
\hline Triple generations and children & 8.9 & 8.5 & 8.5 & 8.3 & 8.2 \\
\hline Other households and children & 8.4 & 8.3 & 7.4 & 7.4 & 6.0 \\
\hline Other households & 17.0 & 17.5 & 18.5 & 18.9 & 19.8 \\
\hline \multicolumn{6}{|c|}{ Distribution (mean per capita expenditures per quintile in real 1992 ruble): } \\
\hline I & 614 & 756 & 730 & 852 & 805 \\
\hline II & 1,189 & 1,436 & 1,468 & 1,566 & 1,529 \\
\hline III & 1,759 & 2,041 & 2,118 & 2,242 & 2,224 \\
\hline IV & 2,518 & 2,954 & 3,017 & 3,247 & 3,184 \\
\hline V & 6,364 & 6,411 & 6,931 & 8,203 & 7,090 \\
\hline
\end{tabular}

Note: ${ }^{1}$ Children aged between 1.5 and 18 .

Source: Own calculations based on RLMS. 


\section{Poverty and consumption smoothing in - Russia}




\subsection{Introduction $^{12}$}

During the last decade, the Russian Federation experienced that the transition from a centrally planned economy to a market based economy is full of bumps, potholes and off-road experiences. For the Russian people, the transition process involved a surge in uncertainty. Unemployment was essentially an unknown phenomenon in pre-transition Russia. The closing down or privatization of the large public industrial and agricultural companies resulted in mass unemployment and decreased job security. Those still having a job faced wage payment arrears and enforced unpaid leave arrangements. The cuts in subsidies on food and energy resulted in an increase in the cost of living. Additionally, in order to make a living in this new market economy, other skills and abilities were required.

The Russian people needed all their resourcefulness in this transition phase simply to make ends meet. Participatory poverty studies indicate that people in transition economies do indeed associate the transition period with substantial increases in uncertainty (World Bank, May 1999). Economic theory shows that uncertainty about future income and consumption flows reduces the expected satisfaction that risk adverse individuals can derive from it. In this respect, people's ability to respond to uncertainty and to deal with shocks reflects an important dimension of well-being. In contrast, widely used poverty statistics merely describe the level of welfare enjoyed by individuals at a particular point in time. The ability to smooth consumption and the level of welfare each reflect relevant but different dimension of welfare. Our aim is to investigate the extent to which Russian households have been able to protect their consumption against income shocks during the transition period and how this ability of consumption smoothing is reflected in terms of poverty risk. We investigate whether the characteristics households with a risk of poverty are the same as those for households with low smoothing abilities. This paper contributes to the literature on welfare and poverty because it enhances our understanding of the relationship between the dynamics of a welfare generating process (ability to smooth consumption) and its outcome in terms of welfare at a particular point in time (poverty).

We use data from the Russia Longitudinal Monitoring Survey (RLMS) from 1994 to 2004. The cross-section component is used to calculate a range of absolute poverty indices and a poverty profile. The panel dimension is used to investigate poverty

\footnotetext{
${ }^{1}$ This chapter is based on: Notten, G. \& D. de Crombrugghe (2006). Poverty and Consumption Insurance in Russia. MGSoG Working Paper(2006/004), Maastricht Graduate School of Governance, Maastricht University.

${ }^{2}$ We thank Chris Elbers, Jan Willem Gunning and Tony Shorrocks for their constructive comments and are especially grateful to Sybrand Schim van der Loeff for his suggestions on the model.
} 
dynamics and to estimate the overall ability of households to smooth consumption. This study is the first to explicitly incorporate short and long run dynamics in consumption smoothing processes: households' income and expenditure flows are modelled using an Error Correction Model (ECM) which better exploits the information in the level data. The short run income elasticity measures the responsiveness of household expenditures to changes in income and is used as a measure for households' consumption smoothing abilities; a high income elasticity reflects a low consumption smoothing ability and vice versa.

The results show that households are only partially able to protect their consumption from income shocks and that income shocks have a smaller impact on food expenditures than on non-food expenditures. Furthermore, we find exploratory evidence of heterogeneity in consumption smoothing abilities; by estimating the model separately for subgroups in the sample we find that the consumption smoothing abilities vary according to household characteristics. As households' average (long term) living standard increases, they are better able to smooth non-food expenditures. However, low consumption smoothing abilities are not always associated with high poverty risk; rural households, who have a high poverty risk, manage to smooth food expenditures quite well, most likely because such households have more opportunities to produce their own food. Households with pensioners, on the other hand, have a low poverty risk and high consumption smoothing abilities. These exploratory results indicate that there is a potential role for development and social protection policies to influence households' abilities to deal with risks and that the scope of such policies should be broader than the social assistance type of poverty-reduction policies. This may involve an extension of the coverage of the social security net but can imply improving the functioning of market-based institutions such as increased monitoring and supervision of the financial sector.

This paper is organized as follows; section 5.2 describes the RLMS data and the main variables used. Section 5.3 reports the main developments of the Russian economy followed by the results from our poverty analysis. In section 0 , we discuss the relevance and theoretical background of consumption smoothing. Section 5.5 specifies the dynamic model of consumption smoothing abilities after which the estimation strategy is set out in section 5.6. Section 5.7 reports the results from the exploratory analyses and relates the findings on households' consumption smoothing abilities to those on the duration of poverty and poverty risk. Section 5.8 concludes. 


\subsection{Data and methodology}

We analyse poverty and consumption smoothing abilities using data from the RLMS project for the years 1994-2004. ${ }^{3}$ These data can be analysed as (repeated) crosssections and as a panel. We selected those households that were observed in at least one round and had no missing observations on any of the variables used in the analysis. For the poverty analysis, we use predominantly the cross-section dimension of the RLMS but we also use the panel to compute some indicators of poverty dynamics. Measuring consumption smoothing abilities requires panel data. Because of missing surveys in 1997 and 1999, the time intervals between surveys are not equally spaced, a complicating factor for the dynamic analysis. To solve this problem we selected those households that were observed for at least three consecutive two year periods (i.e. 1994, 1996, 1998, 2000, 2002 and 2004). Households that had missing observations on any of the variables were dropped. The sample includes so-called offspring households; these are households that are created when a household has split up into two households and both households remain in the RLMS sample. Whenever this happened, from that round on, one household kept the original identification code while the offspring household received a new identification code. However, for the previous rounds both households shared an identical past. We treated offspring households as new households. ${ }^{4}$

We have included the following variables: food-, non-food-, and total expenditures, total household income, number of household members divided over six age categories (children 0-6, children 7-18, male aged 19-60, female aged 19-55, male aged 60 and above and female aged 55 and above) and categorical variables providing information on the household's location such as rural, urban, semi-urban, region and community.

The poverty analysis is performed using the poverty lines constructed by the RLMS. These are based on regional age-gender specific food-baskets that are valued at regional prices. The absolute poverty lines were calculated for each household and are adjusted for the demographic composition of the household. As a welfare indicator we use total household expenditures. Total food consumption is obtained by adding the expenditures on dairy, meat, fish, potatoes, alcohol, bread, eggs, fats and oils, fruits, sugar, vegetables, other foodstuffs, the value of food eaten outdoors and the value of food consumed and produced at home. Total non-food consumption is obtained by

\footnotetext{
${ }^{3}$ Detailed information on the RLMS project can be found on the following website: http://www.cpc.unc. edu/projects/rlms/home.html.

${ }^{4}$ The appendix provides a table comparing household characteristics in the cross-section with those of the panel. More information about sample attrition of the RLMS can be found on the RLMS website in a document written by Heeringa (1997).
} 
summing expenditure items such as tobacco, clothing, fuel, services, durables, luxury items, recreation, rent ${ }^{5}$, utilities and other payments such as tuition and insurance (excluding loans). ${ }^{6}$ The value of total consumption is expressed in June 1992 prices by dividing the current price of expenditures by the regional consumer price index. The welfare indicator differs slightly from the RLMS total household expenditure variable as we excluded savings and expenditures on bonds from the aggregation because these flows reflect investments in the stock of assets and as such do not contribute to current consumption. ${ }^{7}$

For the analysis of consumption smoothing we have composed real household expenditures in the same way as for the poverty analysis. Household income consists of cash income as well as the monetary value of in-kind income. The income variable is also expressed in constant prices and is constructed by summing income from salary, rent, interest receipts, pension benefits, child allowances, maternity benefits, family and other benefits, gross income from farm products and other income. We excluded the income from unemployment insurance, insurance benefits, property or jewellery sales, transfers received from friends and relatives and money borrowed, because these sources of income are likely to reflect ex post adjustments to income shocks. ${ }^{9}$

Data inspection showed that a small number of households did not have positive values for the expenditure variables. We have excluded households for which food or total expenditures were not positive. Table 5.1 provides the average per capita values of the key variables in each round for the cross-section dimension of the survey. Expenditures are systematically above income for two reasons. Firstly, as explained above we have excluded a number of income categories because they are likely to reflect ex post shock

\footnotetext{
${ }^{5}$ This expenditure category does not include any imputations for the rent of house owners.

${ }^{6}$ Although income and expenditures are expressed in monthly values, the reference period in the questionnaire for the various expenditure and income categories varied from a week for items such as food, a quarter of a year for durables to a year for the harvest from home produced foodstuffs.

${ }^{7}$ Due to limitations in the data the welfare indicator does not include values for the consumption of public goods or for house ownership while consumption of these goods clearly contributes to the level of household welfare.

${ }^{8}$ From round 9 on, the expenditure section of household questionnaire has been adjusted resulting in more detailed questions for expenditures on health and other services. This change lead to an increase in reported expenditures in these categories. For time consistency reasons, the poverty rates reported in this paper are calculated excluding these new categories. Poverty estimates using the expenditures aggregate including these categories yield lower poverty rates but this does not seem to have a large impact on the relative poverty risks of groups in the poverty profile.

${ }^{9}$ As will be explained further in section 0 , we measure the consumption smoothing abilities by analyzing the responsiveness of household expenditures to income shocks. When an income shock occurs, households may smooth consumption by asking help from friends, selling assets, borrowing money, applying for unemployment benefits and the like. These sources of income are the result of post-shock smoothing efforts and should not be included in the income indicator as they would underestimate the magnitude of income shocks.
} 
Table 5.1: Per capita average of income and expenditures (monthly - 1992 ruble)

\begin{tabular}{lrrrrrr}
\hline Round & Year & \# of households & \multicolumn{3}{c}{ Expenditures } & Income \\
\cline { 4 - 5 } & & & Food & Non-food & Total & \\
\hline 5 & 1994 & 3,586 & 2,485 & 1,263 & 3,747 & 2,736 \\
6 & 1995 & 3,441 & 2,124 & 1,165 & 3,287 & 2,159 \\
7 & 1996 & 3,234 & 1,753 & 1,194 & 2,946 & 2,060 \\
8 & 1998 & 3,108 & 1,312 & 843 & 2,154 & 1,596 \\
9 & 2000 & 3,015 & 1,401 & 1,139 & 2,539 & 1,907 \\
10 & 2001 & 3,137 & 1,505 & 1,355 & 2,859 & 2,300 \\
11 & 2002 & 3,132 & 1,514 & 1,435 & 2,948 & 2,582 \\
12 & 2003 & 3,102 & 1,505 & 1,723 & 3,227 & 2,758 \\
13 & 2004 & 3,052 & 1,496 & 1,766 & 3,262 & 2,941 \\
\hline
\end{tabular}

Source: RLMS cross-sections

adjustments. However, even when these categories would be included a discrepancy would remain. Another reason for this gap between income and expenditures suggested is that households have a tendency to underreport income from informal and semiformal activities (Atkinson et al., 1995; Deaton, 1997; Ravallion, 1994). Alternative explanations such as dissaving or memory failure cannot convincingly explain the discrepancy over time. Dissaving can of course explain why some households maintain expenditures above their income, but the data suggest that the gap is a general phenomenon which would imply that the whole society would be dissaving during the transition. Higher levels of dissaving are likely to occur during financial crises and high inflation periods but at the time of the financial and economic crisis in 1998, the gap between income and expenditures was actually smallest. Similarly, because survey methodology often relies on respondents' memory for the collection of income and expenditures (and the RLMS is no exception) such data suffer from underreporting, particularly because respondents forget to report sporadic expenses or income. But this type of memory failure applies to both income and expenditures.

\subsection{Russia in transition}

The first stage of the transition from a centrally planned economy to a market economy was characterized by a sustained fall in production in all sectors of the economy that lasted until the mid-nineties. Table 5.2 reports a number of macroeconomic indicators which reflect this trend. Annual GDP growth was negative during the first years of transition. Both the GDP deflator and the consumer price index show evidence of high and increasing inflation rates. This trend was accompanied by a development of rising 
Table 5.2: Macro-economic indicators

\begin{tabular}{lrrrrrrrrrr}
\hline & \multicolumn{1}{c}{1994} & 1995 & 1996 & 1997 & 1998 & 1999 & 2000 & 2001 & 2002 & 2003 \\
\hline GDP growth (\%) & -12.6 & -4.1 & -3.6 & 1.4 & -5.3 & 6.4 & 10.0 & 5.1 & 4.7 & 7.4 \\
GDP deflator & 24.4 & 59.6 & 86.9 & 100 & 119 & 204 & 281 & 328 & 379 & 434 \\
$(1997=100)$ & & & & & & & & & & \\
CPI (2000=100) & 6.9 & 20.6 & 30.4 & 34.9 & 44.6 & 82.8 & 100 & 121 & 141 & 160 \\
Unemployment (\%) & 8.1 & 9.5 & 9.7 & 11.8 & 13.3 & 12.6 & 9.8 & 8.9 & 8.6 & - \\
Employment in: & & & & & & & & & & \\
Agriculture (\%) & 16.1 & 15.7 & 15.3 & 12.2 & 11.5 & 11.8 & - & - & - & - \\
Industry (\%) & 35.9 & 34.0 & 32.5 & 30.0 & 29.4 & 29.4 & - & - & - & - \\
Services (\%) & 47.7 & 50.0 & 52.2 & 57.8 & 59.1 & 58.8 & - & - & - & - \\
\hline
\end{tabular}

Source: World Development Indicators (2005)

inequality and poverty (Commander et al, 1999; Milanovic, 1998; World Bank, 1995, 1998). In 1997, the Russian economy was showing some hesitant signs of recovery that were swiftly followed by the financial and economic crisis of 1998; a default on domestic and foreign debts was announced followed by a wave of bankruptcies in the banking sector, a devaluation of the ruble and a collapse of the stock market (Brown, 1999; Buchs, 1999; Sapir, 1999; Slay, 1999). Since 1999 there has been a period of sustained recovery, reaching positive GDP growth rates with a peak of $10 \%$ in 2000 . The sustained increase of unemployment rates from 1994 to 1999 mainly reflects the process of structural change in the Russian economy but also the impact of the economic crisis in 1998. Other indicators for the structural changes in the economy during the transition phase are the employment shares in different sectors of the economy: we can see a large decrease in employment in the industrial sector, a somewhat more modest decrease in agricultural sector employment and a large increase in service employment. ${ }^{10}$

Such dramatic macro-economic developments must have also affected the living standards of the people. We analyse the impact of the transition phase on the Russian population in terms of absolute poverty. We compute aggregate poverty and a poverty profile using the Foster Greer Thorbecke class of decomposable poverty indices (Foster et al., 1984): ${ }^{11}$

$$
F G T=1 / n\left[\sum_{c_{i} \leq z}\left[\frac{z-c_{i}}{z}\right]^{\alpha}\right]
$$

\footnotetext{
${ }^{10}$ During the transition many industrial and agricultural state monopolies were privatized, restructured or shut down, in all cases leading to a reduction in the employment in these sectors.

${ }^{11}$ We have also performed the same poverty analyses using total income. The poverty indices and poverty profile decompositions show similar trends and poverty prone groups. Since reported income is structurally lower than expenditures in the RLMS data, the estimated poverty levels and poverty gaps are higher when using income as a welfare indicator. We interpret this discrepancy to be the result of a tendency of households to underreport income.
} 
Table 5.3: Poverty indices

\begin{tabular}{lrrrrrrrrr}
\hline & 1994 & 1995 & 1996 & 1998 & 2000 & 2001 & 2002 & 2003 & 2004 \\
\hline Headcount & 11.9 & 19.0 & 22.2 & 34.3 & 23.3 & 16.7 & 14.4 & 11.5 & 12.3 \\
Poverty gap & 3.8 & 6.3 & 8.2 & 12.7 & 8.0 & 5.7 & 4.8 & 3.6 & 3.8 \\
Poverty severity & 1.9 & 3.1 & 4.5 & 6.7 & 3.9 & 2.8 & 2.5 & 1.8 & 1.8 \\
\hline
\end{tabular}

Source: RLMS cross-sections

where $n$ is the total number of individuals, $z$ is the absolute poverty line and $\mathrm{c}_{\mathrm{i}}$ is the welfare indicator of an individual (measured by expenditures). If $\alpha=0$, then equation 5.1 represents the headcount index which simply displays the percentage of individuals living below the poverty line. Taking $\alpha=1$ results in the poverty gap index; this index measures the mean proportionate expenditure shortfall over the total population. The poverty severity index is calculated by squaring the expenditure shortfalls before aggregation (setting $\alpha=2$ ), thus putting a higher weight on larger shortfalls. These poverty indices are calculated using household post-stratification weights and thus are representative for the Russian population. ${ }^{12}$

The 1998 crisis had a severe impact on the level of well-being. All poverty indices show an increase from 1994 to a peak in 1998, followed by a sustained fall (Table 5.3). The headcount index shows that the percentage of poor individuals nearly triples from $11.9 \%$ in 1994 to $34.3 \%$ in $1998 .{ }^{13}$ The average expenditure shortfall rose to a peak of $12.7 \%$ in 1998 , decreasing until $3.6 \%$ in 2003 . The poverty severity index reveals that, in addition to an increase in the number of poor individuals and the average poverty shortfall, poverty also became more severe in the sense that more individuals were experiencing larger shortfalls during the crisis. In 2004 there was a small increase in poverty to $12.3 \%$.

Table 5.4 illustrates the headcount index for subgroups of the Russian population. ${ }^{14}$ The trends observed in the aggregate poverty indices are also reflected for these subgroups; the impact of the crisis was felt by a large proportion of the population, irrespective of their characteristics. Individuals living in rural areas are disproportionately more often poor than those living in urban areas. However, it is clear

\footnotetext{
${ }^{12}$ These weights attempt to match certain demographic characteristics of the sample to those observed in the 1989 census. The household-level weights adjust according to household size and urban-rural residence.

${ }^{13}$ The dramatic trend in poverty indicators appears even more exacerbated because there were no RLMS surveys in 1997 and 1999 and the 1998 survey was performed in November/December, when the impact of the August financial crisis was transmitted to the Russian population.

${ }^{14}$ Albeit not reported here, we also calculated poverty gap and poverty severity indices for different household characteristics. These indices also show higher values when the poverty headcount rates are high.
} 
Table 5.4: Poverty profile based on headcount index

\begin{tabular}{|c|c|c|c|c|c|c|c|c|c|}
\hline & 1994 & 1995 & 1996 & 1998 & 2000 & 2001 & 2002 & 2003 & 2004 \\
\hline Overall & 11.9 & 19.0 & 22.2 & 34.3 & 23.3 & 16.7 & 14.4 & 11.5 & 12.3 \\
\hline \multicolumn{10}{|l|}{ Settlement type: } \\
\hline Urban & 10.8 & 17.3 & 17.8 & 33.3 & 20.9 & 14.3 & 10.8 & 7.9 & 8.0 \\
\hline Semi-urban & 13.2 & 16.0 & 26.2 & 34.9 & 19.4 & 8.7 & 16.0 & 13.6 & 25.9 \\
\hline Rural & 14.7 & 24.1 & 32.3 & 36.4 & 29.8 & 24.6 & 22.6 & 18.9 & 18.5 \\
\hline \multicolumn{10}{|l|}{ Household size: } \\
\hline 1 & 16.9 & 19.2 & 18.4 & 30.9 & 16.0 & 14.3 & 12.2 & 11.0 & 9.9 \\
\hline 2 & 10.5 & 14.1 & 18.4 & 28.8 & 20.0 & 14.9 & 12.9 & 10.7 & 10.2 \\
\hline 3 & 11.0 & 20.5 & 21.2 & 35.5 & 21.6 & 16.1 & 15.2 & 11.9 & 10.8 \\
\hline 4 & 10.8 & 18.2 & 23.7 & 37.6 & 25.7 & 15.4 & 11.2 & 10.1 & 11.9 \\
\hline 5 & 12.4 & 24.0 & 24.0 & 35.9 & 25.7 & 19.4 & 13.6 & 11.5 & 16.2 \\
\hline$>5$ & 17.7 & 21.2 & 29.8 & 33.1 & 31.0 & 26.0 & 28.8 & 18.0 & 20.9 \\
\hline \multicolumn{10}{|l|}{ Number of children: } \\
\hline 0 & 11.9 & 15.5 & 18.1 & 31.4 & 19.6 & 16.1 & 14.2 & 11.0 & 11.1 \\
\hline 1 & 9.7 & 19.3 & 21.3 & 32.0 & 21.7 & 15.5 & 12.3 & 10.8 & 11.3 \\
\hline 2 & 11.2 & 20.7 & 26.1 & 40.4 & 29.0 & 18.2 & 13.0 & 10.2 & 12.9 \\
\hline$>2$ & 23.9 & 28.8 & 34.7 & 39.8 & 35.5 & 23.9 & 32.0 & 25.2 & 27.3 \\
\hline \multicolumn{10}{|l|}{ Number of pensioners: } \\
\hline 0 & 11.8 & 19.9 & 24.1 & 36.8 & 24.1 & 17.1 & 14.6 & 11.2 & 12.2 \\
\hline 1 & 13.6 & 21.2 & 21.3 & 36.3 & 26.4 & 16.5 & 15.1 & 13.6 & 14.9 \\
\hline$>1$ & 9.4 & 11.6 & 16.6 & 21.8 & 15.5 & 15.7 & 12.2 & 9.3 & 8.5 \\
\hline \multicolumn{10}{|l|}{ Household type: } \\
\hline Single adult & 16.4 & 16.8 & 17.5 & 33.3 & 20.0 & 15.7 & 14.3 & 11.3 & 11.5 \\
\hline Single pensioner & 15.1 & 18.6 & 15.5 & 28.4 & 13.4 & 11.6 & 10.2 & 9.2 & 7.6 \\
\hline Adult couple no children & 7.6 & 12.7 & 19.1 & 32.9 & 17.8 & 15.9 & 13.7 & 13.5 & 8.7 \\
\hline Elderly couple ( $\geq 1$ pensioner) & 10.3 & 11.2 & 14.4 & 22.4 & 16.2 & 12.7 & 8.7 & 8.7 & 8.6 \\
\hline Single adult and children & 15.2 & 22.6 & 27.3 & 42.8 & 33.2 & 19.8 & 20.3 & 11.3 & 16.9 \\
\hline Adult couple and children & 10.0 & 18.5 & 22.7 & 35.7 & 22.0 & 14.5 & 10.2 & 8.2 & 8.1 \\
\hline Triple generations household & 10.9 & 22.2 & 20.8 & 33.2 & 25.8 & 19.1 & 17.4 & 14.9 & 14.5 \\
\hline Other households with pensioners & 13.4 & 16.2 & 21.6 & 34.5 & 26.2 & 17.2 & 15.1 & 11.7 & 14.4 \\
\hline Other households & 12.8 & 21.9 & 23.3 & 36.7 & 24.9 & 18.3 & 16.3 & 12.3 & 14.6 \\
\hline
\end{tabular}

Source: RLMS cross-sections 
Table 5.5: Poverty dynamics (1994-2004, two year intervals)

\begin{tabular}{lr}
\hline & $1994-2004$ \\
\hline Average poverty ratio: & \\
$\leq \mathrm{PL}$ & 8.1 \\
$>\mathrm{PL} \leq 1.5 \mathrm{PL}$ & 15.8 \\
$>1.5 \mathrm{PL} \leq 2 \mathrm{PL}$ & 17.0 \\
$>2 \mathrm{PL} \leq 2.5 \mathrm{PL}$ & 16.9 \\
$\geq 2.5 \mathrm{PL}$ & 42.2 \\
Chronic poverty groups: & \\
Always poor & 2.1 \\
Sometimes poor \& average expenditures below poverty line & 6.0 \\
Sometimes poor \& average expenditures above poverty line & 40.6 \\
Never poor & 51.1 \\
\hline
\end{tabular}

Source: RLMS panel (measured at two year intervals from 1994 to 2004)

that people living in urban and semi-urban areas greatly suffered from the crisis: the urban headcount index tripled from 1994 to 1998 while the rural headcount doubled. In urban areas, on the other hand, individuals seemed to recover faster from the crisis. In an absolute sense poverty is higher in urban areas, as individuals from rural areas comprise about $27 \%$ of the Russian population.

Individuals living in larger households typically have higher than average poverty rates than those in smaller sized households. Households with children are more likely to live in poverty than households with no children and the higher the number of children, the higher the poverty headcount. It seems that this situation changes for 2002 and 2003; in these years only individuals living in households with more than two children have above average poverty risk. For the households including elderly household members (age $\geq 55$ for women and age $\geq 60$ for men) the results are somewhat mixed; individuals living in households with more than one elderly household member clearly fall less often into poverty than those in households without elderly members, but individuals living in households including one elderly person seem to have an above average poverty risk. When decomposing according to specific household types it can be seen that households comprised only of elderly couples and elderly singles have lower poverty risk. The household types show that single adults (usually women) are also particularly vulnerable to poverty.

Insights into longitudinal aspects of poverty in Russia can be gained using RLMS panel (Table 5.5) ${ }^{15} \mathrm{An}$ interesting indicator in this respect is the average ratio

\footnotetext{
${ }^{15}$ The panel comprises those households that were observed for at least three consecutive two year periods (i.e. 1994, 1996, 1998, 2000, 2002 and 2004).
} 
of household's total expenditures over its respective poverty line. ${ }^{16}$ This poverty ratio shows the distance of the average living standard of the household relative to the poverty line: a value below 1 indicates that a household, on average, lived in poverty during the transition period and vice versa for an average above 1. Of the RLMS panel, $8 \%$ of the households had a ratio below $1,16 \%$ a ratio between 1 and $1.5,17 . \%$ between 1.5 and $2,17 \%$ for the range 2 and 2.5 , and $42 \%$ of the households had poverty ratios well above the poverty line $(>2.5)$. This shows that many households were living close to the absolute poverty line during the transition period. From a slightly different perspective, $2 \%$ of the RLMS households were always poor during the observed period, $6 \%$ was sometimes poor but had average expenditures below the poverty line. $41 \%$ of the households had on average above poverty line expenditures, but still experienced poverty. The first two groups are also often labelled as 'chronic poor' while the third group is called 'occasional poor'. Only $51 \%$ of the households did not experience poverty during the transition period.

\subsection{Consumption smoothing: conceptual and theoretical framework}

The previous section showed that the period from 1994-2004 has been very volatile in a macro-economic sense and this instability is clearly reflected in the annual and long term absolute poverty indicators as large parts of the Russian population experienced poverty and/or had on average a living standard just above the minimum acceptable living standard. As much as $49 \%$ of the households experienced one or more poverty spells in the period although some households have a higher poverty risk than others. The economic transition in Russia thus represents an important aggregate source of uncertainty for Russian households. Participatory poverty studies indicate that people in transition economies indeed associate the transition period with substantial increases in uncertainty (World Bank, May 1999). On top of that, households in Russia are exposed to a wide range of idiosyncratic risks and shocks such as illness, disability or death of a household's member, job loss, crop failure or loss of assets. In this section, we firstly discuss why and how households respond to uncertainty and shocks and introduce the concept of consumption smoothing. Thereafter, we set out our theoretical approach.

Economic theory suggests that uncertainty about future income and consumption reduces the expected satisfaction that risk adverse households ${ }^{17}$ can derive from income

\footnotetext{
${ }^{16}$ The absolute poverty lines in the RLMS are household-specific; they take the demographic composition and size of the household into account. The poverty ratio can thus also be viewed as equivalent household expenditures.

${ }^{17}$ We take households as the units of analysis because the household represents the first level at which individuals typically share resources. We thus implicitly assume that resources are equally shared within the household. In the analysis we control for (changes in) household composition.
} 
and consumption. At the same time, uncertainty represents a motivation for households to respond to the risks threatening their future well-being. When such responses are successful, households are able to smooth consumption over time, even when faced with income shocks. Consequently, the ability to smooth consumption reflects an important dimension of well-being.

Households respond to risks and shocks through saving, borrowing, adjusting labour supply, cultivating land and selling assets. Such strategies are sometimes classified as 'self-insurance' (Skoufias, 2003). Alternatively, households can also rely on other people through informal, private or government risk sharing or private market insurance schemes offered by financial institutions (Deaton, 1997; Fafchamps \& Lund, 2003). The possibilities for coping with shocks are partly determined by households' assets (Neubourg de \& Notten, May 2002; Neubourg de \& Weigand, 2000). These assets can be examined in a broad context: households have assets in the form of human capital (skills, experience), physical capital (land, house), social capital (friends, family, and acquaintances) and financial capital (cash holdings, savings). In addition, the household environment partly determines the possibilities of what households can do with these assets. For example, if banks do not provide loans to households or the household lacks sufficient financial collateral to obtain one, households are effectively constrained in their access to financial services. Households might however, obtain credit through other channels, such as social networks (through family members, neighbours or acquaintances) or informal money lenders. Given differences in households' assets and environment, it is very likely that households are not able to smooth consumption to the same extent.

Our aim is to investigate the overall ability of Russian households to smooth consumption during the transition period and whether this smoothing ability differs between household characteristics. We are further interested in the relationship between households' poverty risk and their consumption smoothing abilities. We measure consumption smoothing abilities by looking at the extent to which households are able to protect their consumption against income shocks. Shocks such as illness, disability or the death of a household member have a direct impact on household income when they involve a household member that actively participates in household's income generating activities. However, even when such shocks affect non-active family members there may be an indirect impact on household's income through adjustments in the internal household task division. Active members can reduce labour supply so that they have more time for caring activities or household tasks. Job loss, wage payment arrears and involuntary unpaid leave also affect household income. Extremes in climate (i.e. drought, floods) or diseases leading to crop failure also affect household income as fewer home produced products can be sold or consumed. Inflation or price adjustments 
for goods directly impact the real value of consumption that can be attained, particularly if income is not or only partly adjusted for price increases. ${ }^{18}$

In the economic literature there are a number of approaches modelling consumption smoothing behaviour (Deaton, 1992; Deaton \& Muellbauer, 1980). One approach models households' insurance decisions using an Arrow-Debreu economy. In this economy uncertainty exists because there are different possible states of the world that can prevail in the future. The concept 'state of the world' is analogous to the range of weather types that can occur; just as there can be rain, sunshine or snow, the economy can find itself in an upturn, slump or crisis. Each state of the world yields different opportunities for different consumers resulting in different income distributions over states. As a result, opportunities for risk sharing between risk adverse consumers arise. Risk sharing can take place through trading state contingent claims on a complete 'Arrow securities' market. This implies that, for each state of the world and time period, there exists an asset that will pay out if that state occurs and does not pay in any other state of the world. Under this framework, perfect consumption insurance against idiosyncratic risks is possible; for every state of the world consumers can buy a different security. Although it is very abstract, this market for state contingent claims could be considered as a simple approximation to the wide range of formal and informal insurance arrangements across space and over time that households can enter into to protect them from risk (Deaton, 1992, 1997). This model has been used in a number of empirical studies (Altonji et al, 1992; Cochrane, 1991; Mace, 1991; Skoufias, 2003).

Townsend (1994) also developed a risk sharing model within a general equilibrium framework which allows for the evaluation of the joint impact of all insurance arrangements within a village economy. In his model uncertainty exists but there is no such thing as a market for state contingent claims nor is there any modelling of risk-sharing markets or institutions; the assumption that individuals are risk averse provides sufficient rationale for risk-pooling but the theory does not take into account how this risk-sharing takes place. The solution to this intertemporal choice model suggests that in a Pareto optimal allocation all variation in consumption across households is related to variation in aggregate, village level, consumption because all the impact of all other shocks is shared among the villagers.

Finally, there are also models where consumption is smoothed through savings and credit markets (Deaton, 1992). The basic model draws upon the work of Friedman's permanent income theory of consumption which predicts that consumption is determined by the value of lifetime resources. The main feature of this model is the permanent income hypothesis: consumption is the annuity value of the sum of expected human

\footnotetext{
${ }^{18}$ By using real values for income and expenditures one can measure the impact of such shocks.
} 
and financial resources i.e. the consumer plans to die with no assets. The model implies that the rational and risk adverse consumers prefer stable consumption and use financial markets to achieve this stability. Therefore, anticipated changes in income should not affect consumption. Only unanticipated shocks influence consumption and the impact depends on the nature of the shock; if a shock is temporary, consumption will only change a little. If the shock is permanent, the change in consumption can be considerable. In the basic permanent income model, future income flows are certain implying that the only savings motive is consumption smoothing over the life cycle. Deaton (1997) shows that when income flows are uncertain, precautionary savings motives exist. Intertemporal choice models using utility functions $\mathrm{f}(\mathrm{x})$ that are continuously differentiable, where $\mathrm{f}(\mathrm{x})^{\prime}>0$ and $\mathrm{f}(\mathrm{x})$ " $<0$, additionally provide information about 'prudence' of the consumer. 'Prudence is meant to suggest the propensity to prepare and forearm oneself in the face of uncertainty' (Kimball, 1990, p.54). The degree of prudence is reflected in the third derivative of the utility function; if $\mathrm{f}(\mathrm{x})$ "' $>0$ (i.e. when the marginal utility function is convex) a consumer who is confronted with an increase in uncertainty of future consumption will reduce current consumption and increase saving.

The theoretical models discussed above describe perfectly functioning institutions: whatever the instruments available for consumption smoothing (whether through insurance markets, credit and savings markets or informal risk sharing), the main idea behind these models is that risk averse consumers prefer, and therefore make arrangements to obtain stable consumption. Empirical tests of consumption smoothing following from these theoretical models are very similar: in one way or another they envisage the estimation of the income elasticity of consumption. ${ }^{19}$ The value of this parameter constitutes a test of the functioning of these markets or the presence of uninsurable risks. In the basic life cycle model used by Friedman, positive income elasticity implies the presence of unanticipated shocks which induce consumers to make adjustments in their life-time consumption plans. In the Arrow-Debreu economy, positive income elasticity implies the incompleteness of the market for state contingent assets so that, when a household is confronted with a shock, it must adjust its consumption accordingly. For the risk sharing model used by Townsend a positive parameter also means that the insurance institutions cannot provide full insurance. ${ }^{20}$ This literature is useful in the sense that it provides various models that give a rationale for consumption smoothing as well as the ways in which economic agents can smooth

\footnotetext{
${ }^{19}$ The empirical models are estimated using various estimation strategies and include of course a range of control variables for demographic composition of households, regional diversity and time. For more information about the models we refer to the references mentioned in this section.

${ }^{20}$ For instance, institutions in risk sharing communities are unable to insure against co-variant shocks. When the community is hit by such a shock, households will have to adjust their consumption.
} 
their consumption. However, as the empirical tests of the models discussed above are very similar, it does not make much sense to choose one of these models to be an abstract representation for the Russian federation. The empirical test will not provide conclusive evidence in favour (or against) the theoretical model. Additionally, in reality households use a combination of various market and non market institutions, a point that is certainly valid for Russia, where market institutions are being developed. Thus, if the test suggests that households cannot fully smooth their consumption, it does not help us in finding out which institution fails. As the focus in this paper is on the overall ability of households to deal with income shocks, we decided to follow an exploratory approach.

\subsection{Theoretical model of consumption smoothing}

The innovative aspect of this study is that our model explicitly takes short and long run dynamics of the process of consumption smoothing into account; we investigate the ability of households to protect their consumption against income shocks using a dynamic panel analysis. A dynamic perspective is important because differences in the pre-shock level of household resources also influence the ability of households to protect themselves against income risks. Furthermore, short run consumption smoothing abilities may differ from long term consumption smoothing abilities. Finally, the economic, social and geographic diversity encountered in the Russian Federation makes it is relevant to take (un)observed heterogeneity between households into account. We therefore propose the following random effects panel model:

$$
\Delta c_{i, t}=\alpha_{0}+\alpha_{1} c_{i, t-1}+\beta_{1} \Delta y_{i, t}+\beta_{2} y_{t, t-1}+\sum_{j=1}^{6} \gamma_{j} x_{j, i, t},+\sum_{k=1}^{K} \delta_{k} D_{k}+v_{i}+\varepsilon_{i, t}
$$

where, in addition to the change in expenditures and income $\left(\Delta \mathrm{c}_{\mathrm{i}, \mathrm{t}}\right.$ and $\left.\Delta \mathrm{y}_{\mathrm{i}, \mathrm{t}}\right)$, the lag of income $\left(\mathrm{y}_{\mathrm{i}, \mathrm{t}-1}\right)$ and expenditures $\left(\mathrm{c}_{\mathrm{i}, \mathrm{t}-1}\right)$ are included. All income and expenditure variables are expressed in natural logarithms. Further, $x_{j, i, t-1}$ denotes the number of household members in the $j^{\text {th }}$ age category ${ }^{21}, D_{k}$ represents a set of binary variables specifying each community separately by survey round, $\mathrm{v}_{\mathrm{i}}$ is a random individual effect and $\varepsilon_{i, t}$ is the error term. $\beta_{1}$ is the short-run income elasticity of consumption and provides information about the question whether households are able to protect their

\footnotetext{
${ }^{21}$ The demographic characteristics of household members are summarized in six variables, where each variable represents the number of household members in a particular age-gender category. These categories are children below age of 6 , children aged between 6 and under 18, adult males, adult females, males in a pensionable age group ( 60 and above) and females in a pensionable age group (55 and above). The postworking categories are in accordance to the legal retirement age in Russia.
} 
consumption from short term fluctuations in their income. The effect of changes in household composition on consumption is assumed to be practically immediate.

The model specified above is an error correction mechanism (ECM). Assuming $\alpha_{1} \neq 0$, the error correction representation of the model can also be written as

$\Delta c_{i, t}=\alpha_{0}+\beta_{1} \Delta y_{i, t}+\alpha_{1}\left(c_{i, t-1}-\left(-\frac{\beta_{2}}{\alpha_{1}} y_{t, t-1}\right)+\sum_{j=1}^{6} \gamma_{j} x_{j, i, t},+\sum_{k=1}^{K} \delta_{k} D_{k}+v_{i}+\varepsilon_{i, t} \quad 5.3\right.$

This specification reflects the idea of an intertemporal budget constraint; as the stock of wealth is limited, consumption can diverge from income for some time (i.e. due to an income shock). However, at some point, resources are depleted and consumption levels will have to adjust to (new) income levels. $\alpha_{1}$ is the so-called equilibrium correction coefficient, which compensates for the short term overshooting or undershooting of consumption $\left(\alpha_{1}<0\right)$; in case of a complete correction this parameter will have a value of -1 . The long term income elasticity of consumption is indicated by $-\beta_{2} / \alpha_{1}$; it is likely that the value of this parameter is higher than that of its short term counterpart because it is more difficult to smooth consumption over a longer period (assets or savings can be depleted; friends and family will stop assisting at some point). The application of an advanced panel model to measure consumption smoothing, and in particular the error correction interpretation of the model, contributes to the literature on consumption smoothing in various aspects. First, in comparison to the models used in the literature our model explicitly takes the dynamics of consumption and income patterns and unobserved heterogeneity into account (Deaton, 1992, 1997; Ravallion \& Chaudhuri, 1997; Skoufias, 2003; Townsend, 1994). Secondly, the error correction interpretation of our model is innovative in this application because it incorporates the idea that households are able to smooth consumption but on the condition that income and expenditures should balance in the long term. As such it provides a more realistic representation of the determinants of consumption smoothing abilities.

The model thus allows us to assess the joint effect of short term consumption smoothing activities of households. Note, however, that the impact of income shocks such as shocks in labour supply need not be fully reflected in changes in income because other household members may take up extra income generating activities as a response to the job loss of another member. Morduch (1995) classifies such responses as income smoothing. In the RLMS data it is difficult to distinguish between such income smoothing responses and 'normal' income generating activities. There is also evidence that low wealth households in developing and transition economies smooth their consumption by means of other income smoothing strategies such as choosing crops with low variance yields or low risk-low return entrepreneurial activities. Our indicator of consumption smoothing ability does not capture the impact of such 
income smoothing channels. Another limitation of the analysis is that the model does not indicate at which cost consumption is smoothed. For example, households may accumulate non-productive assets that they can sell in times of trouble but this capital could have been used for investments (for example in human capital) with a higher expected return.

\subsection{Estimation and specification}

In the model outlined above, $\mathrm{c}_{\mathrm{i}, \mathrm{t}-\mathrm{k}}$ for any $\mathrm{k}$ is correlated with the unobserved household fixed effect, $v_{i}$. In order to obtain consistent estimates for this model a number of subsequent steps need to be taken. If we rewrite equation 5.2 in levels.

$$
c_{i, t}=\alpha_{0}+\left(1+\alpha_{1}\right) c_{i, t-1}+\beta_{1} y_{i, t}+\left(\beta_{2}-\beta_{1}\right) y_{t, t-1}+\sum_{j=1}^{6} \gamma_{j} x_{j, i, t},+\sum_{k=1}^{K} \delta_{k} D_{k}+v_{i}+\varepsilon_{i, t}
$$

This model can be estimated using the Generalized Method of Moments (GMM) estimator. The GMM estimator yields consistent and more efficient estimators than other linear method of moments estimators (Arellano \& Bond, 1991; Greene, 2003; Wooldridge, 2001). ${ }^{22}$ The efficiency increase results from the use of additional instruments (i.e. more instruments than needed for model identification) which become available when using the orthogonality conditions that exist between lagged values of the dependent variable, consumption, and the disturbances $\varepsilon_{\mathrm{i}, \mathrm{t}}$. Taking differences of equation 5.4 removes the household unobserved effects, $v_{i}$ :

$$
\Delta c_{i, t}=\left(1+\alpha_{1}\right) \Delta c_{i, t-1}+\beta_{1} \Delta y_{i, t}+\left(\beta_{2}-\beta_{1}\right) \Delta y_{t, t-1}+\sum_{j=1}^{6} \gamma_{j} \Delta x_{j, i, t},+\sum_{k=1}^{K} \delta_{k} \Delta D_{k}+\Delta \varepsilon_{i, t}
$$

The disturbance $\Delta \varepsilon_{\mathrm{i}, \mathrm{t}}$ follows an MA(1) meaning that the model is subject to firstorder autocorrelation, though presumably not to any higher order of autocorrelation. In this model, $\Delta \mathrm{c}_{\mathrm{i},-1-1}$ is still correlated with $\Delta \varepsilon_{\mathrm{i}, \mathrm{t}}$. However, $\mathrm{c}_{\mathrm{i}, \mathrm{t}-2}$ is a valid instrument for $\Delta \mathrm{c}_{\mathrm{i}, \mathrm{t}-1}$, for it is in principle not correlated with $\Delta \varepsilon_{\mathrm{i}, \mathrm{t}}$, and negatively correlated with $\Delta \mathrm{c}_{\mathrm{i}, \mathrm{t}-\mathrm{l}}$. As the number of time periods in the panel increases, more lags can be added as instruments. $^{23}$

It is also important to consider the influence of possible measurement error in the income and expenditure variables on the model estimation. As with all household

\footnotetext{
${ }^{22}$ Using a 2 SLS estimator is also a consistent, albeit less efficient method.

${ }^{23}$ We have estimated this empirical model for the overall panel as well as for a number of sub-samples using the Stata 9.0 software package. For the GMM estimator (level GMM) we have used the userwritten programme 'xtabond2' instead of Stata's 'xtabond' because 'xtabond2' provides more possibilities for the definition of the instrument matrix. 'xtabond2' is written by David Roodman, Center for Global Development, Washington, DC.
} 
surveys, measurement error is inevitably present in the RLMS data. Different types of measurement error arise because of inconsistencies in the respondents' memories, deliberate underreporting of income but also errors in, for instance, imputations in home production. The dependent variable, household per capita expenditures, includes the value of home production consumed and the explanatory income variable includes the total value of home production. Deaton (1997) explains that in this type of specification, measurement error caused by imputations in home production can generate an upward bias when the coefficient is positive. To deal with this problem, Deaton suggests using instruments for the income and lagged expenditures variables; income is instrumented by the value of income minus the revenues from home production while the lagged expenditure variable is instrumented with expenditures minus the value of home production consumed. We found evidence for this type of measurement error in the RLMS data and therefore used these instruments in our estimations. ${ }^{24}$

The aim of our analysis is exploratory; we estimate equation 5.5 not only for the overall sample but also for a selection of socio-economic groups in Russia. ${ }^{25}$ These partial analyses allow us to gain insights into whether there are differences in consumption smoothing abilities between these subgroups. Furthermore in section 5.7 we use these results to study the relation between the degree of poverty risk for these socio-economic groups and their abilities to smooth consumption. We estimate equation 5.5 for the following decompositions: settlement type; household size; number of children; number of pensioners; household type and according to poverty characteristics (chronic poverty and average poverty ratio).

Table 5.6 reports the results for the main parameters (in reduced form), the specification tests and the number of observations for the full sample, and the decomposition by settlement area. The demographic variables and time-community dummies that have been included as control variables in the estimations are not reported in the tables. $\beta_{1}$ is the short run income elasticity of expenditures; a $10 \%$ decrease in income will only result in a $1.6 \%$ decrease in overall expenditures. ${ }^{26}$ This

\footnotetext{
${ }^{24}$ To test whether this type of measurement error is present in the RLMS data we estimated a simplified version of our model (excluding the lagged levels) using a 2SLS estimator with and without the instruments for income and expenditures. The estimated coefficients of the model using the instruments are indeed lower than those in the other model.

${ }^{25}$ We use the two step GMM estimator which includes a finite-sample correction to the two-step covariance matrix derived by Windmeijer (2005). This can make the two step robust estimator more efficient than the one step robust estimator. However, for some partial estimations this correction could not be estimated ('matrix not positive definite'). In these cases we have used the results from the robust one step GMM estimator.

${ }^{26}$ Note that the size of the estimated parameters is sensitive to the choice of time period; including more or fewer survey rounds will change the estimates. It also cannot be excluded that these results may, to some degree, suffer from attenuation bias caused by uncontrolled heterogeneity or other measurement error.
} 
Table 5.6: Results overall and partial estimations for total expenditures

\begin{tabular}{lcccrrrr}
\hline & $1+\alpha_{1}$ & $\beta_{1}$ & $\beta_{2}-\beta_{1}$ & $\begin{array}{r}\text { Hansen } \\
(\text { P-value })\end{array}$ & $\begin{array}{r}\text { AR(1) } \\
(\text { P-value })\end{array}$ & $\begin{array}{r}\text { AR(2) } \\
(\text { P-value })\end{array}$ & Obs. \\
\hline Overall & $0.059^{01}$ & $0.160^{01}$ & 0.014 & 0.647 & 0.000 & 0.101 & 9,187 \\
Settlement type: & & & & & & & \\
Urban & $0.080^{01}$ & $0.159^{01}$ & 0.014 & 0.321 & 0.000 & 0.043 & 5,742 \\
Semi-urban & 0.151 & $0.179^{05}$ & -0.423 & 0.000 & 0.150 & 0.505 & 576 \\
Rural & -0.004 & $0.150^{01}$ & 0.019 & 0.355 & 0.000 & 0.844 & 2,869 \\
\hline
\end{tabular}

Note: ${ }^{10} 10 \%,{ }^{05} 5 \%$ and ${ }^{01} 1 \%$ significance level. Two step GMM estimator including standard errors estimated with Windmeijer's Finite Sample Correction (Windmeijer, 2005). Control variables included in estimation: changes in demographic composition and time-community dummies (at level of primary sampling unit).

Source: RLMS panel (measured at two year intervals from 1994 to 2004)

parameter can also be interpreted as an indicator for the short run ability of smoothing consumption: when it is close to zero, households are able to protect themselves against income shocks; when it is close to one, households do not smooth consumption or are not capable. A value between zero and one indicates partial consumption smoothing. $\beta_{1}$ is significant on a $1 \%$ level for the overall sample and the decompositions by settlement area; we can thus reject the null-hypothesis of perfect consumption smoothing. As the short term elasticities also differ significantly from one (not shown here), our results therefore provide evidence of partial consumption smoothing (Skoufias, 2003; Townsend, 1994). The other parameters of the error correction model are not estimated directly but are reported in the appendix (Table 5.10 ). Although the parameters for lagged consumption $\left(1+\alpha_{1}\right)$ and lagged income $\left(\beta_{2}-\beta_{1}\right)$ are only significant for some sub-samples, the parameters of interest $\left(\alpha_{1}\right.$ and $\left.-\beta_{2} / \alpha_{1}\right)$ differ significantly from zero. ${ }^{27}$ The value of $\alpha_{1}$, the error-correction coefficient, is expected to be negative because of the need to compensate for under-consumption and over-consumption in previous periods. A value of $\alpha_{1}=-1$ indicates immediate adjustment to disequilibrium. Table 5.10 shows that the estimated error correction parameters are close to minus one. $-\beta_{2} / \alpha_{1}$ represents the long term income elasticity of consumption; in line with our expectations we find that the estimated long term income elasticities are higher than their short term counterparts indicating that it is harder to smooth consumption over a longer period.

We also performed a number of tests to evaluate the validity of the model specification. First, a consistent GMM estimator requires that there is no second-order

\footnotetext{
${ }^{27}$ The standard error of the long term elasticity $\left(-\beta_{2} / \alpha_{1}\right)$ is estimated using the delta method. The standard error of the error correction term $\left(\alpha_{1}\right)$ can easily be obtained by testing the hypothesis that $\left(1+\alpha_{1}\right)=1$ which is mathematically equivalent to testing that $\alpha_{1}=0$.
} 
autocorrelation. ${ }^{28}$ It is also important to check whether the residuals actually display first-order autocorrelation or whether they follow a random walk. The test statistics for the estimated sub samples reported in Table 5.6 and Table 5.10 confirm that these assumptions of the model are acceptable in most cases. ${ }^{29}$ The Hansen test evaluates the validity of the over-identifying restrictions used in the GMM estimator. A failure to reject the null-hypothesis indicates that there is no violation of the zero correlation assumption between additional instruments and the error term. The null-hypothesis cannot be rejected for the overall sample as well as for most of partial estimations. ${ }^{30} 31$

\subsection{Consumption smoothing abilities and poverty risk}

The results in the previous section show that a dynamic specification of households' consumption smoothing behaviour is appropriate. The other key result is that households are indeed able to protect their consumption partially from income shocks. We now focus on the short-term ability of households to smooth consumption. This ability reflects an important dimension of welfare, namely the capacity of households to maintain their standard of living in an uncertain environment. It is important to keep in mind that $\beta_{1}$ represents the outcome of a mix of consumption smoothing strategies; it does not only reflect self-insurance strategies such as borrowing and selling assets, but also all formal and informal risk sharing arrangements that spread the effects of income shocks across households at any point in time. We are further interested in the manner in which consumption smoothing abilities are related to poverty risk; do households with a higher poverty risk also have more difficulties with consumption smoothing? From the development literature we know that poor households have fewer assets and are more likely to face borrowing constraints (Bardhan \& Udry, 1999; Deaton, 1997). But such households might alternatively make use of other consumption smoothing strategies such as risk sharing arrangements. By comparing the results of the poverty analysis with the short run smoothing abilities of households from the partial analyses, we aim to get some preliminary insights into the relationship between poverty risk,

\footnotetext{
${ }^{28}$ Testing this condition requires a number of time periods $\mathrm{T} \geq 5$ (Baltagi, 2001).

${ }^{29}$ The AR(1) test only finds no evidence of first order autocorrelation for the two household types (Single adult and kids and the triple generations household). The AR(2) test fails to reject the zero second order correlation at a $1 \%$ level for the Adult couple with no kids and at a $5 \%$ level for the urban sub sample.

${ }^{30}$ Only for the semi-urban sub sample and for households with two or more pensioners the null hypothesis can be rejected.

${ }^{31}$ Not reported here are the results of the Hausman model specification test that provides information on how the income variables should be treated, i.e., as predetermined or endogenous (Hausman, 1978). The Hausman test is a test of endogeneity based upon a direct comparison of coefficient values. The test indicated that income can be treated as exogenous.
} 
Table 5.7: Short-run consumption smoothing abilities by poverty characteristics

\begin{tabular}{lccc}
\hline & Total expenditures & Food expenditures & Non-food expenditures \\
\hline Overall & $0.160^{01}$ & $0.120^{01}$ & $0.366^{01}$ \\
Average poverty ratio: & & & \\
$\leq \mathrm{PL}^{1}$ & $0.160^{01}$ & $0.182^{01}$ & 0.248 \\
$>\mathrm{PL} \leq 1.5 \mathrm{PL}^{1}$ & $0.134^{01}$ & $0.091^{05}$ & $0.561^{01}$ \\
$>1.5 \mathrm{PL} \leq 2 \mathrm{PL}^{1}$ & $0.160^{01}$ & $0.086^{05}$ & $0.415^{01}$ \\
$>2 \mathrm{PL} \leq 2.5 \mathrm{PL}^{1}$ & $0.211^{01}$ & $0.179^{01}$ & $0.307^{05}$ \\
$\geq 2.5 \mathrm{PL}^{1}$ & $0.154^{01}$ & $0.114^{01}$ & $0.266^{01}$ \\
Chronic poverty groups: & & & \\
Chronic poor & & $0.182^{01}$ & 0.248 \\
Occasionally poor & $0.160^{01}$ & $0.150^{01}$ & $0.436^{01}$ \\
Never poor & $0.188^{01}$ & $0.068^{01}$ & $0.255^{01}$ \\
\hline
\end{tabular}

Note: ${ }^{1}$ One step GMM. ${ }^{10} 10 \%,{ }^{05} 5 \%$ and ${ }^{01} 1 \%$ significance level.

Source: RLMS panel (measured at two year intervals from 1994 to 2004)

poverty duration and consumption smoothing ability. At the end of this section we also compare our results those of Skoufias (2003) who estimated households' consumption smoothing abilities with the RLMS data but using a differenced model instead of a dynamic specification.

Table 5.7 and Table 5.8 summarize the consumption smoothing abilities for the overall sample and the decomposition by household's social-economic characteristics (the $\beta_{1}$ 's of the partial analyses); a high consumption smoothing ability is reflected by low income elasticity $\left(\beta_{1}\right)$. We also estimated the model separately using either food expenditures or non-food expenditures as independent variable. ${ }^{32}$ The reason for making this distinction between expenditure categories is that the previous section showed that households only partially smooth consumption. Partial smoothing thereby also implies a choice about which expenditures to smooth and which not. The results show that the short term income elasticity of food expenditures is considerably lower than that of non-food expenditures and that this is the case for all partial estimations; households smooth their food consumption better than their non-food consumption. Intuitively, when households are unable to fully protect their consumption from an income shock,

\footnotetext{
${ }^{32}$ From an econometric perspective this actually implies that the model with total expenditures is not adequate when the estimated parameters of food and non-food expenditures are different. Given the exploratory character of this analysis we decided to report the short term elasticities for total, food and non-food expenditures. The specification tests using food and non-food expenditures do not vary much with those obtained using total expenditures.
} 
they prefer to cut expenditures of less essential items instead of cutting on food items. The motivation for such choice is explained by Maslow's theory of needs (1987), which distinguishes between basic needs and higher needs such as love/belonging, esteem and self actualisation. Once basic needs are satisfied, individuals will seek to fulfil their higher needs. However, when basic needs are not met, individuals will prioritize the satisfaction of those needs. If resources are even more limited, it may be necessary to choose which basic needs are most important. ${ }^{33}$ In this respect, households' expenditures are a reflection of their efforts to satisfy their needs. Expenditures on items such as food, shelter and clothing can be associated with basic needs. The difference between food and non-food smoothing abilities may thus reflect a prioritization of households' basic needs with food expenditures receiving priority above non-food expenditures.

At the same time, the tables also show that consumption smoothing abilities vary according to households' long-term living standard and socio-economic characteristics. We proceed by discussing the smoothing results by decomposition and discuss to what way the smoothing abilities of particular characteristics of households may be related to our findings in terms of poverty risk and long term poverty (Table 5.4 and Table 5.5). We start with the long term welfare indicators and decompose the sample according to the average poverty ratio and our indicator of chronic poverty. The average poverty ratio shows the distance of the average living standard of the household relative to its household specific poverty line while the chronic poverty groups are a combination of the frequency of poverty spells experienced and the average living standard with respect to the poverty line (the first average poverty ratio group $(\leq \mathrm{PL})$ is the same as the chronic poor). The decompositions of the average poverty ratio groups indicate how consumption smoothing abilities vary as the average living standard of a household increases (i.e. whether the average level of well-being plays a role). Patterns in smoothing abilities by chronic poverty groups are interesting because smoothing abilities may also be related to the experience of poverty or not (i.e. whether the occasional or chronic experience of absolute poverty plays a role).

The results show that non-food expenditure smoothing abilities increase (i.e. $\beta_{1}$ decreases) as household's average living standard rises. However, the income elasticity of the group with the lowest living standard (i.e. the chronically poor) does not differ significantly from zero suggesting that this group has the highest non-food smoothing ability. When faced with an income shock, this group cuts predominantly food expenditures (chronically poor have the lowest food smoothing ability of all groups). Food smoothing abilities follow a wave pattern, with chronically poor having the lowest

\footnotetext{
${ }^{33}$ Maslow postulated that there is a particular hierarchy in these needs. What is of relevance for our discussion is the notion that individuals prioritize needs and distinguish between more and less essential needs (essential in terms of survival).
} 
smoothing abilities, households just above the poverty line having the highest food smoothing ability, followed by lower food smoothing abilities for the next group ( $>2$ $\mathrm{PL} \leq 2.5 \mathrm{PL})$ and higher abilities for the wealthiest group ( $\geq 2.5 \mathrm{PL})$. Again Maslow's theory provides clues for a possible interpretation for these patterns. The chronically poor face a continuous struggle to meet basic needs. They spend all available resources on the satisfaction of those basic needs; of which a large share is spent on food. ${ }^{34}$ Remaining expenditures on non-food items also reflect essential expenditures to satisfy the bare minimum of other basic needs (shelter, heating/utilities, clothing/shoes and transport). When resources are so low, cutting non-food expenditures further after an income shock would mean not having a roof above your head, not being able to cook your food or not going to work anymore. Cutting expenditures on food further may then be the only feasible alternative. Groups with a higher average living standard can choose to cut expenditures in other categories if they cannot fully smooth the income shock; those households just above the poverty line cut expenditures on less essential non-food items while better off households may prefer to cut less essential food expenditures (cheaper products, fewer luxury food stuffs) and/or other items (buy fewer (designer) clothes, one holiday less).

The decomposition by chronic poverty groups additionally suggests that household who experienced a temporary drop of living standard below the absolute poverty line make the largest expenditure adjustments, both in terms of food and non-food items. Households that never experienced poverty are better able to protect themselves against income shocks. Especially food expenditures are well protected. It is not clear to what extent these differences in smoothing abilities are the result of differences in the available means to smooth consumption (i.e. chronic and occasionally poor groups have fewer smoothing possibilities) and/or differences in the magnitude of income shocks (i.e. the occasionally poor experiencing more severe shocks). In conclusion, both longitudinal decompositions show that consumption smoothing abilities improve as the living standard increases. Furthermore, finding that chronically poor households also seem to be able to partially smooth consumption is not reassuring; the uninsured part of the shock affects expenditures on food, with potentially long-term consequences on health. Moreover, the cost of the smoothed part of the income shock may be very high and further limit the opportunities for future improvements in living standards.

The decomposition of the full sample into rural and (semi-)urban settlement areas for total household expenditures suggests that rural households are somewhat

\footnotetext{
$\overline{34}$ Indeed, the proportion of income spent on food (per capita) is highest for chronically poor households and lowest for households that did not experience poverty in the observed period. In 2004, the average food share was $61 \%$ for chronically poor households, $58 \%$ for occasional poor households and $55 \%$ for the other households.
} 
Table 5.8: Short-run consumption smoothing abilities by household characteristics

\begin{tabular}{|c|c|c|c|}
\hline & Total expenditures & Food expenditures & Non-food expenditures \\
\hline Overall & $0.160^{01}$ & $0.120^{01}$ & $0.366^{01}$ \\
\hline \multicolumn{4}{|l|}{ Settlement type: } \\
\hline Urban & $0.159^{01}$ & $0.127^{01}$ & $0.304^{01}$ \\
\hline Semi urban & $0.179^{05}$ & 0.074 & $0.327^{10}$ \\
\hline Rural & $0.150^{01}$ & $0.100^{01}$ & $0.519^{01}$ \\
\hline \multicolumn{4}{|l|}{ Household size: } \\
\hline 1 & $0.086^{10}$ & 0.065 & $0.456^{01}$ \\
\hline 2 & $0.203^{01}$ & $0.141^{01}$ & $0.409^{01}$ \\
\hline 3 & $0.158^{01}$ & $0.122^{01}$ & $0.289^{01}$ \\
\hline$\geq 4$ & $0.191^{01}$ & $0.141^{01}$ & $0.370^{01}$ \\
\hline \multicolumn{4}{|l|}{ \# of children: } \\
\hline 0 & $0.141^{01}$ & $0.110^{01}$ & $0.361^{01}$ \\
\hline 1 & $0.191^{01}$ & $0.155^{01}$ & $0.300^{01}$ \\
\hline$\geq 2$ & $0.200^{01}$ & $0.112^{01}$ & $0.526^{01}$ \\
\hline \multicolumn{4}{|l|}{ \# of pensioners: } \\
\hline 0 & $0.204^{01}$ & $0.140^{01}$ & $0.400^{01}$ \\
\hline 1 & $0.107^{01}$ & $0.102^{01}$ & $0.440^{01}$ \\
\hline$\geq 2$ & $0.111^{10}$ & 0.077 & $0.283^{01}$ \\
\hline \multicolumn{4}{|l|}{ Household type: } \\
\hline Single adult ${ }^{1}$ & $0.264^{05}$ & 0.131 & -0.145 \\
\hline Single pensioner ${ }^{1}$ & 0.052 & 0.018 & $0.538^{01}$ \\
\hline Adult couple no children ${ }^{1}$ & $0.276^{01}$ & $0.178^{01}$ & $0.457^{01}$ \\
\hline Elderly couple ${ }^{2}$ & $0.198^{01}$ & $0.157^{01}$ & $0.408^{01}$ \\
\hline Single adult and children $(<18)^{1}$ & $0.207^{01}$ & 0.048 & $0.449^{01}$ \\
\hline Adult couple and children $(<18)$ & $0.199^{01}$ & $0.087^{01}$ & $0.430^{01}$ \\
\hline Triple generations household & 0.200 & 0.128 & $0.244^{10}$ \\
\hline Other households with pensioners & $0.120^{00}$ & $0.172^{05}$ & 0.229 \\
\hline Other households & $0.185^{01}$ & $0.159^{01}$ & $0.306^{01}$ \\
\hline
\end{tabular}

Note: ${ }^{1}$ One step GMM. ${ }^{2}$ Household with at least 1 pensioner. ${ }^{10} 10 \%,{ }^{05} 5 \%$ and ${ }^{01} 1 \%$ significance level. Source: RLMS panel (measured at two year intervals from 1994 to 2004)

more capable of protecting their overall consumption against income shocks than urban households (Table 5.8). When decomposing expenditures into food and non-food expenditures, rural households appear to be quite able to smooth food expenditures but have a much lower ability to protect their non-food expenditures. The poverty profile shows that households in rural areas have a higher poverty risk. A likely explanation 
for this difference is that rural households have higher food smoothing abilities because they have more opportunities to produce their own food and make use of these opportunities. ${ }^{35}$ In Notten (2007) it is shown that rural households are more likely to produce their own food and that home produced food constitutes a large share of total household income. It is also shown that households themselves consume a large part of home produced food. Households in urban areas are more dependent on the proceeds from cash income generating activities than rural households, which renders them more vulnerable to income shocks in general; the poverty analysis showed that during the 1998 crisis the number of poor urban households roughly tripled while the number of poor rural households doubled. At the same time, it seems that the urban environment provides more opportunities for making a decent living (above the poverty line) and to accumulate savings or other assets that can be used in difficult times.

The decomposition of the sample according to the number of household members shows that 'single person' households have a higher smoothing ability in terms of food expenditures but the lowest ability in terms of non-food expenditures as compared to larger households. There is no clear pattern in smoothing abilities as the number of household members rises; the decompositions of the overall sample with respect to children, elderly and household types suggest that the observed pattern may be related to the structure of the household (dependency ratios) and eligibility to old age pensions.

Firstly, having an elderly household member increases the households' consumption smoothing ability in terms of total and food expenditures but only enhances smoothing abilities for non-food expenditures if there is more than one elderly living in the household. According to the poverty profile, households comprised of only elderly persons or at least including two elderly persons have lower poverty rates of this category. In the Russian Federation, every elderly citizen is entitled to a pension (the eligible age is 55 for women and 60 for men). This pension consists of a basic amount plus increments depending on the employment record but in reality the amounts of pension received did not differ widely during the transition period (International Social Security Association, 2002; Zurabov, July 2002). ${ }^{36}$ In this respect, one hypothesis is that pensions in Russia are typically sufficient to lift the elderly out of poverty and even allow them to accumulate some assets (savings) which can be used as a consumption smoothing strategy. However, this is only partially true as the high inflation during the

\footnotetext{
${ }^{35}$ The value of home produced food is included in the income variable and the value of consumption of home produced goods is included in the expenditure variables.

${ }^{36}$ As a result of the pension reform in 2001 it can be expected that this discrepancy will increase in the coming years.
} 
economic crisis of 1998 eroded the real value of pensions. The poverty profile shows a clear jump in elderly poverty rates during this time. The old age pension might be sufficient for maintaining a welfare level above the poverty line, but when the real value of pension declines (as it did in 1998) expenditures have to be cut. Additionally, the decomposition by household type shows that the demographic structure of pensioner households is relevant; single elderly households and triple generation households have high abilities of smoothing food expenditures while the other pensioner household types smooth predominantly through non-food expenditures.

Looking at the decomposition by household types we can further see that households with children and single person households have higher than average food smoothing abilities while households without children and consisting of two or more members have lower than average food smoothing abilities. However, the correspondence between poverty risk and the food/non-food smoothing abilities of these household characteristics is not so clear. Generally, we observe that as the number of children in a household increases, the poverty risk also increases while the overall consumption smoothing ability is lower than that of households with no children. However, the decomposition by household types shows that the demographic structure of households with children matters a lot for poverty risk as well as non-food smoothing abilities; single parent households have a high poverty risk and well below average non-food smoothing abilities, extended households also have a somewhat higher poverty risk but below average non-food smoothing abilities while households consisting of two adults and children have a below average poverty risk and above average non-food smoothing ability. These differences are likely to be the result of a combination of factors we already discussed (the typical living standard of such household types, eligibility to an old pension and perhaps also rural/urban settlement area) and varying dependency ratios. Households with children in general, but especially single parent households, extended family households and households with several children have higher dependency ratios because there are fewer economically active adults who have to make a living for themselves and their dependent family members. A higher dependency ratio thus increases the risk of poverty. However, inactive (adult) household members may facilitate labour participation of other household members and can also contribute to household (food) production or households' income by receiving a pension. These effects are likely to contribute to the poverty risk and consumption smoothing abilities of households consisting of several adults while they are out of reach for single parent households.

Finally, we briefly compare our results with a paper that has been an important source of inspiration for this research. In his paper titled 'Consumption Smoothing in Russia', Emmanuel Skoufias (2003) also estimated households' responses to income 
shocks. Skoufias used a differenced model which related changes in income to changes in consumption. The model was estimated by pooled Ordinary Least Squares (OLS) using RLMS 1994 to $2000 .{ }^{37}$ In broad lines the results of both studies are comparable; Skoufias finds that households are only partially insured against income shocks and that food expenditure is better protected than non-food expenditures. We argued, however, that a dynamic specification is more appropriate in a theoretical sense because households' abilities to smooth consumption in the short run are also determined by a long term relation between income levels and consumption levels. The empirical results further support the appropriateness of a dynamic specification. Unfortunately, the short run income elasticities in both studies are not directly comparable due to other methodological differences. ${ }^{38}$ A comparison of determinants of smoothing abilities suggests further differences: Skoufias finds that rural households and households with children have higher consumption smoothing abilities whereas we find the opposite result. It is likely that these differences arise due to measurement error caused by imputations in home production; estimates of our model without instrumenting the home production component resulted in similar outcomes for rural households and households with children as Skoufias' results. As mentioned before, this type of measurement error can generate an upward bias when the coefficient is positive. It is not surprising that this type of measurement error has a large impact on rural households (rural household tend to have more children as well).

\subsection{Conclusion}

In this paper we examined the extent to which Russian households have been able to protect their consumption against income shocks during the transition period and how households' consumption smoothing abilities are related to the risk of poverty. We used cross-section data to estimate the absolute poverty profile in transition Russia and panel data to describe the longitudinal characteristics of poverty. An innovative aspect of the study is that we modelled households' consumption smoothing behaviour by an

${ }^{37}$ Skoufias estimated the following model $\Delta \mathrm{c}_{\mathrm{it}}=\alpha_{0}+\beta_{1} \Delta y_{i, t}+\sum_{j=1}^{J} \gamma_{j} x_{j, i, t}+\sum_{k=1}^{K} \delta_{k} D_{k, t}+\Delta \varepsilon_{i, t}$ where $\Delta \mathrm{c}_{\mathrm{i}, \mathrm{t}}$ represents the change in natural logarithm of total consumption for household $\mathrm{i}$, in period $\mathrm{t}, \Delta \mathrm{y}_{\mathrm{i}, \mathrm{t}}$ represents the change in natural logarithm of total household income, $\mathrm{x}_{\mathrm{j}, \mathrm{i}, \mathrm{t}}$ is a particular household characteristic, such as family size and demographic composition, $\mathrm{D}_{\mathrm{k}, \mathrm{t}}$ is a binary variable specifying each community separately by survey round, and $\varepsilon_{\mathrm{i}, \mathrm{t}}$ is a random error term.

${ }^{38}$ Skoufias uses a shorter time period (1994-2000), uneven time intervals (because of missing surveys in 1997 and 1999) and does not correct for measurement errors in home production. We estimated our model for a shorter time period which resulted in higher short run income elasticities (compared to our current results). Taking unevenly spaced time intervals also increases the short run income elasticities. Not instrumenting home production also results in higher elasticities. 
Error Correction Mechanism (ECM), distinguishing between short term and long term smoothing dynamics. We estimated a reduced form of this model using Generalized Method of Moments (GMM) techniques. To study heterogeneity in consumption smoothing abilities and its relation to poverty risk, we followed an exploratory approach and estimated the model not only for the complete sample but also for various socioeconomic subgroups. Empirical analyses of consumption smoothing behaviour have often been based on differenced data in order to eliminate individual household effects. However, such specification fails to incorporate long term effects, which are also likely to influence short run smoothing abilities. The error correction mechanism underlines the special relationship of income and expenditures; expenditures can deviate from income in the short term but, in the long term, income and expenditures should balance. The results from the specification tests indicate that our model does not violate the assumptions required for estimation.

We find that Russian households are partially able to smooth expenditures in the short run and that food expenditures are better protected than non-food expenditures. The partial estimations according to various levels of average living standards and chronic poverty groups show that consumption smoothing abilities improve as the living standard increases. Although chronically poor households are partially able to protect their consumption from income shocks, at the same time, they respond by further reducing already low levels food expenditures. Occasionally poor households are found to have the lowest consumption smoothing abilities. However, low abilities of consumption smoothing are not always associated with high poverty risk. For instance, we find that rural households, who have a high poverty risk, manage to smooth food expenditures quite well, most likely because they have more opportunities to produce their own food. But households with pensioners, who have a lower poverty risk, have higher consumption smoothing abilities.

These results support the arguments of scholars such as De Neubourg and Holzman who propose a new orientation for social protection policies; such policies should not only focus on basic poverty relief but there is also an important role for the government in terms of assisting households manage risks (Holzman \& Jorgensen, February 2000; Neubourg de \& Weigand, 2000). Social insurance programmes can play an important role in this respect; our findings suggest that in Russia pensions received by elderly household members reduce the risk of poverty and enhance consumption smoothing abilities. However, the scope of policies to improve household consumption smoothing abilities extends beyond that of social protection policies. Rural development policies such as investments in infrastructure may simultaneously reduce the poverty risk of rural households and improve their (non-food) consumption smoothing abilities because of improved possibilities to generate (cash) income (i.e. 
through selling home produced produce in regional towns). Furthermore, governments play an important role in market economies and can exercise a positive or negative influence on macroeconomic stability and on the labour market (thus affecting the sources of uncertainty in households' environment). Governments can reduce the likelihood of aggregate shocks by means of legislation, monitoring and evaluation. At the same time, better functioning financial markets allow households to use markets to protect themselves against risks through lending, saving and insurance products.

We have provided a number of intuitively appealing explanations for our results but further research is required to understand the underlying determinants of poverty risk and consumption smoothing abilities. Firstly, the partial analyses are only of an exploratory nature; it is preferable that the influence of household characteristics is directly incorporated in a model of consumption smoothing. Secondly, research into the specific smoothing strategies followed by households and the institutions which assist them with smoothing is needed. Such analysis would also yield more concrete policy recommendations. In Notten (2007), we follow up on this issue and develop a conceptual framework to analyse such consumption smoothing arrangements. We also apply this framework to the RLMS data and explore how Russian households may smooth consumption. Finally, it should be noted that we have thus far analysed the impact of income shocks on consumption. Households may also pursue income smoothing strategies instead of consumption smoothing (Morduch, 1994, 1995).

\subsection{Appendix}

\subsubsection{Comparison cross-section and panel dimensions RLMS}

The RLMS is a sample of dwelling places, which means that when a household moves, it is removed from the cross-section dimension. However, once moved, the RLMS tried to locate these households and remained interviewing them for the panel dimension (this strategy has been implemented since round 7). This explains why the size of panel increases over time. New households that moved into a sampled dwelling place were added to the cross-section. Also note that each sampled dwelling place was visited every survey year; even if a household refused to cooperate or was not present in one round, the household was visited again in the subsequent survey round. Thus in 1994, all households in the panel are also part of the cross-section. We have included households in the panel once they have been observed for at least three consecutive periods (two-year periods in this case). For example, a household is part of the panel when it is observed in 1994, 1996 and 1998 but also when it is observed in 1996, 1998, 2000 and 2002. 


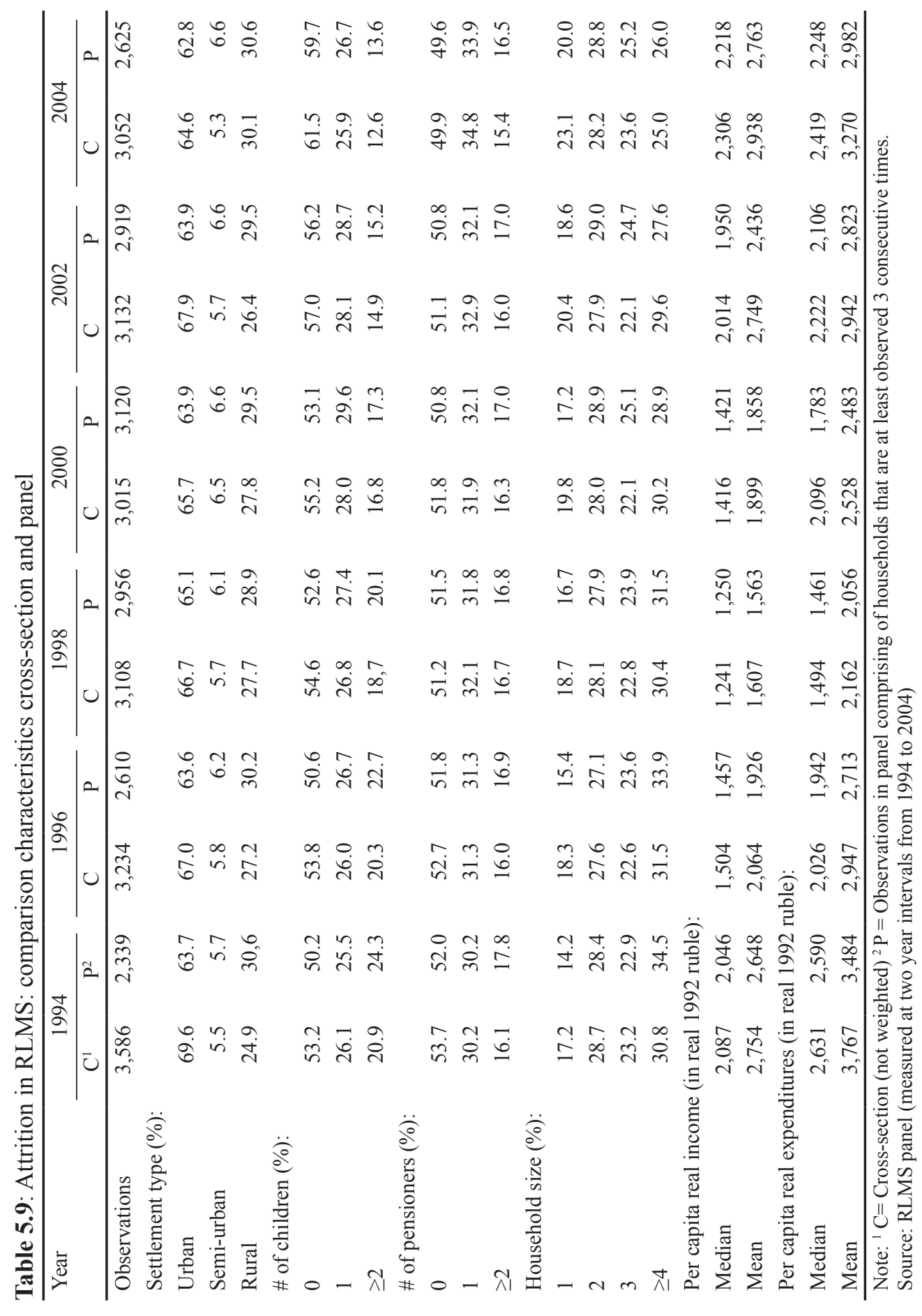


Comparison of the characteristics of the weighted cross-sections with the unbalanced panel reveals a number of differences. ${ }^{39}$ Rural households are overrepresented in the panel in comparison to the cross-section. An important factor for this difference is the higher attrition rate of households in Moscow and Saint Petersburg. For this reason the RLMS included a new sample of households from these areas in 2001. Single households and childless households are somewhat underrepresented in the panel. Median income and expenditures are slightly lower in the panel while the differences for the averages are somewhat larger, albeit in the same direction.

\subsubsection{Estimations error correction coefficients and specification tests}

\footnotetext{
${ }^{39}$ Note that we have used the yearly adjusted household post-stratification weights computed by the RLMS for the cross-sections. These weights attempt to match certain demographic characteristics of the sample to those observed in the 1989 census. The household-level weights adjust for household size and urban-rural residence. There are no such weights available for the panel dimension.
} 


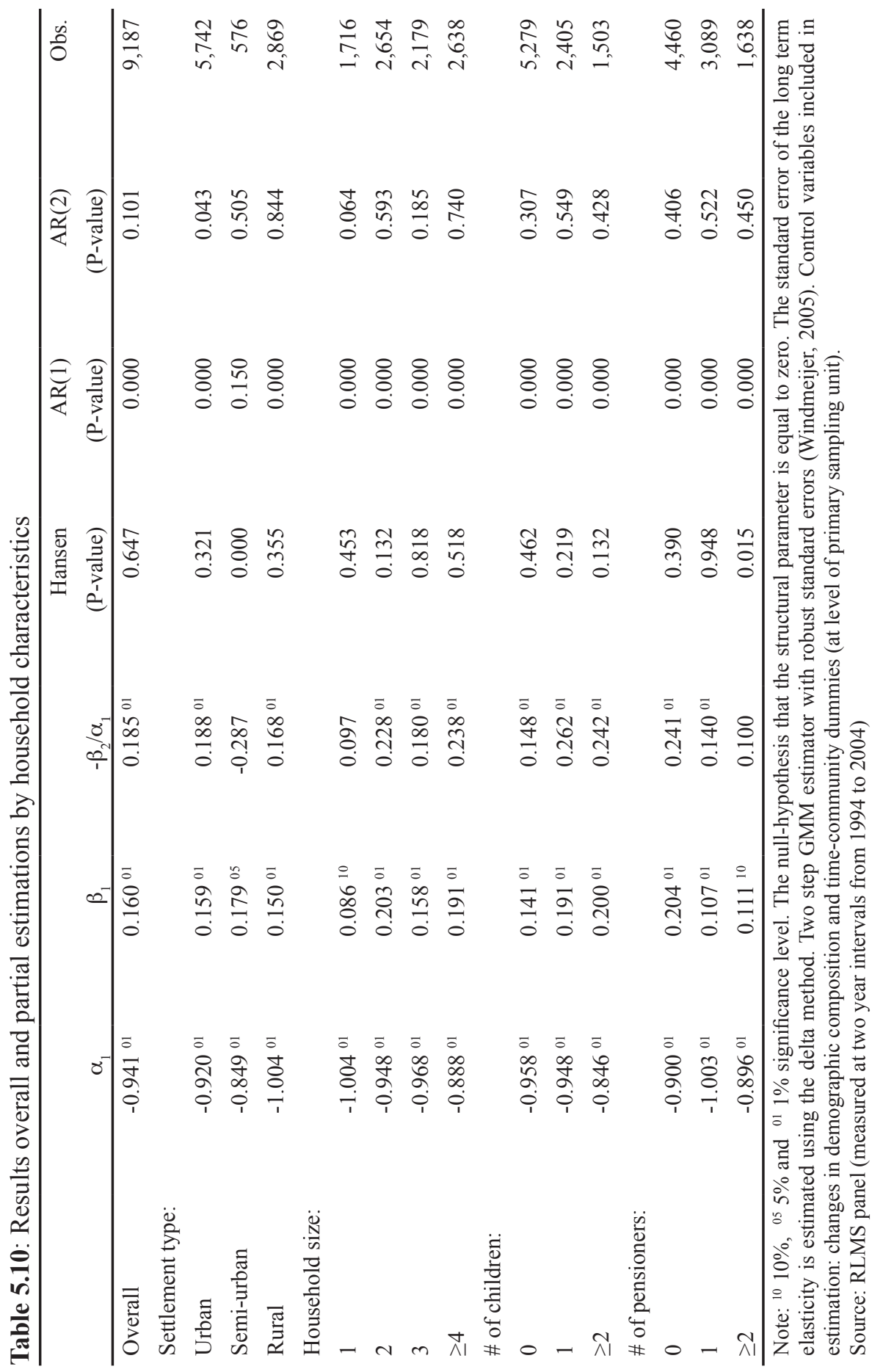




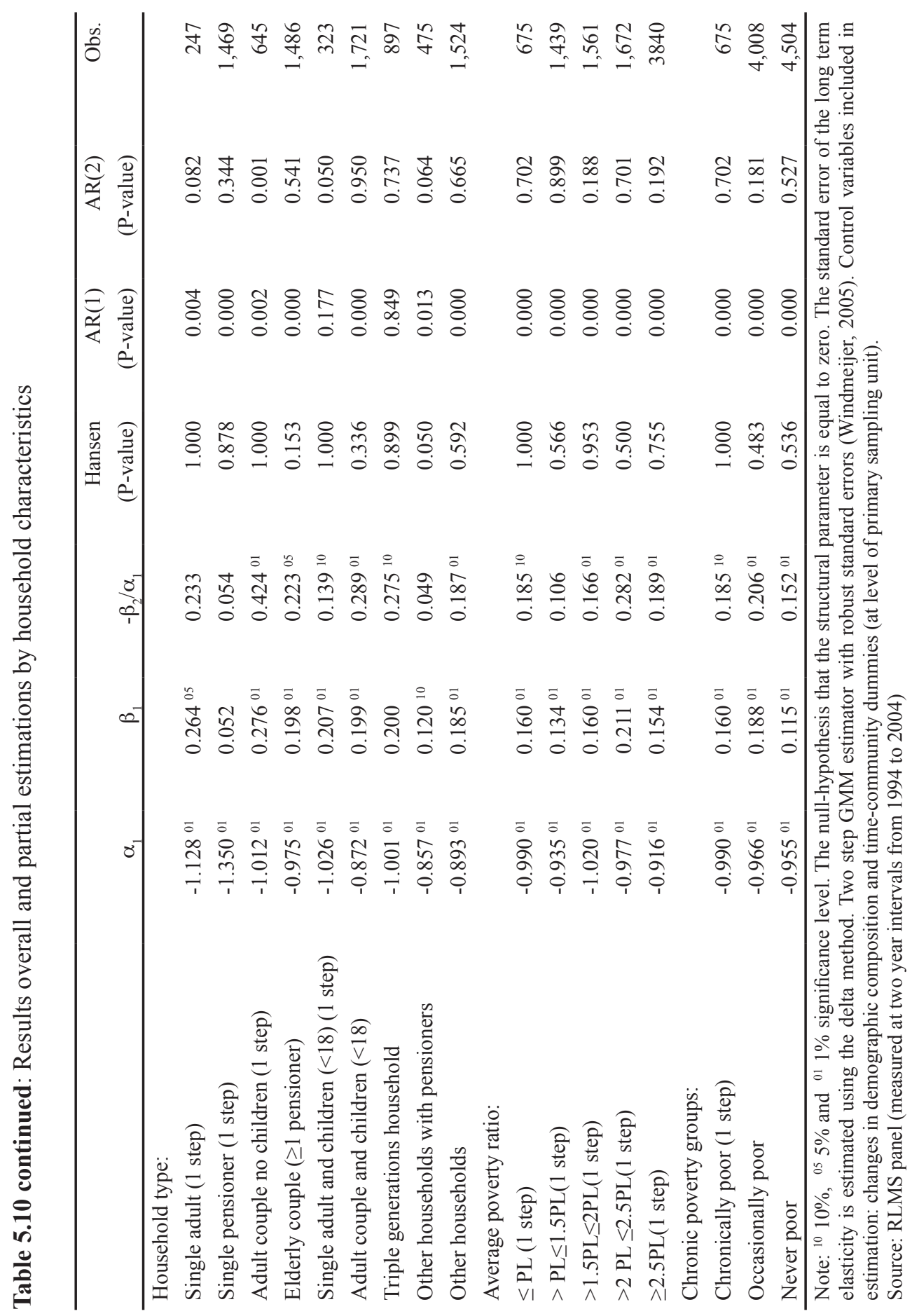



Managing risks: what do Russian households do to smooth consumption? 


\subsection{Introduction ${ }^{1}$}

Households face the risk that they may not be able to fulfil the basic needs of their members, today as well as tomorrow. To prevent this risk from materializing, households set aside part of their current resources to finance future consumption in the form of savings or insurance. Additionally, when it becomes clear that income will not suffice, households can seek alternative funding. When these measures are effective, households are able to maintain a particular welfare level, even when expected income falls short. The ability of households to smooth consumption over time thus reflects a key dimension of well-being. Although the underlying smoothing mechanisms are similar, the ways in which households smooth consumption are highly context dependent, i.e. on the particular institutional, social and economic context they live in.

Households in transition economies face a wide range of risks and shocks similar to those experienced by households all over the world. ${ }^{2}$ At the same time, the drastic structural changes taking place in transition economies form an additional source of risk; the transition from a centrally planned to a market economy has been accompanied by macro-economic instability such as high inflation, declining real wages, unemployment and financial crises, thereby shaping a highly uncertain environment for households in transition economies. In spite of this, Russian households are able to partially smooth consumption when they are hit by such shocks (Notten \& Crombrugghe de, 2006; Skoufias, 2003). ${ }^{3}$ But how do these households smooth consumption? Strategies that were successful during Soviet times may or may not work anymore while the changing structures in the economy may provide new, perhaps market-based, smoothing opportunities. In this paper, we want to explore how Russian households smooth consumption.

To guide our analysis we propose a conceptual framework to analyse households' consumption smoothing strategies. Central in this framework is a classification of consumption smoothing strategies which is based on what actions households may take to smooth consumption. Then, we relate these smoothing strategies to possible institutional smoothing partners and the assets that may be required to follow a particular smoothing strategy. We apply this framework to Russia and empirically explore the rich survey data to find out what Russian household do at a given point in time and

\footnotetext{
${ }^{1}$ This chapter is based on: Notten, G. (2007). Managing risks: what Russian households do to smooth consumption. MGSoG Working Paper, 2007/004, Maastricht Graduate School of Governance, Maastricht University, Maastricht.

${ }^{2}$ These are for instance shocks such as natural disasters, crime, illness, disability or death of a household member and job loss.

${ }^{3}$ The paper of Notten and de Crombrugghe (2007) is included as chapter 5 in this dissertation.
} 
how these actions may contribute to consumption smoothing. We focus on the 2003 survey to analyse a broad range of indicators on smoothing actions. We also investigate whether the observed patterns differ according to levels of wealth and across rural or urban areas.

By focusing on the household as the central institution to manage risks, our conceptual framework offers an alternative way to analyse and interpret existing survey data without a priori restricting the scope of the analysis to a particular smoothing mechanism or smoothing channel. The results can be used to formulate hypotheses on household smoothing behaviour and to delineate the features of an analysis beyond the exploration offered in this paper; it provides information about which smoothing channels are worth further investigation and which linkages have to be taken into account in a country/community. Moreover, the conceptual framework guides thinking about the role, scope and type of government interventions and possible feedback effects to other smoothing channels.

This paper is structured as follows; in section 6.2 we set out our conceptual framework and in section 6.3 we explain the selection and characteristics of the household sample from the Russia Longitudinal Monitoring Survey (RLMS) and point out in what way the range of selected smoothing indicators are linked to the conceptual framework. Section 6.4 analyses the smoothing indicators; it sketches a picture of how Russian households smooth consumption, using which smoothing channels. Section 6.5 concludes with a summary of the main findings and hypotheses and discusses the relevance of followed research approach.

\subsection{Conceptual framework}

Being able to smooth consumption reflects an important dimension of well-being as it reflects people's capacity to satisfy their basic needs tomorrow as well as today, despite the existence of risks and the occurrence of shocks. Studies analyzing the relation between income and consumption show that, over time, household consumption is considerably smoother than income; a reduction (or increase) in household income is not accompanied by a similarly large decline (or increase) in consumption. Although there is considerable evidence that consumption smoothing takes place in both developed and developing countries, the economic literature also shows that the actual smoothing mechanisms employed can be very context specific, especially 
in developing economies. ${ }^{4}$ Mechanisms that work for one group, country or region may not work for others or are not accessible. Moreover, households may use various smoothing mechanisms that complement each other. It is important to better understand how households smooth consumption, not only for academic purposes but also for governments that wish to improve the capacities of their citizens to manage risks.

In this section we develop a conceptual framework which guides the exploration of potential smoothing mechanisms but that does not restrict the particular forms they may take in various environments. Central to the framework is a typology of consumption smoothing strategies, with each strategy depicting a different smoothing mechanism. Subsequently, we define a range of institutional counterparts and assets that can be used to follow a particular smoothing strategy. The combination of a smoothing strategy, institutional counterpart and required assets reflects a specific smoothing channel. We take the perspective of the household as point of departure as the household reflects the first risk sharing level for individuals in many societies, including our case-study Russia.

The analysis assumes a one generation - one period world. In this world, wealth is not accumulated across generations; any existing wealth has been accumulated by the household itself. Each household has to be self-sufficient, exchange its home production for goods (or money) or sell its labour on a labour market (or a combination of all of this). In this world, households face the risk of not being able to cover their basic needs. In order to reduce the impact of this risk, households may follow a combination of different consumption smoothing strategies (Table 6.1). We distinguish six strategies or actions that can be grouped under two broader categories; ex ante strategies and ex post strategies. Each strategy reflects a distinct smoothing mechanism. The ex ante or mitigating strategies create alternative funding sources in case future income falls short of what is expected. These strategies imply that part of current income is reserved for future contingencies. We distinguish between financial and physical capital accumulation because physical capital may additionally contribute to current consumption (if durable) and can also function as collateral for using other smoothing mechanisms (i.e. getting a loan). Insurance, on the other hand, only provides funding when a particular contingency materializes. The ex post or coping strategies are employed to create

\footnotetext{
${ }^{4}$ The economic literature typically analyses consumption smoothing behaviour following two approaches; the first approach models household behaviour using a permanent income model or risk-sharing model and focuses on the overall smoothness of consumption vis-à-vis income flows (see (Deaton, 1992) for an overview). The second approach models and tests particular consumption smoothing mechanisms for specific groups of households or regions (Alessi \& Lusardi, 1997; Dercon, 1998; Dubois et al, December 2006; Hoogeveen, 2001; Kochar, 2004; Ligon, 1998; Rosenzweig, 1988; Rosenzweig \& Wolpin, 1993; Udry, 1994, 1995).
} 
Table 6.1: Typology of consumption smoothing strategies

\begin{tabular}{|c|c|}
\hline Strategies & Consumption smoothing mechanism \\
\hline \multicolumn{2}{|c|}{$\begin{array}{l}\text { Ex ante - create alternative funding sources in case future income falls short } \\
\text { (mitigating strategies): }\end{array}$} \\
\hline $\begin{array}{l}\text { Accumulation of financial } \\
\text { capital }\end{array}$ & Financial savings finance future consumption. \\
\hline $\begin{array}{l}\text { Accumulation of physical } \\
\text { capital }\end{array}$ & $\begin{array}{l}\text { Physical assets can be sold to finance consumption, they can } \\
\text { be used as physical collateral for a loan or credit but they also } \\
\text { contribute to current consumption. }\end{array}$ \\
\hline Seek insurance & $\begin{array}{l}\text { Insurance mitigates the impact of shocks by providing resources to } \\
\text { finance consumption when a specific contingency occurs. }\end{array}$ \\
\hline \multicolumn{2}{|c|}{$\begin{array}{l}\text { Ex post - create alternative funding sources when current income is insufficient } \\
\text { (coping strategies): }\end{array}$} \\
\hline $\begin{array}{l}\text { Adjust income generating } \\
\text { activities }\end{array}$ & Generate additional income to finance consumption \\
\hline Seek loans or credit & Loans or credits finance consumption. \\
\hline Seek transfers & Transfers finance consumption. \\
\hline
\end{tabular}

alternative funding sources after it becomes clear that current income is not sufficient to satisfy basic needs. We distinguish three different mechanisms: generate additional income (i.e. increase labour supply, home production or the selling of home produced goods), seek credit/loans and seek transfers.

To follow a particular consumption smoothing strategy, households may use different institutions. Take for instance the borrowing strategy; households can borrow funds from financials institutions, informal money lenders, family and friends or by buying products on credit. A particularly useful concept for thinking about consumption smoothing strategies and the possible smoothing partners of households is the Welfare Pentagon (Neubourg de, 2002). The Welfare Pentagon represents the five core institutions that households may use to satisfy current and future needs in a given society: family, markets, social networks, membership institutions and public authorities (Figure 6.1). ${ }^{5}$ Even though historical and geographical appearances differ,

\footnotetext{
${ }^{5}$ The Welfare Pentagon is a central and distinctive element in the 'Social Risk Management' approach as developed by Chris de Neubourg (Neubourg de, 2002; Neubourg de \& Weigand, 2000). The Social Risk Management framework is formulated to analyse the role and scope of public interventions and foremost, but not exclusively, that of public social protection policies. Although there are some differences, the Social Protection Unit of the World Bank uses a similar framework (Holzman \& Jorgensen, February 2000). The innovative aspect of both approaches is that it provides both a rationale for, as well as a tool to think about ex post and ex ante public measures to deal with risks in society.
} 
Figure 6.1: Welfare Pentagon

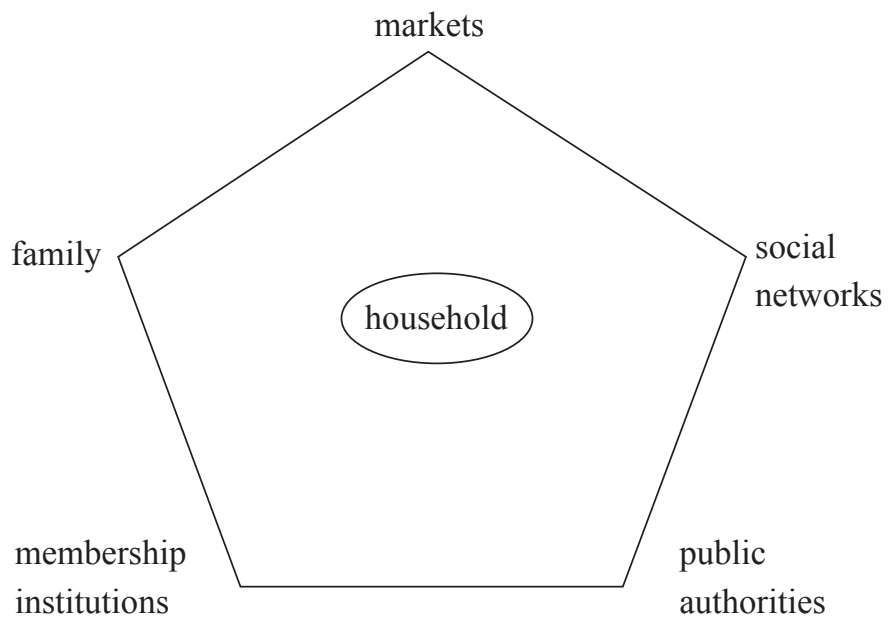

Source: (Neubourg de, 2002)

these institutions are found in all societies across time and locations. The relevance of each institution and the exchange relations between households and these institutions may differ by society.

Households use these institutions to generate income but also to smooth consumption: labour markets, product markets and capital markets allow households to trade and exchange in order to secure resources to satisfy the main needs at a certain moment. In the labour market households exchange effort for a (future) wage; in product markets households trade effort for a (future) profit; on the capital market households trade income against future income by investments, savings, insurances, borrowings and the like. Families, social networks and membership institutions address the risk of not being able to satisfy basic needs by means of various and different mechanisms of solidarity. Membership institutions are institutions of which individuals can become a member and from which they can resign. Examples of such institutions are unions, mutual insurance companies, co-operatives, neighbourhood associations or saving and credit societies. Public authorities can assist households directly by means of public social protection (pension schemes, child benefits, unemployment insurance) but also indirectly by enforcing contracts through a judicial system, introducing legislation aimed at correcting market failures (such as minimum reserve requirements 
for banks). However, the household can also internalize income generating activities and consumption smoothing by self-sufficient home production, accumulating physical assets or holding cash savings.

In addition to time or effort, following a specific consumption smoothing strategy typically also requires some kind of asset. Assets can be financial (cash, money in a bank account, stocks and shares), physical (land, house, machines, jewellery), human (education, skills), social (family ties, acquaintances) or collective (citizenship, contribution record). Combining the classification of consumption smoothing strategies in Table 6.1 with the institutions in the Welfare pentagon and the notion that each consumption-smoothing channel requires some kind of input or investment, we obtain the possible consumption smoothing channels as shown in Table 6.2. For instance, households can buy private insurance against certain risks using part of their financial assets to pay the insurance premium. Alternatively, households can be insured for certain risks by public authorities through paying taxes or social insurance contributions or simply because they are a citizen. They may also rely on social networks or family to compensate them after a shock occurs. Depending on the characteristics of these arrangements a social input is required (promise of reciprocity, 'good' reputation or family relation). Alternatively, households can also adjust their income generating activities i.e. supply more labour, sell more home produced goods and increase home production.

We further assume that households differ in their capacities to produce wealth, in their exposure to risks which endanger the production of wealth and in their degree of risk aversion. Together with the initial wealth distribution, these factors result in households adopting different income generating and consumption smoothing strategies. The differences in the economic activities of households result in an income distribution and a corresponding consumption distribution. In that distribution, some households are poor in the sense that they do not have enough resources to satisfy their basic needs (according to a pre-set poverty definition). More importantly, the position of households within the income distribution will affect their consumption smoothing behaviour. This will alter their position in the income distribution, or alternatively, reinforce it.

Depending on the community or country, some smoothing channels may be more prevalent than others. It is also possible that several institutions are active in providing assistance with the same type of consumption smoothing. This may be because a part of the population does not have access to a particular consumption smoothing channel because it lacks the required assets to establish an exchange relationship with an institutional counterpart. For instance, for poor entrepreneurs it is often difficult to get credit from formal financial markets because they do not have physical assets that 
Table 6.2: Consumption smoothing channels

\begin{tabular}{|c|c|c|}
\hline Strategies/Actions & Institutional counterpart & Assets needed by household \\
\hline \multicolumn{3}{|c|}{$\begin{array}{l}\text { Ex ante - create alternative source of funding in case future income falls short } \\
\text { (mitigating strategies): }\end{array}$} \\
\hline \multirow{3}{*}{$\begin{array}{l}\text { Accumulation of financial } \\
\text { capital }\end{array}$} & Market (financial) & Financial assets (liquid assets) \\
\hline & Household & \\
\hline & Membership institution & \\
\hline \multirow{2}{*}{$\begin{array}{l}\text { Accumulation of physical } \\
\text { capital }\end{array}$} & Market (financial) & Financial assets (liquid assets) \\
\hline & Household & \\
\hline \multirow[t]{2}{*}{ Seek insurance } & $\begin{array}{l}\text { Market (financial) } \\
\text { Social networks / Family } \\
\text { Public authorities } \\
\text { (social protection policies) }\end{array}$ & $\begin{array}{l}\text { Financial assets (insurance policy), } \\
\text { social assets (reputation, relations), } \\
\text { collective assets (citizenship, } \\
\text { contribution history / rights) or } \\
\text { membership (i.e. trade union) }\end{array}$ \\
\hline & Membership institution & \\
\hline \multicolumn{3}{|c|}{$\begin{array}{l}\text { Ex post - create alternative funding sources when current income is insufficient } \\
\text { (coping strategies): }\end{array}$} \\
\hline \multirow[t]{2}{*}{$\begin{array}{l}\text { Adjust income generating } \\
\text { activities }\end{array}$} & Market (goods - labour) & $\begin{array}{l}\text { Labour, productive assets, } \\
\text { financial assets (working capital) }\end{array}$ \\
\hline & Household & \\
\hline \multirow[t]{4}{*}{ Seek loans or credit } & Market (financial) & $\begin{array}{l}\text { Physical assets (collateral), social } \\
\text { assets (reputation, relations) }\end{array}$ \\
\hline & Social networks / Family & \\
\hline & Market (goods) & \\
\hline & Membership institution & \\
\hline Seek transfers & $\begin{array}{l}\text { Social networks / Family } \\
\text { Public authorities } \\
\text { (social protection policies) }\end{array}$ & $\begin{array}{l}\text { Social assets (reputation, relations), } \\
\text { collective assets (citizenship, } \\
\text { rights) }\end{array}$ \\
\hline
\end{tabular}

can serve as collateral for the credit. Instead, such persons may obtain a loan through their social network where reputation, kinship or social pressure may function as some kind of 'social' collateral. This framework helps to analyse consumption smoothing behaviour because it provides a general framework of thought which encompasses 
most, if not all, potential consumption smoothing strategies of households in a society. In the next sections, we use this framework to formulate and classify a wide range of indicators of consumption smoothing channels in Russia. There are, however, a number of aspects that the conceptual framework does not directly address. By taking the household level as the unit of analysis, we abstract from household formation as the ultimate consumption smoothing strategy of individuals. ${ }^{6}$ Furthermore, focusing on a one period analysis also implies that we do not analyse the role of human capital investment.

Secondly, the framework categorizes a range of actions as potential consumption smoothing strategies but it does not indicate which strategy would be preferable on what grounds. One concern in the development literature is that some households smooth consumption using inefficient and ineffective channels and are thereby unable to improve their lives (Dercon, 1998; Eswaran \& Kotwal, 1989; Rosenzweig, 1988; Rosenzweig \& Wolpin, 1993; Zimmerman \& Carter, 2003). Due to a combination of risk aversion and few resources, households do not follow strategies that increase the probability that their consumption will fall below a certain minimum level. This 'disaster management' is characterized by different asset accumulation strategies for low and high wealth households, where the latter group is more successful in improving their welfare in the long term. Lack of access or failure of certain consumption smoothing channels, are additional reasons for the existence of a poverty trap. Whether a particular smoothing channel is welfare improving or not, is highly context dependent. In Western Tanzania high wealth farmers accumulate cattle while low wealth farmers engage in low risk-return non-agricultural activities (Dercon, 1998) while in Georgia activities not involved with farming are seen as a way out of poverty (Kobaladze, November 2002). Alternatively, in Burkina Faso low wealth individuals invest relatively more in buffer assets (i.e. grain) than in productive assets (land)(Zimmerman \& Carter, 2003). While the farmers in Tanzania and Burkina Faso can choose to follow either strategy, the rural inhabitants of Georgia indicate that there is no opportunity to engage in nonfarm activities. Given this context specificity, we do not attempt to specify a priori a preference ranking of smoothing strategies or channels. ${ }^{7}$

Finally, certain smoothing channels may be more suited to help manage particular types of shocks or risks than other channels. Some consumption smoothing channels are relatively successful to deal with shocks arising from idiosyncratic risks, but fail

\footnotetext{
${ }^{6}$ The occurrence of shocks, a rise in uncertainty or the availability of consumption smoothing channels may affect households' living arrangements or fertility decisions.

${ }^{7}$ In the empirical analysis we also decompose the indicators according to permanent consumption quintiles and test whether there are significant differences in the use of particular channels between these quintiles.
} 
when there is an aggregate or covariant shock such as an economic crisis or a natural disaster (Hoogeveen, 2001; McKenzie, 2003; Skoufias, 2003; Udry, 1994). Moreover, if a household perceives that it is vulnerable to a particular kind of risk, it will adjust its consumption smoothing strategies accordingly. For instance, Indian households with a higher risk of illness or bad health choose to accumulate more liquid and fewer productive assets (Kochar, 2004) and wage arrears induce Russian households who are more vulnerable to that risk to save more (Guariglia \& Kim, 2003). A possible extension of the framework could encompass the inclusion of various types of risks.

\subsection{Data and methodology}

Previous research has shown that Russian households have been capable of partially smoothing their consumption despite suffering from many income shocks during the transition period (Notten \& Crombrugghe de, 2006; Skoufias, 2003). The objective of our empirical analysis is to get an impression of how Russian households currently smooth consumption after more than a decade of structural change. We use the conceptual framework developed in the previous section to select indicators of possible smoothing channels from rich survey data. Subsequently, we explore the prevalence and differential use of consumption smoothing channels by Russian households at $a$ given point in time (2003). ${ }^{8}$ We restrict our focus to a single year because we want to study indicators for a wide range of smoothing channels. The resulting analysis is interesting because the conceptual framework guides the use of typical household survey data to create a broad and novel household perspective on the use of consumption smoothing channels. This broad perspective is important because a household most likely uses a range of smoothing channels at the same time and the use of smoothing channels can differ with household characteristics. The results can be used to formulate hypotheses about consumption smoothing behaviour and to indicate areas (or institutions) in which government intervention is needed to enhance households' risk management. However, more rigorous analysis is needed to prove whether the identified channels do actually have a smoothing function, to what extent and how they help households to smooth consumption, and how government intervention can enhance the functioning of a given channel. $^{9}$

\footnotetext{
${ }^{8}$ After the 1998 financial and economic crisis Russia experienced a period of sustained economic recovery combined with ongoing structural reforms. The smoothing behaviour of households in times of large aggregate shocks (and the outcome in terms of consumption smoothness) can be very different from behaviour in more stable periods (Hoogeveen, 2001; McKenzie, 2003; Skoufias, 2003; Udry, 1994).

${ }^{9}$ Such analysis is beyond the scope of this paper.
} 
We use the Russian Longitudinal Monitoring Survey (RLMS) to analyse the prevalence of consumption smoothing channels used by Russian households. ${ }^{10}$ The sample includes all households that have been observed annually in the RLMS from 2000 to 2003; this balanced panel consists of about 2,700 households. We selected a panel because we also want to study differences in the use of smoothing channels for different levels of wealth. ${ }^{11}{ }^{12}$ As explained before, depending on the level of wealth, households may follow different smoothing strategies using different channels. To approximate the wealth of a household we average annual equivalent household expenditures over the period 2000 to 2003 and divide the resulting distribution in quintiles. Equivalent expenditures are obtained by dividing household's expenditures by its household specific poverty line. ${ }^{13}$ The resulting values thus reflect the average distance of a household's living standard relative to its absolute poverty line; a value below one indicates that a household, on average, lived in poverty during the period 2000-2003 and vice versa for an average above 1 .

Table 6.3 lists some characteristics of this distribution. Clearly, the distribution is very dense at low expenditure levels; only the fifth quintile has considerably higher expenditures (on average more than six times the value of the poverty line). Quite a number of households were living in the vicinity of the absolute poverty line from 2000-2003; average expenditures in the lowest quintile are about 1 and that of the second quintile is 1.7. ${ }^{14}$ The group of households in the lowest quintile can be considered as chronically poor according to a common definition of chronic poverty (having average expenditures below the poverty line over a given period). But if a

\footnotetext{
${ }^{10}$ Detailed information on the RLMS project is provided on the following website: http://www.cpc.unc. edu/projects/rlms/home.html.

${ }^{11}$ The RLMS does not have post-stratification weights for its panel dimension. In Gassmann and Notten (2006) we compare the characteristics of the cross-sections with the five year balanced panel (2000-2004) and find a number of differences. Urban households (especially from Moscow and St Petersburg), are underrepresented in the panel. Households with children are somewhat overrepresented while there are fewer single person households in the panel sample. Average income and expenditures are somewhat lower in the panel. Despite the level effects (i.e. poverty rates are somewhat higher in the panel) we find that both samples reflect the same trends (time) and similar differences between subgroups of the population (ruralurban and by expenditures). This is in line with the findings of an earlier attrition study of the RLMS by Heeringa (1997).

${ }^{12}$ Differences in means between urban-rural and average expenditure quintiles are statistically tested using a Wald test in which we control for clusters in the sampling design of the RLMS.

${ }^{13}$ We use the absolute poverty lines provided in the RLMS data. These household specific poverty lines are adjusted for the size and composition of the household and valued at regional price levels. We further use the expenditure and income variables as constructed by the RLMS which include the value of home produced (and consumed) goods (http://www.cpc.unc.edu/projects/rlms/home.html).

${ }^{14}$ Especially in countries with high (expenditure) inequality such as Russia, poverty statistics are very sensitive to the level of the poverty line. The RLMS poverty line is on average about $2 / 3$ of the value of the (official) Minimum Subsistence Level of the Russian Federation (Notten \& Gassmann, 2006).
} 
Table 6.3: Average equivalent expenditure distribution (2000-2003)

\begin{tabular}{ll}
\hline Characteristics & $\begin{array}{l}\text { Equivalent expenditures } \\
\text { (relative to poverty line) }\end{array}$ \\
\hline Average & 2.93 \\
Median & 2.35 \\
Ratio at 5\% of distribution & 0.83 \\
Ratio at 95\% of distribution & 6.80 \\
Standard deviation & 2.44 \\
Average by quintile: & \\
1 & 1.01 \\
2 & 1.71 \\
3 & 2.37 \\
4 & 3.25 \\
5 & 6.32 \\
\hline
\end{tabular}

Note: We obtained the distribution as follows: first, we divided households' annual expenditures by its household specific poverty line to adjust for demographic differences between households and differences between regional price levels. Subsequently, we averaged households' equivalent annual expenditures over the period 2000-2003. Finally, we divided the resulting household distribution in five equally sized quantiles.

Source: Own calculations RLMS

somewhat less stringent subsistence level is taken, that label could even be applied to many households in the second quintile. Table 6.4 further summarizes characteristics of the households for the whole sample, by rural ${ }^{15}$ and urban settlement area and by average expenditure quintiles. A large part of Russian households live in urban areas $(62 \%)$ and those households are more likely to be found in the higher regions of the average expenditure distribution.

Even though the multi-purpose RLMS survey contains a wealth of information, it is not designed or structured specifically to analyse consumption smoothing behaviour and thus only allows us to analyse a limited part of the puzzle. On the other hand, it also allows us to identify which pieces of the puzzle are missing. Using the conceptual framework as a guide, we selected a range of smoothing indicators from the 2003 RLMS questionnaires (Table 6.5). Some of the selected variables function as indicators for a particular consumption smoothing strategy, but do not provide sufficient information about the institutional counterpart or the required assets. For instance, as indicators for the 'seek loans or credit' strategy we use a set of variables indicating whether a

\footnotetext{
${ }^{15}$ We included households living in semi-urban settlement areas in the rural group because this group is too small too analyse separately and appears to be more similar to rural households.
} 
Table 6.4: Characteristics of household panel (2000-2003 panel, in 2003)

\begin{tabular}{|c|c|c|c|c|c|c|c|c|}
\hline & \multirow[b]{2}{*}{ Total } & \multirow[b]{2}{*}{ Urban } & \multirow[b]{2}{*}{ Rural } & \multicolumn{5}{|c|}{ Average expenditure quintiles } \\
\hline & & & & 1 & 2 & 3 & 4 & 5 \\
\hline \# of observations & 2,718 & 1,690 & 1,028 & 544 & 544 & 543 & 544 & 544 \\
\hline Share population $(\%)$ & 100 & 62.3 & 37.8 & 20.0 & 20.0 & 20.0 & 20.0 & 20.0 \\
\hline Urban area $(\%)$ & 62.3 & 100 & 0 & 51.1 & 57.4 & 64.8 & 69.7 & 67.8 \\
\hline \multicolumn{9}{|l|}{ Household size (\%): } \\
\hline 1 & 19.9 & 21.3 & 17.5 & 15.6 & 18.0 & 16.9 & 23.4 & 25.4 \\
\hline 2 & 28.7 & 30.2 & 26.2 & 24.8 & 22.1 & 30.9 & 32.0 & 33.7 \\
\hline 3 & 24.3 & 26.0 & 21.5 & 26.8 & 26.1 & 24.5 & 21.7 & 22.5 \\
\hline 4 & 16.7 & 15.8 & 18.2 & 16.5 & 22.1 & 17.3 & 14.9 & 12.7 \\
\hline$>4$ & 10.4 & 6.4 & 16.6 & 16.2 & 11.7 & 10.3 & 8.1 & 5.7 \\
\hline \multicolumn{9}{|l|}{ Household type (\%): } \\
\hline Single adult & 3.6 & 4.1 & 2.8 & 5.0 & 2.9 & 2.0 & 3.5 & 4.8 \\
\hline Single elderly & 16.2 & 17.1 & 14.7 & 10.7 & 14.9 & 14.9 & 19.9 & 20.6 \\
\hline Adult couple & 7.8 & 8.2 & 7.0 & 8.5 & 5.0 & 9.6 & 6.4 & 9.4 \\
\hline Elderly couple & 9.9 & 10.0 & 9.8 & 4.4 & 7.2 & 9.0 & 14.2 & 14.9 \\
\hline Single caretaker & 4.6 & 5.4 & 3.4 & 6.6 & 4.0 & 5.3 & 3.5 & 3.7 \\
\hline Adults with children & 21.1 & 22.0 & 19.7 & 20.8 & 24.1 & 19.7 & 20.0 & 20.8 \\
\hline Extended family & 9.0 & 7.3 & 11.9 & 10.7 & 12.1 & 9.0 & 7.2 & 6.1 \\
\hline Elderly and adults only & 11.7 & 10.9 & 13.0 & 12.9 & 12.0 & 12.9 & 12.5 & 8.3 \\
\hline Other households & 16.0 & 15.0 & 17.7 & 20.6 & 17.8 & 17.5 & 12.9 & 11.4 \\
\hline Average income ${ }^{1}$ & 7,465 & 7,868 & 6,801 & 4,406 & 5,920 & 7,425 & 7,900 & 11,682 \\
\hline Average expenditures ${ }^{1}$ & 8,711 & 9,098 & 8,074 & 3,390 & 5,383 & 7,188 & 8,981 & 18,626 \\
\hline
\end{tabular}

Note: ${ }^{1}$ Expressed in June 1992 ruble and household averages

Source: Own calculations RLMS

household has debt and whether it made loan repayments but we do not know which institution provided the loan. Similarly, we know about a range of physical assets owned by a household but we do not know whether any of these were used as collateral for obtaining the loan. However, for many indicators we can identify the institutions that households exchange with or we argue which institution is the most likely to be involved. When a household mentions it provided a loan or reported having received repayments from loans, we know that this household is involved in the provision of loans, most likely to other households. Or alternatively, if a household reported having saved money with interest it is likely to have saved using a financial market institution. Finally, the RLMS contains quite a lot of information on the giving and receiving of 
Table 6.5: Indicators of consumption smoothing channels in the RLMS

\begin{tabular}{ll}
\hline Institution & Indicator \\
\hline Strategy: accumulation of financial capital & \\
& - Has accumulated savings last month \\
Financial market & - Has savings on interest bearing account \\
& - Has bought (or derived income from) stocks and/or bonds (last \\
& month)
\end{tabular}

Strategy: accumulation of physical capital

Household

- Asset ownership: owns house, land, durables

- Income from (sale of) assets: rents, sold property, sold jewellery,

currency or depleting savings (last month)

Strategy: seek insurance

Financial market $\quad$ - Income from insurance payments (last month)

- Expenditures on premiums (last month)

Public authorities (social - Incidence of social security type and income share of benefits such

security) as pensions and unemployment benefits

- Pension rights (private and/or federal fund)

Social networks / family ${ }^{1}$ - Gift giving/receiving (yes/no, amounts, income share and to/from who(m)) (last month)

Strategy: adjust income generating activities

Labour market / goods - Has a $2^{\text {nd }}$ or $3^{\text {rd }}$ job

market - Has an informal job

Strategy: seek loans or credit

- Has debt (yes/no, expenditure share)

- Made loan repayments (last month)

Social networks / family - Loans provided by households (last month)

- Net lending (last month)

Labour market - Access to loans from employer (yes/no)

Goods market - Has unpaid utility bills (yes/no, real value)

Strategy: seek transfers

Public authorities (social - Incidence of social assistance type and income share of benefits such assistance) as child benefits and housing benefits

Social networks / family ${ }^{1}$ - Gift giving/receiving (yes/no, amounts, income share and to/from who(m)) (last month)

Overall ability of consumption smoothing

Household - Self-reported survival time in case a household loses all income generating sources

Note: All indicators are analysed at a household level. Those indicators originating from individual questionnaires have been summarized at the household level. For instance, if an adult mentioned he/she had a second job, a household level variable was created indicating that at least one household member had a second job. ${ }^{1}$ Gift giving and receiving can be seen as an insurance or transfer seeking strategy. 
Table 6.6: Indicators of income generating activities in the RLMS

\begin{tabular}{ll}
\hline Institution & Indicator \\
\hline Household production & - Required asset: ownership land / other land use arrangements \\
& - Land use / growing crops / having livestock / gathered nut/mushrooms, \\
& fished etc (last year) \\
& - Monetary value of home production (total, by activity, \\
& amount consumed) (monthly value) \\
& - Employment (last month), having wage income and share of \\
& wage income (last month) \\
& - Having wage earnings (yes/no, share of total income) \\
& - Problems: unemployment, payment arrears, non-cash wage, concern \\
& for loss of job and certainty of finding a new one \\
& - Having an 'entrepreneurial job' \\
& - Ever started a business (yes/no, success/failure) \\
& - Monetary value of home production sold (total, by activity, \\
(monthly value)
\end{tabular}

Note: All indicators are analysed at a household level. Those indicators originating from individual questionnaires have been summarized at the household level. For instance, if an adult mentioned he/she had a second job, a household level variable was created indicating that at least one household member had a second job.

gifts but the information is insufficient to classify particular gifts either as insurance or transfer seeking strategies. As can be seen in Table 6.5, there are indicators for every smoothing strategy and in many cases part of the consumption smoothing channel can also be identified. We also included an indicator for the consumption smoothing ability of households indicating the self-estimated survival period of the household in case it would lose all sources of income.

In our conceptual framework we distinguish between income generating activities and consumption smoothing activities but we also include the adjustment of income generating activities as one of the ex post coping strategies. The 2003 RLMS questionnaires did not include any specific shock response questions, which makes it difficult to distinguish between normal income generating activities and post shock adjustments in those activities. Given this difficulty, we also included a range of indicators on income generating activities (Table 6.6) in addition to the shock adjustment indicators (Table 6.5). As indicators for post-shock adjustments we constructed a variable indicating whether at least one household member has a second or third job and similarly for having an informal job. These variables can be interpreted as second-best responses to unemployment, underemployment and other problems with income generating activities (wage arrears, forced leave, non-cash wage 
payments, unsuccessful home production etc.). As these activities also include informal entrepreneurial activities (providing services, selling home produced foodstuffs) the institutional counterparts can be labour and goods markets. Table 6.6 displays a range of income generating activities distinguishing between home production, labour supply and entrepreneurial activities. We further discuss the interpretation and limitations of the indicators in the next section.

\subsection{Consumption smoothing in Russia: what do Russian households do?}

What do households in Russia do to ensure that they have sufficient resources to finance their (basic) needs today as well as tomorrow? The conceptual framework developed in this paper identifies a wide range of possible strategies, institutional counterparts and required assets and we have selected a considerable group of indicators for some of these possibilities. We now analyse and interpret the descriptive results and simple significance tests in order to gain an idea of which consumption smoothing channels Russian households may use or not. We also briefly analyse indicators of household's income smoothing activities because we the adjustment of income generating activities is also included as a consumption smoothing strategy. This resulting picture is not complete (by any means) and alternative interpretations that are also consistent with the observed results can certainly be formulated. Despite these limitations, this exercise is valuable because it gives an indication of the prevalence of certain consumption smoothing channels as well as the differential use of these channels by various groups of households (we distinguish between wealth quintiles and rural/urban settlement area). In the context of Russia's ongoing structural reforms, it is of particular interest to explore the extent to which households use markets to smooth consumption. Thus, the aim of this paper is not to prove the existence, functioning and motivations for these consumption smoothing channels but to formulate interesting and relevant hypotheses on how households may smooth consumption in Russia. Testing these hypotheses requires more theoretical and empirical work and we discuss some of these options for further research.

This section first discusses households' perceptions on their smoothing abilities, followed by the analysis of the indicators for ex ante and ex post consumption smoothing strategies, and is concluded by viewing some indicators on income generating activities. 
Table 6.7: Self-perceived ability of consumption smoothing

\begin{tabular}{|c|c|c|c|c|c|c|c|c|c|c|c|}
\hline \multirow[t]{2}{*}{$\%$ of households } & \multirow[t]{2}{*}{ Obs. $^{2}$} & \multirow[t]{2}{*}{ All } & \multirow[t]{2}{*}{ Urban } & \multirow[t]{2}{*}{ Rural } & \multirow[t]{2}{*}{ Test $^{1}$} & \multicolumn{5}{|c|}{ Average expenditure quintiles } & \multirow[t]{2}{*}{ Test } \\
\hline & & & & & & 1 & 2 & 3 & 4 & 5 & \\
\hline \multicolumn{12}{|c|}{ How long can the household survive if all income is lost? } \\
\hline $\begin{array}{l}\text { More than } 6 \\
\text { months }\end{array}$ & & 4.2 & 2.6 & 6.9 & & 2.0 & 2.7 & 2.5 & 4.4 & 9.4 & \\
\hline A few months & & 13.2 & 11.7 & 15.7 & & 8.5 & 10.4 & 14.9 & 15.3 & 16.9 & \\
\hline $\begin{array}{l}\text { Less than a } \\
\text { month }\end{array}$ & & 27.2 & 25.6 & 29.9 & & 21.3 & 30.5 & 28.4 & 27.1 & 28.4 & \\
\hline $\begin{array}{l}\text { Less than } 2 \\
\text { weeks }\end{array}$ & 2,581 & 12.8 & 13.7 & 11.3 & .05 & 11.9 & 11.3 & 15.4 & 13.0 & 12.5 & .01 \\
\hline $\begin{array}{l}\text { Less than } 1 \\
\text { week }\end{array}$ & & 26.5 & 28.8 & 22.5 & & 31.4 & 29.9 & 24.9 & 24.4 & 21.9 & \\
\hline Not even 1 day & & 16.1 & 17.6 & 13.6 & & 24.9 & 15.2 & 13.9 & 15.8 & 10.9 & \\
\hline
\end{tabular}

Note: ${ }^{1}$ Wald test on difference means urban-rural and average expenditure quintiles (controlling for clustering effects): not significant (ns), significant at $10 \%(.1)$, significant at $5 \%(.05)$ and significant at $1 \%(.01) .{ }^{2}$ The full sample consists of 2,718 households. The number of observations in this column can be different due to missing information in the questionnaire and / or because the information is only applicable to a sub-sample of the households.

Source: Own calculations RLMS

\subsubsection{Perceived ability of consumption smoothing}

We start with an impression of households' self-estimated consumption smoothing abilities (Table 6.7). The respondent of the household questionnaire was asked to estimate the period that the household could survive without income; $83 \%$ of the Russian households expect they could survive less than a month if they would lose all income sources. The results of the Wald test suggest that households in rural areas and households in higher average expenditure quintiles estimate having longer periods of survival without income. We will discuss below how these two groups of households are likely to use different smoothing mechanisms and channels. The case that was suggested to the respondents is extreme but it nevertheless shows that, unless alternative income sources are found, the time horizon of consumption smoothing opportunities for Russian households is limited to months rather than years. ${ }^{16}$

\footnotetext{
$\overline{16}$ In Notten and de Combrugghe (2006) we incorporate this temporary ability of consumption smoothing into a model of consumption smoothing by distinguishing between short and long term relationships; while allowing for short term deviations between income and consumption, the model stipulated a balanced long term relation between those variables.
} 
Table 6.8: Accumulation of financial capital - financial market / household

\begin{tabular}{|c|c|c|c|c|c|c|c|c|c|c|c|}
\hline \multirow[t]{2}{*}{$\%$ of households } & \multirow[t]{2}{*}{ Obs. $^{2}$} & \multirow[t]{2}{*}{ All } & \multirow[t]{2}{*}{ Urban } & \multirow[t]{2}{*}{ Rural } & \multirow[t]{2}{*}{ Test $^{1}$} & \multicolumn{5}{|c|}{ Average expenditure quintiles } & \multirow[t]{2}{*}{ Test } \\
\hline & & & & & & 1 & 2 & 3 & 4 & 5 & \\
\hline Has savings & 2,718 & 12.6 & 14.1 & 10.1 & .1 & 4.2 & 9.6 & 12.9 & 18.2 & 18.2 & .01 \\
\hline Saves with interest & 1,914 & 2.8 & 3.5 & 1.9 & ns & 0.7 & 3.1 & 3.0 & 2.3 & 3.3 & ns \\
\hline $\begin{array}{l}\text { Bought bonds/ } \\
\text { shares }\end{array}$ & 2,718 & 0.1 & 0.2 & 0 & ns & 0 & 0 & 0 & 0.6 & 0 & ns \\
\hline $\begin{array}{l}\text { Received payments } \\
\text { from bonds/shares }\end{array}$ & 2,718 & 1.1 & 1.4 & 0.6 & ns & 0.6 & 0.7 & 0.4 & 1.5 & 2.2 & .1 \\
\hline
\end{tabular}

Note: ${ }^{1}$ Wald test on difference means urban-rural and average expenditure quintiles (controlling for clustering effects): not significant (ns), significant at 10\% (.1), significant at 5\% (.05) and significant at $1 \%(.01) .{ }^{2}$ The full sample consists of 2,718 households. The number of observations in this column can be different due to missing information in the questionnaire and / or because the information is only applicable to a sub-sample of the households.

Source: Own calculations RLMS

\subsubsection{Ex ante consumption smoothing strategies: asset accumulation and insurance}

After a decade of severe macro-economic instability, the new millennium brought Russia a period of stable growth which was also transmitted into sustained improvements in living standards. The poverty rate, peaking at $34 \%$ in 1998 , has declined substantially to $12 \%$ in 2003 (Notten \& Crombrugghe de, 2006). As noted in Table 6.4, household income and consumption increased considerably during this period. In such good times, it makes sense to use part of this extra income to re-build stocks of capital or to arrange insurance. We look for evidence of these strategies and their corresponding channels using a snapshot of this period ( $4^{\text {th }}$ quarter 2003). Table 6.8 to Table 6.12 display the results for the indicators of ex ante smoothing channels.

Surprisingly however, only $13 \%$ of Russian households reported having saved any money in the month prior to the survey (Table 6.8). There is virtually no investment in more sophisticated financial products such as stocks and shares: few households report buying such products or receive income from them. The percentage of households saving is higher in urban areas and increases as average expenditures increase; $4 \%$ of the households in the lowest quintile save as compared to $18 \%$ in the $4^{\text {th }}$ and $5^{\text {th }}$ quintiles. Unfortunately, the information on savings does not unambiguously reveal whether households save using financial markets or store cash in their homes. However, few households get interest payments for their savings (less than 3\%) which suggests that a large part of household savings are in cash and may be deposited 'under the mattress' instead of in a bank account. Buying an insurance product from a financial 


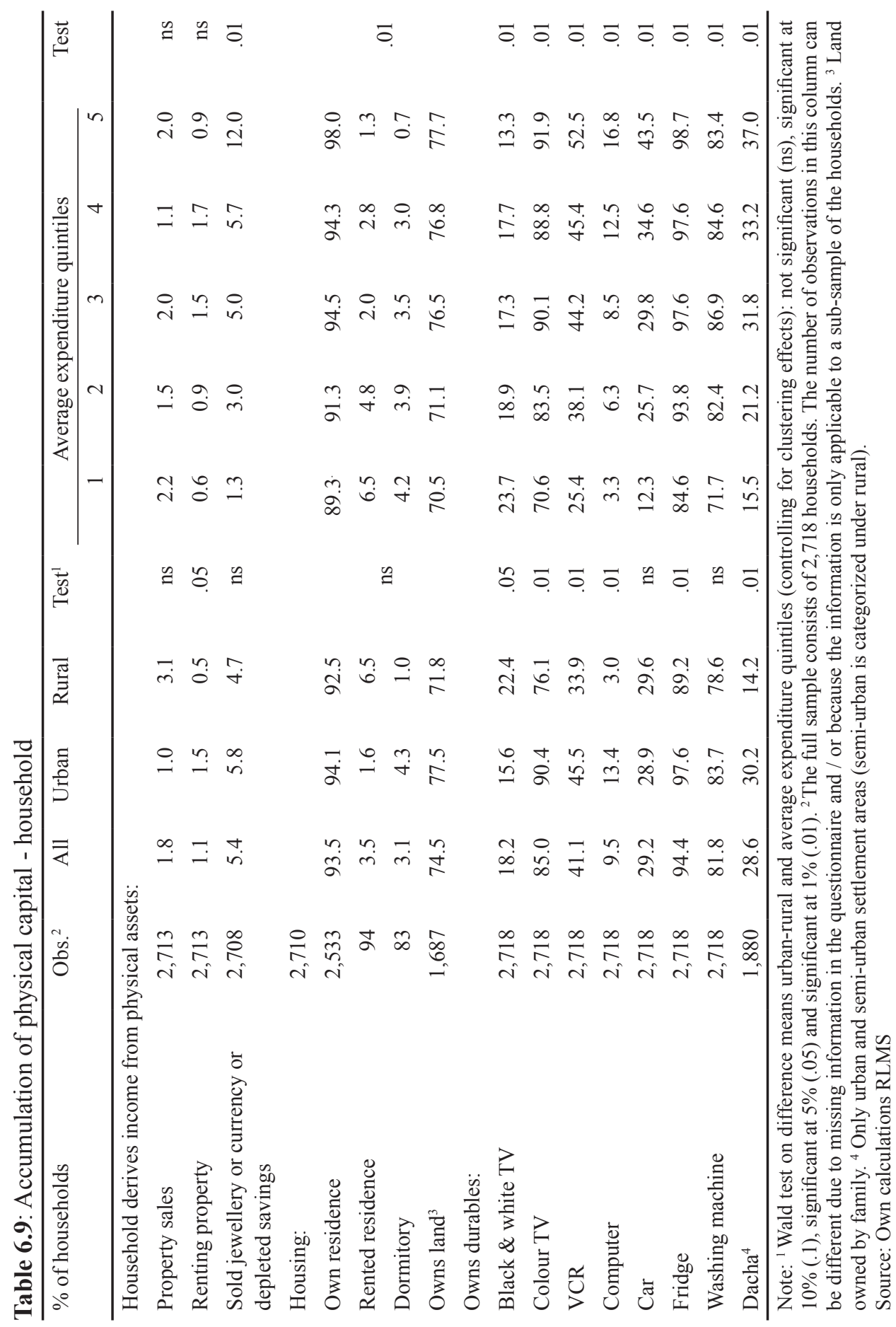


Table 6.10: Seek insurance - financial market

\begin{tabular}{|c|c|c|c|c|c|c|c|c|c|c|c|}
\hline \multirow[t]{2}{*}{$\%$ of households } & \multirow[t]{2}{*}{ Obs. $^{2}$} & \multirow[t]{2}{*}{ All } & \multirow[t]{2}{*}{ Urban } & \multirow[t]{2}{*}{ Rural } & \multirow[t]{2}{*}{ Test $^{1}$} & \multicolumn{5}{|c|}{ Average expenditure quintiles } & \multirow[t]{2}{*}{ Test } \\
\hline & & & & & & 1 & 2 & 3 & 4 & 5 & \\
\hline Insurance payout & 2,718 & 0.2 & 0.2 & 0 & .05 & 0 & 0.2 & 0.2 & 0.2 & 0.2 & Is \\
\hline Premium paid & 2,718 & 4.6 & 4.3 & 5.3 & $\mathrm{~ns}$ & 2.0 & 3.1 & 3.3 & 5.2 & 9.6 & .01 \\
\hline
\end{tabular}

market institute is also not very popular; less than $5 \%$ of the households report to having spent money on insurance premiums (Table 6.10). ${ }^{17}$ These findings suggest that financial markets play only a very limited role in households' smoothing strategies. One explanatory factor for this may be that households' confidence in Russia's financial institutions has not yet been restored, despite the reforms in this sector after the 1998 banking crisis. ${ }^{18}$ During this crisis, many households lost their savings as a result of the bankruptcies. ${ }^{19}$

If this explanation holds true than it would make sense that households prefer to accumulate physical assets by, for instance, buying durables. ${ }^{20}$ In 2003 expenditures on durables were restored to their mid-nineties but Mroz et al (April 2004) report that such expenditures are mainly made by higher income groups. Table 6.9 shows that many households own durable goods such as a television, fridge and washing machine but that poorer households and rural households own fewer durables. ${ }^{21} \mathrm{We}$ have little information on whether these assets are sold when other income sources fall short. Using a set of questions only asked in the 1998 RLMS survey, Lokshin and Yemtsov (February 2001) report that only 4\% of Russian households reported having

\footnotetext{
${ }^{17}$ There is no information available on the type of insurance products bought.

${ }^{18}$ Although reforms have been taking place since 1998, a series of World Bank and OECD reports from 2001 and 2002 indicates that reforms have been very slow and insufficient (Fuchs, 2002; OECD, 2001a, 2001b, 2002; World Bank, 2003). Comparison with other countries shows that the Russian banking system is small by regional standards and underdeveloped compared to countries with similar per capita income. The lack of credit and deposit insurance has the consequence that banks are hesitant to provide credits to a wide variety of enterprises while households do not trust banks to manage their savings appropriately.

${ }^{19}$ Using the cross-section of round 8 (1998) of RLMS we find that about $10 \%$ of the household reported to have lost a large part (on average $82 \%$ ) of their savings.

${ }^{20}$ Guariglia and Kim (2003) and Foley and Pyle (September 2005) analyse household savings in Russia incorporating expenditures on durable goods as savings.

${ }^{21}$ These durable goods are typically rather old; the average age of a car, fridge, freezer, washing machine is over 10 years old.
} 
sold belongings in order to cope with the impact of the 1998 crisis. The only indicator available is a grouping of strategies including that of selling jewellery; about $5 \%$ of the households report having sold jewellery, currency or having depleted savings in $2003 .{ }^{22}$ This tendency was higher among the wealthier households were $12 \%$ sold such assets or depleted their savings.

Physical assets such as a house or land may be used as physical collateral or as a source of income (rent). The majority of households own their residence but low wealth households are somewhat more likely to rent a residence rather than own it (Table 6.9). However, even when real estate is privately owned it may be difficult to use a house or apartment as financial collateral for a loan. A World Bank study (October 2003) on the mortgage and the housing market in Russia reports that there are information problems regarding the assessment of the market value of housing and that it is extremely difficult to expropriate a house from its defaulting owner. Land ownership is also high; three quarters of the households own a piece of land. As we will see below, most households use land to produce foodstuffs (including those living in urban areas).

To sum up, most households own a stock of physical assets and expenditures on durable goods have picked up again signalling increased accumulation. However, few households report income from the sale or renting of assets and information problems severely restrict the selling of property or the use of it as physical collateral. The information discussed above suggests that there is little evidence that these assets are used as buffer-stock strategy or as a means to generate (cash) income. It seems that Russian households use their stock of assets mainly for consumption and (home) production purposes.

In their role as a provider (or legislator) of social security programmes, public authorities provide insurance against the impact of risks such as insufficient income in old age, unemployment or disability. The eligibility and benefit levels of such programmes are contingent on citizenship and/or contributions history. Social security in Russia means first and foremost pensions: $59 \%$ of the households receive some kind of pension and, in recipient households, pensions make up on average half of total household income (Table 6.11). ${ }^{23}$ Receipt of an old age pension ${ }^{24}$ is most prevalent, followed by a disability pension. Interestingly, the incidence of pensions does not

\footnotetext{
${ }^{22}$ Unfortunately this question includes both physical (jewellery) and financial assets (currency and savings).

${ }^{23}$ The share of pension income may be overestimated because other income sources are more likely to be underreported (MGSoG, 2006).

${ }^{24}$ In Russia, men above the age of 60 are entitled to an old age pension (for women above age 55). In addition in certain professions (military, mining) workers can retire at the age of 45 or after had a particular length of service (IAAC, October 2006; MGSoG, 2006).
} 


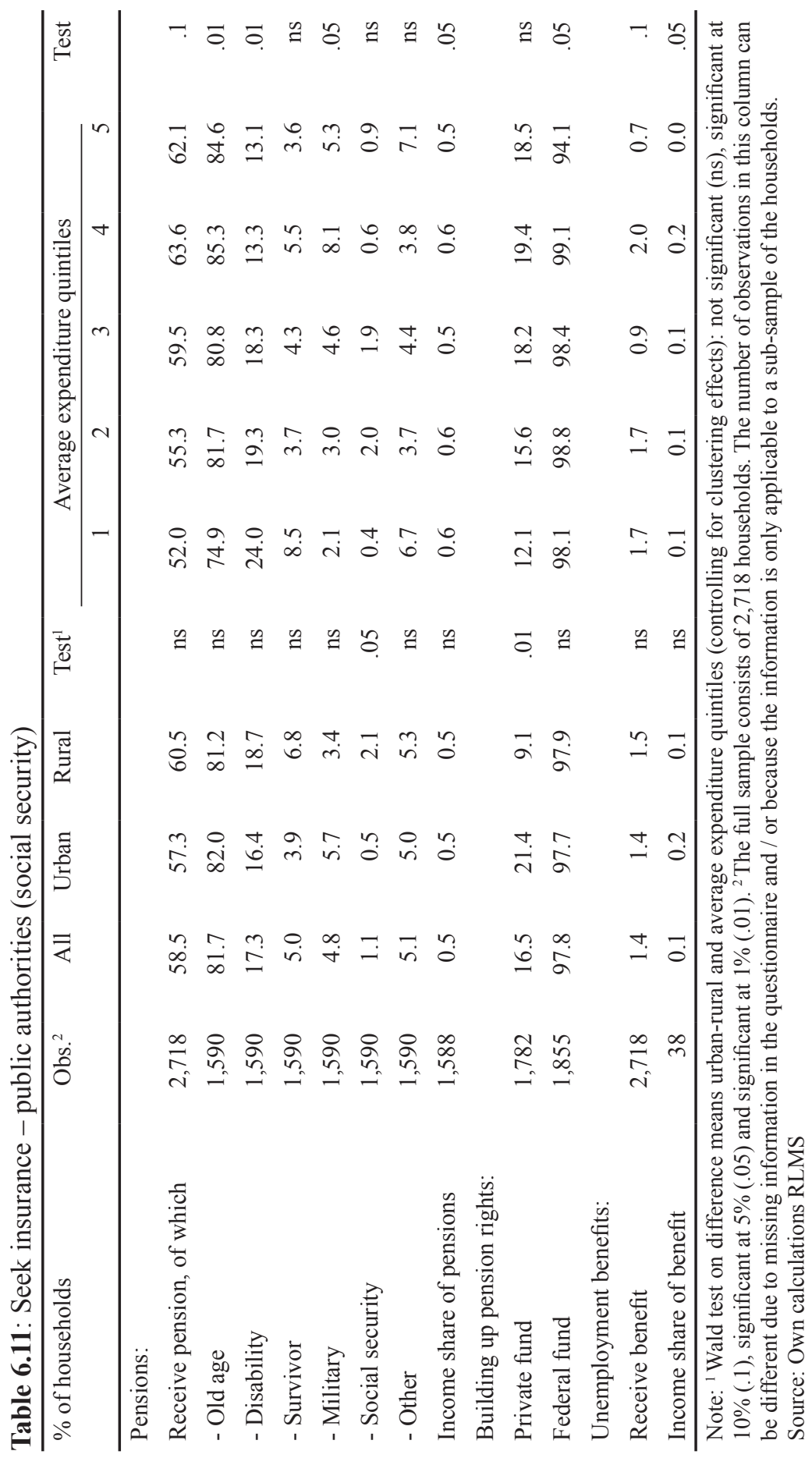


differ much across the population, except for the lowest wealth quintile; this group of households is less likely to receive an old age pension but considerably more likely to receive a disability pension ( $24 \%$ as compared to a population average of $17 \%$ ). The receipt of unemployment benefits and its contribution to total income is very low.

Coverage of the (old age) pension system is very high; nearly every household has adults reporting that they are building up (or have built up) pension rights from the Federal fund. About $17 \%$ of the households have adult members that are also contributing to a private pension fund ${ }^{25}$. However, these percentages are much lower for households in rural areas and in lower wealth quintiles. Thus, the old age pension system in Russia plays an important role in terms of benefit incidence (many households benefit), size of benefit (benefit is high share of income) and coverage (virtually all citizens are insured). As for the adequacy of pensions, the benefit does not guarantee a living standard above the poverty $\operatorname{line}^{26}$ but pensioners and households with pensioners are considerably less likely to be poor as compared to the rest of the population (MGSoG, 2006). Together with the results discussed in Table 6.12 and Table 6.13, we hypothesize that these relatively generous old age pensions induce a specific inter-generational consumption smoothing channel whereby elderly family members assist their offspring.

\subsubsection{Ex post consumption smoothing strategies: transfers, credit and adjustment in income generating activities}

In times of trouble households can also rely on their family and (broader) social networks such as relatives, friends or others. Depending on the motives and nature of such exchanges, they could be labelled as insurance or transfer smoothing mechanisms. When arrangements are reciprocal or involve risk-sharing they can be classified as insurance. Arrangements based on altruistic motives may be characterized as transfers. The RLMS does not provide much insight into the nature of such arrangements but it includes a range of variables on gifts received and given by households. We use these indicators to explore the existence of such solidarity based networks, including indicators for the direction of gift giving/receiving and its relative importance (Table $6.12)^{27}$

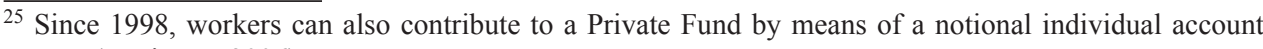
system (Kazianga, 2006).

${ }^{26}$ High risk (old age) pension beneficiaries are single pensioners and pensioners living in large (extended) families.

${ }^{27}$ Households were asked to indicate if they have been involved in gift giving (money or goods) with people that are not part of their household in the past month. If yes, the respondent estimated the monetary value of the gift. It is not clear what share has been given / received in cash and what in kind. Only for home produced food it would be possible to construct an estimate for the value of goods given to others.
} 
Table 6.12: Seek insurance / seek transfers - family / social network

\begin{tabular}{|c|c|c|c|c|c|c|c|c|c|c|c|}
\hline \multirow[t]{2}{*}{$\%$ of households } & \multirow[t]{2}{*}{ Obs. $^{2}$} & \multirow[t]{2}{*}{ All } & \multirow[t]{2}{*}{ Urban } & \multirow[t]{2}{*}{ Rural } & \multirow[t]{2}{*}{ Test $^{1}$} & \multicolumn{5}{|c|}{ Average expenditure quintiles } & \multirow[t]{2}{*}{ Test } \\
\hline & & & & & & 1 & 2 & 3 & 4 & 5 & \\
\hline $\begin{array}{l}\text { Gives and/or } \\
\text { receives gifts }\end{array}$ & 2,717 & 47.1 & 50.2 & 41.9 & .05 & 36.6 & 39.9 & 47.3 & 54.2 & 57.3 & \\
\hline \multicolumn{12}{|l|}{ Net giving/receiving: } \\
\hline Giver only & 535 & 41.8 & 40.2 & 45.0 & & 23.6 & 35.9 & 44.0 & 47.5 & 50.5 & \\
\hline Net gift giver & 95 & 7.4 & 7.3 & 7.7 & \multirow{3}{*}{$\mathrm{ns}$} & 5.5 & 6.5 & 9.3 & 7.5 & 7.7 & \multirow{3}{*}{ ns } \\
\hline Net gift receiver & 123 & 9.6 & 10.0 & 8.8 & & 9.1 & 9.2 & 9.3 & 10.9 & 9.3 & \\
\hline Receiver only & 526 & 41.1 & 42.5 & 38.5 & & 61.8 & 48.4 & 37.4 & 34.2 & 32.5 & \\
\hline Given gifts & 2,717 & 28.3 & 29.5 & 26.4 & $\mathrm{~ns}$ & 14.3 & 21.0 & 30.3 & 36.4 & 39.8 & .01 \\
\hline $\begin{array}{l}\text { Income share of gifts } \\
\text { given }\end{array}$ & 769 & 0.24 & 0.19 & 0.35 & .05 & 0.23 & 0.21 & 0.14 & 0.31 & 0.29 & .01 \\
\hline \multicolumn{12}{|l|}{ Given to: } \\
\hline Parents & 768 & 15.8 & 16.5 & 14.4 & ns & 7.8 & 11.4 & 19.5 & 14.1 & 19.5 & .01 \\
\hline Children & 769 & 49.9 & 45.4 & 58.3 & .05 & 57.7 & 50.9 & 50.6 & 50.5 & 45.6 & ns \\
\hline Grandparents & 767 & 1.3 & 1.8 & 0.4 & .1 & 1.3 & 0.9 & 1.2 & 1.0 & 1.9 & ns \\
\hline Grandchildren & 768 & 31.1 & 29.4 & 34.3 & ns & 28.2 & 30.7 & 32.3 & 36.9 & 26.2 & ns \\
\hline Other people & 768 & 31.0 & 35. & 23.3 & .05 & 24.4 & 28.1 & 30.1 & 28.3 & 38.1 & .1 \\
\hline Gifts received & 2,714 & 28.0 & 30.7 & 23.7 & .05 & 28.3 & 26.0 & 27.1 & 29.2 & 29.5 & ns \\
\hline $\begin{array}{l}\text { Income share of gifts } \\
\text { received }\end{array}$ & 761 & 0.22 & 0.22 & 0.22 & ns & 0.23 & 0.21 & 0.19 & 0.20 & 0.25 & ns \\
\hline \multicolumn{12}{|l|}{ Received from: } \\
\hline Parents & 756 & 47.4 & 46.0 & 50.2 & ns & 49.7 & 55.0 & 46.3 & 46.2 & 40.5 & ns \\
\hline Children & 759 & 27.3 & 25.0 & 32.1 & ns & 23.4 & 22.1 & 26.5 & 29.8 & 33.8 & ns \\
\hline Grandparents & 757 & 5.0 & 5.1 & 4.9 & ns & 7.8 & 3.6 & 4.1 & 5.7 & 3.8 & ns \\
\hline Grandchildren & 756 & 1.7 & 2.0 & 1.2 & ns & 1.3 & 2.9 & 2.1 & 1.3 & 1.3 & ns \\
\hline Other relatives & 758 & 19.3 & 20.4 & 16.9 & ns & 18.8 & 22.1 & 22.5 & 14.6 & 18.9 & ns \\
\hline Friends & 759 & 12.5 & 13.2 & 11.1 & ns & 13.0 & 10.6 & 12.2 & 8.2 & 18.2 & .1 \\
\hline Former employer & 759 & 6.9 & 8.3 & 3.7 & .1 & 5.2 & 7.8 & 7.5 & 6.3 & 7.6 & ns \\
\hline Social state organs & 759 & 4.6 & 4.8 & 4.1 & ns & 5.8 & 3.6 & 3.4 & 5.1 & 5.0 & ns \\
\hline Other & 759 & 3.3 & 4.3 & 1.2 & .05 & 4.6 & 2.1 & 2.0 & 4.4 & 3.1 & ns \\
\hline
\end{tabular}

Note: ${ }^{1}$ Wald test on difference means urban-rural and average expenditure quintiles (controlling for clustering effects): not significant (ns), significant at $10 \%(.1)$, significant at $5 \%(.05)$ and significant at $1 \%(.01) .{ }^{2}$ The full sample consists of 2,718 households. The number of observations in this column can be different due to missing information in the questionnaire and / or because the information is only applicable to a sub-sample of the households.

Source: Own calculations RLMS 
A first observation is that the exchange of gifts is rather popular in Russia: $47 \%$ of the households give or receive gifts and households generally receive gifts or give them to others. This observation supports the interpretation of gifts as a consumption smoothing mechanism between households. ${ }^{28}$ Also in favour of this hypothesis is the proportionality in incidence rates of giving / receiving as well as in the relative magnitude of the gifts; $28 \%$ of the households reported giving gifts while $28 \%$ reported receiving them. The average value of the given gifts is $24 \%$ of total household income while the income share of a received gift represents on average $22 \%$. Thus, at a given point in time, Russian households are either giving or receiving considerable gifts on a regular basis. Furthermore, most gifts occur within family relations and the direction of flows goes from older generations to younger ones. Additionally, 31\% of the gifts are given to people outside the family while $13 \%$ of the received gifts come from friends and $7 \%$ from former employers. The exchange of gifts seems to be a relevant and popular smoothing strategy in Russia, especially within families.

There are however some differences between population groups suggesting that not everyone is equally likely to make use of this smoothing mechanism. Urban households are more likely to be involved in exchanging gifts (both giving and receiving), suggesting that this smoothing channel is more important for urban areas. Nevertheless, when rural households give, the value of this gift constitutes a higher share of income. Higher wealth households give more often and are equally likely to receive gifts. But, even though lower wealth households give less often, those in the lowest wealth quintile are not more likely to receive gifts. Moreover, the income shares of received gifts are similar for all subgroups implying that the absolute value of the gift increases with wealth. Gifts do not go more often towards those who are (supposedly) more in need. ${ }^{29}$ Explanations could be that lower wealth households have fewer social assets, which prevents them from using family and social networks to smooth consumption. Or, alternatively, the smoothing counterparts of such households themselves have fewer means to assist them.

These findings suggest that gift exchange as a means to smooth consumption is a promising area for further research. Moreover, the prevalence and direction of intergenerational gifts combined with the importance of (old age) pensions yields another interesting hypothesis: the relatively generous old age pensions give rise to an intergenerational risk-sharing in which the elderly financially assist their children and grand

\footnotetext{
${ }^{28}$ Alternatively, a high reciprocity of gifts within the cross-section dimension would have pointed at another explanation in which gift exchange functions as a means to build up, maintain or strengthen family relations or social networks.

${ }^{29}$ As discussed in section 6.3, households in the lowest quintile had average equivalent expenditures around the absolute poverty line (average of 2000 - 2003).
} 
Table 6.13: Households with old-age pensioners

\begin{tabular}{|c|c|c|c|c|c|c|}
\hline$\%$ of households & Obs. $^{1}$ & $\begin{array}{l}\text { Non-elderly } \\
\text { households }^{2}\end{array}$ & $\begin{array}{l}\text { Single } \\
\text { elderly }\end{array}$ & $\begin{array}{r}\text { Elderly } \\
\text { couple }\end{array}$ & $\begin{array}{r}\text { Other elderly } \\
\text { household }\end{array}$ & Test $^{3}$ \\
\hline Number of observations & 2,718 & 1,399 & 440 & 270 & 609 & \\
\hline \multicolumn{7}{|l|}{ Income: } \\
\hline - Receive pension & 2,718 & 20.7 & 100 & 100 & 97.2 & .01 \\
\hline - Mean pension share of income & 1,588 & 0.26 & 0.75 & 0.75 & 0.41 & .01 \\
\hline - Has wage income & 2,713 & 87.0 & 12.1 & 24.8 & 68.0 & .01 \\
\hline - Income share of wage earnings & 1,768 & 0.72 & 0.49 & 0.38 & 0.52 & .01 \\
\hline Poor (expenditures) & 2,718 & 12.0 & 8.2 & 5.6 & 14.6 & .01 \\
\hline Involved in borrowing or lending & 2,708 & 37.5 & 13.4 & 20.4 & 24.5 & .01 \\
\hline - Net lender & 284 & 30.3 & 67.9 & 67.9 & 37.1 & \multirow{2}{*}{.01} \\
\hline - Net borrower & 485 & 69.4 & 32.1 & 32.1 & 62.9 & \\
\hline Has debt & 2,712 & 28.6 & 5.2 & 6.3 & 16.6 & .01 \\
\hline Has unpaid utility bills & 2,707 & 29.5 & 7.5 & 6.7 & 14.6 & .01 \\
\hline Given gifts to: & 2,717 & 24.2 & 28.9 & 48.5 & 28.6 & .01 \\
\hline - Parents & 768 & 31.4 & 0 & 2.3 & 6.9 & .01 \\
\hline - Children & 769 & 41.7 & 52.4 & 61.8 & 55.2 & .01 \\
\hline - Grandparents & 767 & 2.4 & 0.8 & 0 & 0.6 & $\mathrm{~ns}$ \\
\hline - Grandchildren & 768 & 13.7 & 46.8 & 57.3 & 33.9 & .01 \\
\hline Gifts received from: & 2,714 & 32.5 & 30.2 & 24.5 & 17.8 & .01 \\
\hline - Parents & 756 & 73.8 & 0 & 1.5 & 21.0 & .01 \\
\hline - Children & 759 & 6.0 & 68.9 & 74.2 & 37.4 & .01 \\
\hline - Grandparents & 757 & 6.8 & 0 & 0 & 6.5 & .01 \\
\hline - Grandchildren & 756 & 0 & 8.4 & 3.1 & 0 & .05 \\
\hline Net giving: Gift giver only & 535 & 32.5 & 41.7 & 60.8 & 55.5 & \multirow{4}{*}{.01} \\
\hline Net giving: Net gift giver & 95 & 6.3 & 7.3 & 11.4 & 8.0 & \\
\hline Net giving: Net gift receiver & 123 & 11.3 & 6.4 & 8.2 & 8.8 & \\
\hline Net giving: Gift receiving only & 526 & 49.9 & 44.5 & 19.6 & 27.7 & \\
\hline
\end{tabular}

Note: ${ }^{1}$ The full sample consists of 2,718 households. The number of observations in this column can be different due to missing information in the questionnaire and / or because the information is only applicable to a sub-sample of the households. ${ }^{2}$ An elderly household member is a person whose age is above the official retirement age (55 for women and 60 for men). ${ }^{3}$ Wald test on difference means household types (controlling for clustering effects): not significant (ns), significant at $10 \%(.1)$, significant at $5 \%(.05)$ and significant at $1 \%(.01)$.

Source: Own calculations RLMS 
children. In other words, there is a re-redistribution of wealth taking place from public authorities via elderly citizens to their younger family members.

We explore the potential relevance of this hypothesis by decomposing the panel into four (mutually exclusive) household types; single elderly households (16\%), elderly couples $(10 \%)$, other households with elderly members $(22.4 \%)$ and households with no elderly members $(51.5 \%){ }^{30}$ In the first part of Table 6.13 we can see that pension income forms the most important source of income for single pensioners and pensioner couples. These groups are also considerably less likely to be poor. ${ }^{31}$ Other households with elderly members form an 'in between case' where both pensions as well as wage income form important shares of total income. Such households have an above average poverty risk. We expect that intergenerational redistribution may occur either by lending and borrowing or through gifts. However, the incidence of borrowing/lending activities for elderly households is significantly lower than that of non-elderly households. But once elderly households are involved, single elderly and elderly couple households are more likely to be net lenders. ${ }^{32}$ Furthermore, elderly households give gifts more often but there are large differences between elderly households. Only elderly couples give gifts more often than the average population. Elderly couple households and other elderly households are less likely to get gifts. The results in Table 6.13 are consistent with the hypothesis that some kind of intergenerational risk sharing or income pooling takes place, particularly through gift giving. Possibly, such risk-sharing occurs either between related households (from elderly single / elderly couple to other non-elderly households) or within the household (other elderly households). In more profound research such hypotheses on the direction of intergenerational gifts could be tested using inter and intra-household decision models.

When income is low, or falls short of what is expected, households can also seek transfers from the government. Many countries have a range of benefits that are targeted at low income groups (social assistance). Households are eligible for such benefits if they can prove their income falls below a certain threshold and / or if their characteristics fall within a pre-defined category of eligibility criteria. Alternatively, households may seek other benefits that are not specifically targeted at low income households as income shocks change the opportunity costs of seeking transfers; when income is suddenly reduced, the expected benefit (receiving a transfer) may now

\footnotetext{
${ }^{30}$ A household member is considered to be elderly once it has reached the legal retirement age; 55 for women and 60 for men.

${ }^{31}$ We also calculated household poverty rates using household expenditures as a welfare indicator and the RLMS household specific poverty lines (2003) as thresholds.

${ }^{32}$ In studying household budget data from Latvia, Gassmann (2000) also finds that elderly individuals are less likely to borrow or have debt.
} 


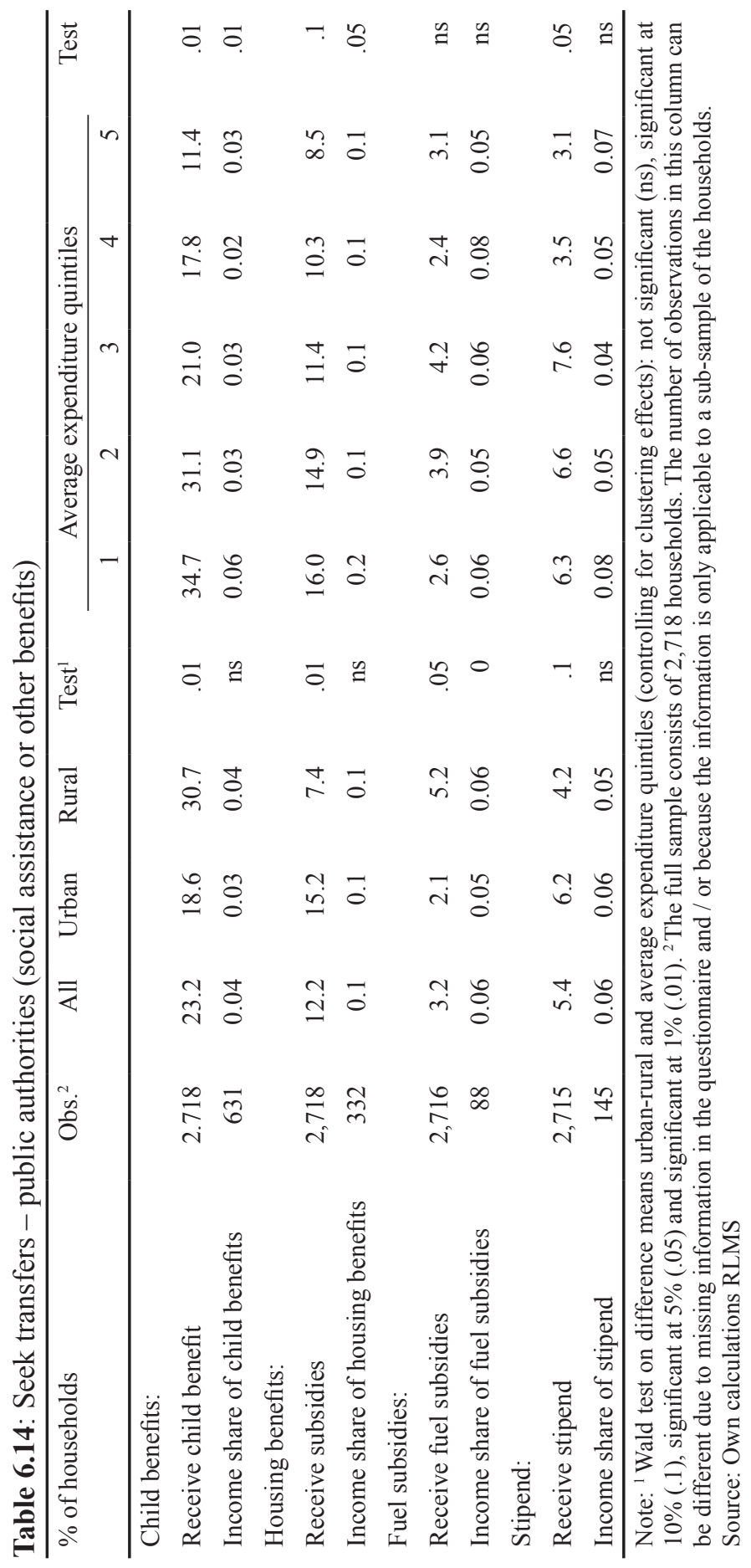


Table 6.15: Adjustment of income generating activities - labour and goods market

\begin{tabular}{lllllllllllll}
\hline \% of households & Obs. $^{2}$ & All & Urban & Rural & Test $^{1}$ & \multicolumn{6}{c}{ Average expenditure quintiles } & Test \\
\cline { 6 - 9 } & & & & & & 1 & 2 & 3 & 4 & 5 \\
\hline $\begin{array}{l}\text { At least 1 member } \\
\text { reports to have 2 }\end{array}$ & 1,955 & 26.2 & 23.9 & 30.2 & ns & 29.9 & 25.1 & 24.3 & 27.1 & 24.4 & ns \\
and/or 3 $3^{\text {rd job }}$ & & & & & & & & & & & \\
$\begin{array}{l}\text { At least 1 member } \\
\text { has informal job }\end{array}$ & 1,955 & 24.3 & 22.4 & 27.7 & ns & 30.7 & 24.6 & 24.1 & 24.0 & 17.8 & .01 \\
\hline
\end{tabular}

Note: ${ }^{1}$ Wald test on difference means urban-rural and average expenditure quintiles (controlling for clustering effects): not significant (ns), significant at $10 \%(.1)$, significant at $5 \%(.05)$ and significant at $1 \%(.01) .{ }^{2}$ The full sample consists of 2,718 households. The number of observations in this column can be different due to missing information in the questionnaire and / or because the information is only applicable to a sub-sample of the households.

Source: Own calculations RLMS

outweigh the costs of applying for a benefit (time, travel, costs of obtaining required documents) while this was not the case before. Table 6.14 summarizes the incidence rates and income shares of a range of benefits; the child and housing benefits are incometested. The incidence of these benefits is considerable and progressive. Child benefits supplement on average $6 \%$ of the household income of the lowest wealth quintile. For housing benefits this number is $20 \%$. While urban households are more likely to receive housing benefits, rural households more often receive child benefits. While these benefits provide an additional source of income, Notten and Gassmann (2006) show that the poverty reduction effect of child benefits in terms of poverty and chronic poverty is rather low indicating that benefit levels are not adequate in this respect. The incidence rates and income shares of fuel subsidies and stipends are low. Stipends are somewhat progressive and contribute $8 \%$ of household income in the lowest wealth quintile. So, even though these benefits may help households to smooth consumption, they are typically not sufficient to cover basic needs.

Instead of, or in addition to, relying on transfers, households can also take up a loan or use credit. Table 6.16 shows that about $20 \%$ of the households have been borrowing funds and a similar share of the households report having debt. Even though we do not know if funds are borrowed from a financial market or from other institutions, it can also be seen that households themselves are active providers of loans; $13 \%$ of Russian households lend money to others. Thus, even though financial markets may play a role, other smoothing channels for credits and loans co-exist in Russia. Household lending activities may be one channel but Table 6.16 identifies two other channels; the goods market and the labour market. Not paying bills can be considered as an alternative consumption smoothing strategy closely related to (consumer) credit. If late payments 


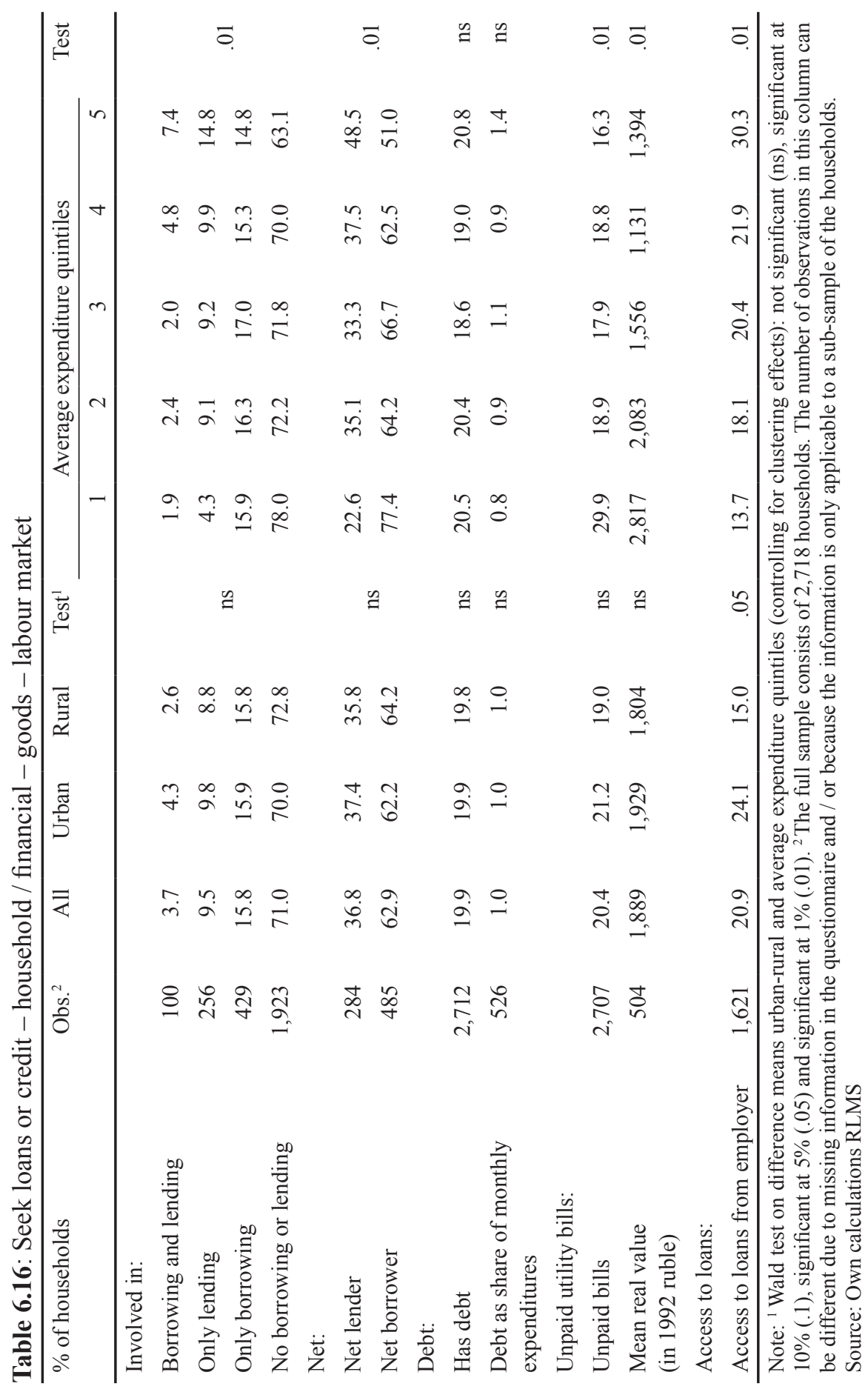


on purchased goods and services do not automatically lead to a discontinuation of the service provided, not paying bills is one strategy that households in need can follow; $20 \%$ of the households reports to have unpaid utility bills. Moreover, it seems that employers are also willing to provide loans to their employees. Working household members were asked whether they could obtain a loan or credit from their employer: one fifth of Russian households have access to such loans.

Taking up credit or a loan seems to be a popular smoothing strategy in Russia. As with gift exchange, low wealth households are less likely to provide loans but equally likely to receive them. The percentage of such households reporting having debt and the mean share of debt in monthly expenditures does not differ significantly across our sample of the Russian population. The information also suggests that, depending on their characteristics, households use other smoothing channels. Urban and high wealth households are more likely to have access to loans from employers while especially one third of the households in the lowest wealth quintile have unpaid utility bills.

Finally, when it becomes clear that current income generating activities will yield insufficient income, adjustments in such activities can be made. We have only two indicators for such adjustments; the percentage of households in which at least one household member reports having an informal job the percentage of households in which members have a second or third job. We selected these indicators because we expect them to be related to situations of unemployment and under-employment. ${ }^{33} \mathrm{~A}$ quarter of the households reports having household members with an informal job or second/third job. ${ }^{34}$ While the incidence of informal jobs is significantly higher for low wealth and rural households, this appears not to be the case for second/third jobs. Given the prevalence of informal and additional jobs, it may be an interesting alley for further research but from these results it is not clear to what extent these indicators indeed represent post shock smoothing strategies.

\footnotetext{
${ }^{33}$ Thus, using these variables as indicators for smoothing mechanisms assumes that these income generating activities are second best options. Having an informal job implies that such workers are less likely to be protected by labour legislation and are also less likely to build up a contributions history in public social security programs. This on the one hand, increases the risk of income shocks and at the same time also affects the use of alternative consumption smoothing channels (such as a public social security). Furthermore, having an extra job reflects a situation where a person would want to work more in his/her first job but is not able to, or, the first job pays an inadequate salary. Of course, it is also possible that a person has more than one job because he/she prefers this.

${ }^{34}$ This percentage is based on a question in the individual questionnaire in the work section in which the respondent was asked whether his job was formal. Given the fact that respondents have a tendency not to answer such questions or to report that their job is formal even when it is not, the $24 \%$ should be interpreted as a minimum estimate.
} 


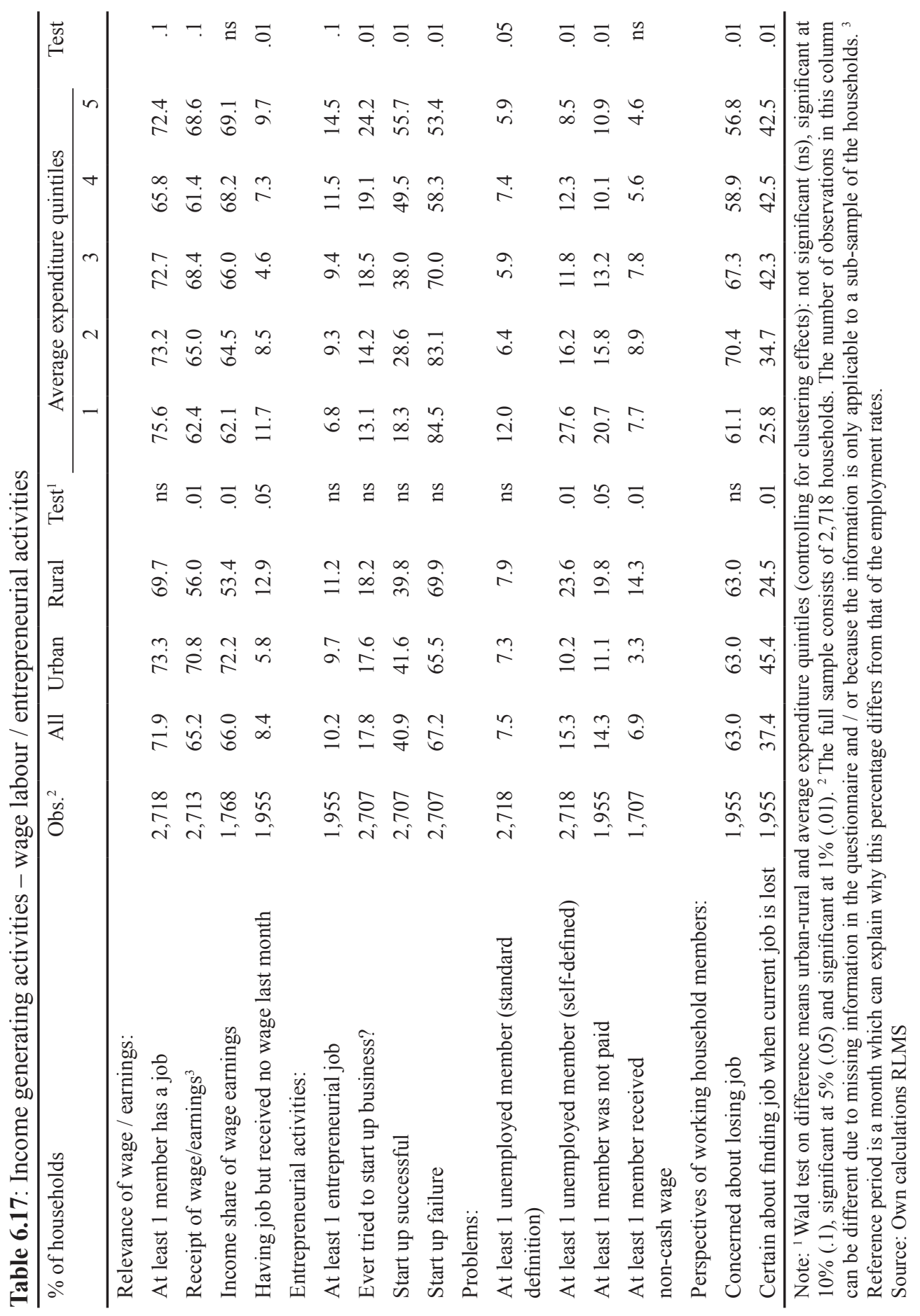




\subsubsection{Income generating activities}

Because it is difficult to distinguish between normal income generating activities and post shock adjustments in such activities in the RLMS, we finally discuss a number of indicators for the type of income generating activities of Russian households. Additionally, we are interested in differences in income generating activities between groups of households because such differences may also influence the choice, availability and success of particular smoothing strategies. For instance, not having a job also implies that one cannot get a loan through your employer but it also restricts the possibilities to pursue ex ante smoothing strategies. We selected indicators on wage generation, entrepreneurial activities, home production and indicators for problems in the processes of income generation. The latter group is interesting because such problems provide insights into (some) sources of income risk and which groups of households are more likely to be confronted with such risks. A higher exposure to shocks is likely to be associated with a higher incidence of ex post smoothing strategies. Taking a long-term perspective, an elevated exposure to shocks may also affect consumption smoothing abilities in general.

Table 6.17 shows that households in the lowest wealth quintile are more likely to have job than higher wealth quintiles. At the same time, low wealth and rural households clearly experience more problems with wage generating activities. Unemployment rates are higher, irrespective of the definition used. ${ }^{35}$ The incidence of irregular wage payments, wage arrears and non-cash wages (mainly rural areas) is significantly higher for these households. Working members in such households are not more concerned about losing their job but are, at the same time, more pessimistic about finding another job when the current job is lost. Starting up a business does not seem to be a realistic alternative; and even if it is tried, the likelihood that the start up of a business fails is much higher among low wealth households. The higher vulnerability of low wealth households to wage shocks may be consistent with post shock adjustments in income generating activities such as taking additional and informal jobs. However, the reverse may also be the case; wage arrears, non-cash and irregular payments are characteristics of informal and additional jobs.

In any case, if wage generating activities are difficult to obtain or if the income from such activities is perceived as risky, households could decide to produce (part of

\footnotetext{
${ }^{35}$ We use two definitions of unemployment; firstly a 'standard' definition according to which a person is unemployed if he/she wants to find a job and applied for a job in the last month and secondly a 'self-defined' unemployed if the respondent indicates that he/she is unemployed. The latter definition is more likely to include discouraged jobseekers or underemployed persons and may thus better reflect structural problems in the employability these persons or of (local) labour markets
} 


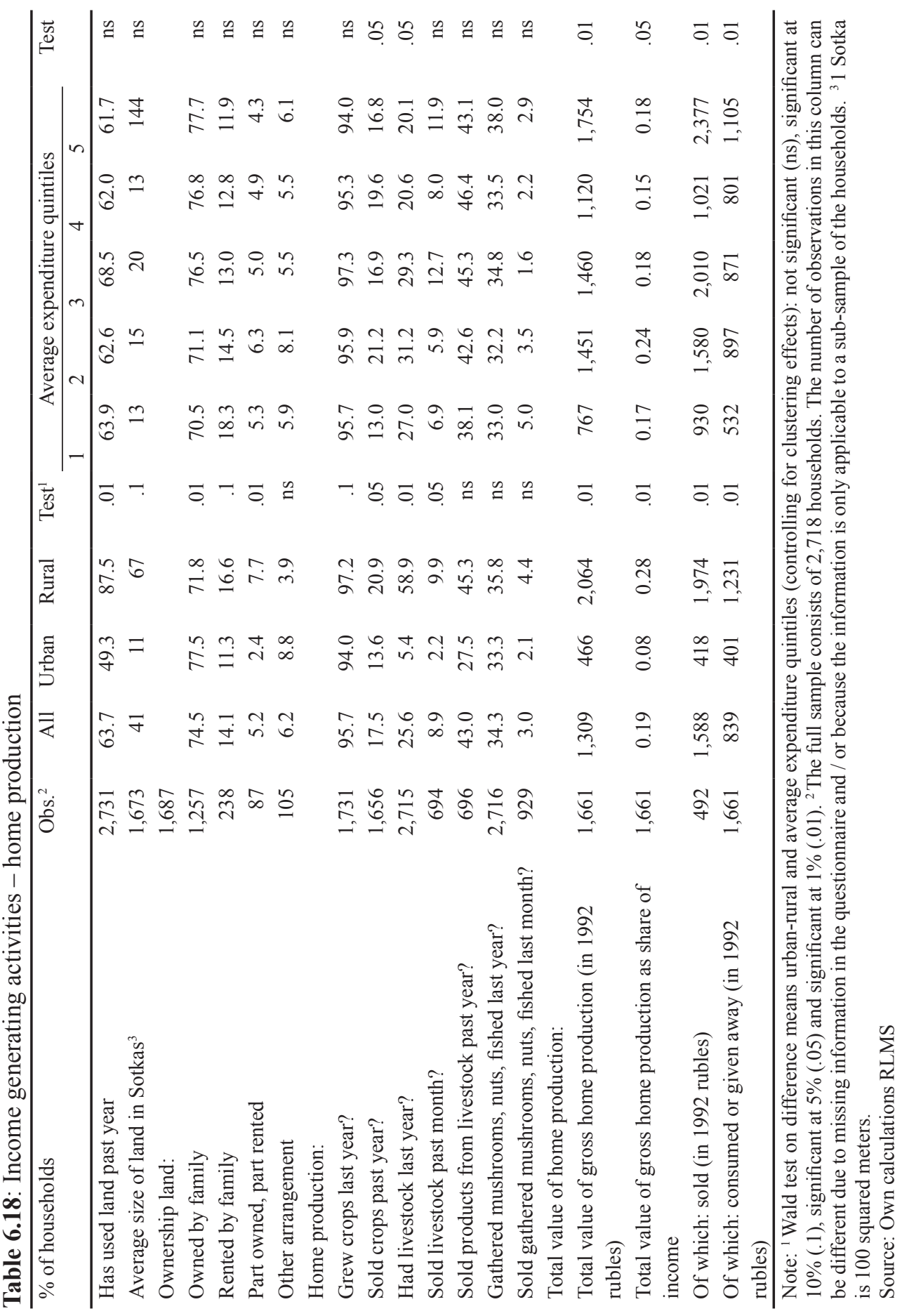


their) needs themselves or, alternatively, sell those goods in return for cash or other goods. In Russia, home production is very popular: $64 \%$ of the households used land to grow their own crops, $26 \%$ held livestock and $34 \%$ fished or gathered foodstuffs such as mushrooms, nuts and berries (Table 6.18). Although rural households are more often engaged in such activities, home food production is certainly not limited to households living in rural settlement areas; about half of urban households used land to grow their own crops and $33 \%$ of urban households reported gathering/fishing activities. The value of home produced foods is rather high for rural households ( $28 \%$ of income) but still considerable for urban households ( $8 \%$ of income). ${ }^{36}$ Table 6.18 also shows that most of the proceeds from home production are destined for home consumption.

Interestingly, there are no differences in household food production across wealth quintiles; low wealth households do not use this income generating activity more frequently than other households, even though they appear to have more problems with wage-generating activities. If anything, low wealth households are more likely to consume crops as opposed to selling them. What explains this popularity of home food production in Russia and why do low wealth households not produce more than others? A first reason may simply be that many households have access to land, either in the place they live or by owning a datcha (cottage) with some land in the rural areas (Table 6.9). Cultural aspects such as preferences on leisure activities may also contribute to the popularity of gardening, gathering and fishing activities. ${ }^{37}$ However, another (perhaps complementary) explanation can be that, by producing (part of) their own food, households ensure they have some of their basic needs covered even if when their other income generating activities fail. Morduch (1995) argues that households can also smooth consumption by choosing low risk -low return income activities or by holding a portfolio of income generating activities. He calls such activities 'income smoothing' behaviour. The experience of a multitude of shocks (both covariant and idiosyncratic) that has so far characterized the transition process in Russia can be hypothesized as a strong rationale for home food production by Russian households. ${ }^{38}$ Whereas in communist times producing your own food provided an insurance against food supply problems it may now function as an insurance against (wage) income risk.

So far, few studies have analysed the role of household food production in Russia and the evidence from those existing studies is ambiguous. Skoufias (2003)

\footnotetext{
${ }^{36}$ The value of home produced food is also included in the estimate of total household income.

${ }^{37}$ Unfortunately not much can be learnt from the RLMS data in this respect. Gassmann (2000) discusses how such activities also form an important component of leisure.

${ }^{38}$ During the nineties, the Russian population experienced a range of large aggregate shocks that influenced their level of well-being but also their perception of risk/uncertainty (Lokshin \& Ravallion, 2000; World Bank, May 1999).
} 
finds little evidence that home food production is used as a response to wage arrears and unemployment while Gronau (June 2006) reports a significantly negative relation between the change in labour status and the hours spent on gardening. Notten and de Crombrugghe (2006) on the other hand find that rural households have higher food consumption smoothing abilities; their food expenditures are less responsive to income shocks than those of urban households. One way of reconciling these findings would be that food production in Russia is used as an income smoothing strategy as opposed to a specific risk/shock response strategy.

This hypothesis can be tested in a number of ways. Firstly, the RLMS data can be used to empirically analyse dynamics between other income sources and 'income' from food production. ${ }^{39}$ Secondly, as home food production may be a typical smoothing strategy in transition economies it would be very interesting to study the main conditions under which such a smoothing strategy is preferred by economic agents and whether this could explain such a high prevalence of this strategy in Russia. For instance, one could think of a basic model in which a household has to decide how much time to invest in home food production versus another (wage) income generating activity. The decision could be modelled using a production model or a portfolio investment model. Everything else being equal, a household will spend more time on home food production in case a) it is more risk averse b) the higher the variance of the wage income generating activity and c) the lower the (expected) return of the wage income generating activity. Moreover, one could introduce an aggregate source of risk that influences the variability of wage earnings but not that of home food production. If the aggregate risk is high, it can be predicted that a large share of households invest more time in food production. From a dynamic perspective, one would expect to see this share decline as the (perceived) aggregate source of risk would decline. The RLMS provides a lot of information to empirically test the predictions of such models but it would also be interesting to apply those models to other (transition) economies. As such this is an area that certainly merits more research.

\subsection{Further research and concluding remarks}

In this paper we developed a conceptual framework representing a portfolio of potential consumption smoothing channels and explored empiric evidence of typical smoothing channels used by Russian households in 2003. The picture that emerged is one in which financial markets play a limited role as a smoothing channel, regardless of the smoothing

\footnotetext{
${ }^{39}$ Information on quantities and the monetary value (valued at local market prices) of home production, proceeds from sales are collected in a consistent way during the second wave (1994-currently). For the years 1994-1996 even (noisy) information on the hours spent on work/gardening is available.
} 
mechanism used (saving, lending, insurance). Instead, households seem to use internal strategies, their family, social networks and the state to smooth consumption through capital accumulation, gift giving, the provision of loans and (pension) benefits. We also find evidence for differential use of smoothing channels of low wealth and rural households and other households. Compared to other groups, low wealth and rural households are less likely to use financial markets as part of their smoothing strategies. Moreover, irrespective of the institution used, these households are less likely to save money, accumulate assets or be involved in borrowing and/or lending activities. They also have less access to loans through employers. 'Consumer credit' through not paying utility bills seems to be an important credit smoothing channel for low wealth households.

The broad scope of the analysis also enabled the formulation of hypotheses on two a-typical smoothing channels. Firstly, the relatively generous old age pensions give rise to an inter-generational risk-sharing in which elderly assist their children and grand children. Important channels for the re-redistribution of old age pensions are gifts to younger family members in other households and the contribution of pensions to the income of extended/multiple generation households. Secondly, many Russian households in rural and urban areas produce part of the food they consume and we find no appreciable differences in the prevalence of this activity across wealth quintiles. We hypothesize that, as opposed to a specific risk/shock response strategy, home food production in Russia may be used as an (in kind) income smoothing strategy; it represents a strategy that safeguards food consumption in a region where households have experienced a high degree of (aggregate) shocks in the recent past. Further investigations into the role of pensions and home food production therefore represent particularly interesting alleys of further research.

Albeit exploratory, this type of research is relevant for academic and policy purposes. The way households in transition economies smooth consumption may be different from that of households in developed and developing countries. In the economic literature, the village economy model is often used to analyse household and individual risk sharing activities in rural developing communities but its applicability to a transition economy has not been tested. On the other hand, the ongoing structural development of market institutions in transition economies may warrant the use of permanent income or life cycle models that are often used to study smoothing behaviour in developed economies. These models may not be appropriate or may have to be adjusted so they can be used for studying consumption smoothing behaviour in transition economies. The conceptual framework and empirical exploratory strategy can be used as tools to obtain an inventory of consumption smoothing channels in a given country or community. The analysis does not prove the existence of smoothing relationships/channels or whether 
certain actions are 'smoothing motivated'. Nevertheless, the information it provides indicates which channels are worth further investigating and which linkages have to be taken into account.

In terms of policy relevance, our research offers an alternative way to use existing survey data to obtain a household perspective on consumption smoothing, with the household being the basic institution within which risk and resources are shared. The environment of households simultaneously is a source of uncertainty as well as a partner in dealing with risks. Households use multiple strategies/channels which may or may not be country/community specific. The conceptual framework guides thinking about the role, scope and type of government interventions and possible feedback effects to other smoothing channels. Public authorities can improve or disturb the functioning of particular smoothing channels or directly assist households in managing (specific) risks by means of social protection programmes. 
7 Conclusion 
This dissertation investigates five specific issues in understanding poverty and designing sound social protection systems. While chapter 2 investigates the implications of using an absolute or a relative poverty indicator on estimating the number of poor, chapter 3 studies the implications of such indicators on social policy. In chapter 4 we compare the effectiveness of means-tested and universal provision of social transfers as poverty alleviating instruments. The relation between poverty risk and the ability of households to smooth consumption when faced with income shocks is studied in chapter 5. In chapter 6 we focus on the ways in which households smooth consumption and the role that social protection policies play in such smoothing arrangements. In this concluding chapter we discuss each study by providing a discussion of its main results, limitations, conclusions and policy relevance.

\subsection{Absolute and relative poverty: what's in a number?}

Financial poverty indicators play an important role in policymaking and the evaluation of economic development. Countries such as the USA and the EU member states use one or several 'official' poverty indicators on which progress is regularly monitored; whereas the US poverty indicator is based on an absolute concept of poverty, the EU poverty indicator is based on a relative concept. In chapters 2 and 3 we investigate the implications of using either an absolute or a relative poverty indicator on estimating poverty as well as on designing and evaluating poverty alleviating policies.

In chapter 2 we apply the official EU (relative) and the US (absolute) poverty measures on survey data for 16 countries and analyse to what extent technical differences in these poverty measures affect the estimates of the number of poor. This study improves our understanding of how poverty statistics are influenced by often hidden and forgotten methodological and technical decisions. A main contribution of our study is that it provides comparable estimates of both absolute and relative poverty for a large group of countries over a range of consecutive years (1993-2000). There is also an added value to using the official poverty measures of the EU and the US as these are influential indicators in the countries where they are used. Another important result is that the conceptual difference between 'not enough to satisfy basic needs' and 'much less than what is normal' may not only result in sizeable differences between absolute and relative poverty levels but it also implies another evaluation of what constitutes economic progress over time. An absolute poverty indicator values any real income increase of low income groups as an improvement while a relative indicator only detects a more than proportional improvement of low income groups. This is a main factor driving differences between absolute and relative poverty rates over time. Furthermore, our analysis shows that equivalence scales can have a very large impact 
on the estimates of poverty and on the poverty risk of population groups, and that this impact differs considerably between absolute and relative indicators. Equivalence scales determine the shape of the income distribution and thereby also the relative poverty line. This has a stabilizing effect on the overall poverty rates, i.e. the net impact of using different equivalence scales is small. However, the underlying changes in poverty risk of various population groups are very sizeable and much more difficult to understand and predict than for absolute poverty indicators.

In chapter 3 we focus on the relation between absolute and relative poverty headcounts and their policy uses: we study whether using only one of these indicators results in the selection of different priority groups for social policies and if the use of an absolute or relative poverty indicator leads to a different evaluation of the success of social transfers. Although we use the same poverty measures as in chapter 2, we additionally estimate long term poverty headcounts because the chronic poor constitute a priority group in itself. We find similar differences in long term poverty between and within countries. We also show that in 'rich' countries, i.e. were absolute poverty is lower than relative poverty; the group of chronic poor (using a relative indicator) does not have much overlap with the group of absolute poor. Thus, long term relative poverty rates can not be used as a proxy for absolute poverty. We further find significant differences between the absolute and relative poverty profiles. Thus, depending on the poverty concept used, some groups will receive more or less attention. When such profiles are used to target social policies this may also affect decisions regarding the design and evaluation of policies. Finally, the distributional patterns of benefit incidence and average benefits show that pensions, family allowances and social assistance are evaluated differently when using absolute or relative poverty measures. In some countries for instance, pensions clearly lift people out of poverty (whether absolute or relative) while in other countries, pensions are successful in lifting people out of absolute poverty but not out of relative poverty.

The cross-national poverty comparisons in chapters 2 and 3 are limited in two ways. ${ }^{1}$ As discussed in chapter 2 , the use of PPP rates to convert the absolute US poverty lines to the national price levels of the other countries may yield poverty lines that are not comparable to poverty lines that would be constructed on the basis of actual living costs in each country. The latter method would be preferable as it is more likely to conform to national views on minimum costs of living. Establishing such thresholds, however, is an ambitious research project in itself. Although this limitation may thus influence

\footnotetext{
${ }^{1}$ We refer to the literature on poverty measurement which discusses the shortcomings of financial poverty indicators in general, such as the use of income as a welfare indicator, the presence of (semi) public goods such as education and health systems and differences between individual needs (Atkinson et al., 2002; Citro et al., 1995; Ravallion, 1994).
} 
the estimated absolute poverty levels, it does not interfere with the key arguments and conclusions of the research. Secondly, based on detailed comparisons of the income components in the ECHP and the CNEF-PSID, we find that the net income variables in both datasets are very similar and can thus be used for cross-national comparative poverty analyses. Nevertheless, we identify two key points that should be kept in mind in the cross-national poverty comparison. Firstly, the use of register data for Sweden, Finland and Denmark may yield higher poverty estimates than if survey data were used. Secondly, the assumption of $100 \%$ take up of low income tax credits (EITC) may underestimate the US poverty rates.

The results of our analysis point out that using a single figure is often misleading. Absolute and relative poverty indicators show related but distinct conceptual dimensions of ill being; a relative poverty concept evaluates whether someone is better (or worse) off as compared to the typical resident in that society, while an absolute poverty concept evaluates whether one has enough purchasing power to afford some minimum living standard. Especially over time, diverging patterns between both poverty indicators arise because each concept evaluates economic development from a different perspective. Using either a relative or an absolute poverty indicator thus implies that one ignores what happens to the welfare situation of another vulnerable group in society. Moreover, in terms of policy it not only affects the setting of priority groups but also the design and evaluation of policy responses and, last but not least, the budgetary implications and feasibility of efforts to reduce poverty. We therefore conclude that it would make sense to use both relative and absolute poverty indicators.

We argue that using absolute and relative poverty indicators is particularly relevant in an enlarged EU context because the new Member States are still in the process of restructuring their economies and it is expected that there will be strong economic growth; all reasons for expecting divergence between absolute and relative poverty levels and trends in these countries. For the reasons indicated above, we do not recommend the use of PPP rates to obtain comparable absolute poverty lines across EU member states. There are a range of methods that could be used instead and we discussed one of them in chapter 2 (poverty PPP rates), but further research is needed to find out which method would be most appropriate in an EU context.

\subsection{Universal versus means-tested provision of social transfers: a cost- benefit analysis}

In chapter 4 we compare the costs and benefits of means-tested versus universal provision of social transfers as effective poverty alleviating instruments. Using a reform in the provision of child benefits in Russia as a case study, we assesses the 
impact of a policy change from universal to means-tested child allowances in terms of targeting efficiency and poverty reduction. We thereby focus on the core costs of targeting including leakage, exclusion errors and total benefit expenditures, and relate these costs to the benefits in terms of poverty reduction. We use the cross-section and panel dimensions of the Russia Longitudinal Monitoring Survey (RLMS) from 2000 to 2004 to analyse the impact of the reforms and to simulate the effects of various meanstested and universal child benefit schemes.

We find that, since the reforms, more children receive benefits and that there is improved targeting of benefits to children living in low income households. Nevertheless, in 2004 one third to a quarter of the poor children does not receive benefits while about $50 \%$ of the benefits leaks to the three highest expenditure quintiles. The poverty reduction impact is modest and improved only marginally since the reforms. The simulations show that universal schemes achieve additional poverty reductions in all indicators because children who were by error excluded under the means-tested scheme now receive a benefit. Furthermore, the simulations point out that more substantial poverty reduction can only be achieved by increasing benefit size. Both scenarios, making benefits universal and increasing benefits, will increase programme costs. Our calculations indicate that, in comparison to other social expenditures, the costs of child benefits are rather low in Russia.

Due to limitations in the data, we could not take into account the administrative costs as well as the influences of behavioural effects on targeting efficiency and poverty reduction. Firstly, the administrative infrastructure needed to screen and disburse benefits is costly. Screening costs of universal targeting are expected to be lower as compared to means-tested schemes because less information is needed to determine eligibility. However, the number of benefits disbursed is higher under a universal scheme and perhaps requires additional capacity. Ceteris paribus, when screening costs outweigh the extra costs associated with an increased scale of operations, a universal targeting mechanism becomes more attractive. In general, little information on administrative costs is available. The collection of such information is not only relevant for academic purposes but governments should also be held accountable for efficient spending of tax funds. Secondly, as the size of benefits increases, more parents will apply for child benefits affecting administrative costs and programme costs. The static simulations do not take such incentive effects into account. It is therefore likely that the programme costs and poverty reduction effects under means-tested schemes using higher benefit levels are underestimated. Thirdly, social transfers also affect the amount of labour supplied by households. The effect of current benefit levels on labour supply in our case study can be assumed to be marginal given the low and flat rate benefit levels. Substantial rises in child benefits, particularly in combination with a means-tested 
scheme, may affect labour supply. It is not clear whether such labour supply effects would be substantial in the higher benefit scenarios that we simulated.

Our results question the relevance of using a means-test when child benefits are so low. The impact of current benefits on poverty is limited and a substantial number of poor children are still excluded. Moreover, the distributional inequality in Russia is high and families with children are disproportionately present at the lower parts of the income distribution. Consequently, a universal benefit scheme would automatically assist these families and leakage of benefits to high income families would be relatively low.

\subsection{Poverty risk and its relation to consumption smoothing abilities}

In chapter 5 we examine the extent to which Russian households have been able to protect their consumption against income shocks during the transition period and how the consumption smoothing abilities of various population groups are related to their relative poverty risk. This study is the first to explicitly incorporate short and long term smoothing dynamics by using an error correction mechanism. This model better reflects smoothing behaviour and its long term constraints: when faced with an income shock, households may use alternative resources to protect their consumption. At some point in time, however, such resources are depleted and consumption and income have to be in balance again. The tests indicate that the use of this model is appropriate.

We find that Russian households can only partially smooth consumption in the short and the long term while food expenditures are better protected than nonfood expenditures. The partial estimations according to various living standards and chronic poverty groups show that consumption smoothing abilities improve as the living standard increases. Although chronically poor households are partially able to protect their consumption from income shocks, at the same time, they respond by further reducing already low levels of food and non-food expenditures. However, low abilities of consumption smoothing are not always associated with high poverty risk. For instance, we find that rural households, who have a high poverty risk, manage to smooth food expenditures quite well, most likely because they have more opportunities to produce their own food. On the other hand, households with pensioners have a low poverty risk and high smoothing abilities.

A limitation in this research is that the consumption smoothing abilities for various population groups are obtained by estimating the model for a selection of socioeconomic groups separately. Preferably, the influence of household characteristics should be directly incorporated in a single model of consumption smoothing. The inclusion of additional variables was not feasible due to insufficient degrees of freedom 
and because some relevant characteristics are constant and would thus be dropped in the (differenced) GMM estimations.

Our results support the arguments of those who propose a new orientation of social protection policies; in addition to policies aimed at poverty relief there is also an important role for the government in terms of assisting households managing risks (Holzman \& Jorgensen, February 2000; Neubourg de, 2002; Neubourg de \& Weigand, 2000). Although we provide a number of intuitively appealing explanations for our results, more in depth research is required to understand the underlying determinants of poverty risk and consumption smoothing abilities in specific contexts.

\subsection{Managing risks: what do (Russian) households do to smooth consumption?}

In chapter 6 we develop a conceptual framework to study how households smooth consumption and apply this framework to Russian household survey data. The conceptual framework of possible smoothing arrangements distinguishes between various smoothing strategies, institutional smoothing partners and required assets. Subsequently, we use this framework to select and analyse a broad set of indicators from household survey data to study what actions Russian households take and how this may help them smooth consumption. This framework enables us to analyse and interpret existing survey data from a different perspective, thereby generating information about which smoothing channels are worth further investigating and which linkages have to be taken into account. The analysis shows that households may smooth consumption through saving and borrowing but that financial markets play a very limited role. Instead, providers of credit are households themselves, the employers of household members or 'credit' is provided in the goods market in the form of unpaid utility bills. The evidence on home food production suggests that this activity is not so much a postshock smoothing response but constitutes a comprehensive part of (in kind) income generating activities in Russia. The results yield another interesting hypothesis which is that the relatively generous pension system induces a re-redistribution of pensions from the elderly to their younger family members through gift giving.

The analysis in chapter 6 does not prove that the observed actions do have smoothing motivations; it only provides a first step in the sense that it helps to formulate hypotheses and provides information about important features of a formal model. The subsequent development and testing of such models is a challenging task. Important topics for further research are the development and testing of models that disentangle the welfare effects of risk response and shock response behaviour, and the analysis of interrelationships between several smoothing arrangements. 
The ability of a household to ensure that it has sufficient means to fulfil the basic needs of its members, today as well as tomorrow, is a key aspect of economic well-being and thereby also an important explanatory factor explaining their behaviour. Individuals manage the risk of not being able to satisfy their needs, by making a complex set of arrangements using various institutional counterparts, the household being the principal risk management institution. It is important, both for academic and policy purposes, to better understand the success or failure of smoothing arrangements and how arrangements complement or substitute each other. The increasing availability of panel data, also in developing and transition economies, provides many opportunities to test theories on consumption smoothing behaviour. At the same time, testing these theories requires a filtering of essential explanatory ingredients from large databases. This chapter shows how conceptual and exploratory empirical analyses can contribute to this filtering process. Moreover, the analysis suggests that the scope of public actions to assist individuals and households to smooth consumption extends beyond the scope of public social protection policies. But before governments can adequately assist households with managing risks, they need to understand how groups in their population currently manage such risks. The conceptual framework in chapter 6 of this dissertation enables one to explore these complex relationships without limiting the scope of potential policy responses to social policies. 
8 References 
Alessi, R., \& A. Lusardi. (1997). Saving and income smoothing: Evidence from panel data. European Economic Review, 41, pp. 1251-1297.

Altonji, J.G., F. Hayashi, \& L.J. Kotlikoff. (1992). Is the extended family altruistically linked? Direct tests using micro data. American Economic Review, 82(5), pp. 1177-1198.

Alvarez, P. (September 2001). The politics of income inequality in the OECD: The role of second order effects. Luxembourg Income Study Working Paper, 284.

Arellano, M., \& S. Bond. (1991). Some tests of specification for panel data: Monte Carlo evidence and an application to employment equations. Review of Economic Studies, 58(2), pp. 277-297.

Atkinson, A.B. (1998). Poverty in Europe. Oxford, UK; Malden, Mass: Blackwell.

Atkinson, A.B., B. Cantillon, E. Marlier, \& B. Nolan. (2002). Social indicators: the EU and social inclusion. Oxford; New York: Oxford University Press.

Atkinson, A.B., L. Rainwater, \& T.M. Smeeding. (1995). Income distribution in OECD countries: the evidence from the Luxembourg Income Study (LIS). Paris: Organisation for Economic Co-operation and Development.

Baltagi, B.H. (2001). A companion to theoretical econometrics: Malden, Mass.: Blackwell.

Bardhan, P., \& C. Udry. (1999). Development microeconomics. Oxford; New York: Oxford University Press.

Barr, N.A. (2004). The Economics of the Welfare State (4 ed.). Oxford: Oxford University Press.

Behrendt, C. (2000). Do means-tested benefits alleviate poverty? Evidence on Germany, Sweden and the United Kingdom from the Luxemburg Income Study. Journal of European Social Policy, 10(1), pp. 23-41.

Besley, T. (1990). Means testing versus universal provision in poverty alleviation programmes. Economica, 57(225), pp. 119-129.

Besley, T. (1995). Savings, credit and insurance. In Behrman, J. \& T.N. Srinivasan (Eds.), Handbook of development economics (Vol. 9, pp. 2123-2207). Amsterdam; New York and Oxford: Elsevier Science, North Holland.

Besley, T., \& R. Kanbur. (1990). The principles of targeting. Poverty, Research and External Affairs Working Paper, WPS 385.

Blank, R. (2002). Evaluating welfare reform in the United States. Journal of Economic Literature, 40(4), pp. 1105-1166.

Brown, A. (1999). The Russian crisis: Beginning of the end or end of the beginning? Post-Soviet Affairs, 15(1), pp. 56-73.

Buchs, T.D. (1999). Financial crisis in the Russian Federation. Economics of Transition, 7(3), pp. 687-716.

Butrica, B.A., \& R.V. Burkhauser. (1997). Estimating federal income tax burdens for Panel Study of Income Dynamics (PSID) using the National Bureau of Economic Research TAXSIM model: Unpublished manuscript, Maxwell Center for Demography and Economics of Aging, Syracuse University, New York. 
Cantillon, B., I. Marx, \& K. van den Bosch. (2004). Welfare state protection, labour markets and poverty: Lessons from cross-country comparisons. In Standing, G. (Ed.), Minimum income schemes in Europe. Geneva: International Labour Organization.

Cantillon, B., \& K. van den Bosch. (December 2002). Social policy strategies to combat income poverty of children and families in Europe. Luxembourg Income Study Working Paper, 336.

Castles, I. (1996). Review of the OECD-Eurostat PPP Program. Economic Studies Branch, STD/ PPP(97)5.

Citro, C.F., R.T. Michael, \& Panel on Poverty and Family Assistance. (1995). Measuring poverty: a new approach: summary and recommendations. Washington, D.C.: National Academy Press.

Coady, D., M. Grosh, \& J. Hoddinott. (2004a). Targeting of transfers in developing countries; Review of lessons and experience. Washington D.C.: IBRD; The World Bank.

Coady, D., M. Grosh, \& J. Hoddinott. (2004b). Targeting outcomes redux. The World Bank Observer, 19(1), pp. 61-85.

Cochrane, J.H. (1991). A simple test of consumption insurance. Journal of Political Economy, 99(5), pp. 957-976.

Commander, S., A. Tolstopiatenko, \& R. Yemtsov. (1999). Channels of redistribution. Economics of Transition, 7(2), pp. 411-448.

Deaton, A. (1992). Understanding consumption. Oxford; New York; Toronto and Melbourne: Oxford University Press; Clarendon Press.

Deaton, A. (1997). The analysis of household surveys: A microeconometric approach to development policy. Baltimore; London: Johns Hopkins University Press for The World Bank.

Deaton, A., \& J. Muellbauer. (1980). Economics and consumer behavior. Cambridge: Cambridge University Press.

Denisova, I., S. Kolenikov, \& K. Yudaeva. (2000). Child benefits and child poverty. CEFIR Working Paper, Center for Economic and Financial Research.

Dercon, S. (1998). Wealth, risk and activity choice: Cattle in western Tanzania. Journal of Development Economics, 55, pp. 1-42.

Dubois, B., B. Jullien, \& T. Magnac. (December 2006). Formal and informal risk sharing in LDC's: Theory and empirical evidence. University of Toulouse, Toulouse.

Duclos, J.-Y., \& A. Araar. (2006). Poverty and equity: Measurement, policy, and estimation with $D A D$. New York: Springer.

Edmonds, E.V. (2005). Targeting child benefits in a transition economy. Economics of Transition, 13(1), pp. 187-210.

Eswaran, M., \& A. Kotwal. (1989). Credit as insurance in agrarian economies. Journal of Development Economics, 31, pp. 37-53.

Euro Panel Users Network. (July 2004). ECHP user Guide [Electronic Version]. Institute for Social and Economic Research, University of Essex. Retrieved August 2005 from http://epunet. essex.ac.uk/ECHP_USER_GUIDE_06-07-2004b.pdf. 
Eurostat. (2002). Imputation of income in the ECHP [Electronic Version], DOC. PAN 164/2002-12. Retrieved August 2005 from http://forum.europa.eu.int/Public/irc/dsis/echpanel/library?1=/ user_db\&vm=detailed $\& s b=$ Title.

Eurostat. (2003a). ECHP UDB description of variables [Electronic Version], DOC. PAN 166/2003-12 Retrieved August 2005 from http://forum.europa.eu.int/Public/irc/dsis/echpanel/library?l=/ user_db\&vm=detailed $\&$ sb=Title

Eurostat. (2003b). Laeken indicators; Detailed calculation methodology [Electronic Version]. Working Group Statistics on Income, Poverty and Social Exclusion, DOC. E2/ISPE/2003. Retrieved August 2005 from http://forum.europa.eu.int/Members/irc/dsis/soipase/home.

Fafchamps, M., \& S. Lund. (2003). Risk-sharing networks in rural Philippines. Journal of Development Economics, 71(2), pp. 261-287.

Federal Service of State Statistics. (2002). Handbook Russia 2002 [Electronic Version]. Retrieved January 2006 from http://www.gks.ru/eng/bd.asp.

Fischer, G.M. (1992). The development of the Orshansky poverty thresholds and their subsequent history as the official U.S. poverty measure [Electronic Version]. Retrieved August 2005 from http://www.census.gov/hhes/www/povmeas/papers/orshansky.html

Foley, M., \& W. Pyle. (September 2005). Household savings in Russia during the transition. Middlebury College Economics Discussion Paper, 05-22, Department of Economics, Middlebury College.

Förster, M., \& M.M. d'Ercole. (2005). Selection of figures: Income distribution and poverty in OECD countries in the second half of the 1990s [Electronic Version]. OECD Social, Employment and Migration, Working Paper 22. Retrieved August 2005 from www.oecd.org/els/ workingpapers.

Förster, M.F., \& I.G. Tóth. (2001). Child poverty and family transfers in the Czech Republic, Hungary and Poland. Journal of European Social Policy, 11(4), pp. 324-341.

Foster, J., J. Greer, \& E. Thorbecke. (1984). A class of decomposable poverty measures. Econometrica, 52(3), pp. 761-766.

Friedman, M., \& R. National Bureau of Economic. (1957). A theory of the consumption function. Princeton: Princeton University Press.

Fuchs, M. (2002). Building trust: Developing the Russian financial sector. Washington, DC.: The World Bank.

Gassmann, F. (2000). On the verge of poverty: Welfare and economic transition in Latvia. Department of Economics, Maastricht University, Maastricht.

Gassmann, F. (2003). Review of targeted social assistance in Russia; Description, analysis and recommendations. Eindhoven Gassmann Consulting.

Gelbach, J.B., \& L.H. Pritchett. (1997). More for the poor is less for the poor: the politics of targeting. Policy Research Working Paper, Washington DC, The World Bank.

Gottschalk, P., \& T.M. Smeeding. (2000). Cross-national comparisons of earnings and income inequality. Journal of Economic Literature, 35(2), pp. 633-687. 
Gouskova, E., \& R. Schoeni. (2002). Comparing estimates of family income in the Panel Study of Income Dynamics and the March Current Population Survey, 1968-1999: Unpublished manuscript, Institute for Social Research, University of Michigan.

Greene, W.H. ( 2003). Econometric analysis (5 ed.). New Jersey: Prentice Hall.

Gronau, R. (June 2006). Home Production and the Macro Economy - Some Lessons from Pollak and Wachter and from Transition Russia. NBER Working Paper, 12287, National Bureau of Economic Research, Cambridge.

Grosh, M. (1994). Administering targeted social programs in Latin America: from platitudes to practise. Washington D.C.: The International Bank for Reconstruction and Development, The World Bank.

Guariglia, A., \& B. Kim. (2003). Wage arrears, uncertainty and precautionary saving in Russia. Economics of Transition, 11(3), pp. 493-512.

Hausman, J.A. (1978). Specification tests in econometrics. Econometrica, 46(6), pp. 1251-1271.

Heady, C., T. Mitrakos, \& P. Tsakloglou. (2001). The distributional impact of social transfers in the European Union: Evidence from the ECHP. IZA Discussion Paper, 356, IZA, Bonn.

Heeringa, G.H. (1997). Russia Longitudinal Monitoring Survey (RLMS); Sample attrition, replenishment, and weighting in rounds V-VII: MI 48106-1248, Survey Design and Analysis Unit, Institute for Social Research, University of Michigan, Ann Arbor.

Hill, M.S. (1992). The Panel Study of Income Dynamics; a user's guide. Newbury Park, California/ London, England: Sage Publications.

Holzman, R., \& S. Jorgensen. ( February 2000). Social Risk Management: A new conceptual framework for social protection and beyond. Social Protection Discussion Paper, 6, The World Bank

Hoogeveen, H. (2001). Evidence on informal insurance in rural Zimbabwe. Tinbergen Institute Discussion Paper, TI 2001-001/2, Tinbergen Institute.

Hulme, D., \& A. Shepherd. (2003). Conceptualizing chronic poverty. World Development, 31(1), pp. 403-423.

IAAC. (October 2006). Analysis of parameters and status of the pension system: Demographic, macroeconomic and pension aspects. Contract No. 2003/071-225, Progress report, as part of the International Technical Assistance Project "Pension System - Russian Federation", Moscow.

Immervoll, H., H. Sutherland, \& K. de Vos. (2000). Child poverty and child benefits in the European Union. EUROMOD Working Paper, EM1/00.

Internal Revenue Service. (2002). Participation in the Earned Income Tax Credit Program for Tax Year 1996 [Electronic Version], performed by SBSE Research, Research Project 12.26, Greensboro (NC) Retrieved February 2007 from http://www.taxpolicycenter.org/taxfacts/ papers/irs_eitc.pdf.

International Monetary Fund. (2005). Country report Russia 
International Social Security Association. (2002). Social security programmes throughout the world [Electronic Version]. Retrieved May 2007 from http://www.ssa.gov/policy/docs/progdesc/ ssptw/.

International Social Security Association. (2003). Social security programmes throughout the world: The Americas 2003 [Electronic Version]. Retrieved April 2007 from http://www.ssa.gov/ policy/docs/progdesc/ssptw/.

Karelova, G.N. (2003). Public allowances to citizens having children: Urgent assignment and payment problems during transition to a new nodel. In MLSD (Ed.), Regionalni opit nasnachenija $i$ viplati gocudarstvennih pocobi grashdanam, imeiushchim dieti (pp. 6-14). Moscow: MLSD.

Kazianga, H. (2006). Motives for household private transfers in Burkina Faso. Journal of Development Economics, 79, pp. 73-117.

Kimball, M.S. (1990). Precautionary saving in the small and in the large. Econometrica, 58(1), pp. 53-73.

Kobaladze, K. (November 2002). Non-farm livelihood activities in three villages in different regions of Georgia. NRI Report, 2736, National Resources Institute.

Kochar, A. (2004). Ill-health, savings and portfolio choices in developing economies. Journal of Development Economics, 73, pp. 257-285.

Ligon, E. (1998). Risk sharing and information in village economies. Review of Economic Studies, 65, pp. 847-864.

Lillard, D.R., M. Grabka, \& S. Freidin. (not dated). Codebook for the Cross-National Equivalent File 1980-2005 BHPS - GSOEP - HILDA - PSID - SLID [Electronic Version], Cornell University; DIW Berlin. Retrieved January 2006 from http://www.human.cornell.edu/che/ PAM/Research/Centers-Programs/German-Panel/cnef.cfm. .

Lokshin, M., \& M. Ravallion. (2000). Welfare impacts of the 1998 financial crisis in Russia and the response of the public safety net. Economics of Transition, 8(2), pp. 269-295.

Lokshin, M., \& R. Yemtsov. (February 2001). Household strategies for coping with poverty and social exclusion in post-crisis Russia. Policy Research Working Paper, 2556, The World Bank.

Mace, B.J. (1991). Full Insurance in the Presence of Aggregate Uncertainty. The Journal of Political Economy, 99(5), pp. 928-956.

Maitre, B., B. Nolan, \& C. Whelan. (January 2006). Reconfiguring the Measurement of Deprivation and Consistent Poverty in Ireland (Vol. 58). Dublin: ESRI.

Marlier, E., A.B. Atkinson, B. Cantillon, \& B. Nolan. (2007). The EU and social inclusion: Facing the challenges. Bristol: The Policy Press.

Marx, I., \& K. van den Bosch. (2007, September 2007). How poverty differs from inequality. On poverty measurement in an enlarged EU context: conventional and alternative approaches. Paper presented at the 34th CEIES Seminar, Helsinki.

Maslow, A.H. (1987). Motivation and personality (3 ed.). New York: Longman. 
Matsaganis, M., C. O’Donoghue, H. Levy, M. Coromaldi, M. Mercader-Prats, C. Farinha Rodrigues, et al. (2004, August 2004). Child poverty and family transfers in southern Europe [Electronic Version], 28th General Conference of the International Association for Research in Income and Wealth, Cork, Ireland. Retrieved August 2006 from www.iariw.org/papers/2004/holly. pdf.

McKenzie, D. (2003). How do households cope with aggregate shocks? Evidence from the Mexican Peso crisis. World Development, 31(7), pp. 1179-1199.

MGSoG. (2006). Assessment of the labor market impact of the pension reform: Final report: Maastricht Graduate School of Governance and Arcadis Moscow, funded by European Commission under Project number 2003/071-225.

Milanovic, B. (1998). The role of social assistance in addressing poverty. In Braitwaite, J., C. Grootaert \& B. Milanovic (Eds.), Determinants of poverty and targeting social assistance in Eastern Europe and the former Soviet Union: Poverty Reduction, Economic Management and Human Development Networks, The World Bank.

Moene, K.O., \& M. Wallerstein. (2001). Targeting and political support for welfare spending. Economics of Governance, 2(2001), pp. 3-24.

Moffitt, R. (2002). Welfare Programs and labor supply. In Auerbach, A. \& M. Feldstein (Eds.), Handbook of Public Economics (Vol. 4).

Moffitt, R. (2003). The temporary assistance for needy families program. In Moffitt, R. (Ed.), Meanstested transfer programs in the United States. Chicago: University of Chicago Press.

Morduch, J. (1994). Poverty and vulnerability. The American Economic Review, 84(2), pp. 221-225.

Morduch, J. (1995). Income smoothing and consumption smoothing. The Journal of Economic Perspectives, 9(3), pp. 103-114.

Mroz, T., L. Henderson, M. Bontch-Osmolovsii, \& B.M. Popkin. (April 2004). Monitoring economic conditions in the Russian Federation: The Russia Longitudinal Monitoring Survey 19922003. Report submitted to the U.S. Agency for International Development.

Nelson, K. (2004). Mechanisms of poverty alleviation: anti-poverty effects of non-means-tested and means-tested benefits in five welfare states. Journal of European Social Policy, 14(4), pp. 371-390.

Neubourg de, C. (2002). The welfare pentagon and the social management of risks. In R. Sigg \& C. Behrendt (Eds.), Social security in the global village (Vol. 8, pp. 313-331). New Brunswick: Transaction publishers.

Neubourg de, C., J. Castonguay, \& K. Roelen. (2007). Social safety nets and targeted social assistance: Lessons from the European experience. World Bank Social Protection working Papers, forthcoming, Washington DC, The World Bank

Neubourg de, C., \& G. Notten. (May 2002). Assessing vulnerability to poverty: the dynamics of risk exposure and risk dealing capacities. Paper presented at the 10e Studiedagen, SISWO, Amsterdam. 
Neubourg de, C., \& C. Weigand. (2000). Social policy as social risk management. Innovation: The European Journal of Social Sciences, 13(4), pp. 401-412.

Notten, G. (2007). Managing risks: what Russian households do to smooth consumption. MGSoG Working Paper, 2007/004, Maastricht Graduate School of Governance, Maastricht University, Maastricht.

Notten, G., \& D. Crombrugghe de. (2006). Poverty and consumption insurance in Russia. MGSoG Working Paper, 2006/004, Maastricht Graduate School of Governance, Maastricht University, Maastricht.

Notten, G., \& F. Gassmann. (2006). Size matters: poverty reduction effects of means-tested and universal child benefits in Russia. MGSoG Working Paper, 2006/001, Maastricht Graduate School of Governance, Maastricht University, Maastricht.

Notten, G., \& C. Neubourg de. (2007a). The policy relevance of absolute and relative poverty headcounts: What's in a number? MGSoG Working Paper, 2007/006, Maastricht Graduate School of Governance, Maastricht University, Maastricht.

Notten, G., \& C. Neubourg de. (2007b). Poverty in Europe and the USA: Exchanging official measurement methods. MGSoG Working Paper, 2007/005, Maastricht Graduate School of Governance, Maastricht University, Maastricht.

Notten, G., \& C. Neubourg de. (2007c). Relative or absolute poverty in the US and EU? The battle of the rates. MGSoG Working Paper, 2007/001, Maastricht Graduate School of Governance, Maastricht University, Maastricht.

O'Boyle, E.J. (1999). Toward an improved definition of poverty. Review of Social Economy, 57(3), pp. 281-301.

OECD. (2001a). Financial market trends (Vol. 70). Paris: Organization of Economic Co-operation and Development.

OECD. (2001b). The investment environment in the Russian Federation: Laws, policies and institutions. Paris: Organization of Economic Co-operation and Development.

OECD. (2002). OECD economic surveys 2001-2002: Russian Federation (Vol. 2002/5 February). Paris: Organization of Economic Co-operation and Development.

Ovcharova, L.N., \& D.O. Popova. (2005). Child Poverty in Russia: Alarming trends and Policy Options: Independent Institute of Social Policy, Moscow.

Ravallion, M. (1994). Poverty comparisons (Vol. 56): Harwood Academic Press.

Ravallion, M., \& S. Chaudhuri. (1997). Risk and Insurance in Village India: Comment. Econometrica, 65(1), 171-184.

Ravallion, M., \& S. Chen. (2003). Measuring pro-poor growth. Economic Letters, 78, pp. 93-99.

Rendtel, U., L. Nordberg, M. Jäntti, J. Hanisch, \& E. Basic. (January 2004). Report on quality of income data, the change from input harmonization to ex-post harmonization in the national samples of the European Community Household Panel - Implications on data quality. Chintex working paper, 21 . 
Rosenzweig, M. (1988). Risk, implicit contracts and the family in rural areas of low-income countries. The Economic Journal, 98, pp. 1148-1170.

Rosenzweig, M., \& K. Wolpin. (1993). Credit market constraints, consumption smoothing, and the accumulation of durable production assets in low-income countries: Investments in bullocks in India. The Journal of Political Economy, 101(2), pp. 223-244.

Sainsbury, D., \& A. Morissens. (2002). Poverty in Europe in the mid-1990s: the effectiveness of means-tested benefits. Journal of European Social Policy, 12(4), pp. 307-327.

Sapir, J. (1999). Russia's crash of August 1998: Diagnosis and prescription. Post-Soviet Affairs, 15(1), pp. 1-36.

Schreyer, P., \& F. Koechlin. (2002). Purchasing Power Parities - Measurement issues [Electronic Version], 3, Statistics Brief, OECD, Paris. Retrieved August 2005 from http://www.oecd. org/dataoecd/32/34/2078177.pdf.

Sen, A. (1995). The political economy of targeting. In van de Walle, D. \& K. Nead (Eds.), Public Spending and the Poor. Baltimore: Johns Hopkins University Press.

Skoufias, E. (2003). Consumption smoothing in Russia: Evidence from the RLMS. Economics of Transition, 11(1), pp. 67-91.

Slay, B. (1999). An interpretation of the Russian financial crisis. Post-Soviet Geography and Economics, 40(3), pp. 206-214.

Smeeding, T.M. (2006). Poor people in rich nations: The United States in a comparative perspective Journal of Economic Perspectives, 20(1), pp. 69-90.

Smeeding, T.M., L. Rainwater, \& G. Burtless. (2000). United States poverty in a cross-national context. Luxembourg Income Study Working Paper, 244.

Smeeding, T.M., \& K. Ross. (1997). Financial poverty in developed countries: The evidence from LIS. Luxembourg Income Study Working Paper, 155.

Soede, A. (2006). Naar een nieuwe armoedegrens? Basisbestedingen als maatstaf voor een tekortschietend Inkomen (Towards a new poverty line? Basic expenditures as a benchmark for insufficient income): Sociaal en Cultureel Planbureau (SCP), The Hague.

Townsend, R.M. (1994). Risk and insurance in village India. Econometrica, 62(3), pp. 539-591.

Udry, C. (1994). Risk and insurance in a rural credit market: An empirical investigation in northern Nigeria. Review of Economic Studies, 61, pp. 494-526.

Udry, C. (1995). Risk and saving in northern Nigeria. The American Economic Review, 85, pp. 12871300.

UNICEF. (2005). TransMONEE: Online database, January 2006, UNICEF.

US Census Bureau. (June 2005). Alternative poverty estimates in the United States: 2003 [Electronic Version], US Department of Commerce, Economics and Statistics Administration, Washington D.C. Retrieved April 2007 from http://www.census.gov/prod/2005pubs/p60-227.pdf.

Walle van de, D. (1998). Targeting revisited. The World Bank Research Observer, 13(2), pp. 231248. 
Whelan, C., Layte, R. , B. Maitre, B. Gannon, B. Nolan, D. Watson, \& J. Williams. (November 2003). Monitoring Poverty Trends in Ireland: Results From the 2001 Living in Ireland Survey (Vol. 51). Dublin: ESRI.

Whelan, C., B. Nolan, \& B. Maitre. (February 2006). Trends in Economic Vulnerability in the Republic of Ireland (Vol. 37). Dublin: Economic and Social Studies.

Windmeijer, F. (2005). A finite sample correction for the variance of linear efficient two-step GMM estimators. Journal of Econometrics, 126, pp. 25-51.

Wooldridge, J.M. (2001). Applications of Generalized Method of Moments estimation. The Journal of Economic Perspectives, 15(4), pp. 87-100.

World Bank. (1995). Poverty in Russia: An assessment: 14110-RU, Washington D.C.: The World Bank.

World Bank. (1998). Poverty policy in Russia: Targeting and the longer-term poor, a policy note: ECSPE and ECSHD ECA, Washington D.C.: The World Bank.

World Bank. (2003). The Russian labour market: Moving from crisis to recovery [Electronic Version], Washington D.C.: The World Bank. Retrieved December 2004 from http://www.worldbank. org.ru/ECA/Russia.nsf/ECADocByLink/91E880C04CBEC533C3256E27004B1C11.

World Bank. (2004). Russian Federation: Poverty Assessment: 28923-RU, Poverty Reduction and Economic Management Unit, Europe and Central Asia Region, Washington D.C.: The World Bank.

World Bank (2005). World Development Indicators 2005. Washington D.C.: The World Bank.

World Bank. (May 1999). Consultations with the poor, national synthesis report: Russia.: Washington D.C.: The World Bank.

World Bank. (October 2003). Developing residential mortgage markets in the Russian Federation: Infrastructure and Energy Department, Europe and Central Asia Region, Washington D.C.: The World Bank.

Zimmerman, F., \& M. Carter. (2003). Asset smoothing, consumption smoothing and the reproduction of inequality under risk and subsistence constraints. Journal of Development Economics, 71, pp. 233-260.

Zurabov, M. (July 2002). Pension Reform in the Russian Federation; Current Questions on Pension Reform. Moscow: Paper presented at the Seminar for Social Security Actuaries and Statisticians: Actuarial Aspects of Pension Reform, International Social Security Association, Moscow. 


\section{Appendix: poverty in Europe and the USA}




\subsection{Introduction ${ }^{12} 34$}

Official poverty rates differ from other poverty rates in the sense that the official ones are more often used as a benchmark to develop new policies as well as to evaluate the performance of existing programs. Europe has the tradition and the practice to use relative poverty (Laeken indicators); the USA use an objective method to estimate official poverty. Although related, each approach portrays different dimensions of poverty. In chapters 2 and 3 we use the official poverty measurement methods of the EU and the United States and apply both methods to USA and EU data. We use the harmonized European Community Household Panel (ECHP) for the EU-15 and the USA section of the Cross National Equivalent Files (CNEF-PSID) for the USA (1994-2001). Chapter 2 shows how some poverty differences are inherent to choosing either an absolute or a relative approach to poverty while other differences are related to more general aspects of poverty measurement. Chapter 3 discusses the relation between policy and the use of absolute and relative poverty indicators as tools to evaluate, monitor and design (social) policies. This appendix explains how we obtained these poverty figures. We firstly explain the origin and main characteristics of each poverty measurement methods and what information is required for a cross-country comparison of both methods. Then, we explain which data are used, how they were prepared for the cross-national comparative analysis and we discuss a number of comparability issues. ${ }^{5}$ Subsequently, we provide a first discussion of the results in which we focus on differences and similarities between both indicators. We compare annual poverty levels and trends between countries and for specific population groups in each country. Moreover, we also compare the USA and EU using absolute and relative indicators of long-term poverty.

\footnotetext{
${ }^{1}$ This appendix is based on: Notten, G. \& C. de Neubourg (2007). Poverty in Europe and the USA: Exchanging official measurement methods. MGSoG Working Paper, 2007/006, Maastricht Graduate School of Governance, Maastricht University, Maastricht.

${ }^{2}$ In this appendix we use data from the European Community Household Panel (ECHP). The results and conclusions of this appendix are ours and not those of Eurostat, the European Commission or any of the national authorities whose data have been used.

${ }^{3}$ This research benefited from a grant provided by the EuroPanel Users' Network (EPUNet) that financed a research visit to CEPS/INSTEAD (Differdange, Luxembourg) as well as from a travel grant provided by the Dutch Scientific Organization (NWO) which funded a research visit to the Kennedy School of Government (Cambridge, USA).

${ }^{4}$ We thank our colleagues at CEPS/INSTEAD (Differdange, Luxembourg), Kennedy School of Government (Cambridge, USA), National Poverty Institute (Ann Arbor, USA), Panel Study of Income Dynamics (Ann Arbor, USA) and the participants in the conference on 'New Directions in the Study of Inequality' (Princeton, April 2006, USA) who have contributed to the progress of this research. We are especially grateful for the constructive suggestions of Emil Tesliuc, Christopher Jencks, Mary Jo Bane, Erzo Luttmer and Gary Sandefur.

${ }^{5}$ If you have further questions please contact Geranda Notten (geranda.notten@governance.unimaas.nl).
} 


\subsection{Official poverty measurement methods in the USA and EU}

The EU methodology, the so-called Laeken At-Risk-of-Poverty indicator, is based on a relative concept of poverty. In this method, the poverty line is set at $60 \%$ of median income, thus relative to the income level in the population. The USA methodology is based on an absolute concept of poverty. The USA poverty line is based on an assessment of the basic cost of living. We named the USA poverty indicator the 'Orshansky' indicator (after the economist who developed the method).

\subsubsection{Poverty measurement in the EU: the Laeken indicators}

During the Nice summit in 2001, the EU Member States decided to combat poverty and social exclusion by means of the open method of coordination. This method 'involves fixing guidelines for the Union, establishing quantitative and qualitative indicators to be applied in each member state, and periodic monitoring' (Atkinson et al., 2002). The design and implementation of policies to fight poverty and social exclusion, however, remained predominantly the responsibility of the Member States. To monitor progress in these areas, a set of common statistical indicators was developed. Named after the Laeken European Council who endorsed the indicators in 2001, these 'Laeken indicators' cover four dimensions of social inclusion; financial poverty, employment, health and education. In this research, we use the subset of the Laeken indicators that is concerned with financial poverty.

Most of the so-called Laeken 'At-risk-of-poverty' indicators are based on a relative poverty line that is set at $60 \%$ of national median adult equivalent income (Eurostat, 2003b). The welfare indicator is based on annual net household income and includes the earnings and transfers received by the household. To control for the demographic composition of the household and economies of scale, household income is adjusted using the modified OECD equivalence scales. ${ }^{6}$ When adult equivalent household income falls below $60 \%$ of national median adult equivalent income, all of the household members are poor. The statistics bureau of the European Union, Eurostat, publishes the Laeken indicators. During the nineties, Eurostat used the European Community Household Panel (ECHP) for the financial poverty estimates.

\footnotetext{
${ }^{6}$ The modified OECD equivalence scale gives a weight of 1 to the first adult in the household, a weight of 0.5 to other members aged over 14 years and a weight of 0.3 for children under age 14 .
} 


\subsubsection{Poverty measurement in the USA: the Orshansky poverty lines}

The USA poverty lines were developed in the 1960s by Molly Orshansky, an economist working for the Social Security Administration. ${ }^{7}$ In that time there was no generally accepted standard of basic needs that could be used to determine a minimum consumption basket. The Agriculture Department, however, had defined food plans which measured the costs of food for various budgets ranging from 'liberal', 'moderate', 'low-cost' to 'economy'. Orshansky used the lowest food plans 'low-cost' and 'economy', where the costs of 'economy' were about $75-80 \%$ of the 'low-cost' plan, to develop two sets of food poverty lines. The current official poverty estimates are based on the thresholds of the 'economy' food plan which was designed for families under economic stress.

To obtain a poverty line that also included the costs of non-food consumption, Orshansky used the 1955 Household Food Consumption Survey to estimate the average share of food expenditures in total income for families of three or more persons. ${ }^{8}$ To obtain the overall poverty line the cost of the food budget was multiplied by the reciprocal of the food share (i.e. the food-ratio method). The poverty line varies with demographic composition of families. Although there have been some minor changes in the methodology over time, the poverty lines currently used are essentially the same as those developed in the 1960s. Currently, there are 48 poverty lines depending on family size and the age of household members. These thresholds are annually adjusted for inflation. ${ }^{9}$ Every year, an inflation adjustment is made using the consumer price index for urban consumers (CPI-U), which is the same for the whole USA.

The official poverty rates are annually estimated by the Bureau of Census using the March Supplement of the Current Population Survey (CPS). The poverty status of a family is obtained by comparing its gross annual income to the poverty line of that family type. The welfare indicator only includes 'money' income (i.e. earnings and money transfers). In-kind transfers such as food stamps or the consumption of public goods are not included. Housing allowances and capital gains (or losses) are also not included in the income aggregate. The demographic characteristics determining the poverty line are based on the current household situation while the welfare indicator reflects total family income of the previous (tax) year.

\footnotetext{
${ }^{7}$ This description of the Orshansky methodology is largely based on the information provided on the website of the Bureau of Census (http://www.census.gov/hhes/www/poverty/poverty.html). Especially helpful was the online paper of G. Fisher on the Development of the Orshansky poverty thresholds (Fischer, 1992).

${ }^{8}$ Orshansky found that the average share of food expenditures was about one third of family income. Also note that this is the average food share of the total population of families and not low-income families.

${ }^{9}$ The thresholds are available for each year on the website of the Bureau of Census on www.census.gov/ hhes/www/poverty/threshld.
} 


\subsubsection{Application of both poverty measurement methods}

The above discussion reveals a number of information requirements which need to be satisfied in each dataset to enable an application of both poverty measurement methods to European countries and the USA. Firstly, to obtain Orshansky poverty estimates for the European countries we need a welfare indicator that is comparable to the one used in the USA and we need to convert the absolute Orshansky poverty lines to comparable values in each of the European countries. Secondly, in order to obtain Laeken poverty estimates for the USA we need a welfare indicator that is comparable to that being used in Europe. Thirdly, the definition of total household income used in the Orshansky indicator differs from that used in the Laeken poverty rates. The main difference is that the Orshansky poverty rates are calculated using gross income while the Laeken poverty rates are calculated using net household income. Fourthly, the Laeken and Orshansky methods use different equivalence scales to adjust for household size and household composition and thus require different identification variables. In the Laeken methodology household income is adjusted using the modified OECD equivalence scales while the Orshansky methodology uses a different set of equivalence scales by distinguishing a specific poverty line for each of the 48 household types.

The ideal approach for comparing both poverty methods on Europe and the USA would require that household data are collected in the same way in both regions (using the same sampling design, questionnaires, data cleaning, methods for constructing variables etc.). Moreover, these data would have to provide all relevant variables needed to compute the poverty rates according to both methodologies (gross income, net income, basic cost of living in each European country etc.). Given time and budget restrictions, we followed a more pragmatic approach. We selected household budget surveys for both regions that are reasonably comparable in terms of collection and variables (see section 9.3). Secondly, we used purchasing power parity (PPP) rates to convert the Orshansky thresholds to the price levels in each of the European countries. The main rationale for this choice is that the current USA thresholds are based on the cost of living in the 1960s and that the construction of up to date thresholds reflecting the cost of living in each country (including the US) would constitute an ambitious research project in itself. Our method is further explained in section 9.3 while the limitations and alternatives are discussed in chapter 2. Furthermore, we decided to use net household income as the principal welfare indicator for the calculation of both Laeken and Orshansky poverty rates. The main reason for using net income is that it better reflects disposable income i.e. the income that a household has at its disposition 
to finance household expenditures. ${ }^{10}$ For the rest, we followed the methodologies as explained above. This implies that the Orshansky poverty rates have been calculated using different equivalence scales than those used for the Laeken poverty rates. The impact of equivalence scales on absolute and relative poverty rates is further studied in chapter 2.

We compare the Orshansky and Laeken indicators using various poverty measures such as the percentage of poor individuals (poverty incidence), the percentage of individuals living in long term poverty (chronic or long term poverty incidence) and the mean proportionate income shortfall in the population (poverty gap). We decompose the poverty incidence of various groups in the population by gender, age, household type and main source of income. We also study the impact of various transfers on Orshansky and Laeken poverty rates.

\subsection{Making poverty rates between Europe and the USA comparable}

The Laeken and Orshansky poverty rates are mainly based on two household surveys: the European Community Household Panel (ECHP) and the USA section of the Cross-National Equivalent Files (CNEF-PSID). We complemented these datasets with information from other sources such as the Panel Study on Income Dynamics (PSID), Bureau of Census, Federal Reserve, Eurostat and the OECD. In sections 9.3.1 and 9.3.2 we describe the main datasets (ECHP and the CNEF), explain how we supplemented these datasets with information from the above mentioned sources and how we further prepared the data for the comparative poverty analysis. In section 9.4 we discuss a number of issues related to the cross-national comparability of both datasets.

\subsubsection{European Union - ECHP}

The ECHP is a harmonized household budget survey for 15 European Union (EU15) member states collected over eight waves from 1994 to 2001. The ECHP contains information for the following countries: Belgium, Denmark, Germany, Greece, Spain, France, Ireland, Italy, Luxembourg, Netherlands, Austria (1995-2001), Portugal, Finland (1996-2001), Sweden (1997-2001) and the United Kingdom. The data provide cross-section and longitudinal information on household and individual level on topics such as income, education, housing, health and social relations. Comparability of the ECHP data is achieved through common survey structure and procedures, common

\footnotetext{
${ }^{10}$ This implies that our US Orshansky poverty rates will differ from the official poverty rates as published by the Bureau of Census.
} 
standards on sampling requirements and where possible on data processing and statistical analysis as well as the use of a 'blue-print' questionnaire used as point of departure for all national surveys. For most of the countries the surveys were collected using a harmonized questionnaire. For Germany, Luxembourg, Sweden and United Kingdom the national surveys of these countries were converted into ECHP format.

We base our analysis on the User Data Base (UDB) of the ECHP which consists of a series of separate files. ${ }^{11}$ For each wave, there is a household and an individual file. These files hold the variables that have been derived from the household and individual questionnaires. The register file includes information on every household and individual that has been interviewed over time. ${ }^{12}$ The longitudinal link file contains some timefixed and wave specific variables on every individual. This information needed for constructing a panel. Finally, there is a country file which includes some country level variables such as exchange rates, consumer price indices, purchasing power parities and population size.

We first extracted all relevant information from these files and constructed a single database. ${ }^{13}$ This household level database holds information on the demographic characteristics of the household and its income (for each country and wave). We also created a number of household variables indicating the total number of males and females in the household as well as the number of household members by age category (age 0-15, age 16-24, age 25-49, age 50-64 and above age 65). These variables were first created in the register file and then merged to the household level file using the appropriate identification variables (country, wave, household identification number). ${ }^{14}$ We did not need to generate an income variable for the Laeken indicators because the total income variable in the ECHP has been constructed following the income definition used in the Laeken indicators. This income variable represents total net household income in the year previous to the survey. We also generated a variable indicating

\footnotetext{
${ }^{11}$ For more detailed information on the UDB, we refer to the ECHP UDB manual (Eurostat, 2003a) and the EPUNet ECHP user guide (Euro Panel Users Network, July 2004).

${ }^{12}$ Individuals that were present in the first wave (1994 for most countries) were re-contacted every subsequent year. These 'sample' persons and the households they were living in were interviewed. We compared the number of 'sample' persons for each country in the first (available) wave with those in wave 8 . In Ireland, only $43 \%$ of the 'sample' persons were interviewed in wave 8 . In Belgium and Denmark retention rates were about $65 \%$ while in the other countries retention rates were above $70 \%$ ( 5 countries) or $80 \%$ ( 7 countries). Low retention rates are of concern because they may reduce the representativeness of the sample (as compared to the countries' population). To counteract this potential problem the cross-section and longitudinal weights are adjusted in every wave.

${ }^{13}$ We used the 'ECHP extract' Stata ado-file written by Philippe van Kerm (CEPS/INSTEAD, Differdange, Luxembourg) and available on http://www.Vankerm.net/stata (retrieved February 2006).

${ }^{14}$ Because there was no household interview date we could not calculate the exact age. Instead we subtracted the age from the year of the wave from the person's birth year.
} 
total gross income using the net/gross factor (hi020) provided in the ECHP as well as income variables indicating pre-transfer income (one excluding all social transfer income and another excluding all non-pension transfers). We further converted the 48 poverty lines ${ }^{15}$ from 1993 to the national living standards of the member states. Finally, we generated a variable that identified each household in a particular wave with one of the 48 USA household level poverty thresholds. Other required variables were already present in the User Database.

Although the data are on a household level, and we determine the poverty status also at this level, we establish the relative poverty line and calculate the aggregate poverty measures by counting each individual. We use the household cross-section sample weights multiplied by household size to get representative estimates for the national population.

To analyse long term poverty, we determined the poverty status at a household level and thereafter continued the analysis at an individual level. We therefore expanded the household level file to an individual level by merging the individual level identification variable and some other variables (gender, age, whether individual is present in household in a particular wave) from the longitudinal file into the household file. To get representative population estimates, we used the longitudinal weights from the ECHP for the analysis of poverty dynamics.

\subsubsection{United States - CNEF-PSID}

Although the official USA poverty estimates are calculated using the March supplement of the Current Population Survey (CPS), we use the Panel Study of Income Dynamics (PSID). The PSID data are available in two formats; the original ones that can be downloaded from the website of the PSID and the so-called Cross-National Equivalent Files (CNEF). The CNEF contains equivalently defined variables for the Panel Study of Income Dynamics (PSID), the German Socio-Economic Panel (GSOEP), the British Household Panel Study (BHPS), and the Canadian Survey of Labour and Income Dynamics (SLID). The most interesting feature of the equivalent files is that they provide a set of constructed variables that are can be used for cross-national comparisons while these variables are not directly available in the original surveys. This is particularly relevant for household income, the welfare indicator for both the Orshansky and Laeken poverty rates. The CNEF data include imputed variables for the tax burden and thereby allow the construction of pre tax and post tax income. This information is not

\footnotetext{
${ }^{15}$ The equivalence scales are included in the poverty lines instead of being applied to household income. There are 48 different household types specified and each household type has its own poverty line.
} 
readily available in the PSID or in the CPS. Moreover, using the CNEF also means that the CNEF-PSID variables are harmonized with two datasets that are also the basis for the ECHP data of these countries (GSOEP and BHPS). ${ }^{16} \mathrm{~A}$ final reason for preferring the PSID-CNEF above the CPS is that the PSID is a panel and thereby also allows the estimation of long term poverty rates. ${ }^{17}$

The PSID is a nationally representative longitudinal dataset containing information on individual and family level on economic and demographic topics such as income, employment, family composition and residential location. Started as an annual survey in 1968, the PSID became a biennial survey since $1997 .{ }^{18}$ We use the CNEF-PSID data from 1994 to 2001 with gaps for 1998 and 2000. Next to a range of demographic and labour variables, the CNEF includes pre tax income variables such as labour income, asset income, transfer income (private and public), social security income and private retirement income (income from the year previous to the survey). It also includes variables on income taxes and social security contributions.

The CNEF data are stored by wave in individual level files which also include household level variables. We merged all waves into one file using the unique person identifier (x1110111). We created a number of household level variables indicating the total number of household members by age category and gender. We also supplemented the CNEF data with some additional variables from the PSID. ${ }^{19}$ This is possible because the CNEF includes the relevant identifiers to match individuals and households in the CNEF with those in the PSID. We obtained the following variables from the PSID: whether a household received food stamps last year and how much, whether a household received heating subsidies from the government and how much and whether the household's dwelling place was owned, rented, or neither of both.

We generated the following variables:

- $\quad$ A variable specifying 48 household types that are needed to match the household with the official United States thresholds.

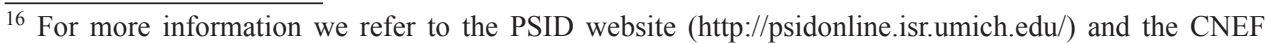
website (http://www.human.cornell.edu/che/PAM/Research/Centers-Programs/German-Panel/Cross-National-Equivalent-File_CNEF.cfm).

${ }^{17}$ Another alternative would have been to use data from the Luxembourg Income Studies (LIS). However, the LIS data are not available for a subsequent range of years nor, do they allow for longitudinal analysis.

${ }^{18}$ In 1997, the original sample was reduced from about 8,500 families to 6,168 and the sample was refreshed by adding a sample of 441 post 1968 immigrant families (the latter are not included in CNEF). The weights are adjusted in every wave to account for sample attrition.

${ }^{19}$ The PSID variables can be downloaded electronically using PSID's Datacenter (http://psidonline.isr. umich.edu/, retrieved October 2006).
} 
- A variable that indicated the household weight using the modified OECD equivalence scales. The modified OECD scales give a weight of 1 to the first adult in the household, 0.5 to every additional adult and 0.3 to every child aged below 14.

- Two total income variables; one that is consistent with the Laeken definition and one largely consistent with the official USA poverty methodology:

- A variable using the Laeken household typology.

- Variables indicating pre-transfer income; one excluding all social transfer income and another excluding all non-pension transfers.

- A variable indicating the Dollar-ECU/Euro exchange rate. ${ }^{20}$

\subsection{Comparability of main variables used in poverty analysis}

We discuss three elements of our poverty analysis that have a key influence on the crossnational comparability of the results; definition of the household, the measurement and construction of household income and the conversion of Orshansky poverty lines to the price level of the countries in the ECHP. With respect to the household definition and household income we focus on the extent to which there are differences in these elements as they are measured in the ECHP and the CNEF-PSID data. For the Orshansky poverty lines we describe the followed methodology.

\subsubsection{Definition of the household}

In poverty analyses the household is often used as the unit of analysis as this is the level at which resources are typically shared. To obtain an indicator of household income (or another monetary welfare indicator) the income of all household members are added. If the joint household income falls below the poverty line, everyone living in that household is considered poor. Both Laeken and Orshansky indicators are using the household as the unit of analysis. For our purposes it is important to find out whether there are any differences in the definition of what constitutes a household in the ECHP and the CNEF-PSID as these differences may influence the poverty measures.

There is no formal definition provided in the codebook of the ECHP. Nevertheless, the codebook describes the possible relationships between members of household (Eurostat, 2003a). Next to family relationships, cohabitants, foster parents there was also a code for 'other' relationship. This suggests that the ECHP uses the common

\footnotetext{
${ }^{20}$ Obtained from the website of the Federal Reserve (http://www.federalreserve.gov/releases/g5a/, retrieved October 2006).
} 
household definition 'individuals living together and sharing resources'. Sweden is an exception. The Swedish data come from the Swedish Living Conditions Survey and this survey uses another definition, namely 'people being taxed together'. This implies that in Sweden only adults and their dependent siblings are part of a household (elderly or other persons present in the household but not filing a joint tax form are therefore not included). If these 'other' people in the household tend to have a lower (adult equivalent) income than of the individuals in the single tax unit, this may increase the Swedish poverty rates.

The household definition in the CNEF is directly taken from the PSID and represents what is called a 'family unit' (FU). The FU is defined as a group of people living together as a family. They are generally related by blood, marriage, or adoption, but unrelated persons can be part of a FU if they are permanently living together and share income and expenses (Hill, 1992). ${ }^{21}$ The discussion above suggests that the household definitions used in the European and United States data are very similar.

\subsubsection{Income}

For the calculation of the Laeken and Orshansky poverty measures we predominantly use net household income as a welfare indicator, but for illustrative purposes we also estimated Orshansky poverty rates using an indicator of gross household income. As indicated above, total net household income the ECHP data is equivalent to the income definition as used in the Laeken indicators. In what follows, we first explain what income information is included in the ECHP, how the net and gross household income variables are constructed and whether there are methodological differences in the income variables between the countries in the ECHP. Thereafter, we explain how we constructed similar income variables for the United States in the CNEF-PSID and discuss the potential poverty impact of differences between the CNEF and ECHP income variables.

\section{Income in the ECHP}

Total net household income in the ECHP is composed of wage income and salary earnings, self-employment earnings, capital income, property/rental income, private transfers and

\footnotetext{
${ }^{21}$ The definition of the family unit used in the PSID differs from that used by the Bureau of Census and their official poverty estimates. The Bureau of Census uses a stricter definition of family and excludes unrelated persons who nevertheless share resources with other individuals living in the same housing unit (Hill, 1992). This means that a cohabiting couple is treated as 2 different families while the PSID treats those individuals as a single family.
} 
social transfers. Social transfers are composed of pensions, unemployment benefits, family related allowances, sickness/invalidity benefits, social assistance, education allowances, housing allowance and any other personal benefits. In kind transfers or home food production are not included. The total income variable (hi100) represents the annual income of the household in the year previous to the survey. The ECHP also includes a household level variable that provides an estimate of the household tax burden. This estimate is obtained from a regression that includes the average tax rates of wage income for various household types. In other words, the estimated tax burden depends on the total household income as compared to the average income of similar incomes (Eurostat, 2002). We use this variable to obtain an indicator of gross income in the ECHP data.

Albeit harmonized, cross-country comparability of the ECHP data is not perfect. Some variables are not available for every country. Sometimes this is because the information was not collected and in other cases information is confidential. ${ }^{22}$ For instance, in the German ECHP data, the values for various income subcategories are confidential but are included in the total income variable. For the UK, Netherlands, Spain and Austria the category 'lump sum earnings' is missing while information on social assistance is missing for the UK. For Austria, sickness benefits also include care allowances. Table 9.1 summarizes these income discrepancies for each country and indicates their potential effects.

Another issue is the fact that the Swedish, Danish and Finnish data are not obtained from surveys but based on register data. A study based on the comparison of Finnish register and survey data shows that the income distribution based on survey data reports higher income levels at the lower end of the distribution than register based data and vice versa for the top end of the distribution (Rendtel et al., January 2004). If this is a general phenomenon, this implies that poverty rates are likely to be higher using register data than survey data. Despite these imperfections, the ECHP remains the best alternative for intra-EU poverty comparisons.

\section{Income in the CNEF-PSID}

The CNEF includes pre- and post government income where taxes and government transfers form the difference between the two. The basis for our net household income aggregate is the post-government income variable. This variable includes all income from labour, assets, social security pensions, private pensions, private transfers and

\footnotetext{
${ }^{22}$ More detailed information on missing information can be found in the extensive variable description (Eurostat, 2003a).
} 
public transfers and is adjusted to net values using an imputed tax variable. Gross household income includes the sum of all (gross) income sources mentioned above.

Overall, analysis of the PSID questionnaires and the CNEF algorithms suggests that the PSID takes similar income sources into account as the ECHP. The level of detail in the PSID questionnaires is somewhat higher for sources of asset and entrepreneurial income and we found different algorithms for the calculation of entrepreneurial income. It is therefore possible that the PSID values for these variables are somewhat different than if the ECHP methodology would have been applied. ${ }^{23}$ The value of food stamps is included in CNEF transfer income while the ECHP labels such benefits as in-kind and does not include them. We think that the value of received food stamps should be included in our welfare indicator for two reasons. Firstly, the food stamp programme is one of the main programmes targeting poor households in the US; not including the value of these benefits would ignore this important poverty reduction effort. Secondly, food stamp benefits are issued as 'near money' in the form of an electronic debit card that can be used to purchase food items in a range of supermarkets. The CNEF does not include the value of housing and heating subsidies and education stipends are likely to be underestimated because there is no specific question aimed at this income source. ${ }^{24}$ The PSID includes variables indicating whether and how much heating subsidies were received. We retrieved this variable from the PSID and included it in the income estimate.

Even when questionnaires include similar questions on particular income sources, methodological differences in data collection and data cleaning may give rise to differences in recorded income. For instance, when income from entrepreneurial activities is negative, the ECHP sets the observed income from this source to zero. As a result, there are no negative observations in the ECHP for this income source while these are present in the PSID and the CNEF. To enhance comparability, we set any negative values from labour earnings to zero in the CNEF. Comparing poverty headcounts with and without the adjustment suggests that the impact of this adjustment on poverty statistics is negligible. Differences in top coding between the ECHP and CNEF-PSID are another issue. Top coding implies that when income exceeds a certain value it is replaced by the (lower) threshold value. In the PSID, the top coding was altered in 1999 (the thresholds were increased). In the ECHP only values above 99,999,990 were top-

\footnotetext{
${ }^{23}$ A higher level of detail in questionnaires typically increases reported income from these sources. The calculation of entrepreneurial income of the PSID also includes certain aspects of asset wage income which can also be negative. It is not clear what impact this has on the values of these income sources.

${ }^{24}$ Education benefits or stipends, if obtained, are typically not in cash but provided in the form of a tuition waver or another fee reduction.
} 
coded, two digits more than the current PSID. As top coding only affects the top of the income distribution and our poverty analyses depend on the lower half of the income distribution, we did not make any corrections. ${ }^{25}$

One of the reasons why we preferred to use the CNEF-PSID data above the original PSID or the CPS data is that the CNEF includes (imputed) indicators on households' tax burden and thus allowed to construct an after tax income indicator. The CNEF includes estimates of the households' federal and state income taxes and payroll taxes. The federal and state income tax burdens are imputed using the NBER TAXSIM model with the available PSID data while the burden of payroll taxes have been estimated using the tax rates reported by the Social Security Bulletin. Butrica and Burkhauser (1997) show in a comparison between the TAXSIM model and the PSID tax burdens that the mean and median tax burdens are very similar but that the TAXSIM model overestimates the tax burden at the higher end of the income distribution. ${ }^{26}$

An issue that is more likely to influence our USA poverty estimates is that the TAXSIM model also incorporates the higher deductions for low income families with children (Earned Income Tax Credit (EITC)). The EITC is one of the principal federal programmes targeted at the poor (together with food stamps and Medicaid). Especially at low income levels, the credit is considerable (the EITC can even exceed the value of income tax). The simulated tax burden assumes a 100 percent EITC take up rate but not all eligible households actually receive the EITC. According to a study of the Internal Revenue Service on participation in the EITC programme for the tax year 1996, up to $18 \%$ of the of the eligible individuals did not file a tax return (Internal Revenue Service, 2002). Because we do not know whether a household actually received EITC, the USA poverty estimates using net household income may be underestimating USA poverty rates. As the EITC is not available as a separate variable, we cannot estimate the potential poverty bias. The difference in Orshansky poverty rates between using net income and gross income is very small but this difference measures the complete tax effect. The small difference in poverty rates possibly masks larger flows of people moving into and out of poverty.

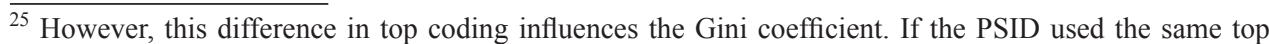
coding as the ECHP, the estimated Gini coefficients would be higher. Summary statistics on total income showed that the income of some households in the CNEF-PSID indeed was top coded but we could not find evidence that top coding actually cut-off top incomes in the ECHP.

${ }^{26}$ Since 1992, the PSID data do not include an estimate for households' tax burden. Since then, the public user version of the PSID even contains fewer variables needed as inputs for the TAXSIM model. The overestimation of the tax burden for the more affluent households is mainly due to the use of standard deductions while richer households can have a higher deduction when they itemize the deductions.
} 
Perfect comparability cannot be achieved. In many cases the information needed to estimate the potential impact of differences in algorithms and other data issues is not available. Where possible we have made adjustments to the CNEF data that enhance comparability with the ECHP. Nevertheless, we think that both the ECHP and the PSID/ CNEF have been designed to take into account those income sources that are relevant in the countries where the survey is held; in kind social assistance plays a much larger role in the USA than it does in continental Europe. Education benefits and housing subsidies are more prevalent in European welfare states than they are in the USA where tuition wavers are more prevalent. Differences in the provision of public goods and services such as education and health care are important factors that ideally should be taken into account in poverty analyses. Generally speaking, the out-of-pocket costs of postsecondary education for a family with children are considerably lower in continental Europe than in the United States. To provide children similar education opportunities, US families thus need a higher income than continental European families. Ideally, such differences should be taken into account.

\subsubsection{Orshansky poverty lines}

The Orshansky thresholds, on the other hand, are distribution independent. These poverty lines can be obtained from the website of the Bureau of Census. We merged the poverty lines into the ECHP and CNEF data. For the USA data we included the Bureau of Census poverty lines for every year. As the household income variables in CNEF and ECHP provide and estimate of households' income in the year previous to the survey, we used the 1993 - 2000 USA poverty lines. For the ECHP we first converted the 1993 Dollar thresholds to the price level of each European country using the 1993 Purchasing Power Parity rates from the OECD. ${ }^{27}$ Subsequently, we adjusted the 1993 thresholds to later years using the Consumer Price Index (CPI) from the country level files in the ECHP. Thus, we used the same price updating mechanism for the European Orshansky poverty lines. This method ensures that poverty lines are not influenced by year to year changes in the exchange rate. We constructed a variable that categorized each household in a particular wave as one of the 48 household types. Finally, we linked each household to their respective poverty line. The Laeken poverty lines depend on the income distribution and are thus only based on the income variable in both datasets.

\footnotetext{
${ }^{27}$ We obtained the 1993 United States thresholds from the website of the Bureau of Census (http://www. census.gov/hhes/www/poverty/threshld.html, retrieved August 2005) and the purchasing power parities from the website of the OECD (http://www.oecd.org/std/ppp, retrieved October 2006)).
} 


\subsection{Exchanging official poverty measurement methods: results ${ }^{28}$}

Existing poverty comparisons most often use relative concepts of poverty and are predominantly made with data from the Luxembourg Income Study (LIS) which does not have annual observations or a panel component. The OECD makes regular poverty assessments using relative poverty concept based on national micro-data (Förster $\&$ d'Ercole, 2005). Another exception is the work of Timothy Smeeding, who often analyses both absolute and relative poverty indicators studying the LIS data (Smeeding, 2006; Smeeding et al., 2000; Smeeding \& Ross, 1997). This study is the first to analyse poverty in both regions using the official poverty methodologies and applying them to both regions. It is also the first to provide a comparison of long term poverty indicators between the USA and Europe. The aim of this section is to provide a general analysis of the poverty results. We focus on the differences between the Orshansky and Laeken poverty estimates using disposable income as a welfare indicator. We analyse poverty incidence and poverty gap estimates for the period $1993-2000$ but we also include estimates for the incidence of long-term or chronic poverty. ${ }^{29}$ We provide breakdowns in poverty incidence according to age, gender, household type and main source of household income, mostly taking 2000 as a benchmark year. Furthermore, we discuss the static effect of social protection benefits on Laeken and Orshansky poverty rates. The poverty measures are calculated using the appropriate weights meaning that these estimates presented below are representative for the whole population.

\subsubsection{Poverty incidence}

The poverty incidence figures represent the percentage of poor individuals in a given country. Looking at the 2000 Orshansky poverty rates (Table 9.2 and Figure 9.1) four main groups of countries can be distinguished: a large group of countries with low to very low poverty incidence (below 7\%) including Belgium, Denmark, Germany, France, Luxembourg, the Netherlands, Austria, Finland and Sweden; a second group

\footnotetext{
${ }^{28}$ Our Laeken At-Risk-of-Poverty estimates for the ECHP are highly comparable with those reported on the Eurostat website (http://epp.eurostat.ec.europa.eu/portal/page? pageid=1996,45323734\&_dad=portal \&_schema=PORTAL\&screen=welcomeref\&open=/\&product=sdi_ps\&depth=3). The difference between our Orshansky estimates for the US and those of the Bureau of Census (http://www.census.gov/hhes/ www/poverty/histpov/histpovtb.html) are larger. Although the poverty trends are similar, our estimates yield consistently lower results. This difference can be attributed to the fact that we use a different dataset. Gouskova and Schoeni (2002) indeed report that PSID income is higher than CPS income. This could explain why we find lower poverty rates than the Bureau of Census.

${ }^{29}$ Figure 9.1 also includes Orshansky poverty estimates using gross income. We incorporated these estimates merely for illustrative purposes as the official US poverty estimates are calculated using gross income.
} 
with medium poverty incidence with the US, United Kingdom and Ireland (between 7 and $11 \%$ ). The Southern European countries Italy and Spain show high poverty levels (17 and 19\%) and Greece and Portugal very high levels (26 and 32\%). In terms of Laeken poverty, differences in poverty rates between countries are smaller and range between 10\% for Sweden and 24\% in the US. The member states from Southern Europe, Ireland and the USA have high levels of relative poverty (between 19 and 24\%) while the Northern European countries have lower levels (between 10 and 14\%). France and the UK are somewhat in the middle of these two groups (with 15 and 17\%).

Comparing the poverty incidence between the Orshansky estimates and the Laeken estimates over time, reveals some interesting observations. Although the ranking from low to high national poverty rates is to a large extent not extremely different, it is still not the same (Table 9.3). The Southern European countries (Italy, Greece, Spain and Portugal) together with Ireland form a group at the low end of the ranking. The Continental and Scandinavian countries form the top of the ranking but their mutual positions change over the years. Compared to the ranking using the Laeken estimates, the Orshansky estimates seem to produce a more stable pattern over time in Europe, while the Laeken estimates are subject to more volatility. The USA is ranked consistently at the lowest end in terms of Laeken poverty but occupies middle ranks for the Orshansky poverty rates.

The Orshansky estimates can by no means be interpreted as a linear transformation of the Laeken indicators or vice versa: in some countries there are large gaps between the lower Orshansky and the higher Laeken estimates and over time this gap may increase, remain constant or decrease. Large differences between Orshansky and Laeken are observed for Belgium, Demark, Luxembourg, Austria and the USA in both 1993 and 2000. Differences are smaller for Sweden, Finland and the Netherlands but in these countries the gap is widening over time. Orshansky estimates produced higher poverty incidence figures for the Mediterranean countries and Ireland in 1993 but in the years thereafter the Orshansky poverty rates became lower than the Laeken poverty rates in Italy and Ireland (Spain shows a similar trend).

Trying to understand why these differences occur is not easy. One of the main elements is that the Laeken poverty line depends on the income distribution (median income) while the Orshansky poverty line is distribution independent. The degree of income inequality therefore also influences the level of the Laeken threshold but not of the Orshansky poverty line. Table 9.4 illustrates this point using a couple of indicators of income dispersion calculated using the Laeken equivalent adult income distribution. Firstly, in countries with a higher income inequality (higher Gini-index) such as Luxembourg and the US, the difference between Orshansky and Laeken poverty rates is large. Comparing both poverty lines to median income, gives $60 \%$ by definition for 
all countries in case of the Laeken indicator, but a far smaller number for many of the other countries in case of the Orshansky. Luxembourg and the USA have Orshansky thresholds that are below $40 \%$ of median income while most of the Scandinavian and Continental European countries have values around 50-55\%. Secondly, for the Mediterranean countries the Orshansky poverty lines are higher in value than the Laeken poverty lines, varying from $66 \%$ of median income in Spain to $91 \%$ in Portugal. Clearly, this explains why in these Southern European countries the Orshansky poverty rates are so much higher than those in the other countries. Nevertheless, the cases of Italy and Spain suggest that differences between the Laeken and Orshansky poverty rates are not just explained by the degree of income inequality and the levels of both poverty lines. In terms of these income dispersion indicators, Italy and Spain are quite similar but whereas Spain has approximately equal Laeken and Orshansky poverty rates, Italy's Orshansky poverty rate is 2.5 percentage points lower than its Laeken poverty rate. A third reason is the fact that the estimates are based on different adult equivalent income distributions: although we use net income to calculate both indicators, the Laeken and Orshansky indicators use different equivalence scales to correct for differences in household size and demographic composition. All these elements play a role in trying to explain the difference in the poverty headcounts using Orshansky and Laeken technology.

To add another complexity, it is also clear that even changes in the poverty incidence over a relative short period $(1993-2000)$ are far from similar (Figure 9.1). ${ }^{30}$ In countries such as Ireland, Spain, Denmark, Greece and Italy, we find opposing trends in Laeken and Orshansky poverty rates. In the other countries, the poverty trends run parallel or show some divergence. Ireland is an extreme case; there was a very large decrease in Orshansky poverty rate during the nineties which was accompanied by considerable increase in Laeken poverty. In Sweden and Finland Laeken poverty increased while Orshansky poverty remained relatively constant at very low levels. In Denmark, Luxembourg and Austria poverty levels have been rather constant or slightly

\footnotetext{
${ }^{30}$ There is a considerable difference between the 1996 USA poverty rates calculated using the individual level data (using individual weights) or the household level data (using household weights multiplied by household size). Both methods can be used and normally yield only small differences, if any. The annual USA poverty results displayed in the figures and tables in the appendix are calculated using the household level data. However, using the individual level files Laeken poverty is $24.6 \%$ in 1996 compared to $21.7 \%$ using household level files. For Orshansky poverty this is $13 \%$ (versus $8.5 \%$ in the household level files). The difference in other years is negligible. We suspect that this difference may be related to the CNEF household weights in the 1997 survey (1996 income data). In 1997, the PSID sample was refreshed by a small sample of post 1968 immigrant families but this group is not included in the CNEF. To be sure, we ignore the 1996 results when we analyse USA poverty trends or differences with other countries.
} 
hovered around a certain level. Another group of countries show parallel decreases in Laeken and Orshansky poverty rates (Belgium, Germany, France, Italy, Portugal, and UK).

All in all the comparison of these two sets of indicators suggest that that the Laeken and Orshansky concepts really grasp related but different phenomena. Generally speaking, for the 'richer' countries the Orshansky poverty estimate is lower than the Laeken poverty headcount. However, in 'poorer' countries Orshansky poverty rates are higher than Laeken poverty rates but, over a longer period, the Orshansky poverty rates are typically moving downward in the direction of the Laeken poverty rates in these countries. Over shorter time periods, Orshansky and Laeken poverty indicators may or may not move less systematically. Chapter 2 further analyses these differences in poverty levels and identifies the various sources for the variance.

\subsubsection{Long term poverty ${ }^{31}$}

Exploiting the panel dimensions of the datasets we also calculated long term Orshansky and Laeken poverty rates using the Laeken at-persistent-risk-of-poverty indicator. This indicator of chronic or long term poverty labels an individual as long term poor if he/ she is currently poor and also lived in poverty in at least two out of three previous years. Compared to other groups in society, this group is of special concern because having low income levels for a long time not only implies the lack of an important source to finance current living standards, but also reduces investment opportunities in health, education thereby also reducing prospects of a better future (especially when asset levels are also low). Generally, the long term poverty levels are considerably lower than annual poverty rates; trends are much smoother but there are similar differences between Orshansky and Laeken indicators (Table 9.5).

Nevertheless, even if countries have similar poverty rates, their long-term poverty rates may differ. For instance, in countries such as Denmark, Germany, the Netherlands, Austria and Finland the Laeken poverty rates in these countries are about $10-11 \%$ but the long term poverty rates vary from $5.2 \%$ in Denmark to $7.1 \%$ in Austria. Long term poverty rates are also high for countries with both high Laeken and Orshansky poverty rates (Greece, Spain, Italy and Portugal). The relatively high long term poverty rates can,

\footnotetext{
${ }^{31}$ The Laeken At-Persistent-Risk-of-Poverty rates for the ECHP countries are equal but in most cases higher than the percentages displayed on the website of Eurostat (but the trends are the same). We calculated these poverty rates according to the methodology described in 'Laeken' Indicators; Detailed Calculation Methodology (Eurostat, 2003b). We could not find a reason to which this difference can be attributed.
} 
in addition to their correspondence to high annual poverty rates, also be explained by the fact that year to year income dynamics takes place in the relatively large left part of income distribution (but below the poverty line); it is less likely that changes in income at low income levels involve the crossing of the poverty line. A similar rationale holds for the observation that long term poverty rates are relatively lower for the Orshansky indicator. Nevertheless, it seems that differences in long term poverty shares between countries are not only related to differences in the level of poverty thresholds. For instance, Luxembourg and France have similar long term Laeken poverty rates (8.6 and $8.7 \%$ ) but the difference between annual poverty rates is about 3 percentage points (12.5 and 15.4\%). The share of long term poor in France is higher than in Luxembourg. One obvious explanation for this is that the degree of income mobility differs between countries (including up and downward mobility).

\subsubsection{Poverty gap}

The poverty gap represents the average income shortfall below the poverty line over the total population. ${ }^{32}$ It is an indicator for the depth of poverty. Using the Laeken indicator, the poverty gap is big in Southern Europe and USA (Table 9.6); it is small in the rest of Europe with the UK and Ireland taking a middle position. Using Orshansky, we find similar differences between countries in the poverty gap. The USA is the exception; the Orshansky poverty gap is now considerably lower than in Southern Europe. Over the period $1993-2000$ the Laeken poverty gap declined in most countries, hovered around for the Netherlands and Sweden, but increased for Denmark, Finland and Ireland. Using Orshansky, even more countries show a declining trend; only for Finland the poverty gap increases. Ireland again stands out as a peculiar case with a decreasing Orshansky poverty gap and increasing Laeken poverty gap. Albeit a difference in magnitude, the trends in poverty gaps are similar to the trends in poverty incidence in most countries. Only in the Netherlands and Austria, the developments in poverty gap are more pronounced that those in poverty incidence.

\footnotetext{
32 The poverty gap in Table 9.6 cannot be compared with the Laeken Relative at-risk-of-poverty gap. Our calculations are based on the Foster Greer Thorbecke (1984) poverty gap which measures the mean proportionate poverty gap over the total population while the Laeken poverty Relative at-risk-of-poverty gap measures the mean proportionate poverty gap over the poor population. We chose the Foster Greer Thorbecke poverty gap because it satisfies the monotonicity axiom: 'given other things, a reduction in the income of a poor household must increase the poverty measure' (p. 762). The Laeken poverty gap may violate this axiom.
} 


\subsubsection{Age, gender and household type $\mathrm{e}^{33}$}

Disaggregating the poverty headcount figures can inform us about the characteristics of poor individuals. When discussing poverty according to age groups and family types, it should be noted that all the estimates are sensitive to the equivalence scales used. ${ }^{34}$ According to Table 9.7, both indicators show that the middle age groups (25-64) have the lowest poverty risk in most countries while children and the elderly more likely to be poor. However, in countries such as the Netherlands, Italy and Luxembourg the risk of poverty seems to decline steadily after childhood. In some countries these agepoverty risk patterns are consistent across both poverty indicators (Italy, the Netherlands and Austria) while in most countries the poverty risk of one age group may differ by poverty indicator. This seems to be the case especially for the elderly age group. Using the Laeken indicator, the poverty risk of elderly is much more pronounced than with the Orshansky indicator. In Denmark, France, Ireland, Finland and the UK persons above the age of 65 clearly have a higher than average poverty risk for Laeken poverty but less so for Orshansky poverty. In the USA and Germany, the poverty risk for the elderly is above average for the Laeken indicator and below average for the Orshansky indicator. This difference in poverty risk for the elderly may be explained by the existence of a basic pension for which each citizen is eligible, irrespective of his/her past contributions. This pension may not be very generous but it provides (a considerable) part of the resources to satisfy a minimum level of expenditures (close to the Orshansky poverty line). In Belgium, young children have a lower poverty risk according to the Laeken indicator but a higher Orshansky poverty risk while older children (age 16-25) clearly have a higher Laeken poverty risk but an average Orshansky poverty risk. What may partly explain a pattern in Belgium is that part of family allowances is provided as an (income) tax deduction. In countries such as Luxembourg, Denmark and the Netherlands older children typically move away from their parents' home at a younger age than their counterparts in Greece or Spain. Even though these children may still receive support from their parents and the state, they are counted as separate households. Moreover, even if children in this age group work, their earnings are still relatively low.

Poverty among children is an important topic as growing up in poverty may jeopardize investment in human capital and thus increase the risk of poverty in later

\footnotetext{
${ }^{33}$ In defining age groups and household types we followed the same definitions as used for the various decompositions of the Laeken poverty indicators. Table 9.15 and Table 9.16 also give the population shares by age group, gender and household type.

${ }^{34}$ In line with current international practice, the Laeken indicator is calculated using the modified OECD equivalence scales. The Orshansky method uses a different non-linear weighting scheme. In chapter 2 we investigate the (impact of) difference in equivalence scales.
} 
stages of the life cycle. Table 9.8 illustrates trends in child poverty for children aged 0-15 years. Only in Denmark and Finland (no data available for Sweden), child poverty is considerably lower than overall poverty rates in all years using both Orshansky and Laeken estimates. In Belgium and Greece, the Laeken indicator points to lower child poverty rates in some of the years while the Orshansky indicator shows an above average poverty risk. In most other countries poverty among children is higher than overall poverty for the entire period according to at least one of the indicators and in most cases consistently according to both the Orshansky and the Laeken estimates. It should also be noted that in most countries child poverty is fluctuating; only Ireland shows a steady decline over the period of observation (Orshansky). In the Netherlands and the United States, the Laeken indicator shows a steady rise in child poverty and a widening gap with the average poverty rate. Also for Portugal the Orshansky indicator the gap with the mean poverty rate is increasing.

Compared to men, women have a higher poverty risk in most countries (except in the Netherlands and Luxembourg). Over time, the gap in male and female poverty rates has been declining in Germany and the Netherlands but it increased in Finland (especially for the Laeken indicator). In other countries the gap remained more or less constant. These patterns are similar for long term poverty, although for countries such as Denmark, Ireland, Austria, Finland,the UK and the USA women are considerably more likely to live in long term Laeken poverty compared to men (Table 9.10). Only for the USA and to a lesser degree the UK, this large difference between male and female poverty is also found using Orshansky long term poverty.

Inspecting poverty incidence according family type reveals that particularly children from single parent households, households with three or more children and other households with children have an increased poverty risk. Extremely worse off are single parent households (except in Finland and Denmark). Table 9.11 also shows that single person households have above average poverty rates. Overall, the Laeken and Orshansky measures indicate the same groups as above or below average, but again we can identify eight cases in which the difference in poverty risk is considerable (couple with at least one person aged above 65 in Belgium, Denmark and the UK, households with three or more children in Germany, France, Sweden and the US).

\subsubsection{Main source of income $\mathrm{e}^{35}$}

It is also interesting to disaggregate the population by the main source of household income. We distinguish between six main income sources (wage income, entrepreneurial

\footnotetext{
${ }^{35}$ Table 9.17 gives the population shares by main source of income.
} 
income, pensions, unemployment benefits, other social benefits and private income). The figures in Table 9.12 reflect whether the main source of income contributes to having an income above the poverty line or not. Poverty among households with wage earnings is extremely low in Belgium and Austria and very low in most of continental Europe, Scandinavia and Finland. Albeit lower than average, the poverty incidence of working households is relatively more important in Southern Europe and the United States. Self employed are well off in Denmark, Finland, Germany, Ireland, Luxembourg, the Netherlands and the UK. In all other countries and especially in Southern Europe, they are overrepresented among the poor. In some countries the difference in poverty risk between households with wages as main source of income and self-employment are very large (Sweden, Greece, Austria) but in most countries this risk is only somewhat higher for self employed households.

In the United States households with pensions as main income source have higher than average poverty risk according to the Laeken indicator but lower than average for the Orshansky indicator. Differences between Laeken and Orshansky patterns are less pronounced in the European countries. Rich pensioner households are found in the Netherlands, Luxembourg and Sweden; pensioners in all other countries are relatively more often poor; especially in Southern Europe and Ireland. This holds regardless of the estimator used (Orshansky and Laeken). In Denmark, Ireland and Finland differences in poverty risk for this group are more pronounced for Laeken poverty than for Orshansky poverty. Something similar can be observed for household receiving other social benefits as main income source in the Netherlands, Luxembourg and Sweden. However, the number of observations is often very small for the categories 'unemployment benefits', 'other social benefits' and 'private income'. These poverty estimates should thus be interpreted with care. People with private income are well off in Belgium, Finland and Luxembourg according to both poverty indicators. Households whose main income source is derived from unemployment benefits and other (often means-tested) social transfers typically have the highest poverty risk.

\subsubsection{Impact of social transfers}

We assess the impact of social protection benefits is by evaluating the effect of such benefits on poverty rates (Table 9.13). Firstly, we calculate poverty rates without including the income from pensions and other social benefits. In a second step, we measure poverty including all market income and pensions but excluding other social benefits. ${ }^{36}$ This indicator is also part of the group of Laeken indicators (At-risk-of-

\footnotetext{
${ }^{36}$ All poverty rates are estimated using the same poverty lines. Thus, we use the Laeken poverty lines from the net income distribution to analyse the poverty reduction effects of social transfers on income.
} 
poverty rate before social transfers). This so-called static analysis abstracts from the behavioural effects that would occur if such benefits would not exist. For instance, without a pension, older persons would work longer or they may receive more support from younger family members. With respect to the US, as special remark needs to be made. Tax credits are an important tool used by the USA to assist low income families with children; at very low incomes households may actually receive more credit than their tax burden. Unfortunately, we only have an estimate of the net tax burden but we cannot distinguish between tax credits and tax burdens. This implies that the figures for the USA do not reflect the poverty reduction impact of this policy measure. This particularly affects the poverty reduction effects of the 'other transfers' category.

Looking at the relative poverty reductions (Table 9.4), it is clear that pensions have the largest impact on poverty rates, particularly in Germany, Greece, France, Italy, Luxembourg, the Netherlands and Austria (poverty rates are reduced by more than $40 \%$ for these countries). Looking at Orshansky poverty, pensions even have a larger impact on poverty (in Luxembourg and Belgium even above 60\%). Interestingly, if we rank countries according to the poverty reduction impact (from a large to small impact), Belgium and the USA are ranked much higher for Orshansky poverty than for Laeken poverty. Pensions in these countries are relatively more successful in reducing poverty at lower (Orshansky poverty line) income levels. In Italy, on the other hand, pensions have by far the largest Laeken poverty reduction of all countries but it only ranks in the middle for Orshansky poverty. In Denmark, Finland, Ireland and the UK the effect of pensions is much smaller, both in Laeken and Orshansky poverty.

The role of other social benefits (family allowances, other social insurance benefits and social assistance) on Laeken poverty is small in Southern Europe. Using both indicators, the role of other social benefits is large but decreasing in Finland and Denmark (Figure 9.2). In Ireland, other transfers are considerably more successful in reducing Orshansky poverty than in reducing Laeken poverty, while in Austria the situation is just the opposite. The figures clearly show that some countries rely more on pension benefits to reduce poverty while other countries such as Finland, Denmark and the UK rely more on other transfers.

\subsection{Conclusion}

This appendix explained how we compared the official poverty measurement methodologies of the USA (Orshansky) and the EU (Laeken) and provided a general discussion of the poverty results. As the official US methodology is based on an absolute notion of poverty and the official EU methodology uses poverty as a relative concept, a comparison of both methods provides insights into different poverty dimensions in 
these countries. Official poverty methodologies differ from other poverty measurement methods in the sense that the official ones are more often used as a benchmark to develop new policies as well as to evaluate the performance of existing programs. Potentially conflicting results between these methods put the desirability of current policies into a wider perspective.

The Laeken and Orshansky methodologies are compared by applying both methods on European and United States data. For the EU-15 we used the harmonized European Community Household Panel (ECHP) for the years 1994 to 2001. For the USA, we selected the Cross National Equivalent Files (CNEF-PSID, 1994-2001). The ECHP and the CNEF-PSID both have a cross-section and a panel dimension and are nationally representative. We obtained the US poverty thresholds from the Bureau of Census and converted the 1993 dollar thresholds to the Member States' currencies using 1993 Purchasing Power Parity (PPP) indices. After the conversion of the US thresholds to national purchasing power values, we updated the thresholds to other years using national consumer price indices. Even though the official USA poverty rates are calculated using gross household income, we used net income for both indicators. Based on detailed comparisons of the income components in the ECHP and the CNEF-PSID, we find that the net income variables in both datasets are very similar and can thus be used for cross-national comparative poverty analyses. Nevertheless, we identified two aspects should be kept in mind when making comparative analyses. Firstly, the use of register data for Sweden, Finland and Denmark may yield higher poverty estimates than survey data. Secondly, the assumption of $100 \%$ take up of low income tax credits (EITC) may underestimate USA poverty rates.

The discussion of the results pointed to considerable differences between the estimates based on Laeken indicators and the estimates based on an Orshansky type of technology. It was expected that in general Orshansky generates lower poverty estimates than the Laeken indicators. However, it is puzzling to find that a.) these differences are less systematic than expected and b.) these differences are not constant over time and in some cases even have the reverse sign. That indicates that Orshansky indicators and Laeken indicators relate to the same phenomenon but from a possibly very different perspective. It is also noteworthy that the differences are more puzzling for the faster growing economies in the European Union. Chapters 2 and 3 further analyse the nature and the background of these differences.

\subsection{Appendix: tables}




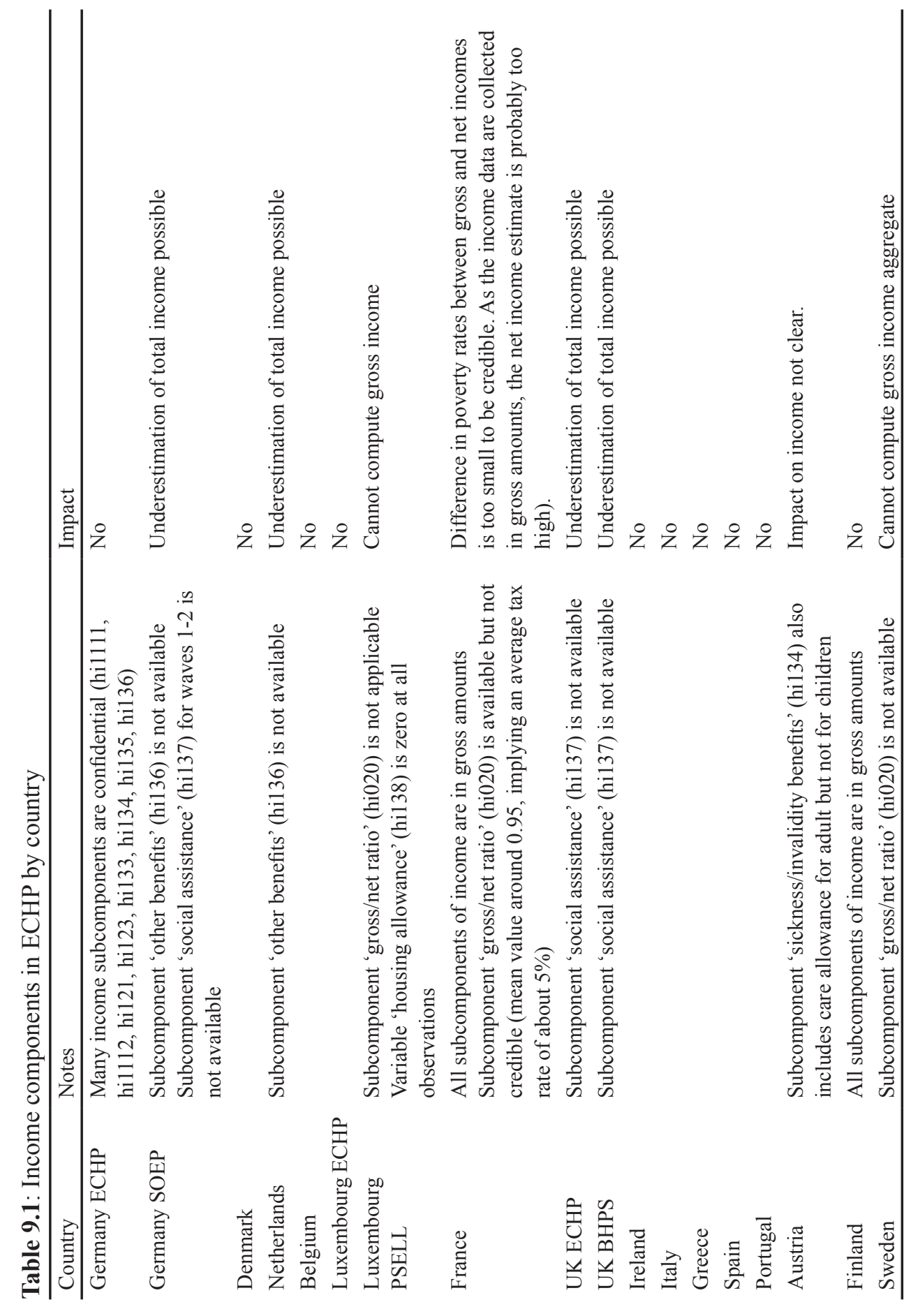




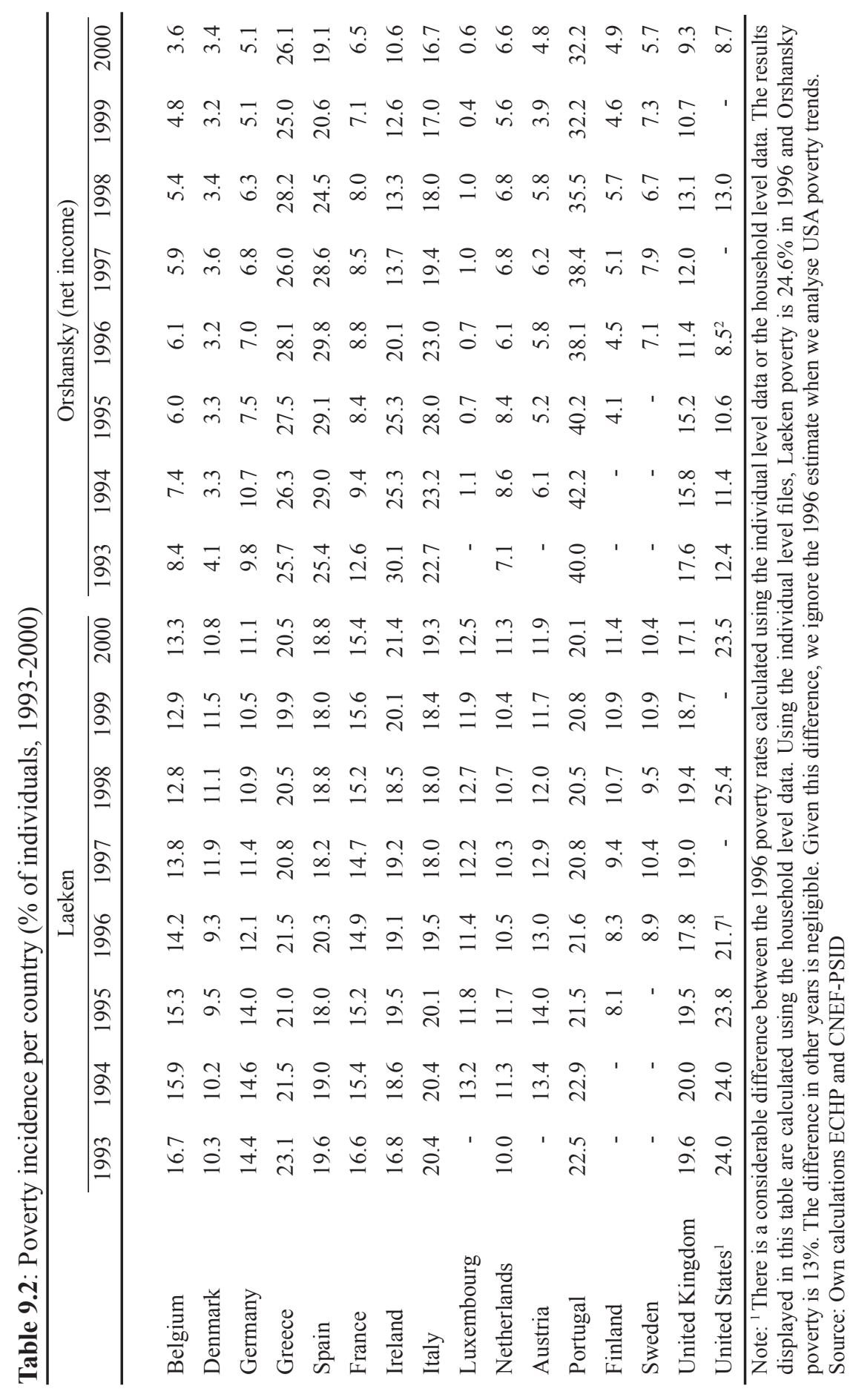


Figure 9.1: Poverty incidence per country (\% of individuals, 1993-2000)
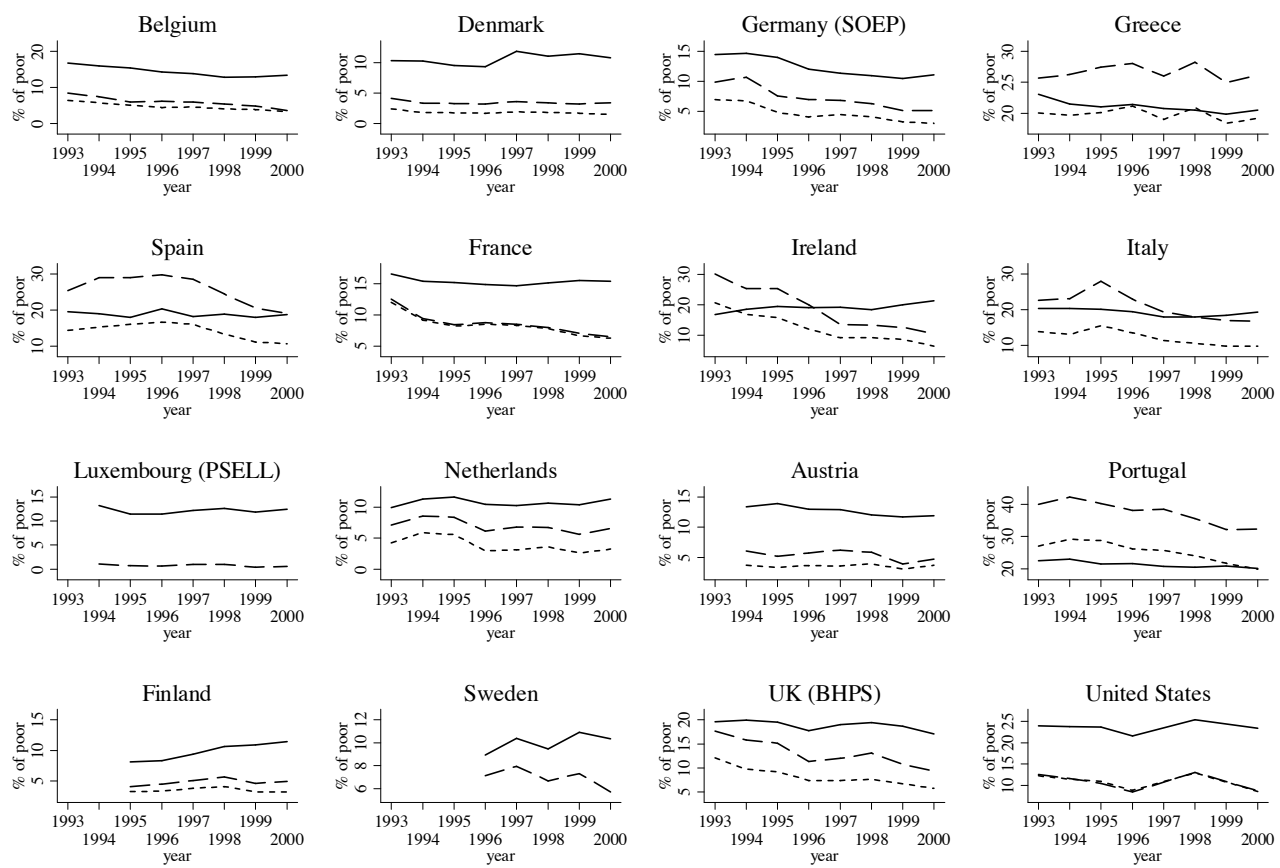

Laeken

Orshansky (net income)

_ Orshansky (gross income)....

Note: To facilitate comparison of Orshansky and Laeken poverty trends within countries, we used different scales on the vertical axes. For the USA there are no observations 1999 and 1997.

Source: Own calculations ECHP and CNEF-PSID 


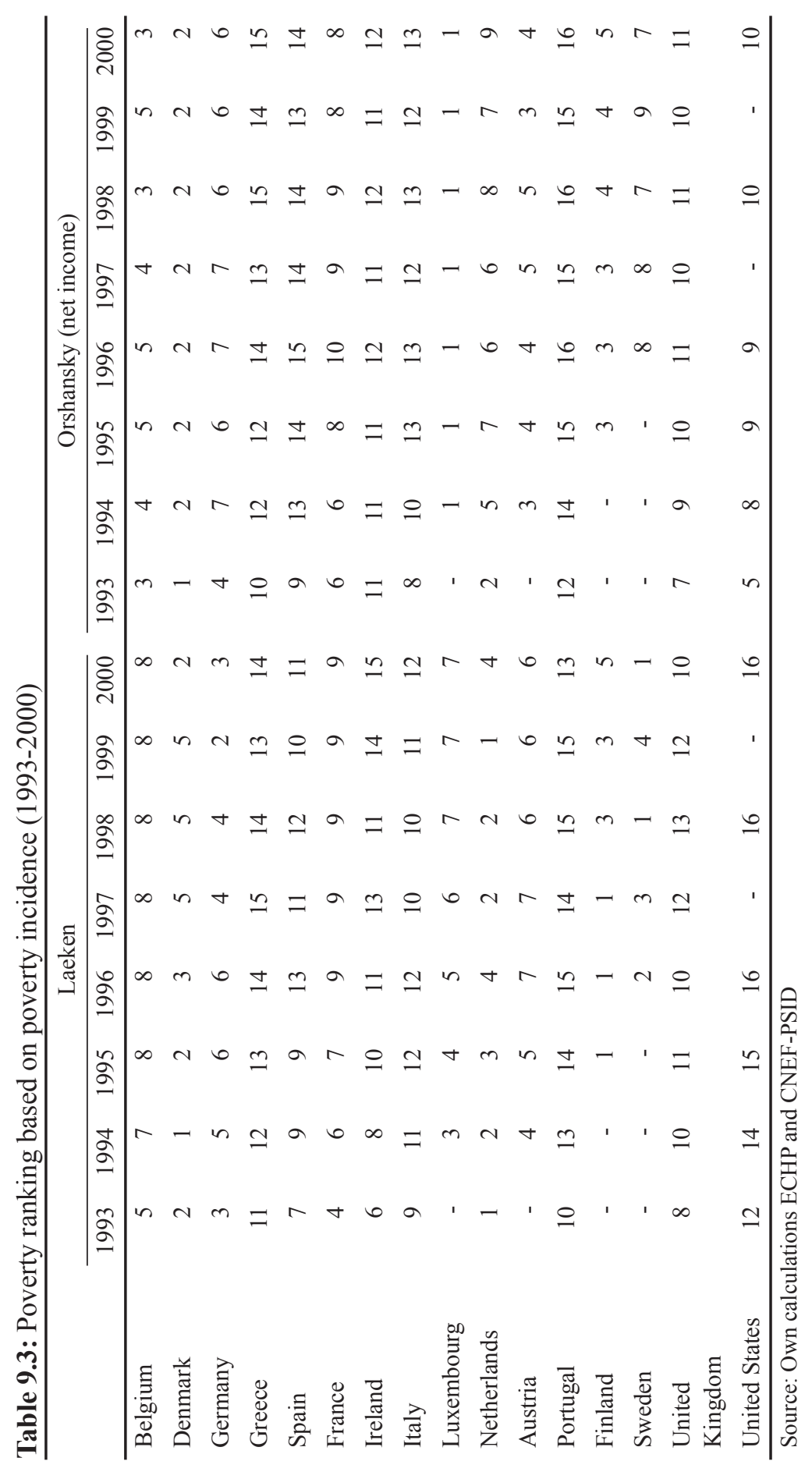




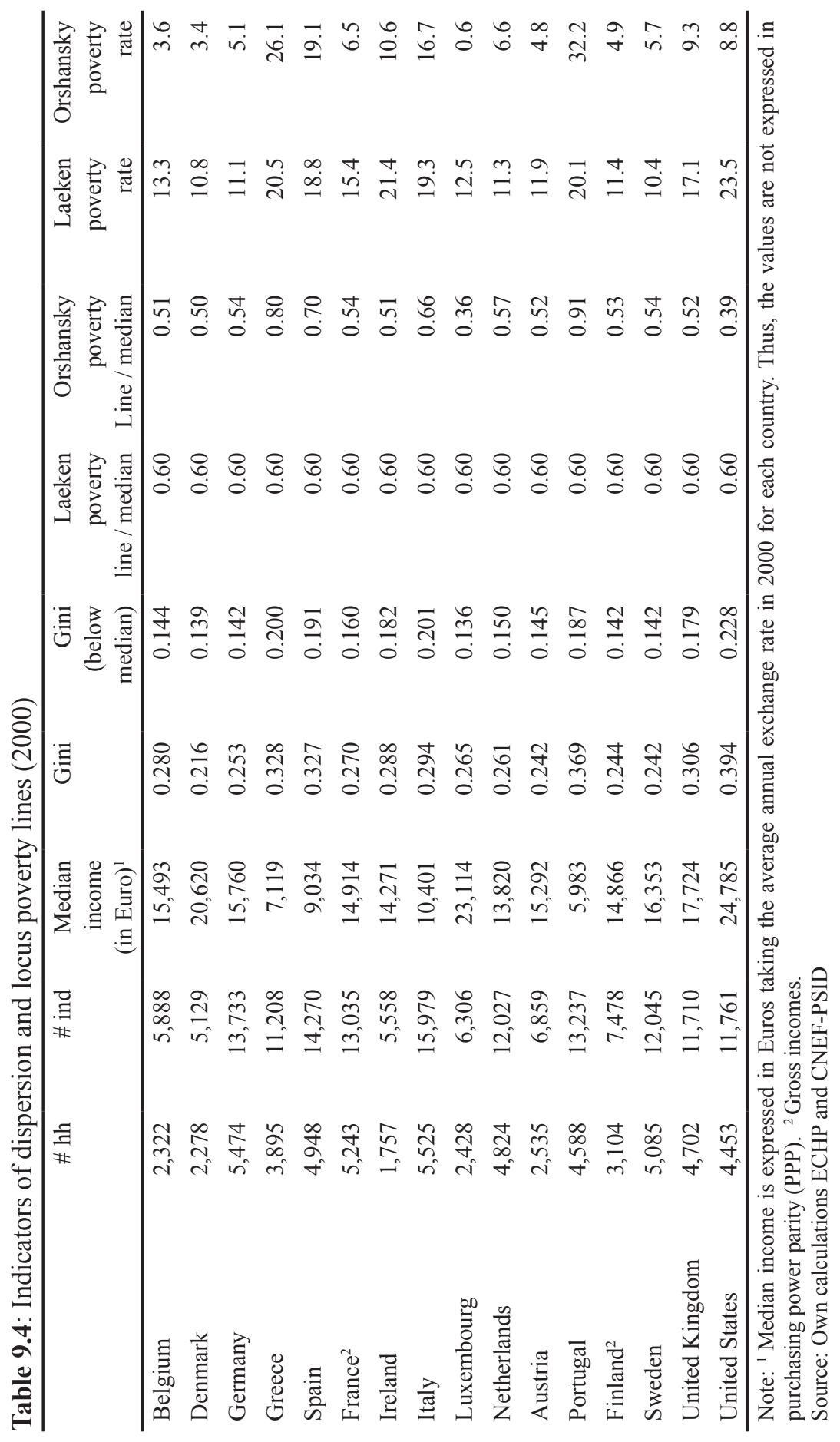


Table 9.5: At-Persistent-Risk-of-Poverty rate (\% of individuals, 1993-2000)

\begin{tabular}{|c|c|c|c|c|c|c|c|c|c|c|}
\hline & \multicolumn{5}{|c|}{ Laeken } & \multicolumn{5}{|c|}{ Orshansky (net income) } \\
\hline & 1996 & 1997 & 1998 & 1999 & 2000 & 1996 & 1997 & 1998 & 1999 & 2000 \\
\hline Belgium & 8.5 & 8.1 & 7.3 & 7.9 & 7.4 & 2.8 & 2.3 & 2.4 & 2.4 & 1.5 \\
\hline Denmark & 4.2 & 4.2 & 4.8 & 6.2 & 5.2 & 0.8 & 0.6 & 0.6 & 0.5 & 0.7 \\
\hline Germany & 5.8 & 6.3 & 6.1 & 5.7 & 6.1 & 3.0 & 3.2 & 3.1 & 2.7 & 2.4 \\
\hline Greece & 13.5 & 12.3 & 13.0 & 13.4 & 14.2 & 17.9 & 16.2 & 18.3 & 18.6 & 19.0 \\
\hline Spain & 11.4 & 11.0 & 10.7 & 10.8 & 10.5 & 19.8 & 19.9 & 17.7 & 15.6 & 14.0 \\
\hline France & 8.7 & 8.4 & 8.5 & 8.6 & 8.7 & 4.3 & 4.1 & 3.5 & 3.0 & 2.5 \\
\hline Ireland & 11.8 & 11.6 & 12.5 & 12.8 & 13.2 & 16.3 & 11.3 & 9.7 & 8.9 & 6.7 \\
\hline Italy & 10.9 & 11.1 & 11.2 & 11.5 & 12.6 & 14.4 & 13.5 & 12.5 & 11.9 & 11.9 \\
\hline Luxembourg & - & 7.8 & 7.6 & 8.1 & 8.6 & - & 0.0 & 0.1 & 0.1 & 0.1 \\
\hline Netherlands & 5.5 & 4.9 & 5.5 & 5.0 & 5.3 & 2.8 & 2.7 & 2.3 & 2.0 & 2.1 \\
\hline Austria & - & 6.9 & 6.8 & 6.7 & 7.1 & - & 2.3 & 2.3 & 2.1 & 1.7 \\
\hline Portugal & 14.9 & 14.3 & 14.9 & 14.5 & 14.8 & 31.7 & 31.6 & 30.0 & 27.4 & 27.5 \\
\hline Finland & - & - & 4.7 & 5.8 & 5.9 & - & - & 2.0 & 2.4 & 2.0 \\
\hline Sweden & - & - & - & - & - & - & - & - & - & - \\
\hline United Kingdom & 10.3 & 10.8 & 11.6 & 11.1 & 10.1 & 6.6 & 6.3 & 6.4 & 5.5 & 5.0 \\
\hline United States & 13.8 & - & - & - & - & 5.1 & - & - & - & . \\
\hline
\end{tabular}

Note: After the poverty status of households in a particular year has been determined, the long term poverty rates are calculated on an individual level only including those individuals in the panel (with a positive longitudinal weight). Note that the annual poverty rates are calculated on a household level (albeit counting all individuals in the household) including all households with a positive household cross-section weight.

Source: Own calculations ECHP and CNEF-PSID 


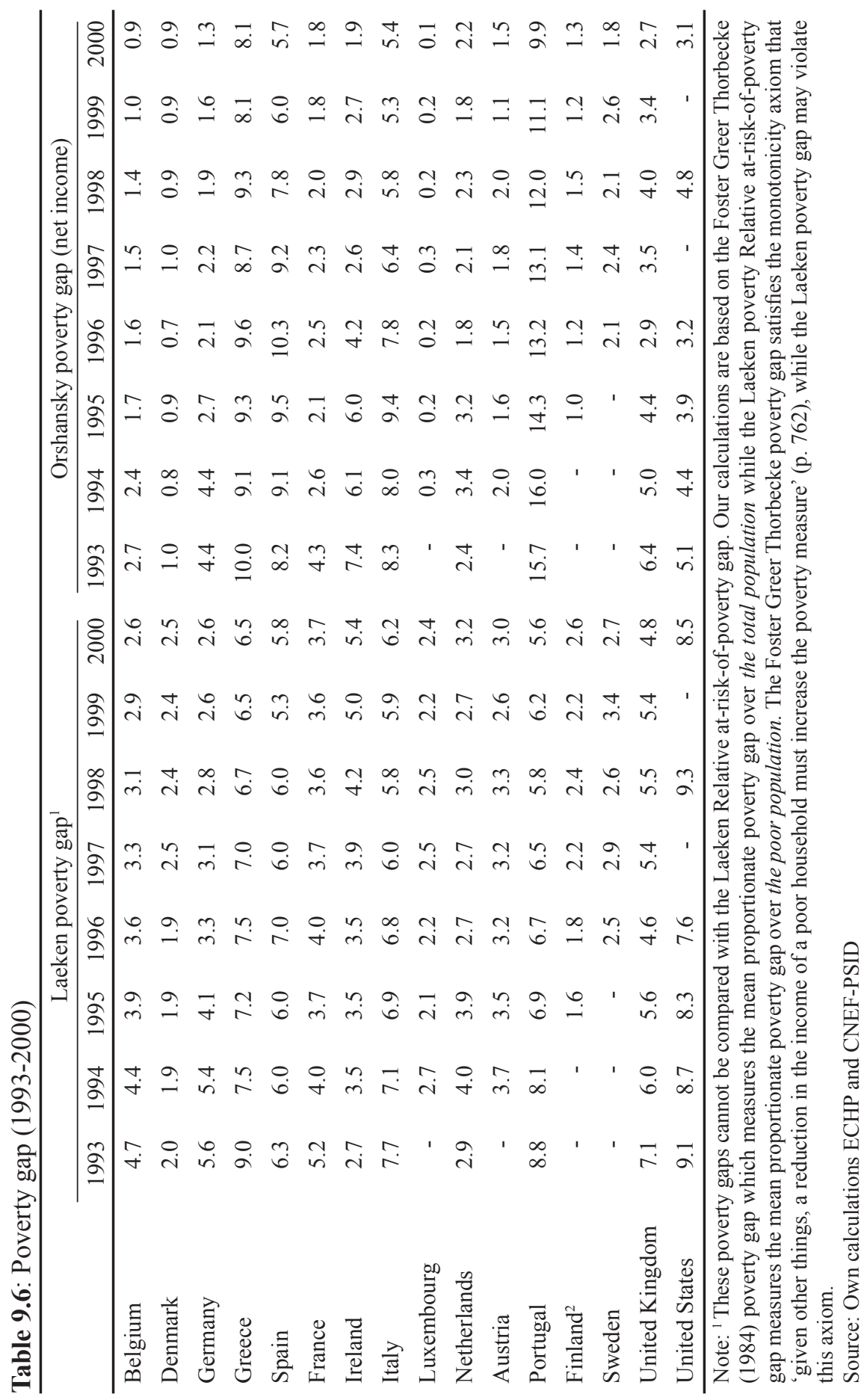




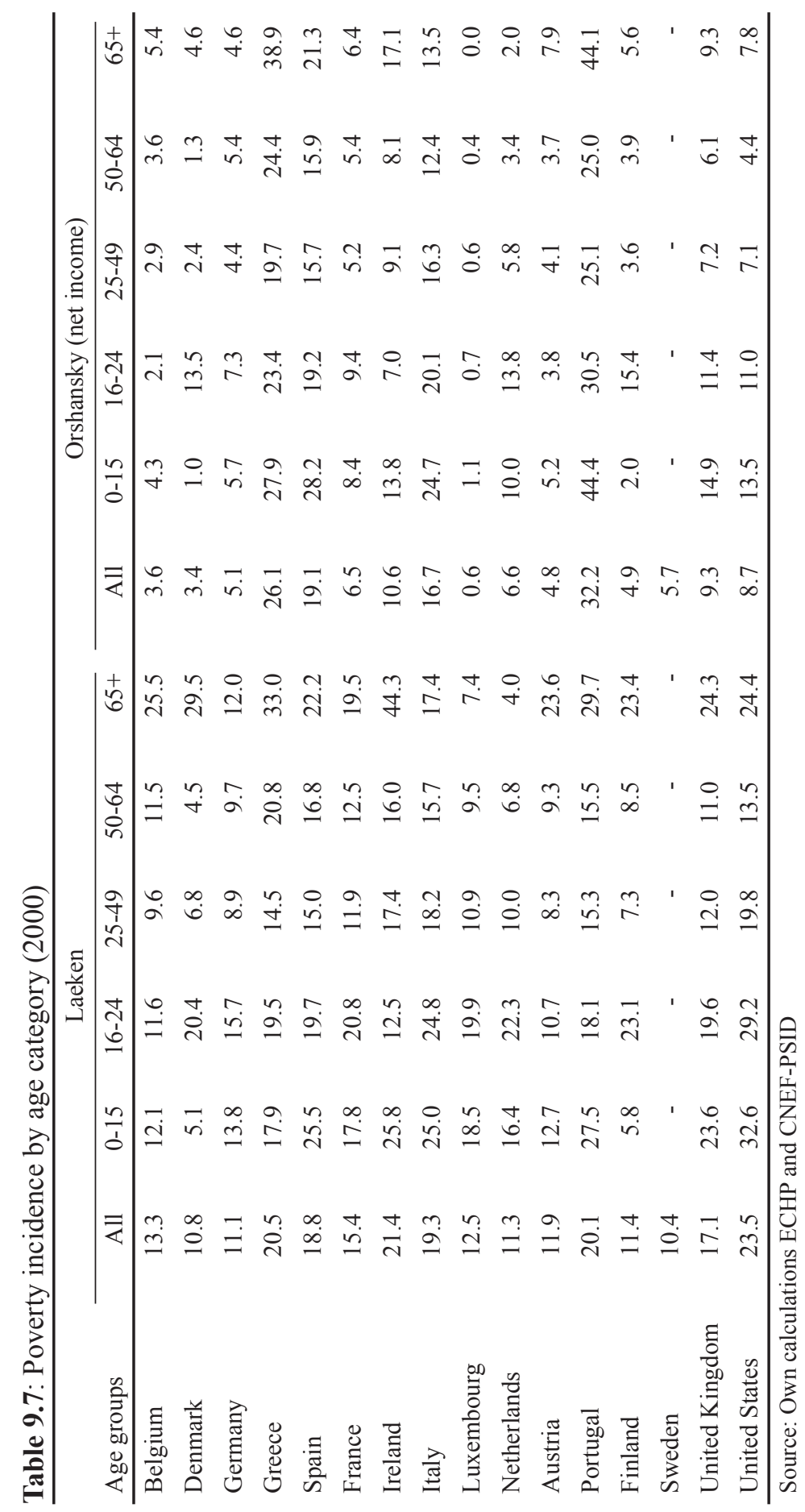


Table 9.8: Poverty incidence for total population and children aged 0-15 (1993-2000)

\begin{tabular}{|c|c|c|c|c|c|c|c|c|}
\hline & \multicolumn{8}{|c|}{ Laeken } \\
\hline & 1993 & 1994 & 1995 & 1996 & 1997 & 1998 & 1999 & 2000 \\
\hline Belgium (all) & 16.7 & 15.9 & 15.3 & 14.2 & 13.8 & 12.8 & 12.9 & 13.3 \\
\hline - Children age $0-15$ & 19.6 & 15.6 & 15.3 & 13.7 & 12.7 & 11.7 & 11.5 & 12.1 \\
\hline Denmark (all) & 10.3 & 10.2 & 9.5 & 9.3 & 11.9 & 11.1 & 11.5 & 10.8 \\
\hline - Children age $0-15$ & 5.5 & 5.4 & 3.6 & 4.7 & 4.8 & 5.7 & 4.1 & 5.1 \\
\hline Germany (all) & 14.4 & 14.6 & 14.0 & 12.1 & 11.4 & 10.9 & 10.5 & 11.1 \\
\hline - Children age $0-15$ & 14.9 & 18.0 & 15.4 & 14.9 & 13.1 & 13.2 & 12.8 & 13.8 \\
\hline Greece (all) & 23.1 & 21.5 & 21.0 & 21.5 & 20.8 & 20.5 & 19.9 & 20.5 \\
\hline - Children age $0-15$ & 21.3 & 18.1 & 19.3 & 17.6 & 16.8 & 17.2 & 18.6 & 17.9 \\
\hline Spain (all) & 19.6 & 19.0 & 18.0 & 20.3 & 18.2 & 18.8 & 18.0 & 18.8 \\
\hline - Children age $0-15$ & 23.4 & 23.7 & 23.4 & 26.2 & 24.4 & 24.9 & 25.1 & 25.5 \\
\hline France (all) & 16.6 & 15.4 & 15.2 & 14.9 & 14.7 & 15.2 & 15.6 & 15.4 \\
\hline - Children age $0-15$ & 17.6 & 16.0 & 16.0 & 16.2 & 16.5 & 17.5 & 17.6 & 17.8 \\
\hline Ireland (all) & 16.8 & 18.6 & 19.5 & 19.1 & 19.2 & 18.5 & 20.1 & 21.4 \\
\hline - Children age $0-15$ & 25.0 & 25.8 & 26.6 & 24.8 & 23.1 & 20.9 & 22.1 & 25.8 \\
\hline Italy (all) & 20.4 & 20.4 & 20.1 & 19.5 & 18.0 & 18.0 & 18.4 & 19.3 \\
\hline - Children age $0-15$ & 24.6 & 24.1 & 23.5 & 22.7 & 21.1 & 22.2 & 25.0 & 25.0 \\
\hline Luxembourg (all) & - & 13.2 & 11.8 & 11.4 & 12.2 & 12.7 & 11.9 & 12.5 \\
\hline - Children age $0-15$ & - & 19.0 & 18.0 & 16.5 & 19.5 & 18.6 & 18.3 & 18.5 \\
\hline Netherlands (all) & 10.0 & 11.3 & 11.7 & 10.5 & 10.3 & 10.7 & 10.4 & 11.3 \\
\hline - Children age $0-15$ & 10.1 & 12.7 & 14.4 & 12.5 & 13.6 & 14.0 & 15.1 & 16.4 \\
\hline Austria (all) & - & 13.4 & 14.0 & 13.0 & 12.9 & 12.0 & 11.7 & 11.9 \\
\hline - Children age $0-15$ & - & 15.8 & 18.1 & 15.1 & 15.5 & 13.7 & 12.4 & 12.7 \\
\hline Portugal (all) & 22.5 & 22.9 & 21.5 & 21.6 & 20.8 & 20.5 & 20.8 & 20.1 \\
\hline - Children age $0-15$ & 23.4 & 25.9 & 23.9 & 25.3 & 26.1 & 26.4 & 25.5 & 27.5 \\
\hline Finland (all) & - & - & 8.1 & 8.3 & 9.4 & 10.7 & 10.9 & 11.4 \\
\hline - Children age $0-15$ & - & - & 4.6 & 5.1 & 4.9 & 7.3 & 5.7 & 5.8 \\
\hline United Kingdom (all) & 19.6 & 20.0 & 19.5 & 17.8 & 19.0 & 19.4 & 18.7 & 17.1 \\
\hline - Children age $0-15$ & 27.7 & 28.7 & 27.8 & 26.8 & 28.8 & 29.3 & 27.5 & 23.6 \\
\hline United States (all) & 24.0 & 24.0 & 23.8 & 21.7 & - & 25.4 & - & 23.5 \\
\hline - Children age $0-15$ & 29.8 & 28.0 & 29.1 & 27.9 & - & 32.6 & - & 32.6 \\
\hline
\end{tabular}

Source: Own calculations ECHP and CNEF-PSID 
Table 9.8 continued Poverty incidence for total population and children aged 0-15

\begin{tabular}{|c|c|c|c|c|c|c|c|c|}
\hline & \multicolumn{8}{|c|}{ Orshansky (net income) } \\
\hline & 1993 & 1994 & 1995 & 1996 & 1997 & 1998 & 1999 & 2000 \\
\hline Belgium (all) & 8.4 & 7.4 & 6.0 & 6.1 & 5.9 & 5.4 & 4.8 & 3.6 \\
\hline - Children age $0-15$ & 11.3 & 8.0 & 7.1 & 7.0 & 6.4 & 5.9 & 3.9 & 4.3 \\
\hline Denmark (all) & 4.1 & 3.3 & 3.3 & 3.2 & 3.6 & 3.4 & 3.2 & 3.4 \\
\hline - Children age $0-15$ & 2.6 & 2.1 & 1.5 & 2.1 & 1.8 & 2.3 & 0.8 & 1.0 \\
\hline Germany (all) & 9.8 & 10.7 & 7.5 & 7.0 & 6.8 & 6.3 & 5.1 & 5.1 \\
\hline - Children age $0-15$ & 9.6 & 13.9 & 8.4 & 9.4 & 8.0 & 7.3 & 5.7 & 5.7 \\
\hline Greece (all) & 25.7 & 26.3 & 27.5 & 28.1 & 26.0 & 28.2 & 25.0 & 26.1 \\
\hline - Children age $0-15$ & 26.9 & 24.9 & 28.3 & 28.2 & 25.6 & 29.3 & 28.2 & 27.9 \\
\hline Spain (all) & 25.4 & 29.0 & 29.1 & 29.8 & 28.6 & 24.5 & 20.6 & 19.1 \\
\hline - Children age $0-15$ & 32.2 & 37.4 & 37.7 & 39.6 & 38.7 & 32.8 & 30.3 & 28.2 \\
\hline France (all) & 12.6 & 9.4 & 8.4 & 8.8 & 8.5 & 8.0 & 7.1 & 6.5 \\
\hline - Children age $0-15$ & 14.5 & 10.6 & 9.6 & 10.0 & 10.3 & 9.5 & 8.9 & 8.4 \\
\hline Ireland (all) & 30.1 & 25.3 & 25.3 & 20.1 & 13.7 & 13.3 & 12.6 & 10.6 \\
\hline - Children age $0-15$ & 41.3 & 35.3 & 34.8 & 27.5 & 18.8 & 16.8 & 15.3 & 13.8 \\
\hline Italy (all) & 22.7 & 23.2 & 28.0 & 23.0 & 19.4 & 18.0 & 17.0 & 16.7 \\
\hline - Children age $0-15$ & 29.6 & 30.6 & 36.6 & 29.0 & 25.4 & 24.9 & 24.9 & 24.7 \\
\hline Luxembourg (all) & - & 1.1 & 0.7 & 0.7 & 1.0 & 1.0 & 0.4 & 0.6 \\
\hline - Children age $0-15$ & - & 1.9 & 1.1 & 0.7 & 1.5 & 1.8 & 0.4 & 1.1 \\
\hline Netherlands (all) & 7.1 & 8.6 & 8.4 & 6.1 & 6.8 & 6.8 & 5.6 & 6.6 \\
\hline - Children age $0-15$ & 7.7 & 9.7 & 10.8 & 7.0 & 9.9 & 9.2 & 8.4 & 10.0 \\
\hline Austria (all) & - & 6.1 & 5.2 & 5.8 & 6.2 & 5.8 & 3.9 & 4.8 \\
\hline - Children age $0-15$ & - & 7.5 & 6.7 & 6.6 & 8.3 & 6.5 & 3.3 & 5.2 \\
\hline Portugal (all) & 40.0 & 42.2 & 40.2 & 38.1 & 38.4 & 35.5 & 32.2 & 32.2 \\
\hline - Children age $0-15$ & 47.0 & 51.5 & 49.3 & 46.5 & 49.7 & 46.7 & 41.1 & 44.4 \\
\hline Finland (all) & - & - & 4.1 & 4.5 & 5.1 & 5.7 & 4.6 & 4.9 \\
\hline - Children age $0-15$ & - & - & 2.0 & 3.0 & 1.7 & 2.5 & 1.7 & 2.0 \\
\hline United Kingdom (all) & 17.6 & 15.8 & 15.2 & 11.4 & 12.0 & 13.1 & 10.7 & 9.3 \\
\hline - Children age $0-15$ & 27.8 & 25.4 & 24.0 & 20.3 & 21.4 & 22.3 & 17.9 & 14.9 \\
\hline United States (all) & 12.4 & 11.4 & 10.6 & 8.5 & - & 13.0 & - & 8.7 \\
\hline - Children age $0-15$ & 18.0 & 16.0 & 14.3 & 11.9 & - & 17.7 & - & 13.5 \\
\hline
\end{tabular}

Source: Own calculations ECHP and CNEF-PSID 
Table 9.9: Poverty incidence by gender (2000)

\begin{tabular}{|c|c|c|c|c|c|c|}
\hline \multirow[b]{2}{*}{ Gender } & \multicolumn{3}{|c|}{ Laeken } & \multicolumn{3}{|c|}{ Orshansky (net income) } \\
\hline & All & Male & Female & All & Male & Female \\
\hline Belgium & 13.3 & 12.1 & 14.5 & 3.6 & 3.2 & 4.0 \\
\hline Denmark & 10.8 & 9.0 & 12.5 & 3.4 & 2.7 & 4.1 \\
\hline Germany & 11.1 & 10.0 & 12.1 & 5.1 & 4.7 & 5.6 \\
\hline Greece & 20.5 & 19.2 & 21.8 & 26.1 & 24.8 & 27.4 \\
\hline Spain & 18.8 & 17.3 & 20.3 & 19.1 & 17.4 & 20.8 \\
\hline France & 15.4 & 14.6 & 16.2 & 6.5 & 5.7 & 7.3 \\
\hline Ireland & 21.4 & 20.0 & 22.7 & 10.6 & 10.3 & 11.0 \\
\hline Italy & 19.3 & 18.7 & 19.9 & 16.7 & 16.0 & 17.5 \\
\hline Luxembourg & 12.5 & 12.4 & 12.6 & 0.6 & 0.4 & 0.7 \\
\hline Netherlands & 11.3 & 11.7 & 10.9 & 6.6 & 6.8 & 6.3 \\
\hline Austria & 11.9 & 9.2 & 14.4 & 4.8 & 4.0 & 5.4 \\
\hline Portugal & 20.1 & 20.1 & 20.1 & 32.2 & 31.3 & 33.1 \\
\hline Finland & 11.4 & 9.1 & 13.6 & 4.9 & 4.1 & 5.7 \\
\hline Sweden & 10.4 & - & - & 5.7 & - & - \\
\hline United Kingdom & 17.1 & 15.1 & 18.9 & 9.3 & 7.9 & 10.6 \\
\hline United States & 23.5 & 22.2 & 24.7 & 8.7 & 8.1 & 9.3 \\
\hline
\end{tabular}

Source: Own calculations ECHP and CNEF-PSID 
Table 9.10: At-Persistent-Risk-of-Poverty rate by gender (2000)

\begin{tabular}{|c|c|c|c|c|c|c|}
\hline & \multicolumn{3}{|c|}{ Laeken } & \multicolumn{3}{|c|}{ Orshansky (net income) } \\
\hline & All & Male & Female & All & Male & Female \\
\hline Belgium & 7.4 & 6.4 & 8.4 & 1.5 & 1.1 & 2.0 \\
\hline Denmark & 5.2 & 3.9 & 6.5 & 0.7 & 0.6 & 0.7 \\
\hline Germany & 6.1 & 5.7 & 6.5 & 2.4 & 2.3 & 2.6 \\
\hline Greece & 14.2 & 13.2 & 15.1 & 19.0 & 17.7 & 20.2 \\
\hline Spain & 10.5 & 9.9 & 11.0 & 14.0 & 12.8 & 15.2 \\
\hline France & 8.7 & 8.2 & 9.2 & 2.5 & 2.1 & 2.9 \\
\hline Ireland & 13.2 & 11.5 & 14.8 & 6.7 & 6.1 & 7.2 \\
\hline Italy & 12.6 & 11.9 & 13.2 & 11.9 & 11.4 & 12.4 \\
\hline Luxembourg & 8.6 & 8.8 & 8.3 & 0.1 & 0.1 & 0.1 \\
\hline Netherlands & 5.3 & 5.6 & 5.1 & 2.1 & 2.4 & 1.9 \\
\hline Austria & 7.1 & 5.0 & 9.1 & 1.7 & 1.3 & 2.1 \\
\hline Portugal & 14.8 & 14.2 & 15.4 & 27.5 & 26.5 & 28.5 \\
\hline Finland & 5.9 & 4.1 & 7.6 & 2.0 & 1.5 & 2.5 \\
\hline Sweden & - & - & - & - & - & - \\
\hline United Kingdom & 10.1 & 8.8 & 11.4 & 5.0 & 4.0 & 5.9 \\
\hline United States (1996) & 13.8 & 11.8 & 15.6 & 5.1 & 3.9 & 6.2 \\
\hline
\end{tabular}

Note: After the poverty status of households in a particular year has been determined, the long term poverty rates are calculated on an individual level only including those individuals in the panel (with a positive longitudinal weight). Note that the annual poverty rates are calculated on a household level (albeit counting all individuals in the household) including all households with a positive household cross-section weight.

Source: Own calculations ECHP and CNEF-PSID 


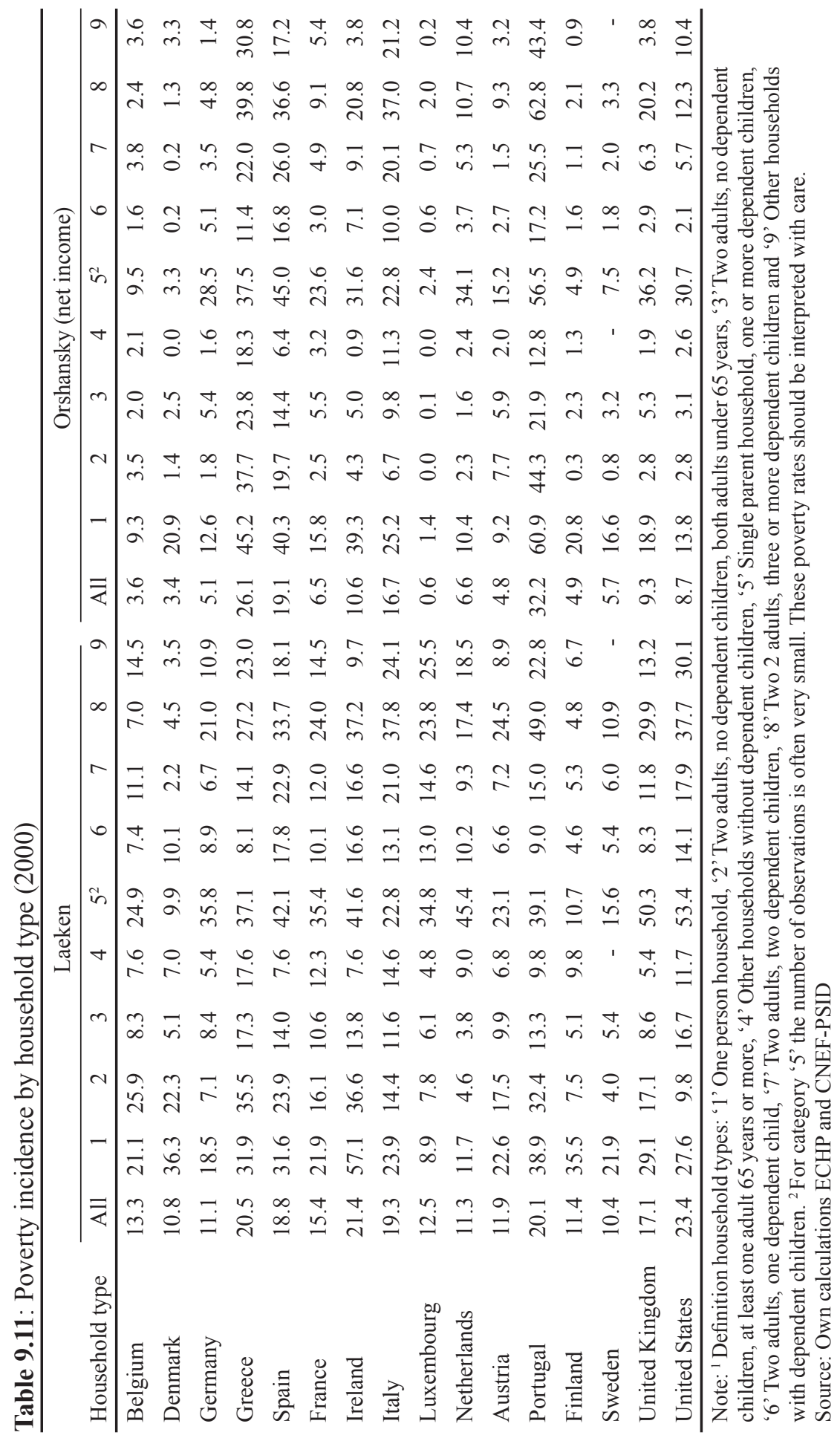




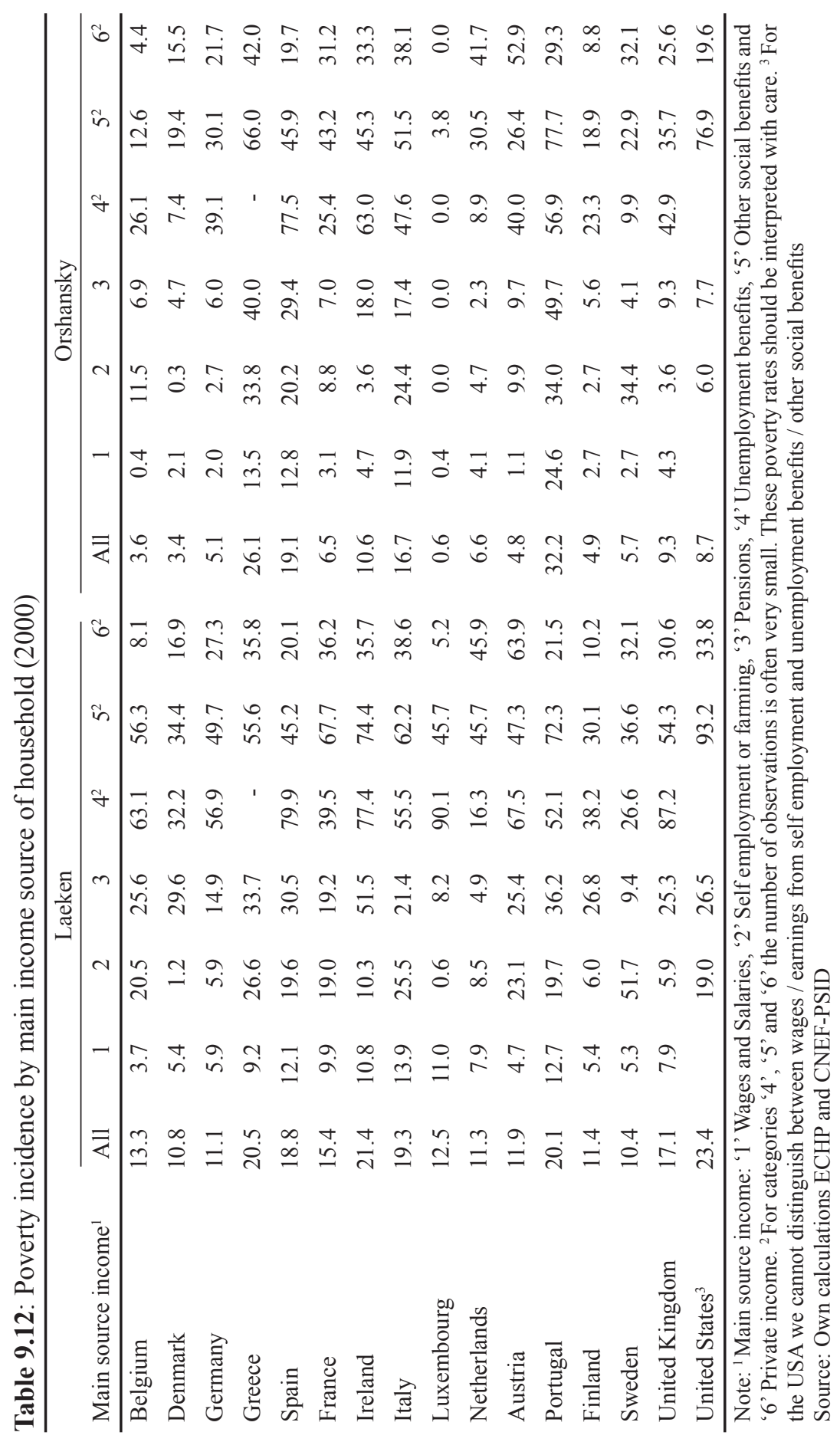


Table 9.13: Poverty incidence using income but excluding social benefits (2000)

\begin{tabular}{|c|c|c|c|c|c|c|}
\hline & \multicolumn{3}{|c|}{ Laeken } & \multicolumn{3}{|c|}{ Orshansky (net income) } \\
\hline & $\begin{array}{r}\text { Before } \\
\text { social } \\
\text { transfers }\end{array}$ & $\begin{array}{r}\text { Before } \\
\text { social } \\
\text { assistance }{ }^{2}\end{array}$ & $\begin{array}{r}\text { Disposable } \\
\text { income }\end{array}$ & $\begin{array}{r}\text { Before } \\
\text { social } \\
\text { transfers }\end{array}$ & $\begin{array}{r}\text { Before } \\
\text { social } \\
\text { assistance }{ }^{2}\end{array}$ & $\begin{array}{r}\text { Disposable } \\
\text { income }\end{array}$ \\
\hline Belgium & 36.8 & 22.4 & 13.3 & 28.6 & 10.9 & 3.6 \\
\hline Denmark & 30.3 & 20.6 & 10.8 & 25.5 & 11.7 & 3.4 \\
\hline Germany & 37.9 & 20.7 & 11.1 & 30.7 & 12.4 & 5.1 \\
\hline Greece & 38.9 & 22.7 & 20.5 & 42.8 & 27.8 & 26.1 \\
\hline Spain & 36.4 & 23.3 & 18.8 & 35.8 & 23.2 & 19.1 \\
\hline France & 41.0 & 24.4 & 15.4 & 33.3 & 15.2 & 6.5 \\
\hline Ireland & 35.2 & 29.5 & 21.4 & 26.1 & 19.5 & 10.6 \\
\hline Italy & 41.4 & 21.9 & 19.3 & 38.1 & 19.2 & 16.7 \\
\hline Luxembourg & 40.3 & 23.1 & 12.5 & 22.2 & 6.9 & 0.6 \\
\hline Netherlands & 35.0 & 20.4 & 11.3 & 29.7 & 15.0 & 6.6 \\
\hline Austria & 37.7 & 21.8 & 11.9 & 27.0 & 11.0 & 4.8 \\
\hline Portugal & 36.4 & 24.4 & 20.1 & 47.3 & 37.5 & 32.2 \\
\hline Finland & 39.1 & 28.2 & 11.4 & 30.2 & 17.3 & 4.9 \\
\hline Sweden & - & - & 10.4 & - & - & 5.7 \\
\hline United Kingdom & 38.5 & 27.6 & 17.1 & 32.0 & 18.7 & 9.3 \\
\hline United States & 32.5 & 24.4 & 23.4 & 18.7 & 9.9 & 8.7 \\
\hline
\end{tabular}

Note: ${ }^{1}$ The threshold (poverty line) is calculated on the basis of the income distribution after transfers. ${ }^{2}$ Pensions are included in income but other social transfers are not.

Source: Own calculations ECHP and CNEF-PSID 
Table 9.14: Poverty reduction impact of social transfers (2000)

\begin{tabular}{|c|c|c|c|c|c|c|c|c|}
\hline & \multicolumn{8}{|c|}{$\begin{array}{l}\% \text { reduction in poverty rates of social transfers } \\
\text { (as compared to pre transfer poverty rates) }\end{array}$} \\
\hline & \multicolumn{4}{|c|}{ Laeken } & \multicolumn{4}{|c|}{ Orshansky (net income) } \\
\hline & \multicolumn{2}{|c|}{ Pensions } & \multicolumn{2}{|c|}{ Other transfers } & \multicolumn{2}{|c|}{ Pensions } & \multicolumn{2}{|c|}{ Other transfers } \\
\hline & $\%$ effect & rank & $\%$ effect & rank & $\%$ effect & rank & $\%$ effect & rank \\
\hline Belgium & 39.3 & 8 & 24.5 & 8 & 62.0 & 2 & 25.4 & 8 \\
\hline Denmark & 31.9 & 11 & 32.6 & 2 & 54.3 & 5 & 32.5 & 3 \\
\hline Germany & 45.4 & 2 & 25.4 & 7 & 59.7 & 3 & 23.6 & 9 \\
\hline Greece & 41.7 & 6 & 5.6 & 14 & 34.9 & 13 & 4.0 & 15 \\
\hline Spain & 36.1 & 9 & 12.3 & 11 & 35.3 & 12 & 11.4 & 11 \\
\hline France & 40.5 & 7 & 21.9 & 10 & 54.2 & 6 & 26.2 & 7 \\
\hline Ireland & 16.1 & 15 & 23.2 & 9 & 25.1 & 14 & 34.1 & 2 \\
\hline Italy & 47.0 & 1 & 6.4 & 13 & 49.4 & 7 & 6.6 & 13 \\
\hline Luxembourg & 42.6 & 3 & 26.4 & 4 & 69.1 & 1 & 28.4 & 6 \\
\hline Netherlands & 41.8 & 5 & 25.9 & 6 & 49.3 & 8 & 28.5 & 5 \\
\hline Austria & 42.2 & 4 & 26.3 & 5 & 59.3 & 4 & 23.1 & 10 \\
\hline Portugal & 33.1 & 10 & 11.8 & 12 & 20.7 & 15 & 11.2 & 12 \\
\hline Finland & 27.8 & 13 & 42.9 & 1 & 42.7 & 10 & 40.9 & 1 \\
\hline Sweden & - & - & - & - & - & - & - & - \\
\hline United Kingdom & 28.2 & 12 & 27.4 & 3 & 41.4 & 11 & 29.5 & 4 \\
\hline United States & 25.0 & 14 & 3.0 & 15 & 47.1 & 9 & 6.1 & 14 \\
\hline
\end{tabular}


Figure 9.2: Laeken poverty trends using income excluding social benefits (2000)
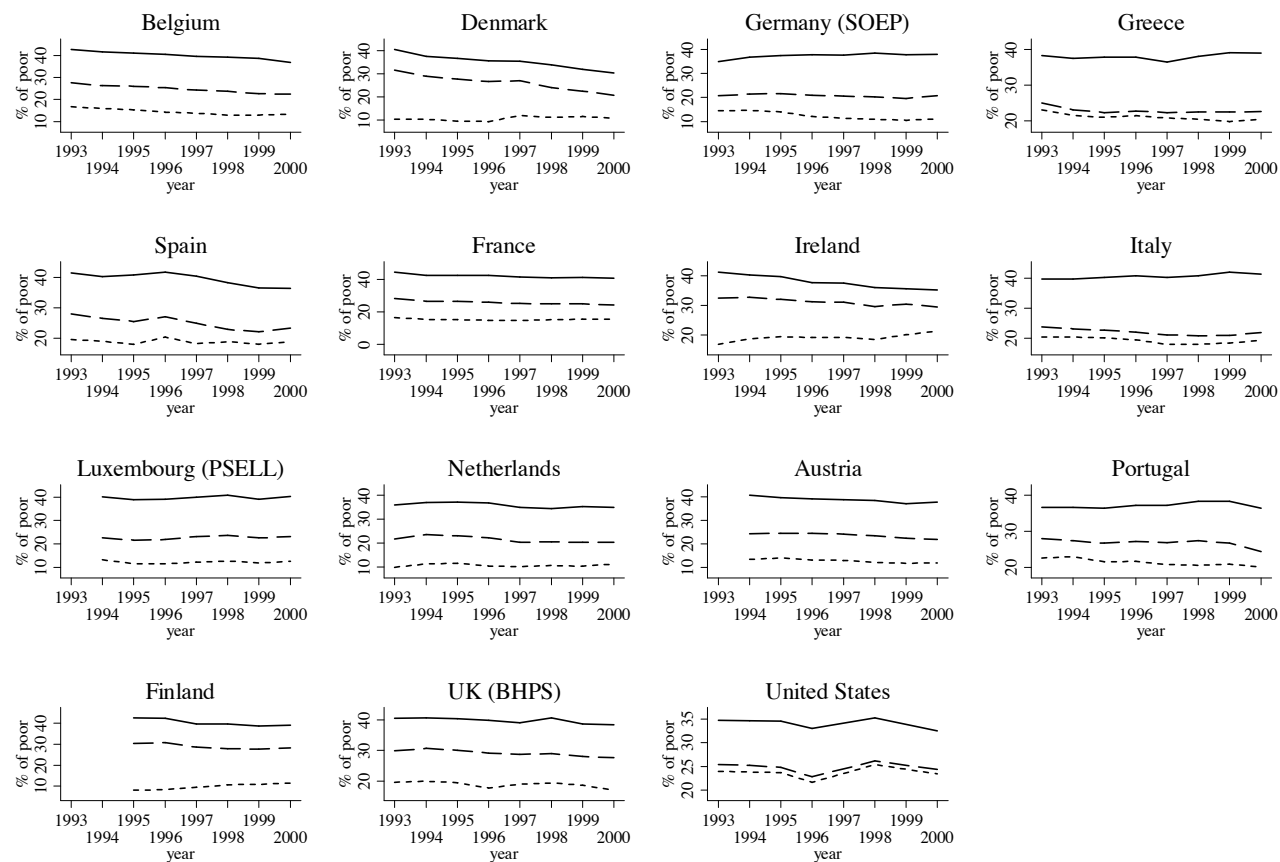

Pretransfer income

Pretransfer income but including pensions Posttransfer income.....

Note: To facilitate comparison of Orshansky and Laeken poverty trends within countries, we used different scales on the vertical axes. For the USA there are no observations 1999 and 1997.

Source: Own calculations ECHP and CNEF-PSID 
Table 9.15: Population shares by gender and age groups (2001)

\begin{tabular}{|c|c|c|c|c|c|c|c|}
\hline & \multicolumn{2}{|c|}{ Gender } & \multicolumn{5}{|c|}{ Age groups } \\
\hline & Males & Females & $0-15$ & $16-24$ & $25-49$ & $50-64$ & $65+$ \\
\hline Belgium & 48.5 & 51.5 & 19.2 & 11.0 & 36.2 & 16.7 & 16.9 \\
\hline Denmark & 49.5 & 50.5 & 20.1 & 10.2 & 35.9 & 19.0 & 14.7 \\
\hline Germany & 49.2 & 50.8 & 15.6 & 10.2 & 36.0 & 20.0 & 18.2 \\
\hline Greece & 48.3 & 51.7 & 14.7 & 11.9 & 34.2 & 19.1 & 20.1 \\
\hline Spain & 48.9 & 51.1 & 15.8 & 13.0 & 38.3 & 15.9 & 17.0 \\
\hline France & 48.6 & 51.4 & 19.3 & 11.8 & 35.7 & 16.9 & 16.3 \\
\hline Ireland & 49.2 & 50.7 & 23.4 & 15.5 & 35.6 & 14.3 & 11.0 \\
\hline Italy & 48.6 & 51.4 & 15.5 & 10.4 & 37.1 & 19.9 & 17.0 \\
\hline Luxembourg & 48.8 & 51.2 & 18.6 & 10.3 & 40.0 & 16.6 & 14.5 \\
\hline Netherlands & 49.6 & 50.4 & 20.1 & 10.7 & 38.6 & 17.6 & 13.0 \\
\hline Austria & 48.4 & 51.6 & 18.5 & 10.4 & 38.5 & 17.4 & 15.2 \\
\hline Portugal & 48.3 & 51.7 & 18.2 & 14.3 & 36.1 & 16.4 & 15.0 \\
\hline Finland & 48.6 & 51.4 & 19.6 & 11.1 & 34.6 & 19.8 & 14.9 \\
\hline Sweden & - & - & - & - & - & - & - \\
\hline United Kingdom & 47.6 & 52.4 & 19.8 & 10.0 & 33.7 & 18.5 & 18.0 \\
\hline United States & 48.1 & 51.9 & 23.1 & 12.4 & 37.7 & 15.9 & 10.9 \\
\hline
\end{tabular}

Note: The 2000 poverty rates are based on wave 8 (2001). Income in wave 8 represents household income in the previous year (2000).

Source: Own calculations ECHP and CNEF-PSID 
Table 9.16: Population shares by household type (2001)

\begin{tabular}{lrrrrrrrrr}
\hline Household type $^{1}$ & 1 & 2 & 3 & 4 & 5 & 6 & 7 & 8 & 9 \\
\hline Belgium & 9.9 & 12.3 & 11.0 & 11.7 & 3.3 & 9.8 & 20.2 & 12.8 & 9.0 \\
Denmark & 10.7 & 11.7 & 20.4 & 7.3 & 1.8 & 11.8 & 18.1 & 9.4 & 8.8 \\
Germany & 17.1 & 9.7 & 11.1 & 17.2 & 2.1 & 9.2 & 13.3 & 7.3 & 13.1 \\
Greece & 6.9 & 11.9 & 7.1 & 21.6 & 1.5 & 9.6 & 22.0 & 4.5 & 15.0 \\
Spain & 5.3 & 8.9 & 6.4 & 22.4 & 1.1 & 6.4 & 15.0 & 7.3 & 27.2 \\
France & 9.9 & 11.2 & 11.1 & 11.5 & 3.4 & 11.8 & 21.5 & 10.8 & 8.8 \\
Ireland & 7.3 & 5.1 & 5.0 & 14.9 & 2.7 & 5.6 & 13.7 & 17.2 & 28.5 \\
Italy & 7.4 & 9.0 & 6.3 & 25.7 & 1.1 & 10.8 & 16.0 & 7.4 & 16.5 \\
Luxembourg & 10.9 & 10.0 & 14.4 & 18.0 & 1.3 & 10.6 & 15.0 & 7.6 & 12.3 \\
Netherlands & 15.6 & 8.6 & 20.0 & 8.3 & 3.6 & 7.7 & 20.2 & 9.3 & 6.8 \\
Austria & 12.8 & 7.0 & 10.2 & 16.5 & 2.6 & 9.1 & 14.9 & 6.3 & 20.7 \\
Portugal & 3.7 & 7.7 & 5.8 & 21.4 & 1.5 & 11.1 & 14.9 & 6.6 & 27.4 \\
Finland & 17.9 & 9.0 & 13.7 & 8.4 & 2.9 & 10.4 & 16.8 & 13.6 & 7.3 \\
Sweden & 20.7 & 10.5 & 16.2 & - & 8.4 & 11.0 & 20.1 & 13.0 & - \\
United Kingdom & 13.2 & 11.4 & 15.8 & 11.7 & 5.8 & 9.1 & 14.8 & 8.8 & 9.4 \\
United States & 13.6 & 14.6 & 7.2 & 8.4 & 6.8 & 9.2 & 14.2 & 10.3 & 15.8 \\
\hline
\end{tabular}

Note: ${ }^{1}$ Definition household types: '1' One person household, '2' Two adults, no dependent children, both adults under 65 years, ' 3 ' Two adults, no dependent children, at least one adult 65 years, '4' Other households without dependent children, ' 5 ' Single parent household, one or more dependent children, ' 6 ' Two adults, one dependent child, ' 7 ' Two adults, two dependent children, ' 8 ' Two adults, three or more dependent children and ' 9 ' Other households with dependent children. ${ }^{2}$ The 2000 poverty rates are based on wave 8 (2001). Income in wave 8 represents household income in the previous year (2000).

Source: Own calculations ECHP and CNEF-PSID 
Table 9.17: Population shares by main income category (2001)

\begin{tabular}{|c|c|c|c|c|c|c|}
\hline & $\begin{array}{r}\text { Wages \& } \\
\text { Salaries } \\
\end{array}$ & $\begin{array}{r}\text { Self - } \\
\text { employment }\end{array}$ & Pensions & $\begin{array}{r}\text { Unemployment } \\
\text { benefits } \\
\end{array}$ & $\begin{array}{r}\text { Other social } \\
\text { benefits } \\
\end{array}$ & $\begin{array}{l}\text { Private } \\
\text { income } \\
\end{array}$ \\
\hline Belgium & 65.7 & 2.7 & 21.5 & 3.5 & 4.3 & 2.3 \\
\hline Denmark & 74.2 & 4.0 & 15.5 & 0.8 & 5.0 & 0.5 \\
\hline Germany & 63.9 & 6.4 & 21.9 & 2.1 & 4.1 & 1.6 \\
\hline Greece & 47.6 & 25.5 & 23.7 & 0.1 & 1.1 & 2.0 \\
\hline Spain & 60.8 & 14.1 & 16.8 & 1.7 & 3.4 & 3.1 \\
\hline France & 65.7 & 6.9 & 21.1 & 1.2 & 4.0 & 1.1 \\
\hline Ireland & 67.8 & 11.6 & 10.2 & 3.2 & 6.6 & 0.7 \\
\hline Italy & 55.1 & 16.6 & 24.0 & 0.9 & 1.9 & 1.6 \\
\hline Luxembourg & 71.2 & 3.2 & 18.2 & 0.3 & 6.3 & 0.9 \\
\hline Netherlands & 70.3 & 3.1 & 15.9 & 0.7 & 9.1 & 1.0 \\
\hline Austria & 70.9 & 6.6 & 17.4 & 0.5 & 3.5 & 1.0 \\
\hline Portugal & 65.4 & 13.7 & 15.0 & 0.9 & 4.2 & 0.9 \\
\hline Finland & 67.5 & 6.4 & 14.9 & 2.7 & 7.5 & 1.0 \\
\hline Sweden & 67.0 & 1.9 & 19.9 & 1.2 & 9.7 & 0.3 \\
\hline United Kingdom & 61.1 & 6.2 & 19.0 & 0.4 & 11.3 & 2.1 \\
\hline United States $^{1}$ & & 82.0 & 11.4 & & 2.8 & 3.9 \\
\hline
\end{tabular}


Table 9.18: Population shares panel by gender (1997-2001 panel)

\begin{tabular}{lrrr}
\hline & $\begin{array}{r}\text { Panel 1997-2000 } \\
\text { (\# of individuals) }\end{array}$ & Male & Female \\
\hline Belgium & 5,000 & 48.8 & 51.2 \\
Denmark & 3,907 & 49.9 & 50.1 \\
Germany & 11,550 & 49.0 & 51.0 \\
Greece & 9,260 & 48.2 & 51.8 \\
Spain & 11,511 & 48.6 & 51.4 \\
France & 10,696 & 48.4 & 51.6 \\
Ireland & 4,916 & 49.3 & 50.7 \\
Italy & 13,338 & 48.7 & 51.3 \\
Luxembourg & 4,793 & 48.2 & 51.8 \\
Netherlands & 8,464 & 49.2 & 50.8 \\
Austria & 5,894 & 48.5 & 51.5 \\
Portugal & 10,721 & 48.1 & 51.9 \\
Finland & 5,905 & 49.0 & 51.0 \\
Sweden & - & - & - \\
United Kingdom & 9,355 & 46.7 & 53.3 \\
United States (1996) & 9,297 & 47.1 & 52.9 \\
\hline Nit Th 2000
\end{tabular}

Note: The 2000 long term poverty rate is based on the 1997-2001 panel.

Source: Own calculations ECHP and CNEF-PSID 


\section{Samenvatting}

Armoede is ellendig: het gebrek aan middelen om in basisbehoeften te kunnen voorzien is een probleem dat moet worden bestreden, en waar mogelijk voorkomen. Vanuit die optiek hebben veel landen een sociaal beleid dat er op gericht is om mensen te assisteren in het hebben en behouden van een acceptabel minimum. Echter, het ontwerpen van een uitvoerbaar, effectief en houdbaar sociaal beleid is moeilijk en vergt veel informatie en analyse. In dit proefschrift worden vier belangrijke stappen in het begrijpen van armoede en het ontwerpen van een goed sociaal beleid aan de orde gesteld: het schatten hoeveel mensen er arm zijn, het identificeren wie die mensen zijn, het begrijpen hoe mensen zelf omgaan met armoede en armoede risico's, en het onderzoeken hoe sociale beleidsprogramma's effectief kunnen bijdragen aan het bijstaan van armen en het voorkomen van armoede. Het doel van de eerste stap is uit te vinden hoeveel armoede er is. Echter, om een schatting te krijgen moeten er veel conceptuele en methodologische beslissingen worden gemaakt die ook weer van invloed zijn op de schatting. In de tweede stap wordt onderzocht wie arm is door middel van het identificeren van karakteristieken die verband houden met een verhoogd armoede risico. De derde stap richt zich op het begrijpen wat mensen doen om van rond te komen, waarom, en hoe deze handelingen bijdragen aan hun welzijn. Het doel van de laatste stap is het bepalen of en hoe sociaal beleid in staat is om armoede te verlichten of the voorkomen.

Uitgaand van wat bekend is uit vorige publicaties; richt dit proefschrift zich op vijf specifieke kwesties die gerelateerd zijn aan de bovengenoemde stappen:

- $\quad$ De effecten van het gebruik van een absolute of een relatieve armoede-indicator op het schatten van het aantal armen;

- De implicaties van het gebruik van een absolute of een relatieve armoede-indicator voor het identificeren van de armen en het evalueren van de mate waarin sociale zekerheidsprogramma's armoede verlichten;

- De kosten en baten van inkomensgeteste versus universele provisie van sociale uitkeringen als beleidsinstrumenten om armoede te verlichten;

- De relatie tussen de armoede risico's van huishoudens en hun vermogen om hun consumptie op peil te houden als ze worden getroffen door een inkomensschok;

- De manieren waarop huishoudens hun consumptie in balans kunnen houden en de rol die sociale zekerheidsbeleid daarin speelt.

Iedere kwestie wordt onderzocht in een apart artikel en draagt bij aan een specifiek academisch debat en een specifieke discussie over beleidsopties. Hieronder worden deze artikelen kort samengevat. 


\section{Relatieve en absolute armoede-indicatoren in de VS en de EU: het gevecht om de cijfers}

Dit artikel schat de omvang van armoede in de VS en 15 EU lidstaten gebruikmakende van de officiële armoede meetmethoden in de VS (absoluut) en de EU (relatief). De publicatie van deze officiële cijfers krijgt veel aandacht in de media en de cijfers worden vaak gebruikt als argument om beleidsaanpassingen te maken. Deze studie is de eerste die vergelijkbare schattingen heeft gemaakt voor deze twee meetmethoden. Armoede in de Verenigde Staten is veel hoger dan in Europa wanneer de Europese relatieve armoedemaatstaf wordt gebruikt. Echter, met een absolute Amerikaanse maatstaf bevinden de VS zich in de middenmoot. Onze schattingen tonen niet alleen behoorlijk grote verschillen in armoede in een land en tussen landen, maar ook over de tijd. Gebruikmakend van jaarlijkse huishoud budget data van 1994 tot en met 2001, laten we zien op welke manier sommige armoedeverschillen inherent zijn aan de keuze tussen een absolute of een relatieve benadering, terwijl andere verschillen gerelateerd zijn aan gemeenschappelijke aspecten betreffende het meten van armoede maar een verschillend effect hebben wanneer een absolute of relatieve benadering wordt gebruikt. Voor iedere factor berekenen we tevens het individuele effect op de armoedeschattingen. Zo laten we zien dat eenzelfde equivalentieschaal een zeer groot en verschillend effect heeft op absolute en relatieve armoedeschattingen en op het armoede risico van bepaalde bevolkingsgroepen. Verder zijn er in landen met een hogere inkomensongelijkheid vaker grotere verschillen tussen absolute en relatieve armoede. Daarnaast laat onze studie zien dat het verschil tussen 'niet genoeg inkomen om in basisbehoeften te voorzien' en 'veel minder inkomen dan normaal' niet alleen leidt to verschillen in absolute en relatieve armoede op een bepaald moment, maar dat deze concepten economische vooruitgang ook anders evalueren. Voor een absolute welvaartsindicator is iedere reële inkomensstijging een verbetering, terwijl een verbetering in relatieve armoede een meer dan proportionele inkomensstijging van lagere inkomens vereist. Onze studie toont empirisch aan dat de ervaringen van landen in bovengenoemde factoren zeer kunnen verschillen. Samen leiden deze resultaten dan ook tot de conclusie dat het zowel voor de VS, als een sterk uitgebreide EU, van belang is om zowel een absolute als relatieve armoedemaatstaven te gebruiken.

\section{De beleidsrelevantie van absolute en relatieve armoedecijfers: wat zegt een cijfer?}

Financiële armoede-indicatoren krijgen niet alleen veel aandacht in de media of politieke debatten maar spelen ook een belangrijke rol in het maken en evalueren van 
beleid. Het percentage armen in de bevolking wordt vaak als uitgangspunt gebruikt om te analyseren wie er arm is en in welke mate een bepaald programma zorgt voor armoedeverlichting. Landen zoals de VS en de EU lidstaten gebruiken één of een aantal 'officiële' indicatoren op basis waarvan het succes van beleid wordt gecontroleerd maar meestal wordt echter maar één soort armoede-indicator gebruikt. In dit artikel onderzoeken wij of het gebruik van een absolute of relatieve armoede maatstaf leidt tot verschillen in het vaststellen van prioriteitsgroepen en het evalueren van de effectiviteit van sociaal beleid in termen van armoedeverlichting. Naast het de armoedeschattingen van het vorige artikel gebruiken we hier ook schattingen van langdurige armoede omdat chronisch armen kunnen worden beschouwd als een prioriteitsgroep op zich. Onze analyses tonen aan dat in rijke landen, waar absolute armoede lager is dan relatieve armoede, er niet veel overlap is tussen de groepen chronische armen en armen in absolute zin. Langdurige armoedecijfers kunnen dus niet als benadering worden gebruikt voor absolute armoedecijfers. Daasnaast vinden we een reeks significante verschillen tussen absolute en relatieve armoedeprofielen: afhankelijk van de gekozen armoede-indicator, zullen sommige bevolkingsgroepen dus meer of minder aandacht krijgen. Ten slotte laten we zien dat het succes van pensioenen, kinderbijslag en bijstandsuitkeringen in termen van armoedeverlichting afhangt van de armoedemaatstaf die wordt gebruikt: zo zijn pensioenen vaak voldoende om absolute armoede te voorkomen maar zijn ze minder succesvol in het voorkomen van relatieve armoede. Kortom, onze conclusie is dat het gebruik van één armoede concept voor het bepalen en evalueren van nationaal sociaal beleid misleidend kan zijn en dat het raadzaam is om zowel een absolute als relatieve armoede-indicator te gebruiken.

\section{Omvang is ook belangrijk: de kosten en baten van inkomensgeteste en universele kinderbijslag in Rusland}

Dit artikel vergelijkt de efficiëntie en effectiviteit van universele en inkomensgeteste kinderbijslag aan de hand van een beleidshervorming in Rusland. We gebruiken panel data van Russische huishoudens over een periode van 2000 tot 2004 om het succes van de hervormingen te evalueren en om de effecten van verschillende inkomensgeteste en universele programma's te simuleren. Onze analyses richten zich op twee aspecten die slechts zelden tegelijkertijd worden onderzocht: of de juiste groep wordt bereikt (targeting efficiency) en of de ondersteuning wel effectief is in het verlichten van armoede? In theorie zijn inkomensgeteste programma's effectiever en efficiënter omdat schaarse fondsen alleen maar gaan naar die mensen die het echt nodig hebben. In de praktijk is het echter moeilijk om te identificeren wie wel en wie niet in aanmerking komt en kost het geld om dat te doen. Het is dus niet duidelijk in welke mate de baten 
van een inkomenstest teniet worden gedaan door de kosten ervan. Onze analyses laten zien dat sinds de hervormingen in 2000, meer Russische kinderen kinderbijslag krijgen en dat arme kinderen een grotere kans hebben om ondersteuning te krijgen. Echter, veel niet arme kinderen krijgen ook ondersteuning terwijl één derde tot een kwart van de arme kinderen niet wordt geholpen. Bovendien is de mate waarin armoede wordt verlicht slechts marginaal verbeterd. Onze simulaties tonen aan dat universele programma's in staat zijn tot extra armoedeverlichting omdat groepen die eerst werden buitengesloten nu wel in aanmerking komen. Echter, de hoogte van de kinderbijslag is het belangrijkst: de zeer lage kinderbijslag in Rusland maakt de keuze tussen beide systemen haast irrelevant. Alleen als de kinderbijslag wordt verhoogd zal er een substantiëlere verlaging in armoede zijn.

\section{Armoede en het effenen van consumptie in Rusland}

Om te kunnen begrijpen hoe mensen met armoede en armoede risico's omgaan moeten we een dynamisch perspectief nemen: zelfs als een huishouden niet arm is, loopt het wel een risico om arm te worden. In dit artikel onderzoeken we in welke mate Russische huishoudens in staat zijn om hun consumptie te beschermen tegen inkomensschokken en hoe deze capaciteiten om consumptie te effenen zijn gerelateerd aan armoederisico's. We schatten deze capaciteiten door middel van een dynamische panel analyse en we onderzoeken of huishoudens met lagere effeningscapaciteiten ook een verhoogd armoede risico hebben. Een innovatief aspect van onze benadering is dat wij het consumptiegedrag van huishoudens modelleren met een error correctie proces; de intuïtie van dit model is dat mensen voor een tijdje in staat zijn om meer uit te geven dan er binnen komt, maar op lange termijn moeten hun uitgaven en inkomsten in evenwicht zijn. Tot zover hebben andere studies alleen naar de korte termijn effecten gekeken. We passen het model toe op panel data van de turbulente transitieperiode in Rusland (1994-2004). Onze resultaten wijzen erop dat huishoudens gedeeltelijk in staat zijn om hun consumptie beschermen tegen inkomensschokken en dat uitgaven aan eten beter beschermd zijn dan andere uitgaven. De partiële analyses voor groepen met een verschillende levensstandaard tonen aan dat effeningscapaciteiten toenemen met de levensstandaard. Hoewel chronisch arme huishoudens gedeeltelijk in staat zijn om hun consumptie te beschermen, reageren ze op schokken door hun al lage uitgaven nog verder te verlagen. Toch hoeven lage effeningscapaciteiten niet altijd te worden geassocieerd met een verhoogd armoederisico: armoede is aanzienlijk hoger in rurale gebieden maar rurale huishoudens zijn juist zeer goed in staat om hun voedingsconsumptie op peil te houden. Deze resultaten geven aan dat de overheid, naast een beleid van armoedeverlichting, mensen ook kan assisteren om beter met risico's om te gaan. 


\section{Risico management: wat doen Russische huishoudens om hun consumptie op peil te houden?}

Mensen worden blootgesteld aan veel en verschillende soorten risico's zoals werkeloosheid, ziekte, een mislukte oogst of het verlies van eigendommen. Ze kunnen zich beschermen tegen de mogelijke effecten van zulke risico's door te sparen, lenen, meer te werken of door hun eigendommen te verkopen. Daarnaast kunnen mensen zich verzekeren door middel van formele en informele verzekeringsregelingen. Sociale zekerheidsvoorzieningen zijn dus niet de enige regelingen die mensen gebruiken om een acceptabele levensstandaard te hebben en behouden. De relatie tussen de verschillende regelingen en de instituties die daarmee gemoeid zijn is complex en zeer specifiek voor een samenleving of bepaalde groepen daarin. Om te begrijpen hoe mensen ervoor zorgen dat ze zich kunnen beschermen tegen risico's of de effecten daarvan, is het belangrijk om na te gaan hoe mensen dat eigenlijk doen. Dit artikel ontwikkelt een generiek raamwerk dat het mogelijk maakt om zulke consumptie effeningsstrategieen te bestuderen in verschillende contexten. In de literatuur worden vooral modellen gebruikt om de stabiliteit van consumptie te meten of om juist een zeer specifieke effeningsstrategie te onderzoeken. Echter, huishoudens gebruiken verschillende regelingen vaak tegelijkertijd en het succes van de ene regeling kan afhangen van de beschikbaarheid en het functioneren van de andere regeling. We passen ons raamwerk toe op Rusland en bestuderen een zeer uitgebreide database om erachter te komen wat Russische huishoudens doen en hoe deze handelingen kunnen bijdragen aan een stabiele consumptie. We kijken hierbij ook naar de rol van sociale voorzieningen in Rusland. Onze analyses tonen dat Russische huishoudens sparen en geld lenen, maar dat ze daarvoor weinig gebruik maken van financiële markten. In plaats daarvan verlenen huishoudens zelf krediet aan anderen, krijgen ze een lening van hun werkgever of nemen ze een 'consumptief krediet' door hun energierekeningen niet of laat te betalen. Verder lijkt het verbouwen van voedsel meer een integraal onderdeel te zijn van de (in natura) inkomensgenerende activiteiten dan een reactie op een specifieke schok. Daarnaast geven de resultaten aanleiding tot de hypothese dat het relatief genereuze pensioensysteem leidt tot een herverdeling van pensioenen waarbij ouderen, door middel van het geven van giften, naar hun jongere familieleden ondersteunen. Hoewel deze studie niet bewijst dat zulke handelingen ook daadwerkelijk consumptie-effeningsstrategieën zijn, resulteert de analyse wel in het formuleren van specifieke hypotheses die het uitgangspunt kunnen zijn van een vervolgonderzoek. 



\section{Curriculum Vitae}

Gertruda Andrea Maria Jacqueline Notten was born on May 30, 1975 in Ulestraten, The Netherlands. She studied International Economic Studies at Maastricht University and graduated in 2000 with a Master's degree in International Economics majoring in money and banking. During her studies, she also obtained credits from courses followed at the Universidad de Zaragoza (Spain) and the Université de Liège (Belgium). For her Master Thesis she evaluated two micro credit projects in Lima and Pisco (Peru).

In 2001, Geranda joined the Department of Economics at Maastricht University to start up and coordinate the Master Programme Social Protection Financing, a joint project with the International Labour Office in Geneva. As of August 2002, she started writing her doctoral dissertation on measuring and managing poverty risks under the supervision of Prof. dr. Chris de Neubourg and Dr. Franziska Gassmann. During this time, she also had a half time position as a lecturer for the Department of Economics and taught a range of basic economics courses and advanced courses on poverty and welfare states.

She has presented her work on many occasions varying from academic conferences and seminars such as the annual meeting of the European Economic Association and the work in progress seminars at the Kennedy School of Government at Harvard University to the New School/UNICEF conference on social protection initiatives for women and children. She has been a visiting researcher at CEPS/INSTEAD in Differdange (Luxembourg) and at the Kennedy School of Government in Cambridge (United States). Part of her research has been published or is forthcoming and other parts have been submitted to international refereed journals.

Since her studies, Geranda has been involved in a number of consultancy projects on poverty and social protection. On behalf of the Maastricht Graduate School of Governance she is currently working on a project for UNICEF involving a multidimensional poverty analysis and the simulation of a series of policy interventions aimed at reducing poverty in Congo Brazzaville. 